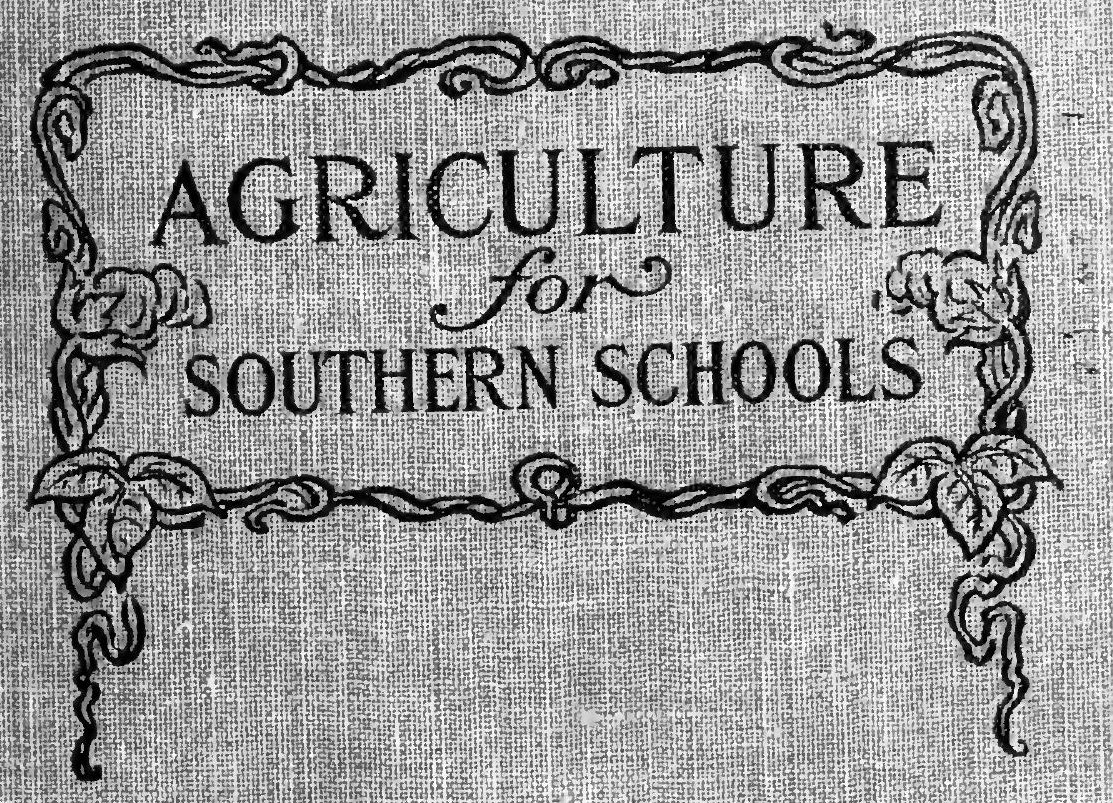

JOHN FREDERICK DUGGAR 

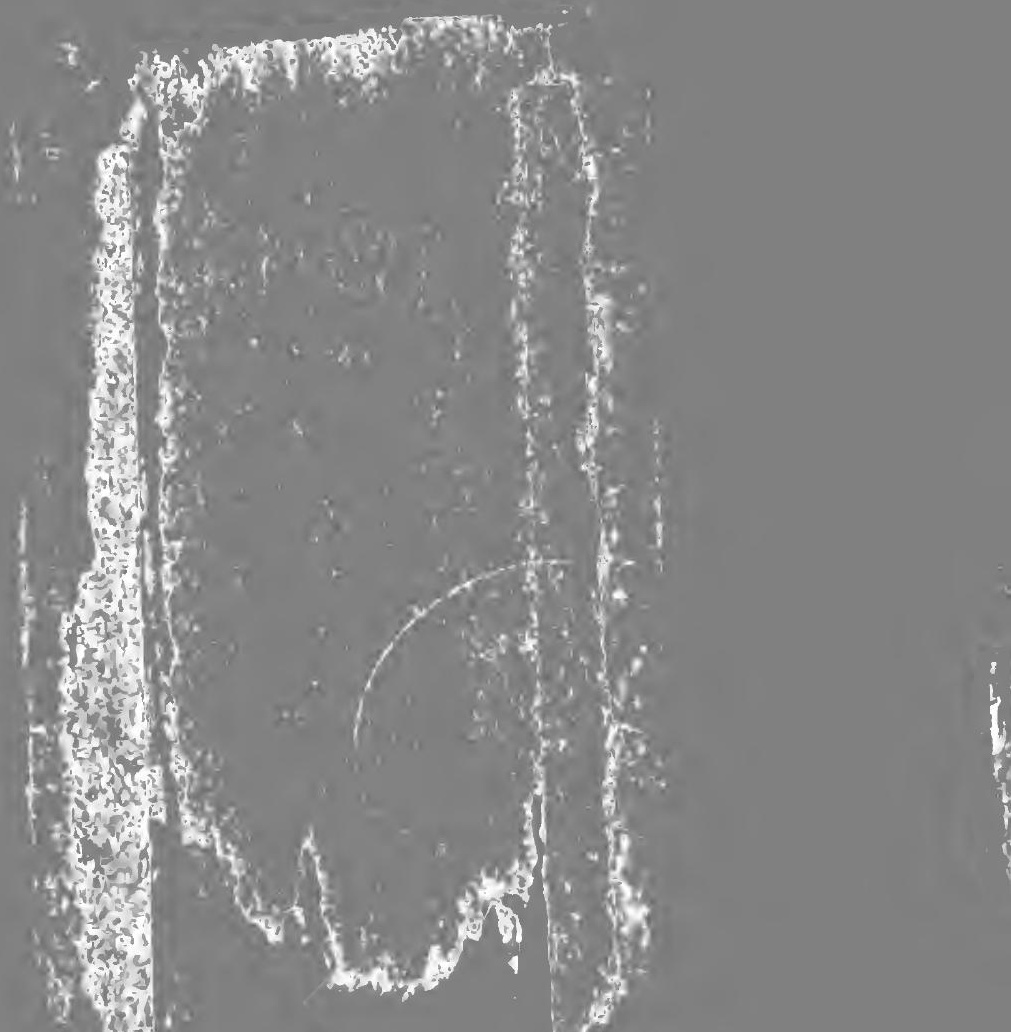


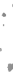

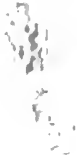

$\therefore$

'
.
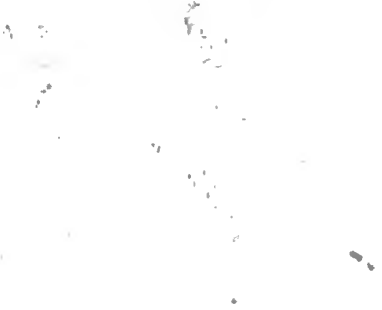

I

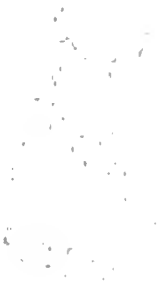

$\vdots$

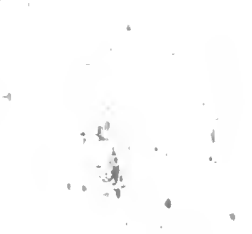


AGRICULTURE FOR SOUTHERN SCHOOLS 


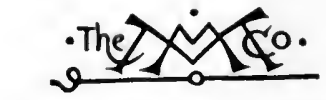

$$
\begin{aligned}
& \text { THE MACMILLAN COMPANY } \\
& \text { NEW VORK - HOSTON - CHICAGO } \\
& \text { arLaNTa - SAN FRANCISCO } \\
& \text { MACMILLAN \& CO., LIMTED } \\
& \text { LONDON - BOMBAY - CALCUTTA } \\
& \text { MeLbourage }
\end{aligned}
$$

THE MACMILLAN CO. OF CANAdA, Lto. TORONTO 
A GR I C ULTURE

\title{
FOR SOUTHERN SCHOOLS
}

\author{
BY \\ JOHN FREDERICK DUGGAR \\ DIRECTOR OF THE ALABAMA AGRICULTURAL EXPERIMENT STATION \\ AND PROFESSOR OF AGRICULTURE IN THE ALABAMA \\ POLYTECHNIC INSTITUTE
}

Now 19ark

THE MACMILLAN COMPANY

1909

All rights reserved

39823 
Copyright, tgo8,

BY THE MACMILLAN COMPANY.

Set up and electrotyped. Published June, 1908. Reprinted July, August, November, December, 1908; August, November, rgog. 


\section{$S 495$
$D 87 a$}

\section{PREFACE}

THis little book has been written with the hope of supplying the need for an elementary text-book on agriculture that shall differ from others in having a definite and limited field, - the South. While many of the principles of agriculture are universal, the application of these principles is somewhat local. By limiting the field of a text-book on agriculture to the Southern states, it becomes possible to treat the subject in a concrete way; to avoid many generalities inseparable from a book intended for use in all latitudes; and to employ as object-lessons unly those plants that any teacher or pupil in a Southern school can easily obtain. For example, it is better that a Southern pupil study the peach bloom fresh from the tree than to read of the flower of some plant rarely found in the orchards or fields in this latitude. The cotton bloom, too, affords a suitable example of how flowers are constructed. This Southern point of view also makes it possible to give fuller, and hence more teachable, treatment to the most widely grown crops of the South.

The principal aims that have guided the author in writing this book are these:-

I. To arouse the interest of the pupil in nature, and especially in the common plants of the Southern farm, orchard, and garden. 
2. So to present the subject that it may be mastered rather by stimulated obscrvation and quickened thought than by mere memorizing.

3. To make a teachable book, - one that will present fewest possible difficulties to a teacher who has had no special training in either the theory or practice of agriculture. The effort has been made to lead the pupil by easy steps from the known to the less familiar subjects, and from the concrete example to the general law or principle.

4. To make the language simple enough to be readily understood by a pupil in the sixth grade of the common schools, and yet to present the subject with enough system and substance to suit the pupils in the high school.

5. To emphasize, amplify, and illustrate a few principles, which, when understood and practiced, have the power to revolutionize Southern farm practice and to promote the permanent prosperity of the farmer and of the state.

The author's experience as a teacher, his long study and practice of agriculture, and his association with children, lead him to think that all these aims can be realized. He must leave to his fellow-teachers of the South the verdict whether this book approaches his cherished ideals.

Recognizing the fact that provision has not been made for the special instruction of teachers in agriculture and that many are not familiar with farm practice, he adds this message to all such teachers. You can teach this subject effectively even without this acquaintance with 
farm work. Your weakness will become your greatest strength if it cause you to step down in this class from the teacher's desk and to be a comrade with your pupils, - a fellow-seeker after the truth that none of us can know completely. Be a leader in raising questions which you need not be ashamed to own that you cannot answer. If you arouse the interest that will make your pupils desire an answer, you arouse in them for the years to come the spirit of inquiry by means of which, as men and women, they will educate themselves. In teaching agriculture, humility is the teacher's proper attitude, and to show it will not forfeit the respect of either pupils or patrons.

The thanks of the writer are due to the many friends who have lent a helping hand in this work. Space does not suffice for acknowledgements to all, but special thanks are here tendered to my associates, Dr. W. E. Hinds, for the sections on insects, and Professor R. S. Mackintosh, for numerous photographs and for critical reading of the chapters on horticulture; to Miss F. E. Andrews, and other.lovers of flowers, for the sections on flower gardening; to Dr. B. M. Duggar, of Cornell University, for writing the chapter on plant diseases; to Professor L. N. Duncan for suggestions and photographs for Figs. 2, 136, I39-I43, and 215 ; to Miss C. M. Cook for drawings; to the editor, Dr. L. H. Bailey, for many improvements; and for illustrations, to the United States Department of Agriculture, and to the Experiment Stations of Georgia, Illinois, Iowa, Kentucky, Louisiana, Michigan, Minnesota, Missouri, New York, and Ohio.

Auburn, Alabama,

THE AUTHOR.

January, 1908. 



\section{CONTENTS}

PAGB

SECTION I. INTRODUCTION

The Plant

Section II. The parts of the flower. Plant families . . 7

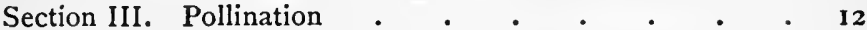

Section IV. Germination of seeds $\quad$. $\quad . \quad$. 2 I

Section V. Water for the plant . . . . . $\quad 28$

Section VI. How plants get food from soil and air $\quad$. 32

Section VII. How plants are propagated . . . $\quad 3^{8}$

Section VIII. Improvement of plants . . . . . 46

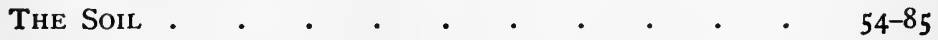

Section IX. How the soil was formed. Kinds of soil . $\quad 54$

Section X. Suiting the crop to the soil . . . . 6I

Section XI. Moisture in the soil . . . . . . 65

Section XII. Preparation and cultivation of the soil . $\quad 70$

Section XIII. Terracing and draining . • . $\quad 74$

Section XIV. How the soil becomes poor • • • $\quad 82$

Fertilizing Materials and Fertilizers • • . 86-i15

Section XV. How trees and leguminous plants improve the soil . . . . . . . . . . . . 86

Section XVI. Barnyard manure . • • . . $\quad$. 93

Section XVII. Commercial fertilizers . $\quad$ - $\quad$ - 97

Section XVIII. Calculating fertilizer formulas . • $\quad 102$

Section XIX. Suiting the fertilizers to the soil . . . 108

Section XX. Lime . . . . . . . . 112

FARM CROPS

II 6-1 $8 \mathrm{I}$

Section XXI. Rotation of crops . • • . • . II6

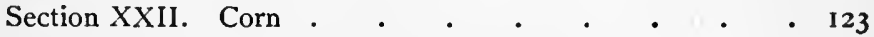

Scction XXIII. Selecting or judging seed-corn . • . 129

Section XXIV. Wheat, oats, rye, and barley . . . 136 
Section XXV. Cotton

Section X.XVI. Sugar cane

Section XXVII. Sweet potatoes.

Section XXVIII. Peanuts and watermelons . . . $16_{5}$

Section X.XIX. Legumes and inoculation . . . . 168

Section X.XX. Some forage plants . . . . . 174

Section XXXI. Weeds . . . . . . . 182

Section XXXII. The vegetable garden . . . . 185

Flowers

Section XXXIII. Planning the flower garden - . 192

Section XXXIV. Growing flowers . • • • 197

Forest and Fruit Trees

203-224

Section XXXV. Forest trees . . . . . . 203

Section XXXVI. Forest trees (Continued) . . . . 208

Section XXXVII. Fruits . . . . . . . 215

Diseases of Plants. Germs in the Soll . . . 225-245

Section XXXVIII. The causes of diseases of plants • $\quad 225$

Section XXXIX. Some diseases of fruits . . . . 229

Section XL. Diseases of oats and wheat . . . . 233

Section XLI. Diseases of Irish and sweet potatoes . . 236

Section XLII. Diseases of cotton . . . . $\quad 23^{8}$

Section XLIII. Germs in the soil . . . . 244

INSECTS

Section XLIV. What an insect is . . . . . 246

Section XLV. How insects grow - • • • • 249

Section XLVI. How insects feed . . . • $\quad 253$

Section XLVII. Insect enemies of the farmer - • $\quad 257$

Section XLVIII. The Mexican cotton-boll weevil . . 264

Section XLIX. Insects and health . . . • 272

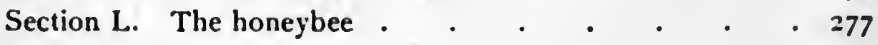

FARM Live-stock • • • • • • • . 281-313

Section LI. Improvement of live-stock . . . . $28 \mathrm{I}$

Section LII. Horses . • . . . • • 284

Section LIll. Beef cattle . • . • • . . 290 
Section LIV. Dairy cattle - . . . . . . 295

Section LV. Sheep . . . . . . . $\quad$. 299

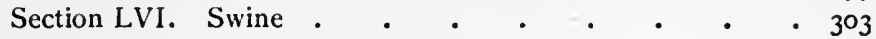

Section LVII. The management of poultry . . $\quad 306$

Section LVIII. Breeds and varieties of chickens . . . 310

Feeding Live-stock . . . . . . . . . 314-322

Section LIX. Principles of feeding animals . . . . 314

Section LX. Calculating rations for live-stock • • • 318

DAIRYING • • • • • . . • • • 323-329

Section LXI. The production and care of milk . . $\quad 323$

Section LXII. Making butter • • • • • 326

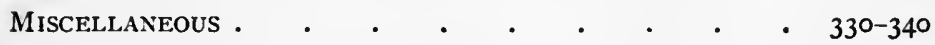

Section LXIII. The cattle tick ..$\quad \cdot \quad \cdot 330$

Section LXIV. Farm implements and machinery . $\quad 333$

Section LXV. Earth roads . • . • . • 338

APPENDIX • . . . . . . . . . . . . i-vii

Fertilizer equivalents $. \quad . \quad$. $. \quad . \quad . \quad . \quad . \quad$ i

Some fertilizer formulas $. \quad . \quad . \quad . \quad . \quad . \quad . \quad$ i

To destroy insects $\quad . \quad$. $\quad . \quad$. $\quad . \quad$. $\quad . \quad$. iii

To prevent or decrease diseases of plants . . . . . iv

To measure grain approximately . . . . . iv

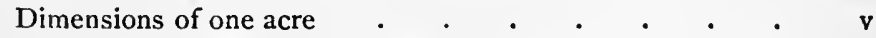

State Agricultural Experiment Stations . . . . v

School gardens . $\quad . \quad$ • . . . . . . . vi

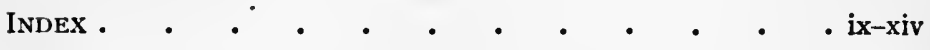





\section{AGRICULTURE FOR SOUTHERN SCHOOLS}

\section{SECTION I. INTRODUCTION}

WE all enjoy a trip to a part of the country in which we have never been. It is the newness of all we see

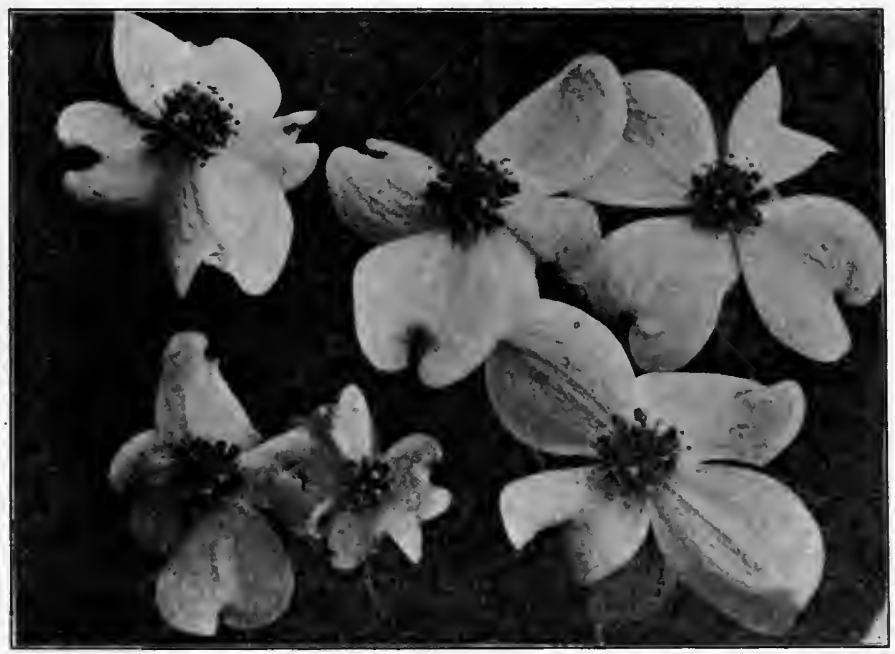

Fig. I. - Awaiting Discovery

Photo by R. S. Mackintosh

Does the showy part of the dogwood consist of petals or of whitened leaves?

that excites our curiosity and interest. Would it not be delightful if we could constantly make discoveries of new 
things about the very places where we live, and so find the same interest and pleasure that a trip affords us? Some persons have learned to do this. They make discoveries on any day that they spend in the woods or fields. They find flowers that they have not noticed before; they learn which wild plants and weeds are kin to useful plants that they know; they observe how plants provide for their seed to be carried by wind, or water, or birds, or by large animals to other parts of the field or pasture. They learn new facts about animals and brooks and the whole out-of-doors. If we try to observe the plants that grow in our woods, or field, or garden, or orchard, we shall always be making interesting discoveries and gaining new plant friends.

There is not only delight in collecting the wild flowers and in observing the trees, but there is also pleasure and profit in learning the nature and habits of our cultivated plants. We will know better how to prune a peach tree, an apple tree, or a grape-vine if we observe whether the fruit is borne on new branches or on those one or two years old. Notice this and tell the teacher what you observe. We shall be able to select better seed corn if we learn which shape of ear or of kernel is found in the most productive varieties. Agriculture deals with such questions as these.

A study of agriculture should enable pupils to understand better the common plants and animals of the farm and cause them to take more interest in them. A book like this can give only a few of the most important principles of plant and animal growth. A knowledge of these 
should help one to observe and to form conclusions about the best way to select, feed, and cultivate plants and to

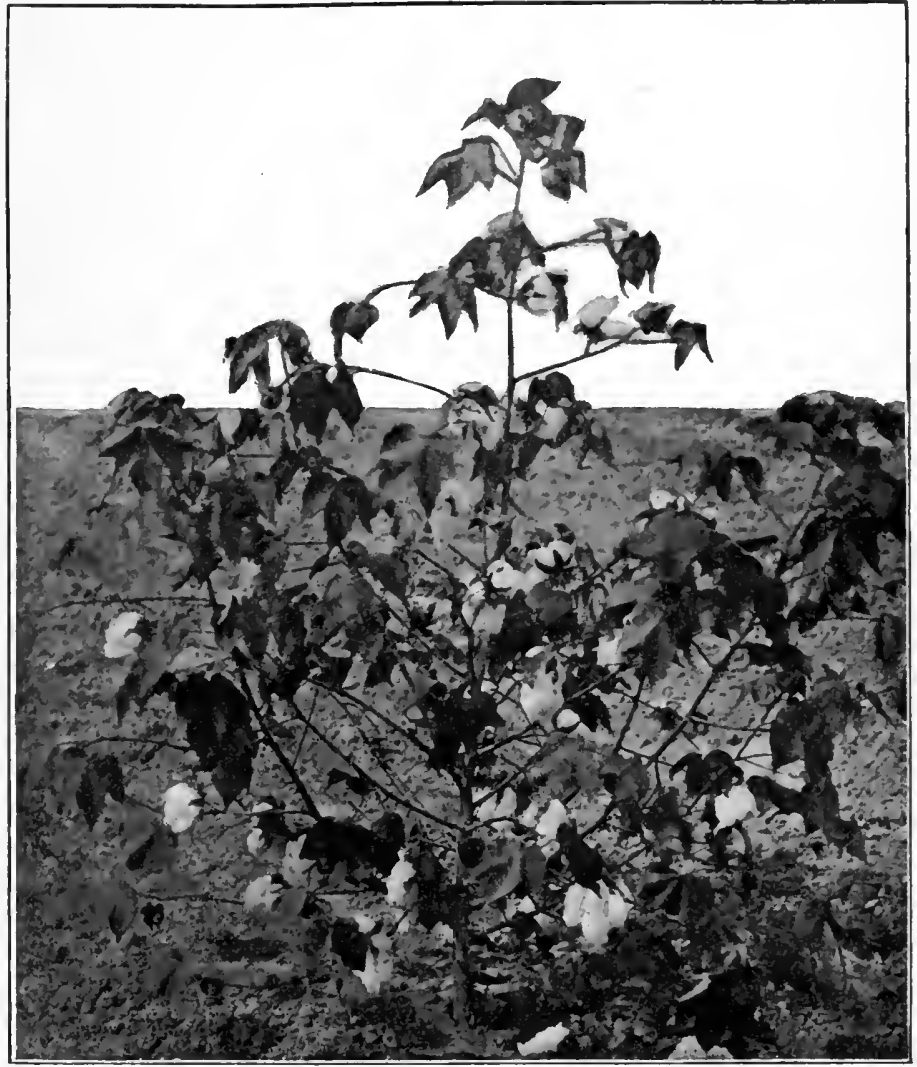

Fig. 2. - Cotton, the Principal Sale Crop of the South

care for animals so that farming may be made more interesting and more profitable. 
Agriculture is the practice of producing useful plants and animals. It is based on physiology, botany, chemistry, and other natural sciences. It is also an art because success in agriculture requires skill and experience and business methods. In agricultural books, papers, and pamphlets is recorded much of the experience of the best farmers. In studying agriculture we shall learn something about flowers, fruits, vegetables, and animals, as well as about crops that grow in the fields.

Reasons for studying agriculture. - Agriculture is worthy of our most earnest study. It is the industry that furnishes food to all mankind and on which many arts and industries are built. Its study teaches us how plants feed, grow, and multiply; how man may take common plants and greatly increase their productiveness, beauty, or hardiness; how he may rear animals; how a farmer may maké his poor soil rich, his scant crops bountiful, and his life and the life of his family full of comfort and pleasure. Surely, it is worth while to learn how to make the crops larger, the farm animals more useful and profitable; how to make the garden and orchard yield a continuous supply of vegetables and fruits; and how to beautify the grounds around the home and the school.

It is worth while, too, for all of us to know how to protect our plants from disease and how to conquer our insect foes. If blights, smuts, and mildews destroy the crops of field, orchard, or garden, knowledge suggests ways of preventing or destroying them. If caterpillars, bugs, weevils, and a host of other insect pests strip bare the growing crops and despoil the stored grain, knowledge 
of their lives and habits is the weapon with which man conquers them.

Wherever farming has proved to be profitable, we may expect to find good roads, good schools, churches, libraries, telephones, and much else that helps to make life in the country pleasant and attractive. Even a child may do his part in bringing these things to pass. Some of the agri-
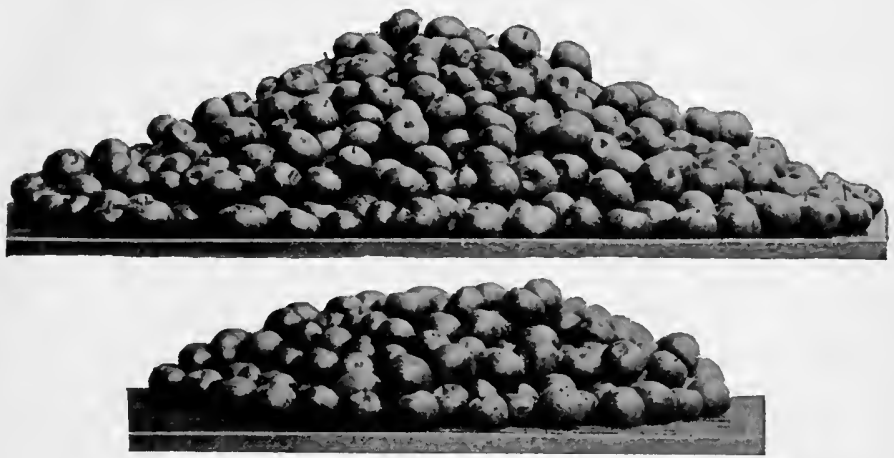

Courtesy Ky. Expt. Station

Fig. 3. - An Example of How Knowledge pays

Above, the yield of apples from one tree sprayed to prevent rot; below, the yield of a similar tree not thus protected.

culture that he learns at school he can promptly make use of at home. Still more of it will be helpful to him in later years if he becomes a farmer. Best of all, the study of agriculture should enable him to find a keener pleasure in observing the ways of plants and animals, and thus enrich his entire life, whatever may be his future occupation.

Even from this book we may learn how to make the soil richer year by year. If we should remember only this, and forget all else, we should be able to help our neighborhood and our country as well as ourselves. He serves his 
country well who transforms a poor and unprofitable soil into a fertile and wealth-producing farm. He serves it also who aids in introducing a better class of live-stock or in producing better milk and butter.

EXERCISE. - Secure a small notebook with a back that will not easily break. Tie to it a pencil. Use this for your agricultural exercises, and for no other purpose. Before the end of the session this little notebook will be more interesting to you than any printed book, - and you will be an author.

As you study this chapter, write in your notebook a numbered list of the plants you know. Write down the names of all the field crops cultivated near your home. Opposite each write all of its uses. Likewise write a list of the names and uses of as many kinds as you can of farm animals and poultry.

Note to the TEACHer. - Question pupils on the text of every chapter. Encourage answers in the language of the child rather than in the exact language of the book. Grade pupils as much on the exercises at the end of each chapter, and on independent observation, as on the text. By grades or other means stimulate the pupils to bring to the class in agriculture object lessons appropriate to the subject in hand. Require notebooks and examine these often. You will be helped in teaching agriculture by having at hand " Exercises in Elementary Agriculture ; Plant Production," by Dick J. Crosby. This bulletin is sent free (on application) by the United States Department of Agriculture, Washington, D.C. Procure bulletins from the Experiment Station in your own state. 
SECTION II. THE PARTS OF THE FLOWER. PLANT FAMILIES

THE chief effort of the plant is to produce seed. A flower must be formed before the seed can be produced. Its beautiful colors, its nectar, and its delicious perfume are means to attract insects whose help it may require in making seed.

Mustard flower. - As our first example, we may inquire what are the parts of a mustard flower (Fig. 4). In the

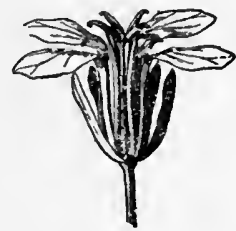

Fig. 4. - Flower of MUSTARD

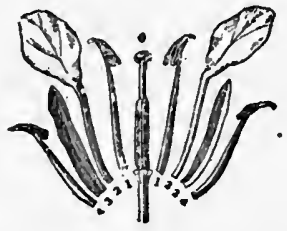

Fig. 5. - Details OF PART of Mustard Flower

center of this flower is a column, at the top of which is a rounded knob (o, Fig. 5). The whole central column is called the pistil. Its important parts are the ovule case; near the base, in which the seeds develop; and the stigma, or knob at the top. In some plants the stigma is divided into several parts. The surface of a full-grown stigma is sticky or rough, so that pollen, which is the yellow dust of the flower, may stick to it. The ovule case, or ovary, 
contains little, immature, seed-like bodies, called oinules. Each ovule may become a seed. But before an ovule can

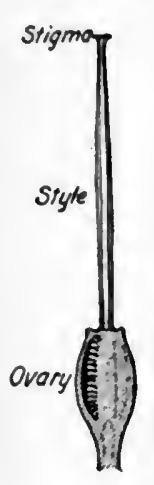

Fig. 6. - A Pistil change into a seed, it must be fertilized; that is, a grain of pollen must fall upon the stigma and grow down into the ovule, after which the latter becomes a seed.

In a circle just outside of the pistil are a number of slender stalks (six on the mustard flower) called the stamens (1, 4, Fig. 5). The most important part of a stamen is the cap at the top. This is the anther, or pollen case. When the anther is mature, it bursts and frees a yellow powder, called pollen. Soon after this powder or pollen is shed, the stamen, now useless, dies. The pollen must be carried by insects or wind or otherwise to the sticky or rough surface of the stigma in the same or in a different flower. If pollen is not brought to the stigma, no seeds develop.

In a layer just outside of the stamens is the brightcolored part of the flower (2, Fig. 5). This is called the corolla. In many plants, as in the mustard, it is divided into a number of distinct pieces, each being really a colored leaf, called a petal. Fig. 4 shows that there are four petals in the mustard flower. In a layer just outside of these are the green parts of the flower, called sepals (3. Fig. 5).

Let us see whether most flowers have their parts arranged in the same order, the pistil in the center, the stamens around the pistil, the petals next to these, and outside of all, the sepals.

Peach blossom. - The peach blossom has this same 
arrangement (Fig. 7). It has one undivided pistil. This is the part that a fruit grower examines after a frost, for he knows that if the pistils are killed there will be no peaches. Notice that there are numerous stamens; that there are five petals; and that there are five sepals, grown together.

Apple blossom. - The apple blossom (Fig. 8) is very much like that of the peach, but its pistil is divided into five parts. Like the peach it has five petals and five sepals.

In all the examples given above, there has been the same number of petals as of sepals. This is often true.

Cotton flower. - The cotton bloom is formed on the plan of fives (Fig. 9). There are

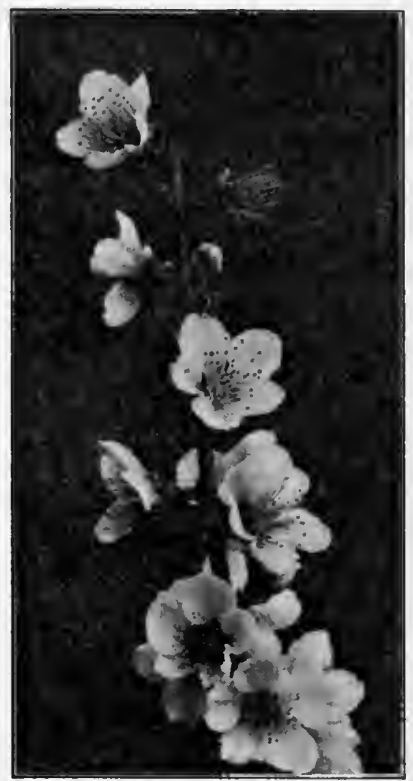

Photo by R. S. Mackintosh Fig. 7.- Peach BLooms five showy petals, and also five short sepals. These last

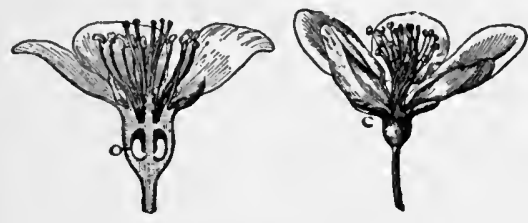

Fig. 8. - Flowers of the Apple are grown together and form a shallow cup, which incloses the base of the boll. The three large green parts that form the square are not sepals, but bracts, or leaf-like extra parts. You also find bracts around some 
other flowers, for example, around the strawberry blossom and the head of the sunflower.

There are usually four or five divisions of the pistil in the cotton bloom. From the number of these you will

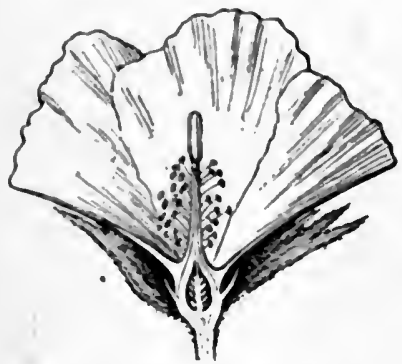

Fig. 9. - Sectron of Cotton BLOON find that you can foretell how many locks of cotton there will be in any boll; for there will be just as many locks in the boll as there are divisions of the pistil.

The stamens in the cotton bloom are numerous. Their lower parts or stalks grow together to form a tube surrounding the pistil.

Plant families. - Plants that produce blooms are divided into more than two hundred families. A family of plants generally includes the kinds that form their flowers in the same general way. For example, the Bean family includes the garden pea, the sweet-pea, the field or cowpea, the locust tree, all kinds of clovers, and many others. If you will pick from a clover head a single tiny flower, you will see that its parts have the same general shape and arrangement as the large flowers of the garden pea, of the cowpea, or of the beautiful sweet-pea.

Perhaps you can find out what resemblances there are between the flowers of the blackberry, the strawberry, the apple, the pear, the peach, the plum, and the wild rose. These all belong to the very large Rose family, which includes most of our fruits and berries. 
It will be easy for you to find scores of plants that belong to the immense family of the Grasses. After carefully examining several well-known grasses, like crab grass, examine plants of corn and oats and see how many resemblances to grasses you find in these useful crop plants. These and other grains are grasses (Fig. IO).

Exercise. - In every large flower you find, point out (I) the pistil, (2) the stamens, (3) the petals, and (4) the sepals. Find the pollen in all the flowers you examine. Does it show in young flower-buds? Why is there little or no pollen in flowers that are nearly ready to wither or drop?

Collect all the cultivated and wild plants that you can find having blossoms shaped like those of the sweet-pea or bean. In your notebook write the names of all these pea-like plants that you know. Leave a long blank space and keep adding to this list all through the season. Examine every kind of plant that

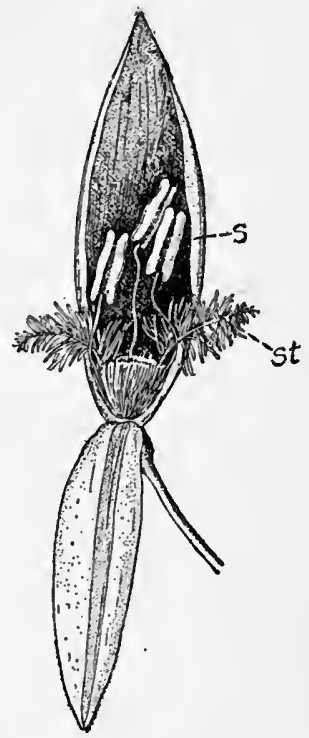

Fig. 10. OAT FLoWER, OPENED TO SHOW STAmens (s), and Stigmas $(s t)$, ENLARGED. (After Roberts and Freeman.) you have ever heard called a clover to see whether its separate blossoms have the shape of a pea or sweet-pea bloom.

Note to the Teacher. - Devote as much time as possible to having pupils point out the parts of each flower that may be brought to the class. Have them place in separate piles (I) all the pea-like flowers, (2) all the flowers that seem to them kin to the roses and blackberries, and (3) all the grasses. Probably one or two reviews of this chapter must be given so as to afford time for examinatlon of every flower that is brought in. 


\section{SECTION III. POLLINATION}

WuIt. you have been learning the names of the different parts of the flowers, you have perhaps been thinking about the uses of each part. The sepals and petals serve to protect the more important parts inside. For example, the peach sepals and petals while still folded together in the bud keep the pistil from being killed by slight frosts in the early spring; thus the peach crop is sometimes saved. That the stamens and pistils, however, are more important than the sepals and petals can be proved by carefully removing all of the petals from a flower of cotton or from a peach blossom. In spite of this injury, a boll or a peach will form if pollen is applied to the stigma.

Flowers without petals. - Since the flower makes seed or fruit by means of the stamens and pistil alone, these two parts are called the necessary or essential parts. The flowers of many plants have no showy sepals and petals. The sepals and the petals are not strictly necessary. When you see the flowers of corn and wheat you may not think of them as flowers, because they have no gay colors. The bees and other insects do not often visit such flowers.

Function or use of the pistil. - The pistil is the part of a flower that develops into the seed-case or fruit. In its 
base it contains the tiny ovules which may develop into seeds. There will be no fruit or seed formed if the pistil is destroyed.

Function or use of pollen. - The part of the stamen that is most important is the pollen or plant dust. This is a fine powder and is set free by the opening of the little pollen case, or anther, at the tip end of the stamen. Pollen must adhere to and

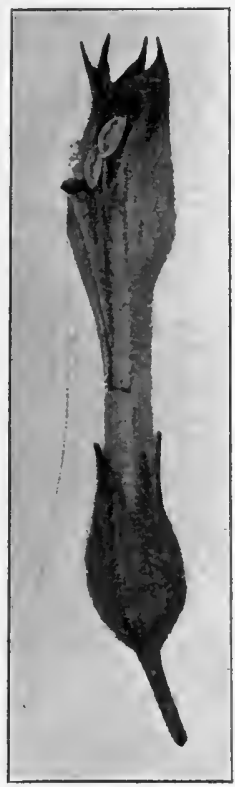

FIg. 1 2. - Tовассо FLOWER grow into the pistil and enter the ovule before seed contained in the pistil can develop. You may learn the importance of the pollen to the plant by carefully picking off all the sta-

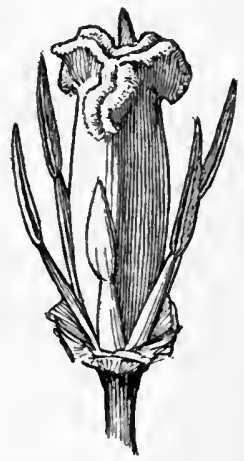

Fig. ir. - Pistil AND Stamens (Tulip) mens of a nearly open flower bud of cotton or peach or other plant. Then tie a small paper sack over the injured bloom to keep the pollen of other flowers from being brought in by wind or insects. In a few days you will find that the pistil to which no pollen can gain access does not grow, but generally dies and falls. If it lives it produces no perfect seed. At the same time, other pistils, on whose stigmas you have noticed tiny grains adhering, will be growing (Figs. 12, I 3, 14).

If you tie a paper bag tightly over a young corn ear 
before the silks show, and keep it there, no grains will form on that cob. This is because no pollen falls on the silks, which are the pistils of an ear of corn. For the same reason, if you cut the young silks from one side of an ear shoot, no grains will grow on that side. Every silk is connected with a grain space on the cob, and if that silk

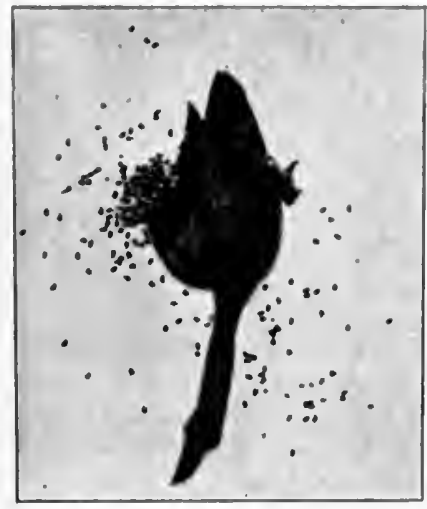

Fic. 13. - SOUND AND Good ToBaCCO SEED WHERE THERE WAS an Abundance of Pollen APPLIED

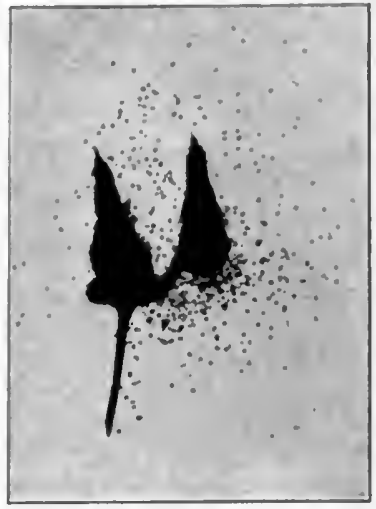

Fig. 14.-Chaft, instead of Tobacco SeEd, Where No Pollen Was allowed to REACH THE STIGMA

catches no pollen, a vacant grain space is left on the cob where this silk arises.

Pollen does not cause fruit or seed to grow or be produced unless the plant that bore it is of the same kind as, or closely related to, the plant on whose pistil it is placed. Thus peach pollen is useless on apple blossoms. The pollen may come from the same flower of which the pistil is a part, from another flower of the same plant, or from a different plant. 
Self-pollinated plants. - In the flowers of wheat, oats, and peas, the pistil is usually pollinated by the pollen that is produced in the same flower. Such plants are said to be self-pollinated. Self-pollinated plants do not mix with other kinds in the field.

Cross-pollinated plants. - On the other hand, the pistils of some kinds of plants generally receive pollen that grows on a different plant. Such plants are said to be crosspollinated. If a farmer grows a white and a yellow variety of corn side by side, these will be mixed in a few years. This is because the light pollen dust from one kind is carried by the wind to the silks of the other kind. Many a boy has had his patch of popcorn ruined by planting it near field corn that bloomed at the same time as the popcorn. You have perhaps noticed the pollen of corn as it was carried by the wind, like fine dust. You have probably also noticed in the spring clouds of yellowish dust blown from the pine trees. This dust is light pollen carried by the wind.

How insects help the flowers to form seed. - Some plants have heavy pollen, which the wind cannot so easily carry. Cotton is one of these. Such plants generally have gayly colored petals that attract the insects. Even children like to taste nectar by touching the tongue to a blossom of honeysuckle after its petals are removed. The flower offers nectar to insects and in return the insects usually bring pollen from a blossom of the same kind and place this on the pistil. If we notice a bee as it enters a flower, we observe that much yellow dust adheres to its body. This is pollen that it rubs against while visiting other 
flowers. While it is in the blossoms, it usually happens to brush against the sticky or rough stigma, which catches some of the pollen it brings. It is interesting to watch the movements of the insects when they are thus helping the flower to form seed.

Gardeners who grow tomatoes in the greenhouse collect the pollen and place it on the flowers by using a brush (Fig. 15). If they fail to do so, they get very few

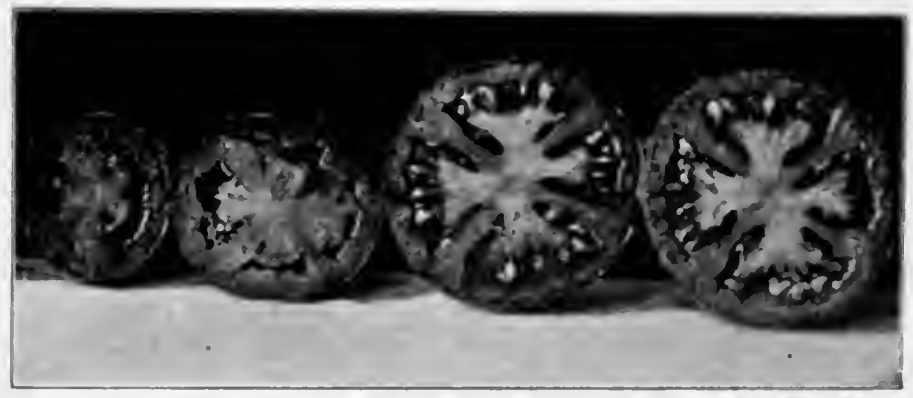

Courteoy Mich. Expt. Station

Fig. 15. - Pollination of Tomatoes

The two on the right grew from pistils abundantly supplied with pollen; the two on the left from pistils receiving but little pollen.

tomatoes. If there were many large insects in the greenhouse, they might not need to take this trouble. We do not need to practice this hand pollination when tomatoes are grown in the garden, for then insects might do this useful work instead of human hands.

In one locality the fruit-growers thought that bees were injuring their ripe fruits, and accordingly made the keepers of bees remove their hives. As a result, the fruit crop decreased. Then the bees were brought back, and the crop 
at once increased. If the weather, when fruit trees are in bloom, is so cold or rainy that the bees do not fly from flower to flower, the crop of fruits is usually small.

Cross-pollinated plants (those that need to get pollen from other plants of the same kind) can be divided into two classes, first, those whose pollen is carried from one plant to another by wind; second, those whose pollen is carried by insects.

Why strawberries sometimes fail to bear. - A gardener once had a well-worked strawberry bed that showed a mass of leaves and runners, but yielded few berries. This was because he had planted only one variety, and that one variety did not have well-developed stamens. His patch of strawberries would have borne good crops if he had planted every fourth row with another variety having stamens as well as pistils. From this you see it pays to know some-

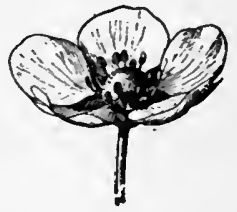

FIG. I6. - F LOWER OF STRAWBERRY with вотH PIStILS and Stamens

thing about how plants are supplied with pollen. Imperfect varieties of strawberries are called pistillate varieties, because they have pistils only, and the perfect kinds are called staminate or perfect varieties, because they have stamens as well as pistils (Fig. I6).

Why the fruit crop sometimes fails. - Even when the flowers contain both stamens and pistils, there is often a failure to produce fruit. This is likely to happen when a single variety of grapes, pears, or apples is planted alone and away from all other varieties of the same fruit. Some varieties of these fruits must get pollen that has 
grown on a different variety. The pollen of a Duchess pear, for example, when it falls on the pistils of a Bart-

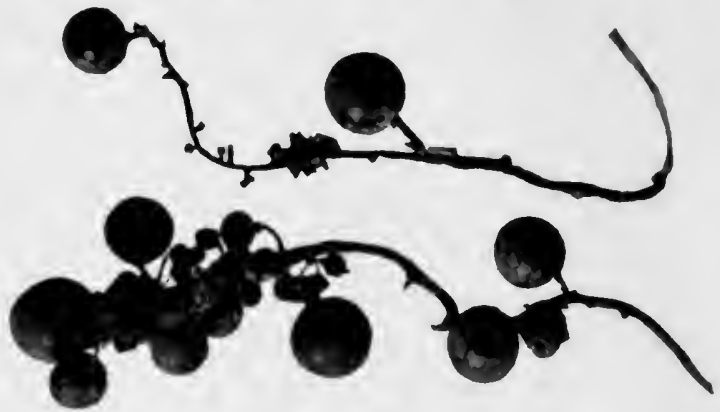

Fig. 17.-Briguton Grapes, SELP-TERTILIZED

lett pear tree will cause fruit to grow; but generally no pear develops when the pollen from a Duchess tree falls

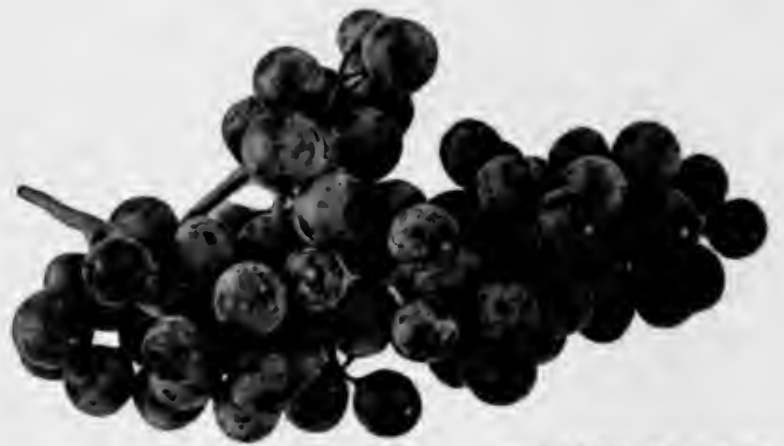

Aner N. Y. State Experiment Station

Fig. 18. - Brighton Grapes, cross-FertiLIEED

on the pistils of another Duchess tree. Trees or grapevines that act thus are said to have pollen that is impotent (powerless) on blossoms of the same variety. Im- 
potent pollen is one of nature's many ways of preventing self-pollination (Figs. I 7 and 18 ).

In planting an orchard or vineyard for home use it is a good rule to plant several varieties of apples, several of pears, and several of grapes, so that one variety may supply pollen for the blossoms of the others.

Pistils and stamens in different parts of the same plants. -We have called the pistils and the stamens the essential parts of a flower because both are necessary to the formation of the seeds. When one flower bears both stamers and pistil, it is called a perfect flower. But the pistil and the stamens are not always found in the same flower. In the corn plant, for example, the silks are the pistils, while the stamens from which comes the pollen are found in the tassel, another part of the same plant. Thus you see that in corn the staminate flowers are borne on the top of the plant and the pistillate on the young ears of corn growing on the stalks of the same plant.

On a squash, cucumber (Fig. I9), or watermelon the pistillate

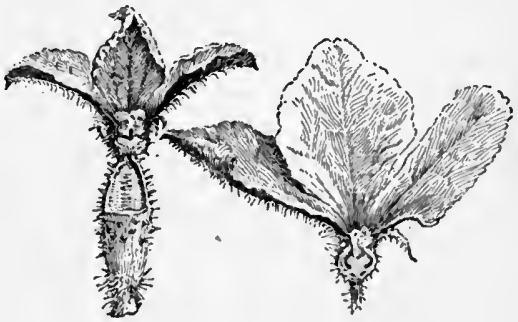

Fig. 19. - Cucumber Flowers On left, pistillate; on right, staminate. blossom may be known by the little squash or melon which shows below its yellow petals. These blossoms have pistils but no stamens. In other parts of the same plants are staminate blossoms, that have stamens, but no pistils and no swollen part. Among other plants having stamens 
and pistils borne on the same plant, but not in the same flower, are the castor bean, the oak, and the pecan.

Pistils and stamens are sometimes on different plants. This is the case with hemp, willows, and poplars.

FXERCISE. - Tie paper bags or pieces of tough paper snugly around the unopened buds of any kind of plants that may be blooming when you study this lesson. In a week notice whether the pistil is growing and seeds are forming If so, these plants do not need visits from insects, but are self-pollinated. Notice what flowers are being visited by insects and especially by honey bees. Notice the kind of insect. Watch them to learn whether they brush off any pollen of another flower against the pistil.

NOTE TO THE TEACIER. - If a catalogue of some nursery company can be had, examine its list of strawberries and by questioning the pupils learn which of these varieties are grown near the school. Have they fruited well? If not, are they marked in the catalogue as pistillate varieties? Blooms of pumpkins or of any kind of melon make a good subject for examination and discussion in this lesson. The questioning on all lessons should be more to encourage observation and understanding than to measure memory work.

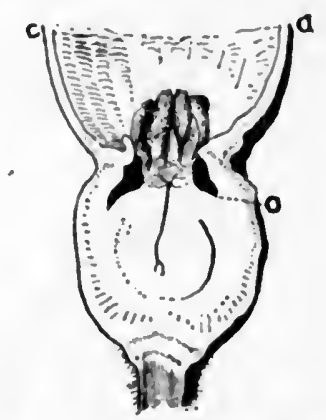

FIG. 20. - SECTION LENGTHWISE turougi a P'istillate SQUasi

BLossou

0 , ovule case; $c$, base of corolla. 


\section{SECTION IV. GERMINATION OF SEEDS}

THE seeds have been called the children of the plant. The parent plant provides the seeds with food enough to serve them until the young plants have formed roots and leaves with which to gather their own food.

Food for the young plant. - Let us examine a grain of corn to see how the plant packs up the good things for its seed children. Soak a few dozen grains of corn in water over night so that for to-morrow's lesson you may be better able to separate their parts. Outside is the tough coat, which you will remove from the soaked kernels. With a sharp knife you will cut crosswise through a dry or soaked kernel, with its groove side

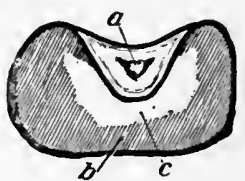
up. You will probably be able to see $a$, germ; $b$, hard starchy first a cream-colored portion or germ next to the groove and near the tip of

Fig. 21.-Cross-Section THROUGH A CORN KERNEL layer; $c$, soft white starchy layer. the kernel; second, a layer of soft white starch; and third, a harder whitish layer, also made up chiefly of starch.

The germ is the only part of the grain that sprouts. It may be called the baby plant. The two layers of starch and other materials are placed near at hand only to supply the germ with food when it first wakes to begin its 
growth. If it is not too cold, plant several dozen grains of corn either in the ground or in a little box inside a

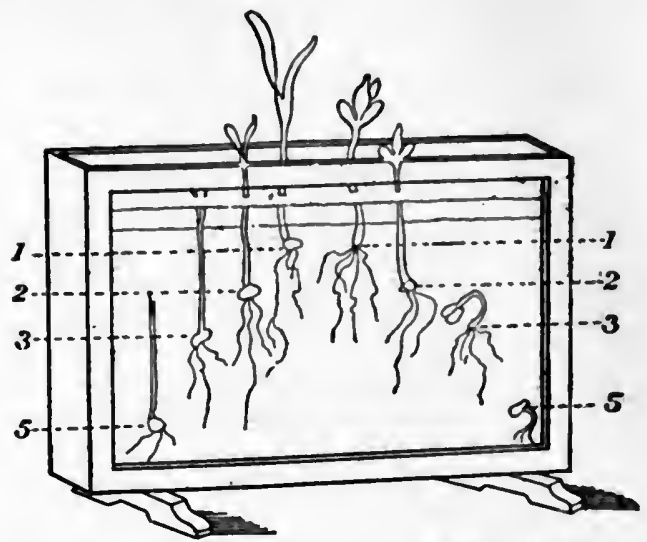

Aner U. 8. Dept. Agr.

Fig. 22. - Corn Grains planted at Variovs Deptis in a BOX Witu Glass Sides

window (Fig. 22). Dig up a few of these every day to learn how the young plant grows.

Roots grow near the tip end. - The sprouting of seeds is called germination. When you dig up seeds that have begun to sprout, you find that a little root has started downward, and that a little shoot has grown upward to make the above-ground part of the plant.

EXPERIMENT. - Each day the root and shoot become longer. Find whether the root grows only near the tip, or whether all parts of it lengthen. To learn this, make two marks with India or drawing ink or other "fast" color on a white root that is about an inch or an inch and a half long. Lay a ruler by the side of the root and make the first mark a quarter of an inch from the tip of the root; make the other mark half an inch nearer the grain. A black thread may be tied 
around the root as a marker instead of using drawing ink. Keep the sprouted grain moist by placing it in damp sand or between moist blotting papers kept either in a small tight box or between two saucers. After a day or two measure the distance between the two marks, which you will find to be unchanged. Now measure from the outer mark to the tip of the root and you will find that this portion has grown rapidly.

Roots of all plants increase in length only near the tips. However, if you make measurements of the stems of young plants, you will find that all parts of the young stem, as well as the tip, increase in length until a certain age is reached.

Moisture necessary to make seed sprout. - Did anybody in this class ever plant seed when the ground was dry and when no rain fell soon afterwards? Did any seed come up? You can prove that seeds need moisture in order to germinate, by planting some seeds in two tomato cans in the window; keep the soil in one can very dry and in the other barely moist. What happens?

Heat required for germination. - Oats that were sown during very cold weather have sometimes remained unsprouted for a month. When the sowing was done in warmer weather, they came up in about one third of that time. Seeds of different plants require very different amounts of heat to wake them and make them sprout or germinate. Seeds of wheat, oats, rye, and barley germinate when the soil is quite cool, and so the farmer sows these crops during the colder part of the year. Corn grains require more heat than oats, but less than the seeds of cotton, cowpeas, or peanuts. A farmer never plants these last crops until the soil has become somewhat warm. 
Sprouting seeds need air. - Corn planted in a field that was afterwards overflowed by a creek for several days failed to come up. It was because the water kept the air away from the seeds.

Three conditions for germination. - We now understand that for a seed to germinate it must have moisture, air, and the proper amount of heat.

How food is stored for the young bean. - You may soak or plant peanuts, beans, or cowpeas to learn another way in which parents pack plant-food for the use of the infant plants. By carefully removing the seed-coat from the soaked seed you find that all the seeds are made up chiefly of two thick "halves," which later will become the seedleaves, or first pair of leaves. These "halves" are storage places or pantries for the food hidden away by the parent plant for its seed-children while too young to get food from the soil and the air. Mankind's supply of bread comes chiefly from tiny pantries stored in the seeds by grain plants. By carefully opening the halves of the seed of bean or cowpea, you will find the germ, which appears as a very small, flattened, white bud near the point where the two fleshy halves are joined together.

"Coming up." - When germination occurs, this bud of the bean, squash, and many other plants is pulled to the surface of the ground in an interesting way. That part of the stem just below the seed-leaves rapidly increases in length, humping itself into the shape of a wire staple. Hence the first thing seen above ground is a part of the stem shaped like the center of a wire staple. One end of this staple is formed by the roots, while the other end 
bears the seed-leaves, which are still imprisoned in the old seed-coat underground. However, the stem is steadily pulling this end out of the old seed-coat, and by a backing process it soon brings above ground both the fleshy seed-leaves and the tiny bud nestling between them. The seed-coat may have been left in the ground or may have been lifted out, still imprisoning the bud. Now the stem lifts its head, straightens its back, and if the seed-coat adheres, pushes it off by the growth of the bud.

On the other hand, the garden or

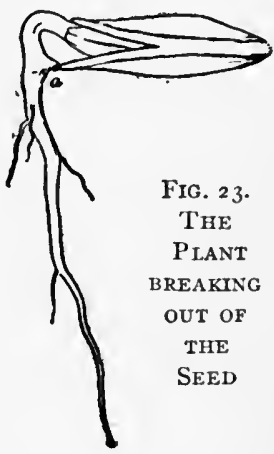
English pea keeps its two seed-leaves underground (Fig. 25), because the part of its stem that grows rapidly is the part above the seed-leaves and between them and the bud. The young pea stem also humps its back and pulls its real leaves out of the soil backward.

The seed-leaves of all these plants, whether coming above ground like those of beans, cowpeas, squash, and cotton, or remaining in the soil, serve to feed the young plant before its own roots and leaves can support it. At first these seed-leaves are thick, but as the food in these pantries is given to the growing plant, the seedleaves shrivel and finally disappear. Since these seedleaves have to do a very different work from that done by the later or true leaves, they naturally look very different.

Large seeds. - The largest seeds usually make a quicker, stronger growth and a larger yield than small or light 
seeds. It is best, therefore, to separate the largest seeds from the others by using sieves or screens.

Testing the germination of seeds. - Seeds of some plants lose the power to germinate after they are a year or two old; athers are good when a number of years old.

If seeds become moist and go through a "heat," they lose their power to germinate. Children can often help

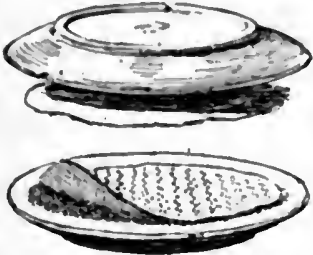

FIG. 24. -A HOME-MADE Seed Tester

their parents by testing the field or garden seeds they expect to plant in order to discover what percentage of them can grow. All that is needed is a plate; a piece of thick, clean, dark cloth, to be dampened and spread on the plate; a similar piece to be dampened and used as a cover for the seeds; and a second plate to place over it all (Fig. 24). Keep this home-made seed tester in a warm room. Examine the seed on the fifth and eighth days, and as much oftener as you wish.

ExERCISE. - With a sharp knife, cut through grains of corn that are soft and dented and through others that are flinty and not dented. Make a drawing to show the difference between the two grains in the thickness of the several layers. Select six grains of corn having the largest possible germs, as shown by the size of the depressed area. Select six others with the smallest possible germs. Which grains would you expect to make the largest, strongest young plants and to be best able to push up if covered rather deep?

Shell ten good ears and measure the shelled corn, so as to calculate how many ears make a bushel ( $56 \mathrm{lb}$. of shelled corn). Write in your notebook the number of ears per bushel.

A good exercise is to go to a number of cornfields and estimate how many bushels per acre each field will yield. If you can get permission, 
gather the corn from a carefully measured area (at least $\frac{1}{20}$ acre). First weigh the ear corn and then compare your estimates with the actual yields. Be sure to record your estimates in your notebook, where you can later write the actual yields.

Note to the TeAcher. - Have the pupils make a home-made seed tester by following the directions in the text or by dampening many folds of old newspapers kept in a small tight box. In it let them place fifty or one hundred seeds of as many kinds as they can find near home. Let them pick out the largest and smallest seeds of wheat, radish, or peas. Place both sizes in different parts of the germinating box or plate and notice which produces the largest shoots. The interest of parents may be enlisted by having the pupils make tests to determine the percentage of germination of the seeds of vegetables or field crops that their parents expect to plant.

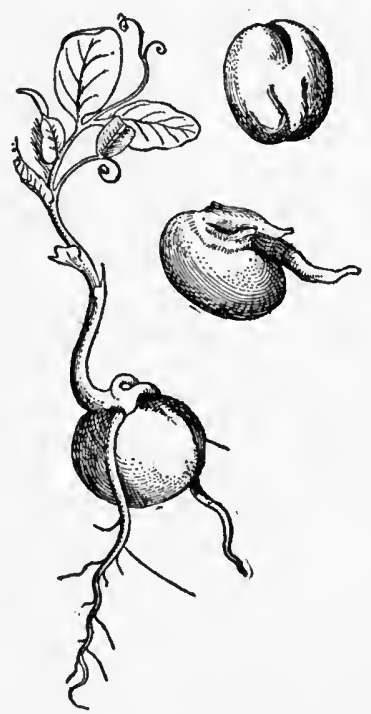

Fig. 25. - Germination of the Pea 


\section{SECTION V. WATER FOR THE PLANT}

Is order that plants may grow, they must obtain water from the soil, and food from both the soil and the air. They must form all parts of the plant out of these materials. We shall first consider how plants get their supply of water.

The need for water. - There is a constant stream of water flowing upward towards the leaves from the roots, which gather it from the soil. The leaves use some of this water and then throw off into the air that which they do not need. We cannot see this current, but careful measurements show that plants send upward through their stems to the leaves an immense amount of water. A clover plant has been found to give off in one day twice its weight of water. A crop of hay on one acre producing two tons has been found to use during its growing season more than six hundred tons or wagon loads of water. Speaking generally, a crop requires about four hundred times as much water in

a season as the weight of the dry substance in the crop.

Experiment. - What becomes of the water? A part of the water that passes into plants is kept there to make the plant plump and stiff and to help in carrying food. Most of the water merely passes through the plant. The roots take it in and send it up to the leaves. The leaves throw it off as water vapor. You can watch leaves getting rid of their surplus water by turning a glass upside down over a plant that is growing rapidly in the sunshine (Fig. 26). Every minute water is coming from 
the leaves as vapor. As soon as the air under the glass receives more moisture than it can hold in the form of a vapor or gas, the extra moisture gathers in drops on the inside of the glass.

How plants lift water. - What force enables plants to collect water from the ground and lift it into the roots and stems? To understand this, we need to study the tiny parts or cells of which the plant consists. We may think of a plant cell as a tiny room, too small even to be seen without a powerful microscope. But this little room or cell has no doors nor windows nor other openings into it. It is completely lined on the inside with a layer of living jelly-like material. This layer lets water and the material dissolved in water soak through it and thus pass to the inside of the cell. An important fact to remember is that the water passes in, but will not pass out into the soil again while the plant is healthy. This is

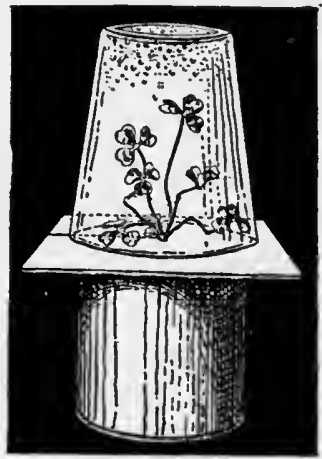

Fig. 26. - SHOWING THAT WATER IS TIIROWN OFF FROM THE LEAVES OP Growing Plants partly because the water in the soil is more dilute than the sap which fills the plant cell; and also because the dilute soil water can flow in through the cell lining more rapidly than the denser sap inside can flow out into the soil. This flow of water towards the sap or denser liquid helps to force water upward from the roots. The leaves assist in the upward flow, for water must rise to take the place of that which the leaves give off into the air. 
The water current. - The current of liquid rising from the roots and soil soaks through tiny canals in the stem up to the leaves. In trees, the tubes that carry water from the soil upiourd are located in the sap-wood, while those that bring the sap downward from the leaves to build up,

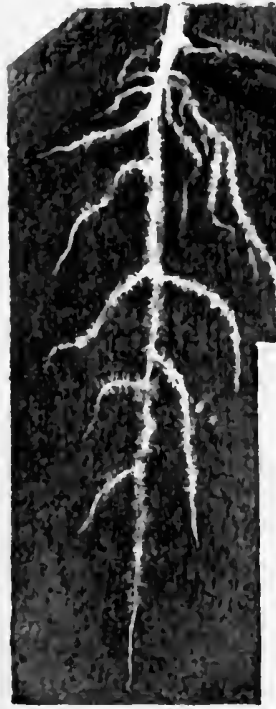

Fig. 27. - ROOT-HAIRS of SQuash all parts of the plant lie between the outer bark and the sap-wood. If you cut off a branch of a grapevine just as the buds are swelling, you will notice next day that the wound has "bled," that is, water has been forced up to and out of the cut portion. When we speak of the sap rising in the spring, we mean that the roots have begun to force water upward. As soon as the leaves appear, the real sap will flow downward in the inner bark at the same time that the water from the soil continues to rise through the tiny channels nearer the center of the stem.

Root-hairs. - The large roots which you easily see when you pull up a plant are not the ones that absorb water from the soil. If you will carefully dig up the smallest roots of a very young plant, you will notice that the slenderest roots are covered near their ends with a white coating like velvet. These white threads are root-hairs (Fig. 27). It is the business of each of these short, velvety threads, or root-hairs, to absorb moisture and 
dissolve plant-food from the soil. You can see the roothairs plainly by causing grains of corn or any other seeds to sprout between moist blotting paper and by examining after a few days the roots that have grown out.

Root-hairs are tiny workers that have to furnish all the water a large plant needs. There are thousands of them on every large growing plant. Root-hairs can be found only near the tips of young roots. They are so slender that they can push in between the particles of sand or clay and absorb moisture from all the soil grains that touch them. It is important therefore to retain the small or young roots on trees or other plants that are to be transplanted.

Leaves do not supply water. - The dew and rain keep the leaves from wasting moisture, but do not enter the leaves themselves. Leaves do not supply the plant with water.

Note to the Teacher. - Crosby's Exercise 2 (see note to Section 1) illustrates how water enters the roots of plants. You may well use Crosby's Exercise 5 to show the rising of water in plants. You can substitute the joint of a reed for his glass tube. Have the pupils place seed in moist newspapers, cloth, or soil to germinate. As soon as the root-hairs develop require every one to hand you a drawing showing these. 


\section{SECTION VI. HOW PLANTS GET FOOD FROM SOIL AND AIR}

No solid matter can enter a plant. The living matter that lines the inside of each cell-wall will not let even the finest solid particles pass, though they be as fine as those of flour or of phosphate. No part of the soil can act as food until it has been dissolved.

Sugar and salt, as you know, dissolve in water, and just so do certain substances in the soil dissolve in the water. In ordinary soil this solution is very weak, so weak that it will usually take several thousand pounds of water to carry to the plant one pound of lime, phosphate, or any other single plant-food. In later chapters, you will learn what food certain plants require and also how the farmer adds this to any soil that is too poor to supply to the plant the needed nourishment.

Plants are made largely from the air. - Fortunately for the farmer and for the food supply of the world, the plant obtains more material for its solid substance from the air than from the soil. In every hundred pounds of dry plants there are usually less than three pounds that come from the soil. The grains of wheat, corn, and rice consist chiefly of starch. Other plants are rich in sugar, while the seeds of still others contain much oil or fat. Starch, sugar, oil, and many other substances in plants are made 
by the leaves largely from one form of carbon, which occurs as a gas in the air. However, there will be no abundant growth of leaves to make this starch, sugar, or oil unless the roots provide the small but necessary amounts of certain other substances.

Food taken from the soil. - There are at least ten elements that plants draw from the soil alone. All but four of these are nearly always present in the soil in quantities sufficient to supply our crops for hundreds of years. The only plant-foods that are taken from the soil and that we need talk about in this book are those four that are sometimes so scarce that the farmer may have to add them to the soil in order to get a good crop.

Precious forms of plant-food. - The four plant-foods or elements that are often not sufficiently abundant in the soil are nī'trō gĕn, phŏs' phō rŭs, pō tăs'si um, and căl' çr̆ ŭm. We call these the precious elements, for they are more important to the plant and to the farmer than the precious metals, silver and gold. Besides, the farmer often has to buy them, paying silver and gold for them.

One cause of poor crops. - These four elements exist in the soil in combinations; we speak of the potassium combinations as potash, and of the calcium combinations as lime. In some soils only one of these four may be insufficient; in another soil there may be a lack of two of them; in a third three of them may be wanting; and in yet another soil all four of them may need to be supplied. If a single one is lacking or insufficient in quantity, there will be a failure of the crop, no matter how abundant the other three may be. So it happens that a farmer may buy 
phosphates and potash and furnish these freely to his crops, and yet have them fail because one of the other elements may be lacking.

These precious elements and all other materials that go from the soil into the plant must first be dissolved in water. This solution of plant-food is then drawn into the cells of the plant and carried up through the stem, the greater part directly to the leaves, where it is used and mixed with

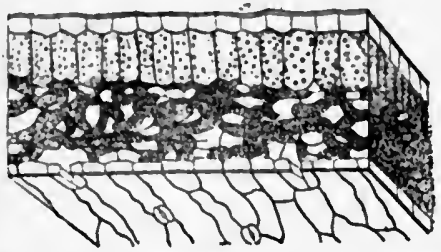

Fig. 28. - Showrsg how a Cut Evge plant, to be used in enlargOF A LEAF LOOKS WIEN HIGLY MAG- ing and making new leaves, NIFIED

A little of the under surface is shown and in it the "gateways" or entrances seeds.

for air. made from the carbon of the air. The result of this digestion and mixing is a liquid called sap. This sap is slowly distributed to all parts of the stems, roots, flowers, and

the substances the leaves have

Roots help to dissolve soil.

- Roots give off small amounts of a weak acid which dissolves more of the plant-food in the soil that the roots touch than pure water can. This food dissolved by acid is added to that already dissolved from the soil by water, and the mixture is drawn into the plant and started towards the leaves. The leaves prepare this solution still further and make it into sap before it can nourish and build up the plant.

Plants need air. - You have doubtless learned in studying physiology how persons and animals breathe. They take the air into the lungs and the oxygen gas which it 
contains is there taken from it for use in the body. If persons and land animals remain long under water they drown, because the supply of air is cut off. Likewise ordinary plants die when their leaves or roots are kept long under water, because they are thus deprived of sufficient air.

How air enters the leaf. - Why do you suppose that the leaf is made so thin and broad instead of being rolled up into a compact, round little bundle? Leaves, even the thinnest, are made up of several very thin layers, each one of which consists of a great number of cells. In the outer layers of the leaf these cells lie close together, making a tight thin sheet which covers layers of more loosely arranged inner cells (Fig. 28). In these thin outer layers are great numbers of tiny openings. These are gateways for the entrance of air into the inside of the leaf. They are also the gates through which leaves get rid of the surplus water sent up by the roots. They are too small to be seen with the naked eye, and exist in large numbers on every square inch of the under side of every leaf. The plant can open and close these by means of special cells called guard-cells. When the weather is very dry, these gateways partly close, to keep moisture from passing too rapidly out of the leaves.

Use of air by plants. - Plants and animals are alike in "breathing" fresh air, containing oxygen. Man and animals take oxygen from the air to use in their lungs and give back a gas called carbon dioxid, which consists of carbon and oxygen united together. Plants, too, use oxygen, although they have no lungs. In making food for 
themselves green plants use also the carbon dioxid of the air, such as the animals give off. In fact, through the pores or little gateways the air enters and comes in contact with the inside cells of the leaves. These cells take from the air the carbon it is holding in the form of a gas. This gas is called carbon dioxid. Out of this carbon dioxid gas and water the leaf cells form starch, sugar, and other substances of which plants are made.

Leaves need light. - An interesting fact connected with this latter use of air by plants is that the leaf cannot use this carbon dioxid unless the leaf contains green coloring matter. This green coloring matter usually forms only when there is light. It disappears from plants when the light is cut off.

EXPERIMENT. - Examine grass covered by a board or straw, or a potato shoot grown in a dark room, and notice that the absence of light has prevented the formation of the green color and left the leaves and stems white. Such plants cannot grow to maturity because they cannot feed on the carbon in the air. So if we accidentally throw dirt over all the leaves of a little corn or cotton plant when cultivating the crop, we cut off the light and stop the growth of the plant. This is one of the ways by which the farmer kills weeds, namely, by covering them with earth.

EXERCise. - What is the color of young corn plants on wet spots after a long period of wet weather ? This unhealthy color was caused by lack of what?

In the middle of a hot, dry day what shape does a large green leaf of corn take? Do the edges roll upward or downward? Do you think this position increases or decreases the loss of water from the leaves? There are special cells in the corn whose work it is to roll the leaf when water is scarce. They are different from the guard-celis, but likewise help the plant to economize water. Observe whether leaves are most abundant on the tips of the branches of trees or nearer 
the center of the tree top. In which position would they receive most light?

Note to the Teacher. Optional Exercise. - Tincture of iodine makes starch change to a purple color. Add a few drops of this to a teaspoonful of water; with this moisten a thin slice of Irish potato, sweet potato, bread, cut corn grain, plant stems, or lettuce leaves. Before staining green leaves with iodine you should dissolve out the leaf green with alcohol very carefully heated in a vessel of hot water. A substance not colored purple by iodine solution lacks starch. Test a slice of meat; a cut stem of whitened grass from under a board; the white inner leaves of cabbage; or the white or white-variegated leaves of coleus, etc. ; and any leaf that has been kept in darkness for several days.

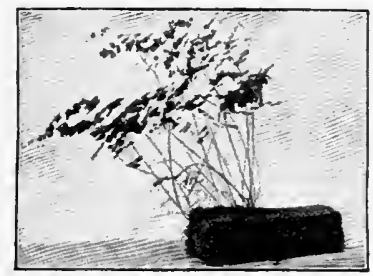

FIG. 29. - A FERN THAT SUFFERS FROM TOO LitTle Sunlight, SHOWING POOR FOLIAGE AND Growth 


\section{SECTION VII. HOW PLANTS ARE PROPAGATED}

Most of our field crops are increased or propagated by means of seed. One plant, because of the seeds it forms, may become the parent of hundreds or of thousands of others of the same kind. This method of increasing plants is well understood.

There are some plants the seed of which must be sown every year, for example, oats and corn. These are called annuals, because they live during only one growing season. Plants that live two years are known as biennials. A third class consists of the perennials, that is, plants that live for more than two years. Bermuda grass, alfalfa, and all trees are examples of perennial plants.

Most cultivated plants, including the perennials, develop from seeds. With most fruit trees and with many other plants, it is best to provide for the increase by budding, grafting, and the like. These and other methods of multiplying plants without the use of seeds are called propagation by division.

Some plants propagated by buds. - Did you ever see seeds on sugar cane or sweet potatoes? In tropical countries these plants make seed, but not usually in our country. Since these plants as a rule form no seed here, 
we must find some other part of them that will grow. The part of the plant that can most nearly take the place of a seed is a bud. The sugar planter places long sugar canes in the ground, expecting the buds on them to grow. In place of the sugar cane he may plant a piece of an Irish potato containing one or more eyes, or clusters of buds. But if he so cuts the potato that one piece has no bud in it, no plant will grow from it and he will have a vacant hill.

Most fruits do not "come true" from seed. - One reason why the grower uses buds of sugar cane, sweet potatoes, and seedless oranges is because he cannot get seeds to plant. There are advantages in using buds instead of seed in some cases even when the seed can easily be obtained.

By planting the seed of the peach we do not get peaches just like the one from which the seed came. The same thing is true with apples, pears, strawberries, and most of our fruits. Of such fruits we say, they do not "come true" from the seed.

Budding. - The method of growing fruit like that on the parent tree is by budding or grafting. If we grow peach, apple, or other trees from buds, we may be quite sure that the fruit on the young tree will be like its parent and much like all other perfect fruit in the same variety. If you take a hundred buds frem one peach tree and cause these to grow into a hundred young trees, they will all bear fruit practically alike. In this case, the trees would be more closely akin to each other than would be a hundred trees grown from the seeds from one tree. This is so because a 
bud is a part of only one plant. A seed is of ten made by lwo plants, and the different seedlings may resemble either parent, while each budded tree has only one parent.

Cuttings. - Plants are increased either by planting seeds or buds. If, however, you should plant in the ground a detached bud from a grape-vine or from

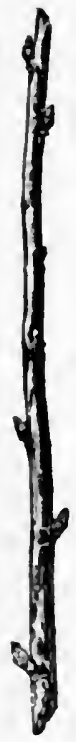
any fruit tree, it would not grow. It would die (1) because a bud cannot at first get any food from the soil, and (2) because such a bud has not much food stored up to nourish it until it forms roots of its own. But you may so plant it that it will have much ready-made food convenient. Before the leaves start, cut off pieces of fig trees or grape-vine of last year's growth six or eight inches long and containing at least three buds (Fig. 30). These pieces of stem or branch are called cuttings. Plant these in sandy soil, the upper bud just above the surface and the lower bud deep in the soil. If you have done this as a skilful gardener does, you will see after Fig. 30. - A CuT- a few weeks that the upper bud has begun to develop into a branch, which in time will be a real bearing grape-vine. If you dig up one of these little grape sticks that has thus begun to grow, you will find that tiny roots have grown. It was the food material stored in the stem or cutting that enabled the buds to grow.

The use of various kinds of cuttings is the usual way of 
increasing grapes, figs, poplars, and many other kinds of plants. The cuttings should have two or more joints. Grape cuttings usually have two or three buds. The usual time to put them in the ground is late winter. Under a cover of glass, and sometimes without this covering, many kinds of flowers can be increased by means of cuttings, for example, roses and geraniums. The chief use of the cover is to keep moisture in the leaf, the soil, and the air.

Uses of budding and grafting. - So if we wish to make a grape, or peach, or apple bud grow, we must plant it, not by itself in the soil, but joined to enough of the wood and bark to furnish it with a supply of ready-made food. This is what the fruit-grower does when he plants cuttings of the grape or when he buds his peach or grafts his apple trees.

You can learn how to bud and graft fruit trees and roses if you will study the pictures and directions and will practice a little every day for a week or two. By budding or grafting the poorer varieties in your parents' orchards with the buds or twigs from the best variety in some neighbor's orchard, you will be of real help at home and will probably be able to enjoy some of the improved fruit yourself.

Directions for grafting. - Grafting consists in making a short piece of twig of one plant unite with the branch or root of another. The plant that furnishes the twig (called a $c^{\prime} \partial \tilde{\partial} n$ ) must be very closely akin to the plant upon whose branch or root the cion is to grow. The plant or piece from which the roots spring is called the stock. Generally, stocks are common young plants that have been grown from seed. Usually, the cion is a short 
piece of twig about one year old and bearing two or three buds. The stock may be a young piece of root, a young or

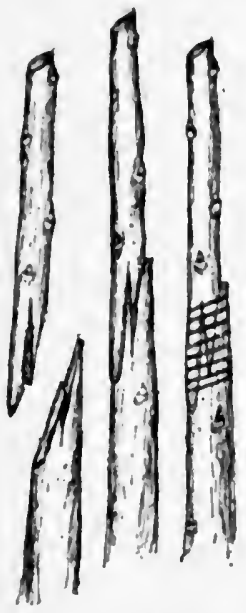

FIG. 3r. - WnipGRAFTING an old branch. Grafting is generally done in the late winter or very early in spring, while the plant is resting.

In Figure $3 I$ is shown one way of cutting the cions and the stocks in grafting apple cions on small branches or small pieces of apple root. Your knife must be sharp and thin, so as not to split the cion or stock in making the slit. After cutting the two pieces as shown in the figure, place their ends together, making the two slender tongues lock. The important point is to Showing how small make sure that on stocks are grafted. one side the bark of the two pieces comes together evenly. The union is caused by the layer just under the bark of the cion growing against the similar layer in the stock. These groaving layers must touch on at least one side of the graft. In setting in the ground cions that have been grafted on roots, the

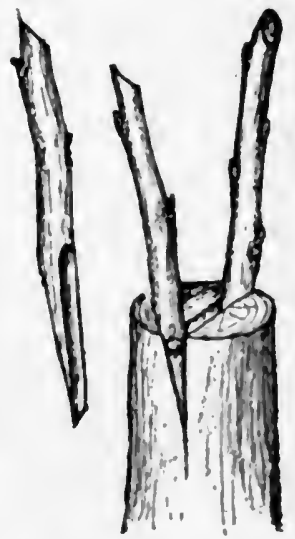

Fig. 32. - SHowisc now LARGE BRANCHES ARE GRAFTED joint or union is placed below the surface of the ground.

Grafting on large branches. - When a small cion is grafted on a branch that is one or two inches through, the 
limb is cut off square, then slightly split (Fig. 32). In this slit is placed the sharpened cion, which is now cut tapering from both sides. The bark of the young cion must join evenly with the bark on one side of the large split limb. To make sure that the two barks are pressed together tightly, the wedge part of the cion is left a little thicker on the outside, that is, on the edge that is going to join the bark of the large branch. In all kinds of grafts, drying must be prevented by covering the cut portions with grafting
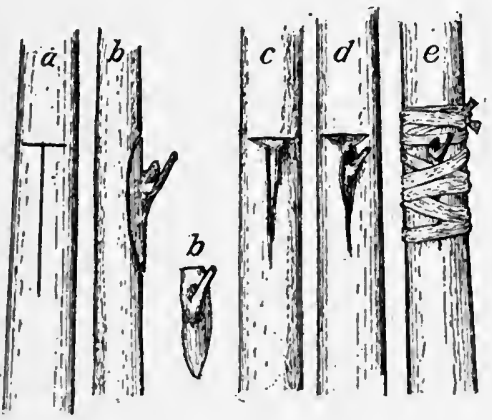

FIG. 34. - BUDDING

$a$, showing the slit; $b, b$, the bud; $c$, the slit opened; $d$, the bud in position, and $e$, after tying.

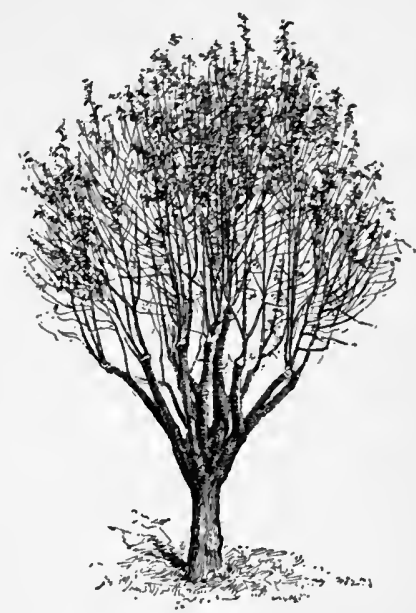

Fig. 33.-AN APPle Tree, the TOP OF WHICH HAS BEEN RENEWED BY GRAFTING wax. Generally, a graft on a small stock is tied with a cloth string and then waxed. Fig. 33 shows a new top made by grafting.

Budding. - Budding consists in inserting a single bud, with a tiny strip of attached bark, just under the bark of a growing shoot. The bud should be cut out with a 
slender piece of bark and wood about three fourths of an inch long, leaving a part of the leaf stem for use as a handle. This is the way in which peach and mest other fruit trees are increased. Budding is usually done in

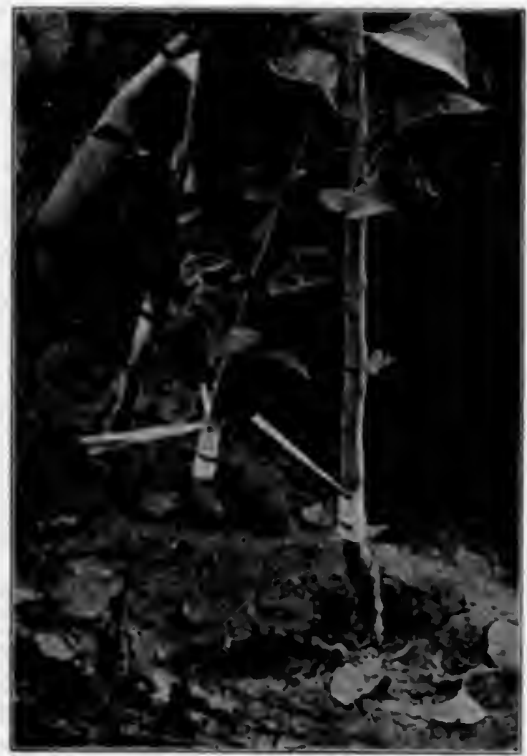

Fig. 35. - Tying the Buds after Budding summer while the plants are in active growth. To serve as stock for budding, an apple tree may be about two years old, but a peach seedling can be budded in its first year of growth.

Two slits in the shape of a $\mathrm{T}$ are cut in the stock, as shown in Fig. 34. The bark below the cross slit is gently lifted and the bud placed under these two flaps of bark, and tied in place. In a few weeks, when the bud has united with the stock, the strings should be cut. Next spring the top of the stock above the inserted bud should be cut off, so as to let the inserted bud become the leading branch of the tree. Fig. 35 shows the budding of trees in the nursery row.

EXERCISE. - Practice grafting short pieces of twigs of plum, persimmon, apple, or other trees and shrubs. Then graft a twig of any of these, that have dropped their leaves, on a slender shoot of the same 
kind. See who can cause the greatest percentage of the grafts to live. In warm weather practice budding on any of these plants. Grafting wax may be made by melting together 5 parts of resin, $2 \frac{1}{2}$ of beeswax, and $\mathrm{I}$ of tallow. When heated, pour the mixture into cold water, grease your hands, and "pull" it as you would "pull" molasses candy.

TEACHer's Note.-Crosby's Exercises Nos. 17, 18, 19, 20, 21, 22, and 23 treat the subjects of this section in much more detail than is possible here. After the pupils have practiced on detached twigs, they may graft on standing plants, provided it is in winter. If no fruit trees or roses can be risked, they may at first practice in grafting wild cherry, wild plums, and others. After growth has been going on long enough for the bark to slip well, budding of wild cherries, peaches, etc., may be attempted.

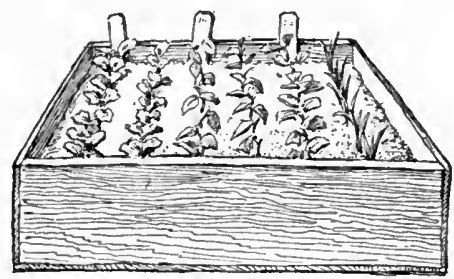

Fig 36. - A Cutting-Box, Filled with SAND, SUITABLE FOR A SCHOOL-ROOM WINDOW 


\section{SECTION VIII. IMPROVEMENT OF PLANTS}

OUr valuable cultivated plants have been changed from poor or useless wild plants. The tomato, for example, bore very small and worthless fruits, and the cultivated rose was once a wild rose with few petals. Greatly as man has improved plants in the past, recent discoveries of some of the laws of improvement should make future progress still more rapid.

Selection. - By selection, or choosing seeds from the most desirable individuals, plants may be slowly changed. Selection is the easiest, surest, and usual method of improvement. In plants and animals the general rule is that the offspring resembles the parents and grandparents. But among the five hundred or more stalks grown by planting the kernels of a single ear of corn, there may usually be found several that have larger ears than others from the same ear. All crops can be made more productive by using seeds from a small seed-plot that is planted every year with the seeds from the best plants of the year before.

In selecting, we may, for example, take a variety of corn that has usually produced only one ear and select the few plants that have several ears. If we plant these seed by themselves and in that crop again select the stalks with most ears, and so on every season, in a few years we shall 
have a new variety in which most of the plants will bear several ears. This is improvement by selection. Even plants such as potatoes, that do not generally produce seeds, have been improved by selecting the best hills for planting the next year.

Select for one quality at a time. - In improving a variety, change can be made most rapidly by selecting

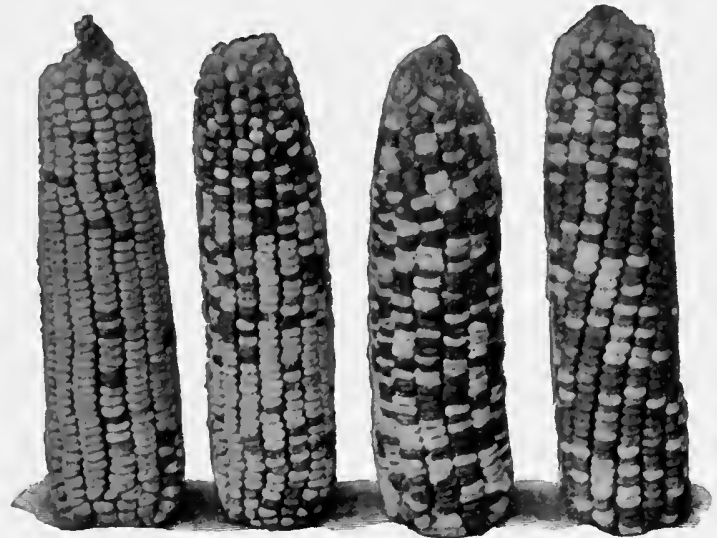

Fig. 37. - Some Results of crossing two Varieties of Corn of Different Colors

chiefly for one thing at a time. That is, we must decide, say with corn, whether we would rather increase the length of ear, or the length of kernels, or the number of ears per plant. We might desire all three of these qualities in our new variety, but it would take many years to make the desired improvement, if we chose one plant for number of ears, another for length of ear, and a third for length of kernel, and planted these seeds together. The better way is to find some variety of corn already existing that is 
really good enough to suit us in all qualities except one. Suppose it is desired to increase the number of ears on one stalk. Rapid increase, in this case, would come from selecting our seed ears only from plants bearing several ears. Among these several-eared plants preference would be given to those that have the other desirable qualities in the greatest degree.

Mixture of pollen from inferior plants. - This improvement by selection could not be made if the ear selected were planted where the pollen from a field of poor, unimproved corn would reach the silks (Fig. 37). If some of the stalks in the field are poor or barren, as shown by having no ear-shoot, the tassels of such plants should be pulled off before the pollen has begun to fall.

The improvement by selection goes on more rapidly if the offspring of each of the best plants is planted separatcly. It is best to plant each set of seeds in a separate row. Selection should be made for planting the seedpatch the next year by choosing the ears from the most productive plants on the best row, or the choice cotton plants in the best row of cotton. Unfortunately the plants of field corn, of cotton, and of most cultivated plants do not show resemblance to the pollen-bearing parent the first season. The crop of common field corn does not suffer in yicld the first scason from a cross with inferior pollen. The next season, however, the corn from such crosses is poor, and even the best ears thus produced will not bear uniform offspring. Popcorn and sweet corn may show the change the first year.

Temporary and permanent improvement. - It is difficult 
to distinguish between temporary improvement, and that which will be permanent through later generations. Usually an increase in the size of a plant due simply to one year of special fertilizing, watering, or extra space is temporary. The large size, it seems, is not inherited by the offspring. Improvement due to years of selection is, however, inherited (Fig. 39). The most valuable plant for seed purposes is not always the plant that happens to be the largest, but rather the one that will produce productive offspring of good quality. This is the reason why in a seed-patch it is better to plant all the descendants of one parent plant together in one row, so that the farmer may judge the parent by the average character of the offspring.

The farmer who would improve or "breed up " his corn, cotton, wheat, oats, or other crop, should have a special breeding plot or seed-patch and should carefully observe each plant grown there. Sometimes it happens that there is a singie plant that is decidedly superior to all the others, and seed of this "sport," or very unusual plant, may start a new and more valuable variety.

Home-grown seed often the best. - If seed of corn grown for many years in a colder country is brought to the Southern 'states and seed from this variety planted for several years in the South, each year the variety gets later and later and the stalks larger and larger.

If early vegetables are desired, make them earlier by getting seed grown far North where the plant has learned to be in a hurry to get ripe in a short season. Field corn from north of the Ohio River is earlier and smaller, and in 
most parts of the South yields less, than our native corn. Likewise, when the cotton-boll weevil invades any region, early varieties of cotton grown on the northern edge of the cotton belt ripen a considerable part of their crop before the weevils destroy the squares and blossoms.

A change of seed should not be made unless there is good reason for it or unless better seed can thus be ob-

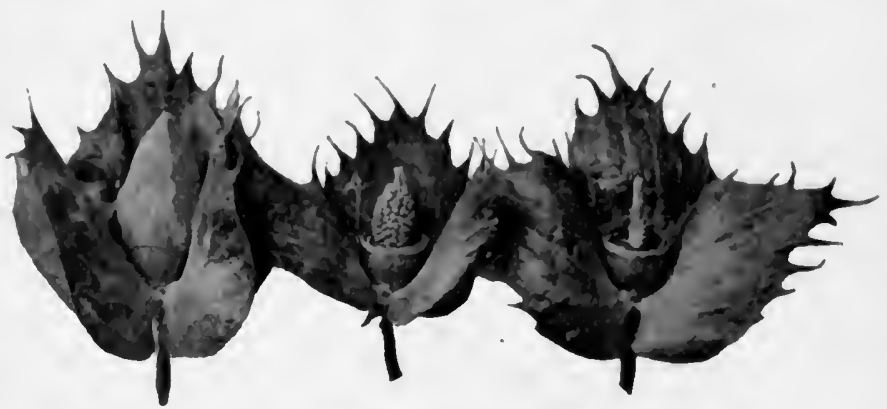

Fig. 38. - Preparing Cotton Blooms for crossing

On left, flower bud; in center, bud after removal of corolla, showing stamens; on right, pistil from around which stamens have been removed.

tained. A crop suited to the South does not "run out" or grow worthless if properly managed. A plant usually becomes better fitted for its new home by being grown there for a number of years. Seed grown from our own field crops in nearly the same climate should be preferred.

Improvement by crossing plants. - Sometimes the plantbreeder must resort to crossing in order to unite in one plant the good qualities of two different varieties. Suppose, for example, he wishes to improve a variety of corn the ears of which are too small, by using the pollen from 
a large-eared variety. Before the silk is seen on the mother plant, he must tie a paper bag over the ear shoot. Soon after the silks show, the plant-breeder carefully pulls a tassel from a plant of the large-eared variety. The pollen should be just ready to fly. He dusts this over the silks of a selected plant and repeats this next day, keeping the shoot under the bag until the silks dry.

He may wish also to cause a big-boll variety of cotton to grow a longer staple. Before the cotton-bud or young bloom of the big-boll variety is ready to open, or about sunset or sunrise, the plant-breeder opens or cuts away the upper parts of the white petals, and with a knife, small scissors, or fingers, removes every anther or pollen case (Fig. 38). This is done before these cases have opened and spilled their pollen on the pistil of the same flower. A small paper bag is then tied over the injured flower to keep insects from bringing any pollen to it. Pollen from a selected long-staple plant can now be used, after the pistil is more mature. After most of the cotton blossoms have opened, or between eight and ten o'clock in the morning, our plant-breeder comes back, removes the paper bag, and gently rubs over the top of the pistil a flower from a plant of the long-staple variety, on which the pollen is beginning to shed. The particles of pollen now cling to the sticky surface on the stigma and grow there. The bag is replaced and removed five days later, when, if all is well, a young boll is found. The seeds produced in that boll are the offspring of both varieties.

If, however, the thirty to forty seeds from that boll all grow into mature plants, the next year these sister plants 
will not be all alike. Some will resemble the big-boll mother plant; some will be like the long-staple father plant; some will be unlike either; and some may combine the likeness of both parents. The plant-breeder must plant the seed, giving a separate row to the seed of each plant; for several years in succession he must select for seed the plants that come nearest to uniting the qualities that he wishes - large bolls and long lint. It will usually be best for the farmer to rely for improvement on selection alone, rather than on crossing.

Cross-pollination generally better than self-pollination.Generally, pollen is most effective in causing seed to develop when the pollen and the pistil are borne on different plants. When the pollen of a corn plant standing alone falls on the silks of the same plants, grains develop. But the plants grown from such corn grains are less vigorous and productive than plants from seed having two parents not closely related. It is to avoid self-pollination that some seed-breeders pull the immature tassels from the corn plants on the rows from which they intend to select their best seed corn.

EXERCISE. - Farmers' boys can greatly increase next year's corn crop by selecting a few bushels of seed from the best plants.

When wheat or oats are ripe, remember, if you live on a farm, to watch for the best plants and to save seeds from a few of them for planting by themselves next year.

Have all the wild plants suitable for human use been cultivated and improved? Perhaps you will be the one to bring another wild forage plant or flower into use.

Note to the TEACHER. - Enphasize the great opportunity for good in selecting seed from the best plants. Weighing the product of good and very poor plants of corn, cotton, potatoes, etc., will help 
to point this lesson, especially if a calculation is made of the difference in yield from an acre of each of the two types of plants.

If any large flowers, like cotton, tobacco, or morning-glory, are blooming, let the pupils carefully remove every stamen from a bud in which the pollen sacks have not yet burst. Tie cloth or paper over the injured flower. Grocers' small paper bags are good. After a number of hours collect pollen from other flowers of the same kind and dust this pollen over the tip of the pistil in the injured flower. Cover it again. In a week or two see whether seeds have formed.

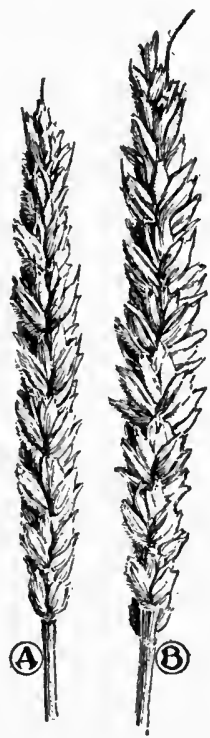

Fig. 39. - Results of Selection in Wheat, after four years. A, head from sowing small grains; B, head from sowing large grains. 


\section{SECTION IX. HOW THE SOIL WAS FORMED. KINDS OF SOILS}

If we hammer a small piece of stone, we can usually change it into a powder. The tiny particles that make up this powder are often like some of the grains of the soil that may be found near the stone. What is now soil, in ages past was solid rock. Far mightier forces than the heaviest of hammers cracked and ground these ancient rocks for thousands of years, until they crumbled into sand and soil. As the earth's surface cooled, and shrunk, and wrinkled, the rocks cracked. Water standing in these cracks and tiny rough places froze. In freezing, the water expanded, and thus broke off great and tiny pieces of rock.

Air and water, just as they eat slowly into iron, forming iron rust, so changed and dissolved some of the cementing material in the rock. Then the remaining parts of the large rocks crumbled.

Water grinds rocks into soil. - Streams of water rolled the sharp-edged pieces of rock against each other, grinding off the sharp points, making sand of the fragments, and leaving rounded stones and pebbles. When a boy wishes nice, smooth stones for his sling shot, he knows he will find them in the bed of a stream. While searching for smooth stones, he walks over a sand-bar. This sand-bar shows how soil was formed. It is made partly of fine gravel, partly 
of similar material ground into coarse sand, and of still finer material which is called soil. When the stream overflows, it sometimes forms a similar sand-bar in the lowlands along its banks (Fig. 40).

Plants aid in forming soil. - At first nothing grows on these sand-bars in the field, but soon a few plants attempt

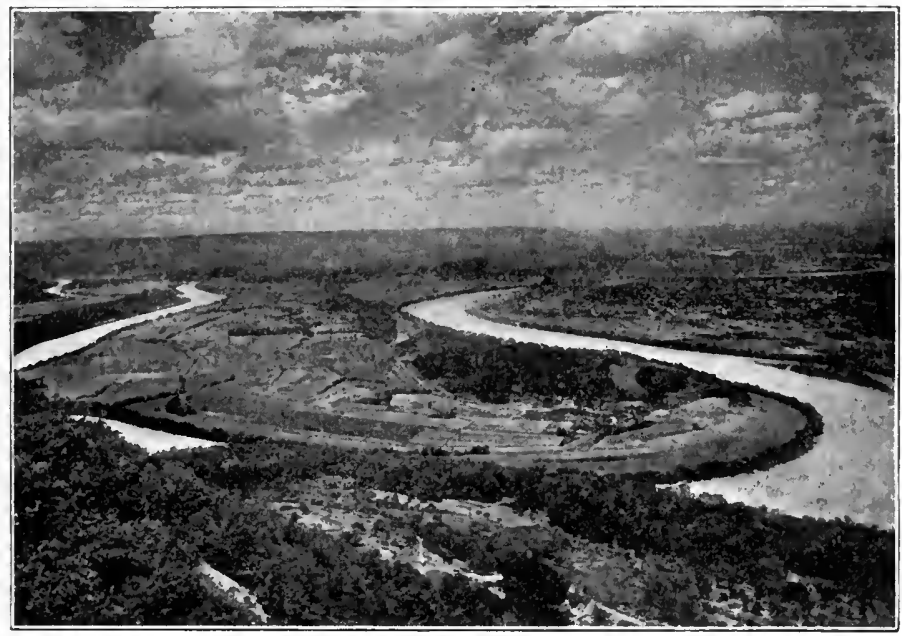

From Fletcher's "Soils." Doubleday, Page \& Co Fig. 40. - Showing how a River forms Soll on the Inside of the Bend to live there. When these decay they serve as fertilizers, so that the next generation of plants is larger. After some years this may become fertile soil.

Tiny plants called mosses and lic' hhens sometimes grow on bare rock. The roots of these not only dissolve the softer parts of the rock, but by their decay fertilize later generations of higher plants, until in time a shallow soil is formed in the pockets in the surface of the rock. 
Soil and subsoil. - We see that the soil is the finely divided surface layer of the earth in which higher plants can grow. It consists of two portions, which are not always alike, (1) the looser, upper layer, or soil proper, and (2) the more compact layer under this, called the subsoil.

The soil consists chiefly of sand and clay, but neither one of these is food for plants. Sand is useful in keeping soil from packing too closely, and from being too wet and sticky. Clay is useful in holding moisture and cementing the sand grains together. A small part of the clay, under proper conditions, can finally be changed into plant-food.

Much more useful to plants as food are the decaying remains of earlier generations of plants. These remains of plants are usually spoken of as vegetable, or organic matter, or luumus. There is much more vegetable matter in the soil than in the subsoil. Hence the soil produces much larger crops than the subsoil can when it is first brought to the surface. This is because the vegetable matter in the soil supplies plant-food, holds moisture, and makes the soil loose and mellow, permitting the roots and air to penetrate it. The subsoil, when first thrown up from the bottom of a ditch, is unsuitable for plant growth, but after it has been exposed to the air for several years, plants grow on this changed subsoil as well as anywhere else.

Available and unavailable plant-food in the soil. - The soil contains all of the chemical elements found in plants, and many more besides. All cultivated soils are rich enough in most of these elements, so only those elements or compounds which are sometimes scarce need be considered. 
These are nitrogen, phosphoric acid, potash, and lime. In a soil that brings poor crops there may sometimes be enough of all of these, but they may be held so tightly by the iron or clay that water cannot dissolve and carry them into plants. Such insoluble substances are spoken of as $u n$ available. These can be changed into soluble forms, or available plant-food, by the oxygen of the air, and the decay of vegetable matter. To make the plant-food in the stiff soil or subsoil useful, therefore, the soil must be loosened with the plow, and the surplus water drained, thus letting in the oxygen of the air. Oxygen is called the restless element, because it is continually seeking change, and causing other elements in the soil to change also.

How decay of vegetable matter prepares plant-food. - The decay of vegetable matter in the soil helps to make the soil elements more soluble, partly by loosening the soil, so that the oxygen of the air can reach all parts of it. It also helps because the carbonic acid formed during its decay is absorbed by the water in the soil; this mixture of water and carbonic acid has a much stronger dissolving power than pure'water alone. The rotting of vegetable matter helps to soften or rot the hardest rock and stiffest soil. Of course the decay of former generations of plants also furnishes plant-food directly to later generations.

Soils not permanently exhausted. - Even in a rich soil only a small part of the nitrogen, phosphoric acid, potash, and lime is in a soluble condition. They become soluble very slowly and gradually, so that roots have near them a small but continuous supply of newly prepared food. This is well, for if all of these elements in the soil were in 
a soluble condition, a succession of heavy rains would dissolve and wash all of the plant-food out of the soil and carry it to the ocean. But since only a small part of the phosphoric acid and potash of the soil are in a soluble condition, no soil can be permanently or completely exhausted. It is possible to restore the fertility of any soil that has a fair proportion of clay in it.

Clay and sand. - Examine a little sample of clay soil and another of sandy soil. When you rub them between your fingers the clay soil feels smooth, while the sandy soil feels coarse and gritty. Sand grains are hundreds of times larger than the tiny grains of clay. They are so large that they do not settle closely together, and the spaces between them allow water to run very rapidly through. Sandy soil, therefore, will not hold water well.

We can scarcely understand how small the separate particles of clay are. It would require more than fifty thousand fine particles of clay side by side to cover a line one inch long. Since the grains or particles of clay are so small, they can be packed tightly together, leaving very little space between. It is difficult, therefore, for air and water to penetrate a clay soil.

Granulation. - Fortunately, in well-cultivated, welldrained, clay soils, supplied with vegetable matter, a number of the tiny particles cling together in one group or granule. Each of these groups acts like a single sand grain, leaving spaces between granules open enough for water to drain through and for air to enter. This granu lation, or grouping into granules, is the condition the farmer wishes his clay soil to assume. If, however, he plows when 
the soil is too wet, the plow breaks up these groups and packs close together the tiny particles that before formed the granule. Great clods are then formed, so that a single plowing when the clay soil is too wet may injure the field for many years.

Coarse- and fine-grained soils. - Soils may be arranged in the following order, according to the coarseness of the particles of which they consist, beginning with the coarsest and ending with the finest:-

Gravel.

Gravelly loam.

Coarse sand.

Sand.
Fine sand.

Sandy loam.

Fine sandy loam.

Loam.
Silt loam.

Clay loam.

Clay.

The most satisfactory soils are those consisting of a mixture of sand and clay. These are called loam soils. They have enough sand to make them pulverize easily and drain well, together with enough clay to hold sufficient moisture for plants and furnish a gradual supply of certain kinds of plant-food. The coarsest soils become "worn out" soonest. Clay soils usually last longer because they contain the largest amount of total plant-food. They require more tillage, however, to make this plant-food available.

Treatment of sandy and clay soils. - You have just learned that a clay soil must not be plowed when wet. But if a soil consists almost wholly of sand, plowing it when rather wet does little harm. After plowing a clay soil the large lumps must be broken with a harrow before they dry and become hard clods. Live-stock should not be allowed to pass over clay soil while it 
is wet because their tracks make clods, just as plow. ing does.

EXERCisE. - Find what curious kinds of tiny plants are growing on the bare rock in some shaded spot.

Dig into several fields to learn how deep is the mellow soil. What differences do you find between the soil and the harder subsoil ? Do annual crop plants send their roots deep into most kinds of subsoil ? Find a tree that has been blown down, or from around the roots of which the earth has been washed away, and see how deep its roots went into the subsoil.

NOTE TO THE TEACHER. - Samples of several soils, as clay, sandy loam, and woods' earth, each on a separate newspaper, where they can be moistened and worked into mud pies, will impress the varying degrees of adhesiveness, grittiness, fineness, and their probable relation to (1) ease of plowing, (2) drainage, and (3) wear on implements during plowing.

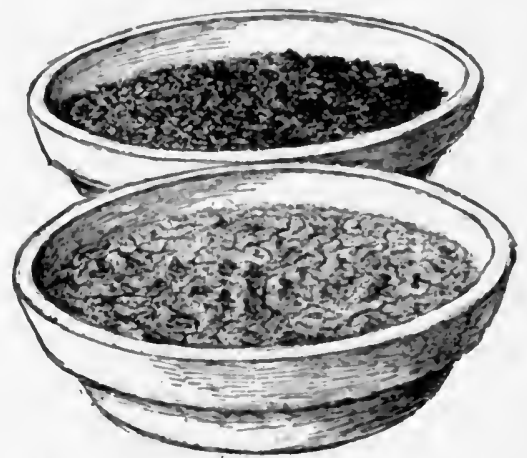

Fig. 41. - A GOOD SCHOOL Exercise

Two kinds of soil that have been wet and then dried. The loamy soil remains loose and capable of growing plants; the clay soil below has baked and cracked. 


\section{SECTION $X$. SUITING THE CROP TO THE SOIL}

THE proportion of sand to clay or silt in the soil and subsoil determines not only how much water the soil will hold, but also for what crops it is best suited. It is important to learn the character of the subsoil by digging down below the layer usually plowed. A sandy soil with a gravelly or sandy, open subsoil may be almost worthless; but a soil which, when plowed, looks exactly like this, but is underlaid by a clay or clay-loam subsoil, may be a productive and durable soil. In choosing a farm or a field, a farmer must look below the surface.

Best uses for sandy soils. - A sandy soil is usually a warm soil for the reason that sand absorbs heat rapidly. Another reason is because it is well drained, there being but little water left in it to be heated, thus allowing the sun's heat to be used to warm the soil grains. This kind of soil, therefore, is one well suited to early vegetables. Peaches also thrive on sandy soils and cotton is better suited to them than is corn. This is because cotton is less injured than corn by a scarcity of soil moisture. A sandy soil is usually not good for wheat nor for hay grasses, but the finer grades of tobacco are grown on it. For certain kinds of tobacco the soils of the Southern states shown on soil maps as "Orangeburg fine sandy 
loam" are especially suited. Peanuts, sweet-potatoes, cowpeas, and watermelons are good crops for sandy soils.

Best uses for clay soils. - Since clay soils contain so much water, they are slow in warming in the spring. You know that if you dip your hand in water, even in rather

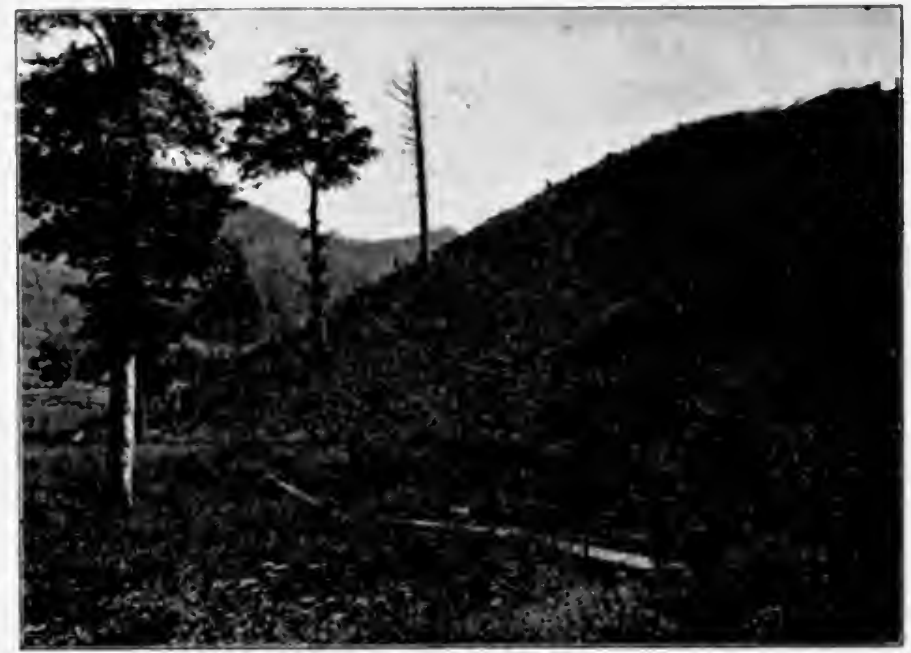

From 17etcher's "Sulla" INoubleday, Page $\&$ Co.

Fic. 42. - A Hillside too Steep for Cultivation

It should be used for pasture or forest.

warm water, and then expose it to the air, the skin becomes cool. This is because evaporation of water (that is, the changing of water from a liquid into the form of a gas or water vapor) has required heat and has drawn this heat from the skin. In a stiff clay soil much of the water must be evaporated from the surface. This uses the heat that ought to be used in warming the soil. Hence a clay soil is a cold soil, and crops growing in it start late. 
Clay soils are moist, and therefore the best crops for them are those requiring much water. As shown in an earlier chapter, a crop of hay requires an immense amount of water. Timothy grass, Johnson grass, red clover, and most hay plants, therefore, do well on clay soils. Apples need plenty of water and accordingly thrive on the best grades of clay soil. Certain kinds of clay soils afford the best summer pastures.

Hiliy, rolling, and level land. - Fields that consist of steep hillsides have a tendency to wash. They must be terraced; but then the terraces and the original steepness of the hill prevent the use of labor-saving implements. For this reason it costs more to cultivate such fields than rolling or nearly level land. The tendency to wash is reduced if the hillsides are covered with a uniform coat of pasture plants, such as Japan clover and Bermuda grass (Fig. 42).

Level lands are often poorly drained and in the spring are slow to get in condition for plowing. When drained, either by man or naturally, such lands can be very economically cultivated. For this reason, drainage ought to be the first thing to receive attention. The best labor-saving implements can be used and, if desired, the crop can be cultivated in hills or checks so as to be plowed in two directions, thus almost avoiding hoeing.

Rolling lands are those with moderate slopes. They have most of the advantages of level lands, and in addition are more easily drained.

Crops for lime soils. - Mọst cultivated plants grow well on a lime soil, while a few are suited only to such a soil. Alfalfa and red clover, both of them forage plants belong- 
ing to the bean or clover family, require land rich in lime.

Thus alfalfa succeeds finely on the best grades of the black lime or prairie lands in Alabama and Mississippi, and on the similar "black waxy" lands of Texas. On the same class of soil, Johnson grass hay is grown for market. Red clover is adapted to the lime lands found in many of the valleys in the northern parts of some of the Gulf states and to limestone soils common in Tennessee, Kentucky, and the sections to the north.

Color of soils. - If two soils are made up of particles of the same size, the darker one is usually the warmer. This is because dark soils, like dark clothes, absorb the sun's heat. A light-colored, sandy soil, however, may be warmer than a dark clay soil.

A dark color generally indicates fertility, and is due to the presence of much humus.

EXERCISE. - In your neighborhood what crops are generally grown on the most sandy soil ? What use is made of the wettest land ? How are clay lands utilized ? Hilly lands ? Very black lands? What are the favorite grass lands? Orchard lands?

Note to tue Teacher. - Write to the Bureau of Soils, Washington, D.C., asking for a report on a soil survey of your county, or of the region most like yours. Explain to the pupils the main features of the colored map in that report. 


\section{SECTION XI. MOISTURE IN THE SOIL}

THE difference between a rich and a poor soil consists largely in the fact that a rich soil is usually able to maintain enough moisture, but not too much; while the unproductive soil does not hold enough water for the use of the plant during periods of dry weather, and becomes too completely saturated during wet weather.

Clay soils hold water. - Soils differ widely in the amount of moisture that they can hold. Test this by filling two tomato cans of equal size with thoroughly dried soil, one of them with nearly pure sand and the other with the stiffest clay you can find. Pack both soils thoroughly, and gradually add equal amounts of water to each. Before any dripping from the clay occurs, water will have begun to drip freely from the sandy soil through the holes in the bottom of the tin can. Thus it is seen that clay will hold much more water than sandy soil.

Capillary moisture. - The water that drains away from the soil is called free water. It is spoken of as free because it always flows toward the lowest point. If cans of soil are allowed to drain for a day or two, although most of the free water will be removed, the soils will still be moist. The moisture remaining in the soil is called căp'il la ry moisture. It is spread out over the surface of the soil grains in such thin layers or films that it cannot collect in drops and drain away. If a bag of pebbles is 
dipped into a bowl of water, the water which adheres to their surfaces is capillary moisture. It forms a very thin layer. There may be millions upon millions of soil grains in every cubic inch of soil, and to cover every one of these

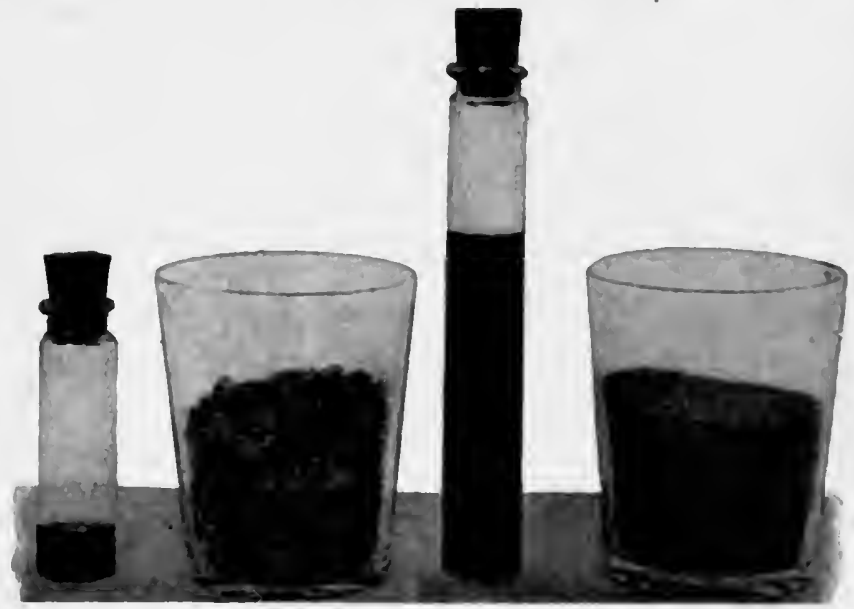

Courteay of Doubleday, Page \& Co.

Fig. 43. - SHowing the AMounts of Liquid required to Motsten tue SURface of Every Pebble in tile TUMbler on the Left aNd of Every GraIN OF SAND IN THAT ON THE RIGHT

over its entire surface with the thinnest possible coat of moisture requires a large amount of water (Fig. 43).

Movements of free and of capillary moisture. - The farmer endeavors to remove a part of the free water from the soil by drainage and to retain in the soil as much cap. illary moisture as possible. He desires the free water to drain away, because it occupies the spaces between the soil grains and thus keeps out the air, which is needed by the roots. Free water moves only toward a lower level; 
but capillary moisture on the other hand moves in any direction, but always very slowly. This is an advantage, for if this moisture moved as rapidly as the free water it would rise to the surface and evaporate. The earth would then become so dry that plants would die (Fig. 44).

It is also fortunate for the farmer that the capillary

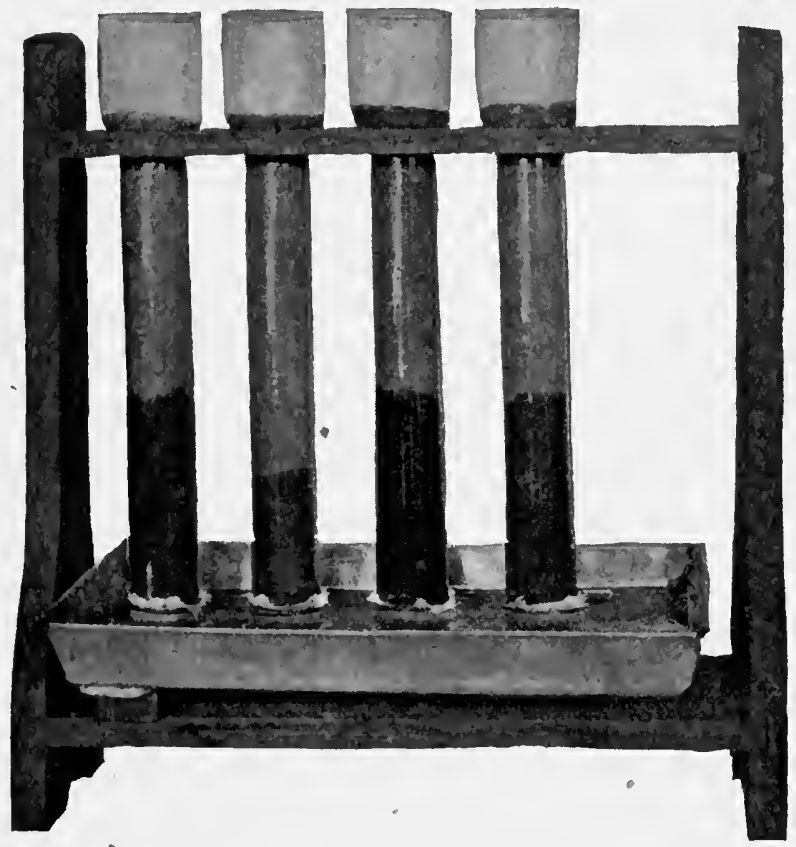

Courtesy of Doubleday, Page \& Co.

Fig. 44. - OUtfit for showing the Heights to which Capillary Moisture RISES IN SoILS

moisture moves toward the dryest soil. Thus root-hairs lying in contact with the sheet of water that wraps up one soil grain, absorb a large part of this moisture, but its 
place is soon taken by capillary moisture which moves in from moister particles ( $\mathrm{Fig} 45$ ).

\section{Air-spaces check the movement of capillary water.}

The farmer's part in preparing the ground and cultivating the soil consists chicfly in controlling the movement of capillary moisture. This moisture moves about only when the soil particles touch each other, so that the dry can

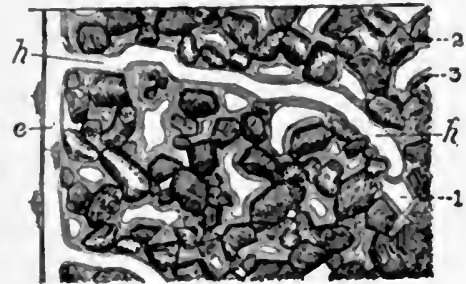

Fig. 45. - MoIsture on Root-itairs AND SOIL GRAINS, GREATLY ENLARGED e, main root; $h$, root-hair. $r$, air-space; a, soil grain; 3 , film of water surrounding soil grains.

which has been loosened up some time before the seeds are planted.

The farmer first loosens his soil, then permits the lower layers to become settled, and later, after the crop begins to grow, he stirs the surface. The surface layer is stirred in order to make large air-spaces, that will prevent the moisture a little deeper down from coming to the surface and being evaporated and carricd off by the wind. Earthworms are found under logs, boards, and stones because these places are moist, while the ground around is dry. The moisture in the soil cannot easily rise up through the logs, boards, or stones and evaporate. The gardener makes 
use of this principle when he places a layer of leaves over strawberries, potatoes, or any crop that he wishes to keep well supplied with moisture.' He calls such a layer of leaves a mulch, which simply means a cover to protect the soil against evaporation. The farmer cannot afford to place layers of leaves over his fields, but he can afford to make a mulch by using material that is alread; there. He can make a mulch of the soil itself, proviaed the top layer can be made loose and ary. How this is done will be iearned in the next chapter.

ExERCISE. - Repeat with several soils the "dripping test "given in the second paragraph (p. 65). Which of these soils is least in need of artificial drainage?

Note to the TEAcher. - If practicable, let pupils weigh cans of two different soils, before adding water and after dripping ceases. How much water does each retain? Emphasize the difference in the water-holding power of the two soils. If possible, compactly fill two lamp chimneys, or bottles with the bottoms off, with rather dry soil, one a coarse sand, and the other a clay (Fig. 46). Tie cloth over one end of each to retain the soil. Several hours before class time, set both in a basin in which the water is kept about an inch deep. Notice difference
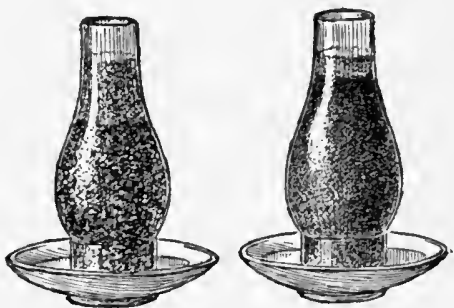

FIg. 46. - SHOwING THE HeIGHT TO WHICH MOISTURE RISES IN DIFFERENT SoILS

On left, coarse-grained soil; on right, fine-grained soil.

in height to which capillary moisture rises in each. Crosby's Exercises 3 I, 33, 40, 4I, will further impress these principles. 
SECTION XII. PREPARATION AND CULTIVATION OF THE SOIL

BEFORE the seed is sown the land is plowed. The main object of early plowing is to form a loose, mellow layer of soil through which the roots can spread in any direction.

When to plow. - When the plowing is well done, the soil is broken into small particles. This will not result, however, if the soil is very dry when plowed, for then great lumps and clods are turned over. On the other hand, the soil does not pulverize well if plowed when wet enough for it to stick together and to show a shiny, polished surface on the furrow slice. Only experience will tell just how wet or how dry the soil should be when plowed. Extremes should be avoided. Plowing when the land is very dry means poor plowing, but it does the land no permanent harm. But to plow land when it is too wet may injure the soil for several years, especially if it contains much clay.

A good seed-bed. - In the previous section it was learned that capillary moisture moves toward the roots best when the soil has no very large air-spaces. It is often well, therefore, to plow land a number of weeks before it is to be occupied by the roots of the crop. An opportunity is thus given the soil to settle and become compact.

A seed must have moisture in order to germinate, and 
the best seed-bed is one compact enough to permit the capillary moisture to move toward the seed, and yet loose enough to permit air also to come in contact with the seed. Roots, as well as seeds, require enough compactness of soil for the easy movement of capillary water toward the thirsty root hairs, and likewise sufficient looseness of soil to admit a little air and to allow the roots to grow freely in any direction.

If the soil is in good condition when plowed, the necessary compactness can often be had simply by allowing several weeks for the rains to make it compact or to settle it. Sometimes it is necessary to use implements for

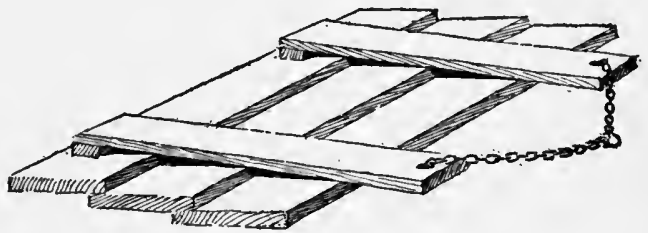

Fig. 47.-A Plank Drag this purpose, especially the harrow, the plank drag, or the roller. Clods are most easily broken when first plowed. Let the harrow therefore follow close behind the plow. After plowing or rolling, the harrow should be used immediately so as to leave on the surface a loose layer of dry soil. This loose surface layer contains so many and such large air-spaces that the moisture from the compacted layer below cannot easily cross these and rise to the surface, where it would be evaporated. Air-spaces in the loose surface layer do good by imprisoning the moisture in the lower layers.

IThe largest crops are generally made on those soils where the roots of cultivated plants grow deepest. This 
shows that it is best to plow deep unless there are reasons for not doing so. If land is plowed two or three inches deeper than it has ever been plowed before, there is danger that the first crop after such deep plowing will be injured by the subsoil which is brought to the surface. This subsoil often dries and forms a hard crust that interferes with plant growth. Moreover, the plant-food in this layer of subsoil may not be in such a form that the plant can immediately use it. But the longer it lies on the surface exposed to the air, the more fertile it becomes. Generally, deep plowing is beneficial to the second and the third crops, even if not to the first crop.

Subsoil plowing. - The depth of plowing can be increased without any danger of injuring the first crop if each year the plowing is about one inch deeper than the year before. The depth of the plowed soil can be suddenly increased by the use of a subsoil plow, which simply loosens the subsoil, but does not bring it to the surface. In using a subsoil plow we must make sure that the lower layers of soil are dry enough to be pulverized. Subsoiling is usually best done in the fall, because at this time the subsoil is apt to be dry and capable of crumbling. Harm and no good comes from plowing the subsoil when it is very damp.

When to cultivate. - Most cultivation consists in destroying the plants not needed and in forming a shallow layer of loose soil at the surface of the ground. It is just as important to form this mulch, or loose, light layer of soil, as it is to destroy the weeds. Cultivation is often needed when there are no weeds. We may be sure that it 
is needed whenever a surface crust forms on the land, as after a rain.

By breaking this crust and the adjacent parts of the soil with a cultivating implement, a layer of loose soil is formed that contains many large air-spaces. Across these air-spaces moisture cannot move, but must remain in the lower layers near the root. A crust must not be allowed to form ; cultivation will prevent it.

ExERCise. - Take two pieces of chalk of the same length. Break one in half. Pour a thin layer of ink into a shallow tin can or can top. At the same moment stand upright in this ink on their flat ends the unbroken and the broken piece of chalk. Carefully place the upper portion of the broken piece on its lower part, in the position it occupied before being broken. Watch the ink rise upward into both. Notice that when the liquid reaches the crack, its rise is checked by the airspace between the two broken pieces of chalk. This shows how airspaces in cultivated soil keep moisture from rising rapidly to the surface, where it would be evaporated.

A similar experiment can be made with entire and broken lumps of sugar placed in a thin layer of coffee.

Note to THE TEACHER. - Designate two or three pupils to make the following experiment : -

Fill five similar open cans with the same amount of damp soil, packed in equally. Leave one as it is, thoroughly cultivate one to a depth of one inch, cover the others respectively with mulches (one inch deep) of leaves, dry sand, and dust from under the house. As soon as prepared, and again after a few days, weigh all cans and see how much water each has lost, so as to learn which best retains the moisture in the lower layer of soil. See also Crosby's Exercises 42 and 44 . 


\section{SECTION XIII. TERRACING AND DRAINING}

After a heavy rainfall the water in the ditches and the furrows is muddy. This mud is soil - the best kind of soil, too - that the currents of water have washed away.

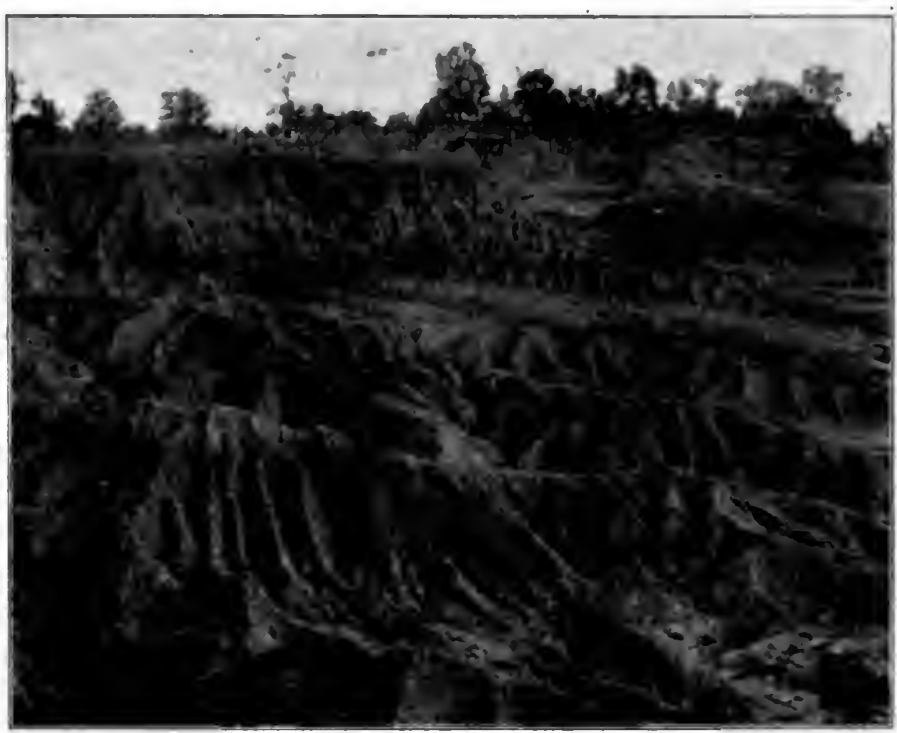

Fig. 48. - A Field RUined bY Washes

The heavy rains not only bear away the fine particles of soil, but in low places where much water collects and where the little currents are strong, grains of sand and 
fine gravel are torn loose and hurried along. The removal of the soil leaves a wash or scar in the field. Every rain repeats the process, so that in time a gully or ditch deep enough to hide a horse and rider is formed. Soon the water in each row that crosses this wash cuts a little channel down to the main gully and, in time, the field becomes unfit for cultivation (Fig. 48). If the first break is mended the field will continue to produce good crops instead of becoming worthless. The old saying that "a stitch in time saves nine" is very true in preventing the washing away of the soil.

Terracing. - Most hillsides in this climate tend to wash if cultivated. Terracing is a system of protecting hillsides

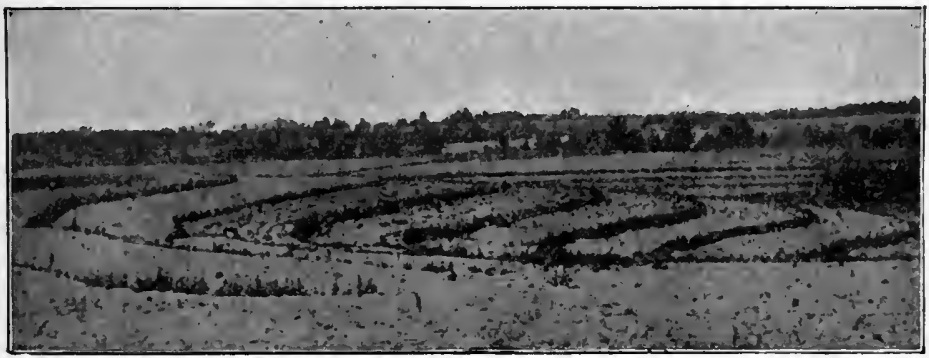

Fig. 49. - A Hillside terraced to prevent Washing

against washing. A terrace is a low bank or ridge, winding around a hill or slope, but always maintaining nearly a perfect level. To keep on a level the terrace often has to wind about with many an inconvenient curve and crook.

When the top of a terrace is kept even and level, it reduces the amount of washing. The level top-line permits the water to run over the top of the terrace bank along 
its entire length in the form of a very thin sheet. Water moving in a very thin sheet meets with so much friction from the ground that it has to move slowly and therefore cannot exert much force to tear away particles of soil.

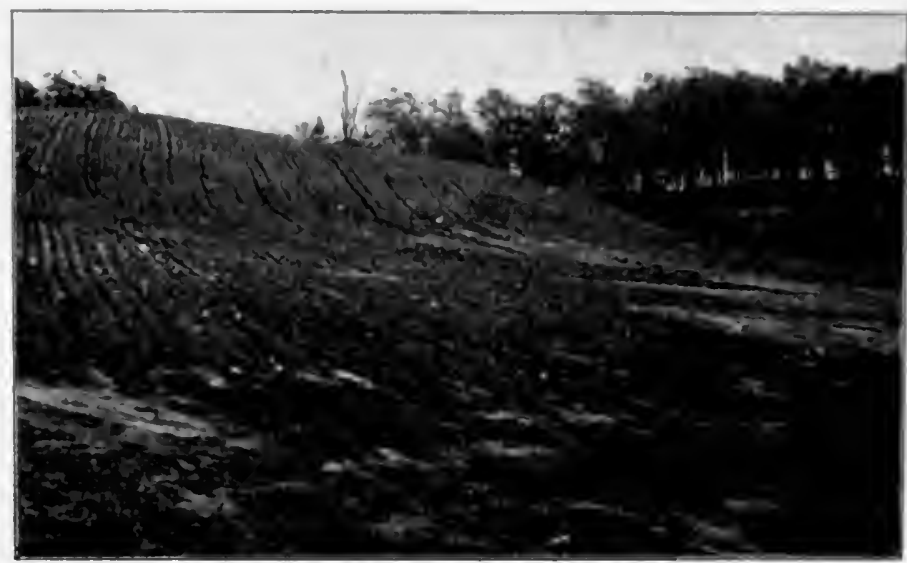

Froin Fletcher'" "Solln." Doubleday, Page \& Co.

Fig. 50. - Showing Washes started by RuNning Rows strajgut UP THE HILL

How a terrace is made. - By means of either a terracing level, or a home-made terracing triangle (Fig. 51 ), a curving line is marked out near the top of the hillside by placing stakes at intervals of about ten steps, all of the stakes being on the same level. In the same way stake the next terrace line at a vertical distance of three feet lower down the hill on gentle slopes, or five feet lower on very steep slopes. Repeat the operation until all the terraces are staked out. Now mark each line of stakes by means of a furrow, not passing exactly under the stakes but very near them, trying to make the curves in the terrace as slight and gradual 
as possible. Below this furrow leave a strip of hard, unbroken ground of about two feet wide. On this throw furrows from above and below, forming a slight ridge or bank. If at first this bank is not level or not high enough, the work must be completed with shovel and hoe.

A terrace on sandy, porous soil will hold back all the water that falls except during and after very heavy rains. Deep plowing will aid terraces to do this and will often keep them from breaking, even after heavy downpours. Breaks, however, will sometimes occur, especially before

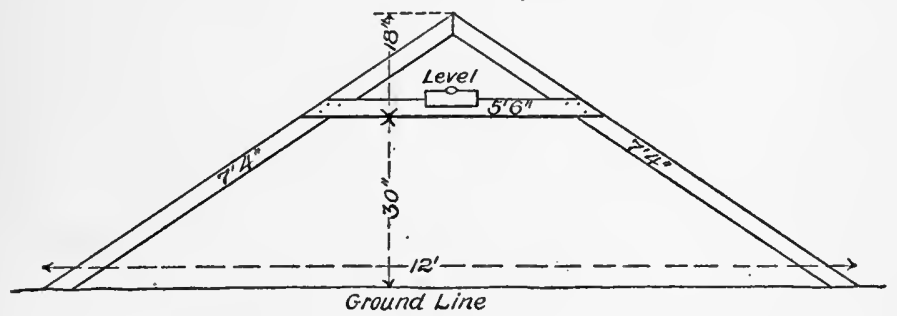

Fig. 51.-A Home-made Level for locating Terrace Lines

weeds and grass have covered the terrace and bound it together with their roots. Such breaks should be mended promptly, using neither logs, stones, nor trash, but soil taken from just below the terrace and some distance from the break.

A crop of cowpeas or cotton on the terrace bank keeps the field much neater and more free from weeds. Terraces may be covered with some winter-growing plant, the living roots of which strengthen them in winter. Among the best plants for this purpose are bur clover, vetch, or Texas blue-grass. 
Terraces often inconvenient, but necessary. - Terraces decrease washing, but make many short rows, increase the cost of cultivation, and interfere with the use of improved implements. They are needed only in hilly regions. In Virginia and Tennessee and northward they are seldom used, partly because wheat or oats, pasture or hay plants, alternate with hoed crops and the fields are not cultivated so continuously as in the cotton belt. Farmers in the Gulf stites who do likewise, and who plow deep, can often do without terraces as long as no washes appear in the fields.

What lands need drainage. - Drainage is needed on fields where water stands in ponds for a long time after a rain, where water oozes to the surface making seepy spots, and on land where swamp plants grow freely or where water stands in a post hole within several feet of the surface, during the growing season. Fortunately the greater part of the hill lands of the Gulf and South Atlantic states needs little or no artificial drainage except that intended to prevent washing. On bottom land and on some very stiff or seepy upland fields, however, drainage is generally needed.

Drainage makes roots go deeper into the soil. - While the purpose of terracing is to cause porous soils to absorb most of the water that falls on them, in order to prevent washing, the object of drainage is to remove the excess of water from soils that otherwise would hold too much water.

Strange as it may seem at first, plants are better able to endure a drought on drained than on undrained land. This is because the roots go only as deep into the soil as the air penetrates freely. Drainage opens channels for the air to 
penetrate farther, and in drained soils therefore plant roots are deeper than in soil that has ordinarily been saturated. When the upper soil dries, the shallow-rooted plants in undrained lands are no longer able to obtain moisture; but the deep-rooted plants in drained soil, being nearer the ever moist subsoil, are uninjured.

Other benefits from drainage.-Drainage makes soils more crumbly and less inclined to be cloddy. It increases in the soil the number of helpful germs, or tiny living plants, that change vegetable matter into available plantfood. This it does by supplying an abundance of air, without which they cannot live. Moreover, drainage makes the land ready for plowing earlier. Plants start to grow earlier on drained than on wet soil, for drainage warms the soil by drawing off a part of the water that would otherwise evaporate, and which, in evaporating, would cool the soil.

Two classes of drains. - The usual drain is an open ditch. Another kind is the covered or underdrain. A field in which there are underdrains shows no sign of them, for they are two to four feet below the surface and completely covered over. One of their advantages over open ditches is that crops can be grown above the drains.

Underdrains. - These are usually made of tiles, which are hollow tubes of burnt clay one foot long, laid end to end. The water runs into them at the joints, which do not fit together tightly, and trickles in through the porous walls (Figs. 52, 53). Sometimes underdrains are made of four narrow planks nailed together like a long box, with numerous holes for water to enter. In other cases they are made of three large poles in a triangular pile, and 
sometimes of old bricks or stones. Although these are buried several feet in the ground, water flows down to them, thus deepening and airing the soil. They usually

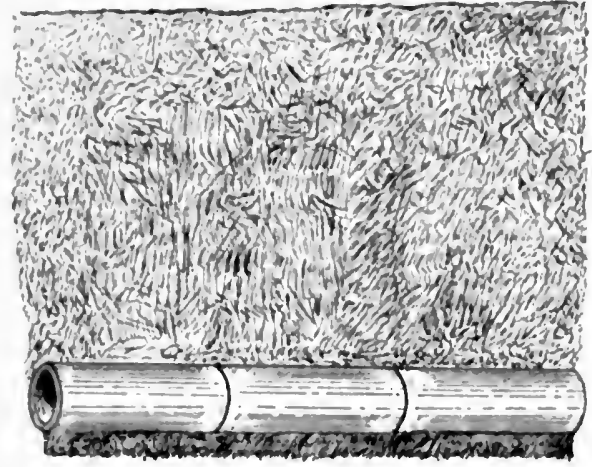

Fig. 52.-Drain Tiles in Position UnderGROUND

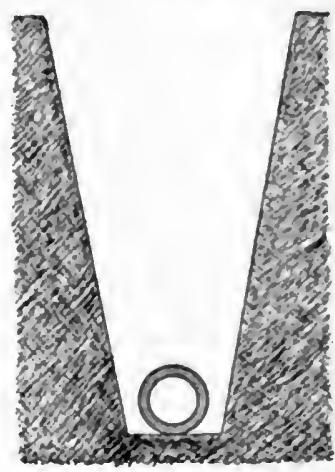

FIG. 53. - END VIEW or DRAIN TILE Before THE DitCH IS FILLED

drain the soil more completely and to greater depth than do ordinary open ditches.

Open ditches. - According to their use, the principal kinds of open ditches are :-

I. Canals, or very large ditches.

2. Deep drainage ditches.

3. Hillside ditches (usually shallow ditches).

The water in open ditches often carries much mud and other fine material. When the current is rapid, this soil material is carried onward by the water, and is not deposited. But if any part of the ditch is less steep than the portion above it, the water must necessarily travel more slowly. A sand-bar generally forms where the current is thus checked, for the slower current is unable to carry its 
burden of fine sand and other soil particles. These are thrown down and fill the ditch, making work for the farmer in opening it again. The banks of a deep open ditch should not be upright nor nearly upright, for they invariably cave in, and the earth fills the ditch.

It is a good rule for a ditch to have a uniform grade, steep enough to carry off the water without filling the ditch with soil, and yet not so steep that the current will cut deep into the bottom of the ditch. This grade varies with the dimensions of the ditch, as you will learn in larger books on drainage. For small ditches there is usually from three to five inches of fall in every one hundred feet.

EXERCISE. - Walk over a field and notice the little washes just beginning. Think of a way by which each one could be stopped. When a ditch or river makes a sand-bar at a curve, is the sand-bar on the inner or on the outer side of curve? Why? Watch a winding brook as it flows and learn why a ditch or river tends to become more and more crooked (Fig. 40). Look at one of the ditches on a farm that you know and plan how it could be improved.

Note to the Teacher. - If a rain occurs soon after this lesson has been studied, point out that the current is strong and washing is possible only in those places on the school yard or an adjoining field where water collects, and not where it is spread in a thin sheet. Does washing occur on the bare or on the grass-covered parts of the school yard? Perhaps some pupil's father has a drainage-level and will bring it to school and show the class how to use it. If he will lend it, the directions above will be sufficient guide for you to use it in locating terrace lines. Why not have a short excursion for using the level and for inspecting ditches and streams? 


\section{SECTION XIV. HOW THE SOIL BECOMES POOR}

SURFACE washing is one of the means by which land becomes poor, and it is one that can be prevented by proper use of ditches and terraces and by better methods of farming. If any fields are so steep that terraces or ditches will not protect them against surface washing, they should be allowed to grow up in useful trees. Otherwise they should be planted to some grass or grazing plant, the matted roots of which will do much to hold the soil in place. Bermuda grass is one of the best of these soilbinding plants. When this is not wanted, other grasses or clovers can be used instead.

Leaching. - On all soils there is a loss of fertility that cannot be seen and is often not suspected. This is leaching or the dissolving of plant-food by the rain water and the draining of this water and of the dissolved plant-food in it through the soil, and into the streams. This loss is greater than any other in our Southern climate. It occurs chiefly during the winter, when rains are heaviest and when there are no living roots to use the soluble plant-food. It can be prevented by causing living plants to occupy the fields during the winter. Wheat, rye, crimson clover, or any other plants in active growth during the winter send their roots throughout the soil. These roots 
absorb the soluble plant-food, leaving very little that can be dissolved by the rain water as it drains through the soil. Even weeds that keep green during the winter do this much good.

Loss of vegetable matter. - Another cause responsible for much of the poor soil in the South is the loss of vegetable matter. This occurs whenever the farmer grows corn, cotton, or any other crop that is kept thoroughly cultivated, and does not leave on the land a large amount of roots, leaves, or stems. Fire is one of the farmer's worst enemies, because it destroys vegetable matter needed to improve the soil.

When vegetable matter in the soil disappears, the soil becomes lighter in color, drier in dry weather, more cloddy, and harder to work. Clay soils then become too compact for roots to thrive in them. In dry weather the crop on such land is parched and stunted or ruined, while on similar land, well supplied with rotted vegetable matter, the crop is much better able to withstand drought. This is partly because rotted vegetable matter is somewhat like a sponge in having the power to hold moisture. When the roots come in contact with this decayed vegetable matter, they absorb its moisture and also use a part of it ior food.

The farmer can replace the vegetable matter that disappears where clean cultivated crops are continually grown by producing an occasional crop that leaves large amounts of roots or foliage and stems on the ground. Some of the crops that thus increase the supply of vegetable matter are the clovers, cowpeas, and kin- 
dred plants, and the grasses that form a sod or dense covering over the entire surface. The surcst and cheapest way for the farmer to curich his land and to make larger profits in farming is by constantly adding vegetable matter.

Sale of plant-food in crops. - If a farmer every year hauls crops of grain, or hay, or potatoes from his field without putting anything back, there will come a time when he will say that the field is too poor to cultivate. Crops differ greatly in the kind and amount of plant-food they remove from the soil. The lint of cotton and the sugar of sugar cane consist almost entirely of materials drawn from the air, and so these products remove almost no plant-food. Yet cotton may make the soil poorer because its clean cultivation causes the loss of vegetable matter; because its seed removes considerable plant-food; and most of all, because it leaves the land without living roots during the winter, and thus permits the rain to leach and to rob the soil. Sugar cane may be an exhausting crop because the stalks that are carried trom the field contain much plant. food and because the leaves are generally burned. This does not mean that exhausting crops should not be grown, but that something must be returned to the land in exchange for what is removed.

Lack of drainage makes soils unproductive. - All the causes of soil-impoverishment mentioned are due to sub. stances taken from the soil. They have all been forms of subtraction. There is, however, an addition to the soil that may make it poor. Too much water injures the soil and the crop if it is not drained away either by 
the porous nature of the soil or by ditches cut by the farmer. This subject was discussed in the last section.

Note to The Teacher. - Ask your pupils to explain how lye is made from ashes kept in hoppers. Point out that this process is leaching. Leaching does more harm to rich than to poor soils. This process removes from the soil chiefly nitrogen and little or no phosphate and potash. The loss of plant-food due to the sale of lint cotton and of cotton seed is shown in Fig. 94.

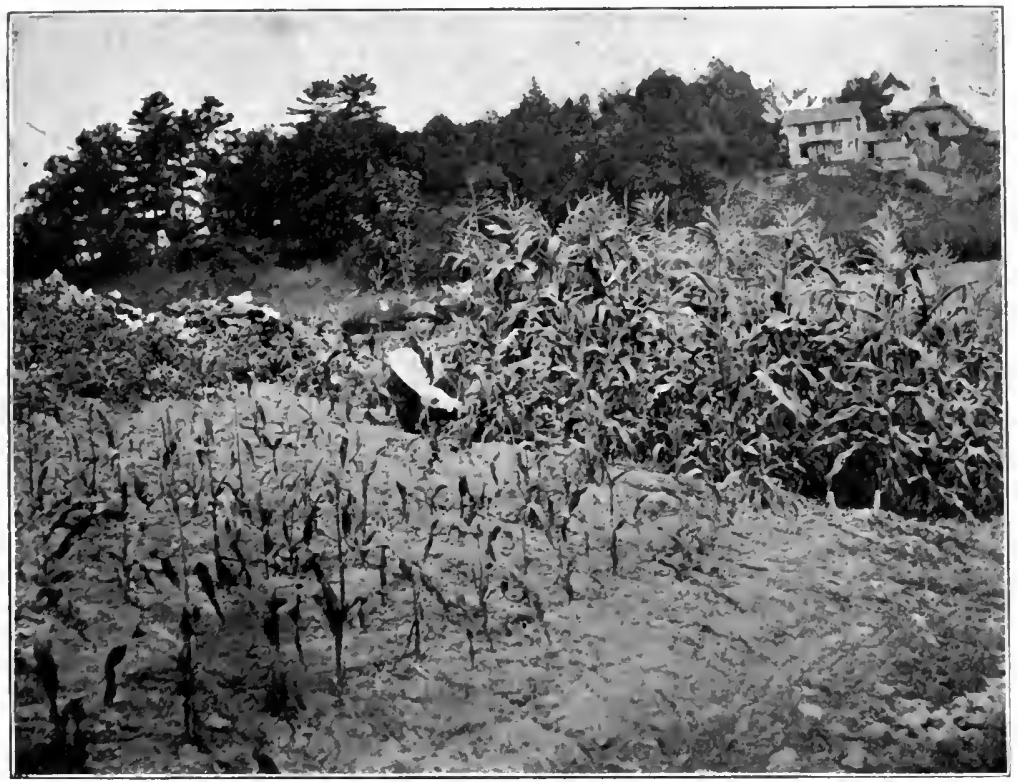

Fig. 54. - The Poor Subsoll

In the foreground the top soil has been removed by grading. Note the contrast with the corn on normal soil. 
SECTION XV. HOW TREES AND LEGUMINOUS PLANTS IMPROVE THE SOIL

In a forest, year after year, the trees drop their leaves; the decayed leaves and roots make the soil very loose and rich. When the trees are removed, the "new-ground" produces good crops that use the vegetable matter as food. The crops are good on "new-ground" also, because the humus in dry weather holds moisture like a sponge. Drought, therefore, is not much felt by crops on land containing much humus. When plowed, the dark, loose soil crumbles readily, for the reason that vegetable matter in the soil keeps the particles of clay from sticking together and from turning up in great useless clods.

Resting land not the quickest way to enrich it. - Farmers have learned that even a crop of weeds adds vegetable matter, and so they sometimes leave certain poor fields uncultivated for a year or two to "rest" or improve. Such improvement of the land is slow under any conditions.

Making land fertile by growing certain crops. - Different plants are very unlike in the value of the vegetable matter they add to the soil. Those that make the best fertilizer are the plants rich in nitrogen. Look carefully at the picture (Fig. I 10) and notice how much more corn grew on a square yard where vetch plants had grown the year before. Twice as large a crop of oats, wheat, or hay has 
flower of each of these consists of (1) a broad petal standing up somewhat like the wings of a butterfly at rest, (2) a folded portion that reminds us of the butterfly's body, and (3) a petal standing up straight and alone on each side of the folded part. The leaves of common

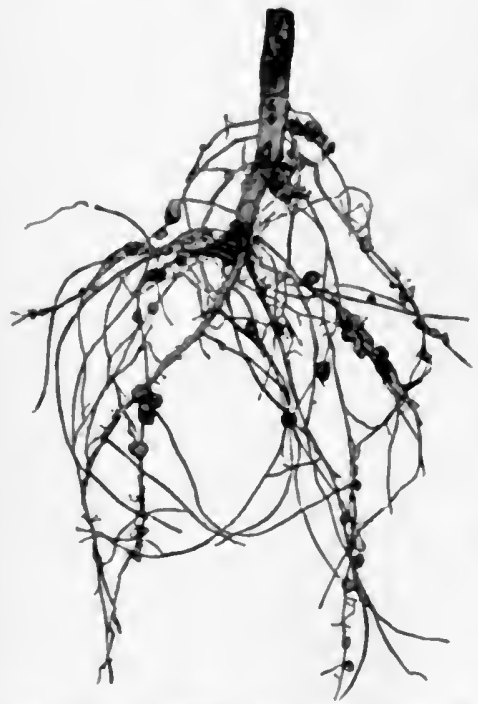

Fig. 56. - TUBERCles on Roots of Cowpeas. (See also Fig. 65.) leguminous plants are compound, that is, made up of several smaller parts called leaflets (Fig. 55). The seeds are in pods that split along both edges when ripe.

You will quickly see that garden peas, cowpeas, sweetpeas, locust trees, and some plants called weeds have blossoms of this shape. The clovers have very different heads, more like the shape of the end of a finger. Each clover head is not a single flower, however, but a mass of dozens of tiny flowers. Each of the little flowers has the same general shape as the pea blossom. Plants on which the flowers are of this shape are found to make the soil richer. These plants have bean-like pods (Fig. 59).

Tubercles or nodules on the roots of legumes. - Carefully dig up cowpea, clover, and other legumes without stripping off the smaller roots. Do you not find little round or pear-shaped knots attached to the roots? This 

is an indication that the plants are legumes and that they

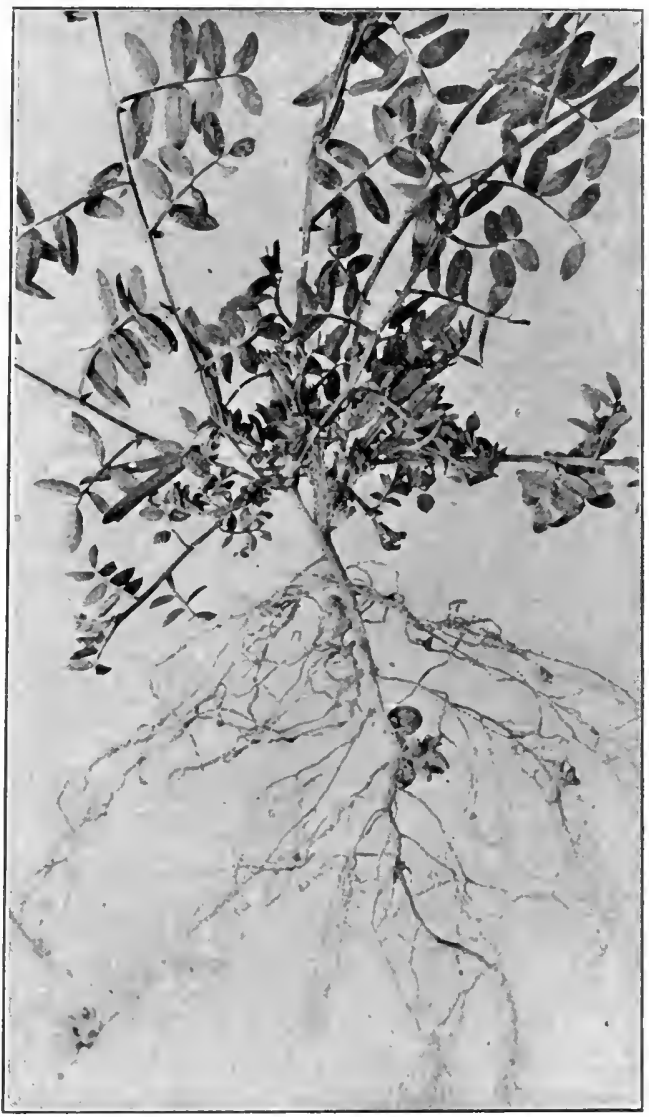

Fig. 57. - Tubercles on the Roots of a Young Vetch Plant are at work making the soil rich. These knots are root tubercles or root nodules (Figs. 56, 57).

The farmer's tiny helpers. - Each tubercle is a busy 
workshop inhabited by multitudes of germs, so small that 25,000 of them could be placed side by side on a line one inch long. These germs are actively at work helping the farmer. The tubercle in which they live serves as a house for them. It is really a fertilizer factory, and the germs are the workmen, busy making fertilizer that will be used by the plant on the roots of which the tubercle grows. The plant on which the tubercle forms is called the host plant. It furnishes the germs in the tubercle with starchy food made by the leaves. In exchange the tubercles send up through the sap a fertilizer rich in nitrogen. This fertilizer nitrogen is constantly being made by the germs in the tubercle from the nitrogen gas in the air. The farmer can help the germs to manufacture fertilizer nitrogen by plowing the land before sowing legumes. Plowing or cultivation permits an abundance of air, with the nitrogen gas which it contains, to pass through the loose soil to the tubercle, where the tiny workmen are ready to use it for the farmer's benefit.

What the cowpea or clover plant does with nitrogen. Let us consider what becomes of the nitrogen a tubercle sends up in the sap current to the cowpea or clover plant on which it is growing. A part of it is deposited in the roots of the cowpea, another part in the stem, another portion goes to make the leaves, and still another part helps to make the seeds. All clovers and most other legumes use their fertilizer nitrogen manufactured in the tubercles just as the cowpea does, and they enrich the. soil in the same way.

Even if the farmer mows and hauls away the vines for 
hay, there is still left in the land the nitrogen that was stored in the roots and lower part of the stem and in the fallen leaves. Even the roots and stubble of legumes, therefore, can enrich the land, both in nitrogen and in vegetable matter. The enrichment is much greater if the

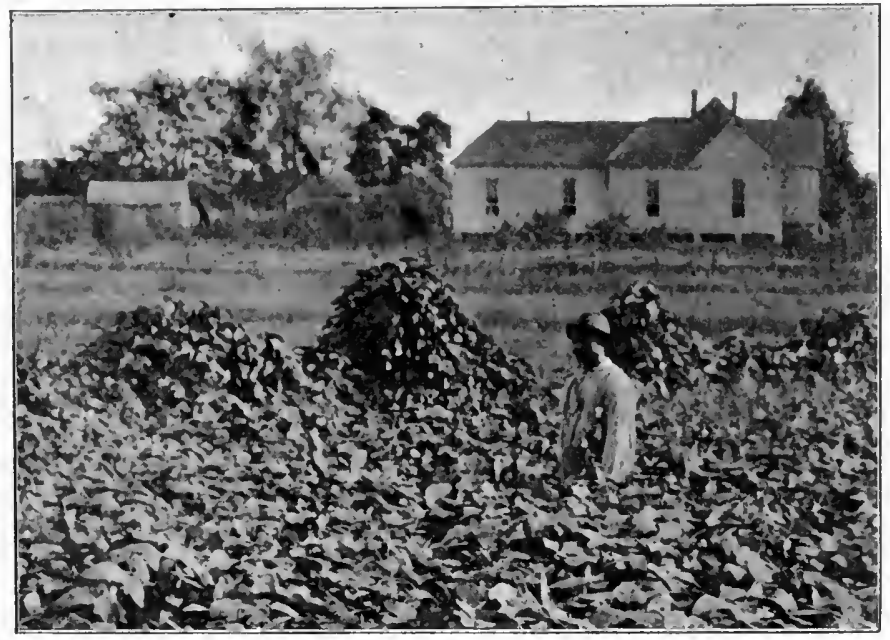

Fig. 58.-A Field of Velvet Beans, one of the Best Soll-improving Plants

tops, as well as the roots, are plowed into the soil, either as soon as growth is finished or after being eaten by animals pasturing on the field.

Shall the tops of soil-improving plants be plowed into the ground? - The plants that most enrich the land are those that make the richest hay and pasturage for horses, cattle, sheep, hogs, and poultry. The farmer often asks, "Does it pay better to use the vines or tops of cowpeas or clover as food for live-stock or to plow them into the 
ground as fertilizer?" The best answer is that letting these crops pass through an animal does not greatly lessen their value as fertilizer. The starch, sugar, and fat that the animal takes out of its food have no value as a fertilizer. Enough live-stock ought to be kept on all farms to consume the legumes that are grown. The farmer can, therefore, make a double use of the leguminous crops: he can use them as stock-food, and later for fertilizer. The roots and stubble of legumes enrich the land. The little fertilizer factories on the roots of leguminous plants are worth more to mankind than all the gold in the whole world. Nearly every farm that to-day is too poor to keep the farmer's family in comfort can be made fertile by the wise use of cowpeas, crimson clover, and related legumes.

EXERCISE. - Make a mud ball of stiff, poor clay and put it away to dry. Make another of half clay and half dark, fine woods' earth. Let it dry. Try to make a firm mud ball of dark woods' earth alone. After drying, which of the first two crumbles most easily? Why? Find all the plants that you think may be legumes. Learn all you can about the leaves, flowers, pods, and about the size and shape of the fertilizer factories on their roots. How many stamens in a pea or cowpea bloom? Are all of them partly grown together?

Note to the Teacher. - Objects needed: (1) soils of different colors, due to different amounts of vegetalble matter; (2) seed, flowers, plants, or roots of any legume, as garden pea, cowpea (Southern field pea), sweet-pea, clover, etc.

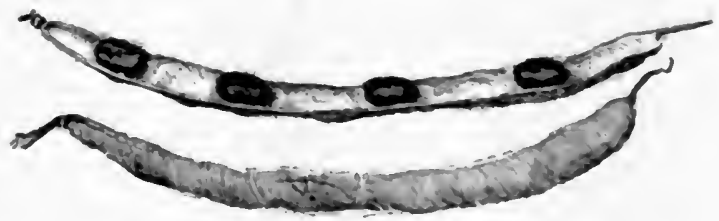

Fig. 59. - Pods op a Leguminous Plant 


\section{SECTION XVI. BARNYARD 'MANURE}

A FARM with many animals is generally rich and productive because of the supply of manure. Experience in all countries shows that this material is an excellent means for enriching all kinds of soil. Some chemical fertilizers, however, are beneficial only on certain soils.

Manure has these good effects: (I) It makes the earth loose and mellow, allowing the roots and air to come into contact with all parts of the soil. (2) After it has rotted, it enables the soil to hold moisture in dry weather. (3) It furnishes plant-food to the roots of growing crops. (4) It adds needed germs and causes the beneficial ones already in the soil to thrive and multiply, thus helping the crop.

Richest manure from richest food. - Barnyard manure is composed largely of ground-up parts of plants, and contains very nearly what the plants contained. The richest is made by feeding cotton-seed meal and other foods rich in nitrogen. Hay from cowpeas and other legumes makes better manure than that from shucks, straw, or grass.

Fertilizing crops by buying food for live-stock.-A farmer may buy Ioo pounds of cotton-seed meal and place it in the ground as fertilizer. It would pay him better first to feed it to cattle and then to use the manure. If all of this, solid and liquid, were carefully saved, it would have the same value as a fertilizer as 80 pounds of cotton-seed 
meal. Auimals take from the food fed them chiefly those substances that are worthless as fertilizers, such as starch and fat. The farmer, therefore, who buys cotton-seed meal to use as a fertilizer for his crop can make two profits by first feeding it and then using the manure as fertilizer.

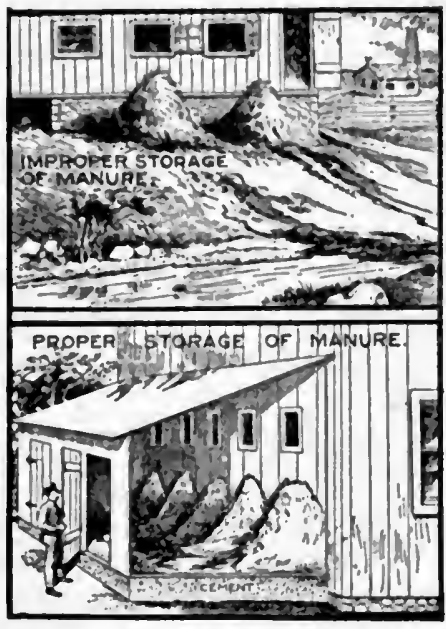

Fig. 60.- Sirow1NG FIRST How MOST of tile Value of Manure is Lost, AND SECOND, HOW MOST OF ITS VALUE IS RETAINED Any pasture or field can be made rich by keeping on it live-stock that is fed partly on purchased food or food grown on other parts of the farm. The manure from different animals is different in fertilizing value largely because they are fed on different foods. Manure from the poultry house is several times more valuable than any other.

When only the solid waste from animals is saved, the farmer gets only about half the fertilizer available. If the manure pile has no roof over it, the rain water destroy's much of the fertilizing value. Manure that has been exposed to rain for a number of months is sometimes worth less than half as much for fertilizing crops as it was at first. Most of the plant-food has been dissolved and carried off by water; some of the nitrogen has changed into ammonia and passed off into the air as a strong-smelling gas; and a large part of the soil-loosening material 
has disappeared or been slowly "burned," for rotting is a kind of slow burning. A roof over the manure pile prevents the great loss caused by water, but the other losses go on even with the roof. The best plan, therefore, is to put manure into the ground as soon as possible and before any waste has occurred.

Composts. - Compost heaps are piles of manure mixed with other materials, such as leaves or cotton seed, with sometimes phosphate added. Partial rotting makes the manure less coarse and makes it act more quickly on the crop. The same materials can be mixed in the furrow in the field. When they rot there, the soil prevents loss. Moreover, when organic matter rots in the soil, it causes the soil touching it to "rot" too, that is, to change some of its compounds into substances that plants can use as food. It is generally best to plow manure under so that the soil will absorb the ammonia that might otherwise be lost.

Barnyard manure is dilute. The farmer must get it to the field with as little labor as possible, for fully three fourths of its weight is water, that has no value. Large amounts must be used on an acre. In a ton of manure there are only about 25 to 35 pounds of the three precious forms of plant-food (nitrogen, phosphoric acid, and potash), or about as much as in 200 pounds of a high-grade complete commercial fertilizer. The plant-food in a.ton of manure could generally be bought in the form of commercial fertilizers for between $\$ 1.50$ and $\$ 3$. But a ton of manure contains, besides direct plant-food, billions of helpful germs and about a quarter of a ton of organic matter that is very 
beneficial in making the soil mellow and able to hold moisture. These cannot be bought in commercial fertilizers, which increase the crops chiefly in the year in which they are used. Stable manure makes the soil richer for a number of years.

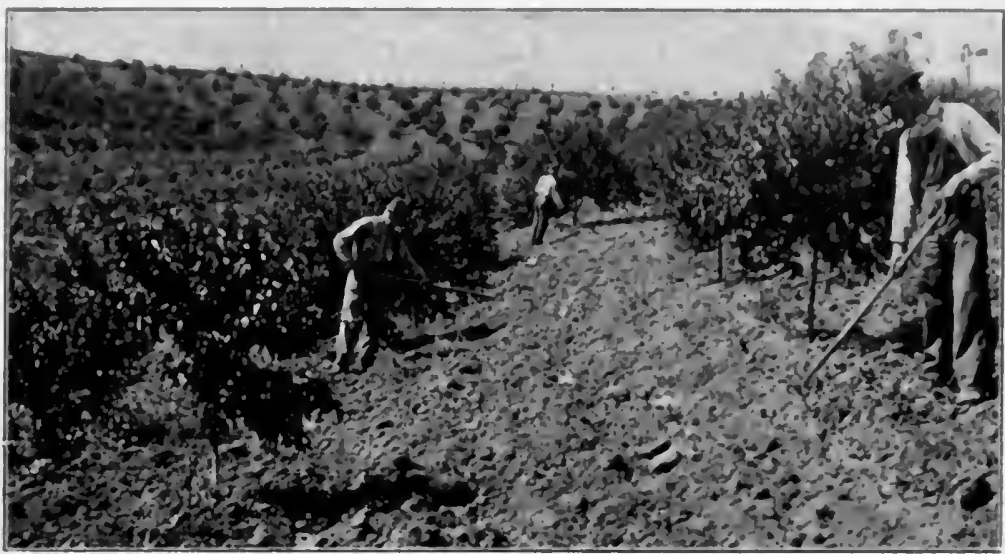

Fig. 6i. - Good Tillage, Making Good Fertilizing Profttable Note, on the left, that the peach trees are set on contours or terraces. 


\section{SECTION XVII. COMMERCIAL FERTILIZERS}

Solls have abundance of all necessary plant-food materials except nitrogen, phosphates, potash, and lime, which may be deficient in some lands. When one or more of these valuable forms of plant-food is deficient, poor crops result unless something containing the element wanted is added.

The lack of even a single one of these precious substances, or forms of plant-food, will cause the crop to be about as poor as if all Fig. 62.-Grass Hay from Equal Areas four of them were de- On left, unfertilized; on right, fertilized with ficient. It is important

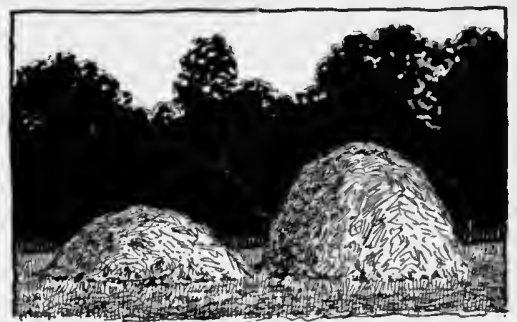
to find out which of these is wanting, and to use on each field a fertiiizer that contains just the kind of plant-food that is needed in that soil. Plants, if denied nitrogen or phosphates, but given an abundance of everything else needed, would die.

Nitrogen and ammonia. - Commercial fertilizers (so named from the word commerce, meaning trade) are those prepared and furnished by merchants or manufacturers. When they contain only nitrogen, they are called nitroge- 
nous fertilizers. The most important commercial fertilizers that are rich in nitrogen are cotton-seed meal and nitrate of soda. If nitrogen occurs in mixtures with other precious plant-foods, the fertilizer may be called an ammoniated fertilizer, or "guano." Ammonia is a combination of fourteen parts by weight of nitrogen with three parts of hydrogen (Fig. 63). Fourteen pounds of nitrogen, the most precious of plant-foods, may become seventeen pounds of ammonia. Hence, if there is printed on a bag

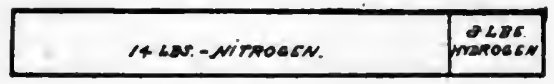

17.285-AMMONIA.

Fig. 63. - SHOWING THE WEIGHT OF AMMONIA EQUivalent to 14 Pounds of Nitrogen

of fertilizer the statement that it contains two per cent of nitrogen, you can calculate how much ammonia this equals, multiplying the amount of nitrogen by 17 and dividing the product by 14 . On the other hand, if the printing on the bag shows that cottonseed meal contains eight and one-half per cent of ammonia, change this to nitrogen by dividing by 17 and multiplying by 14. The amount of ammonia is always larger, because it contains all the nitrogen and another element besides.

Cotton-seed meal. - Cotton-seed meal is a yellowish, powdery material made from the kernels of cotton seed after removing most of the oil and hulls. Cotton-seed meal is more than twice as rich in nitrogen as the whole cotton seed from which it is made.

Cotton-seed meal usually contains between six and seven pounds of nitrogen in each hundred pounds of meal and is therefore expensive. It also contains some phosphate 
and potash. There are several grades of this meal, those that contain the largest proportion of hulls being the least valuable. This meal cannot be used by plants until it has decayed. It is more suitable, therefore, for crops that occupy the land in the warm weather than for very early crops which make their growth in cool weather.

Nitrate of soda. - Nitrate of soda is a fertilizer with more than twice as much nitrogen as cotton-seed meal. It costs more than twice as much per ton, but does not need to be used in such large amounts. It is brought by ships from South America, for in that hot country the nitrogen has already been changed into the form of a nitrate, ready to be used by plants at once.

When nitrate of soda is sown broadcast on the surface of the ground where young wheat or oat plants are growing, the moisture of the soil dissolves the fertilizer and carries it downward to the roots of plants.

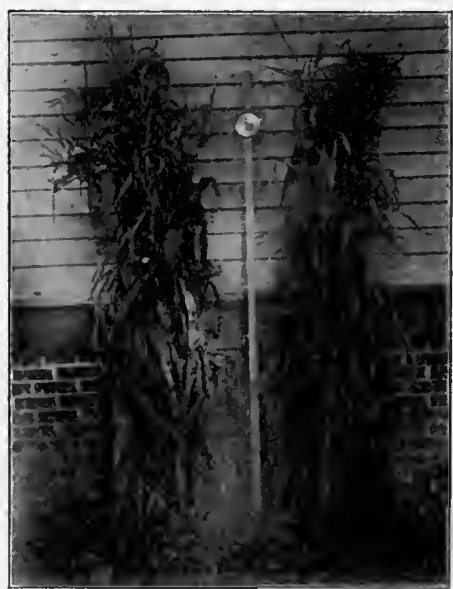

Fig. 64. - Corn from Equal Areas On right, no nitrogen in fertilizer; on left, fertilized with 240 pounds of nitrate of soda per acre. Yield per acre without nitrogen, 3.2 tons; with nitrate of soda, 6.7 tons.

Within a week after this fertilizer is sown, wheat and oat plants become much greener and more luxuriant. It is especially suitable for plants that make their growth during the cool months (wheat, oats, etc.) and for vege. 
tables, like lettuce and radishes, in which quick growth is desired.

Three kinds of phosphates. - Phosphates are those fertilizers that contain the element phosphorus, in the form of phosphoric acid. There are three kinds of phosphate, that are of very different value. The first is natural or raw phosplate, sometimes called Tennessee phosphate, Florida phosphate, or floats. It is simply the phosphate rock just as it is dug or brought up by dredges from its place in phosphate beds, except that it has been ground into a very fine powder. Since roots generally cannot absorb much of this form of phosphate because it will not dissolve in pure water, it is called insoluble phosphate.

Acid phosphate is so called because it is made by adding sulfuric acid to the raw or natural phosphate. This acid so changes the phosphate that roots can immediately absorb it. The phosphate in acid phosphate is called soluble. There is a third or intermediate form that plants can use. This and the soluble phosphate are added together and called the available phosphoric, that is, the kind that plants can use promptly.

Acid phosphate usually contains from 12 to 16 per cent of available phosphoric acid, that is from 24 to 32 pounds of available phosphoric acid in every 200-pound bag. The farmer can afford to pay fully one third more for the acid phosphate with 16 per cent than for that with only 12 per cent of available plant-food. He will need less of the high-grade than of the low-grade fertilizer, and thus will save freight and expense of hauling and handling. Although raw or crude phosphate cannot be dissolved 
in pure water and cannot be used immediately by the roots, nevertheless it has somic value as fertilizer for some soils and crops. When raw phosphate is kept for some time in contact with decaying vegetable matter or mixed with manure, a part of its phosphate changes into a form which roots can use.

Fertilizers containing potash. - The commonest of these is kainit. It is dug from deep mines in Germany. It contains about twelve per cent of potash. Muriate of potash is obtained from the same source. About half its weight, or fifty per cent, is potash. Kainit and muriate of potash are nearly white, resembling somewhat coarse table salt.

EXERCise. - Try to get samples of as many as possible of the fertilizers mentioned above for the teacher to show during class. In your notebook describe them. Be ready to report the effects of any fertilizer test you may know about.

Note To THE TEACHER. - If possible, exhibit small samples of any of the fertilizers mentioned in the lesson. Which ones dissolve quickly ? Which ones get lumpy? Exhibition of ordinary mixed or manufactured fertilizers will be of doubtful profit to the class, and may involve personal interests.

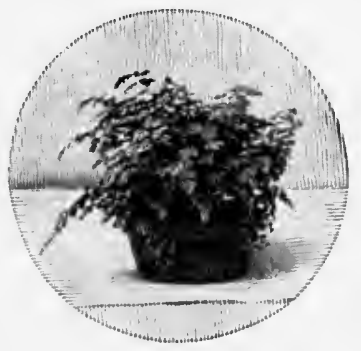

Fig. 65. - A Window Plant well treated AS To Light aNd Food 


\section{SECTION XVIII. CALCULATING FERTILIZER FORMULAS}

Fertilizers are sometimes spoken of as chemicals. Those made by mixing any two such chemicals are called mixed, manufactured, or manipulated fertilizers. The laws of most states require that there shall be printed on the outside of each bag of fertilizer a statement showing the percentage of nitrogen, phosphoric acid, and potash it contains. No fertilizer should be bought until the buyer has calculated its commercial value from these figures on the bag, using the method shown on page 103. After he has calculated the commercial value, he should compare this figure with the cash price asked by the seller. The two figures should differ by only enough to pay the dealer a fair profit and the cost of freight.

The commercial walue of a pound of nitrogen, phosphoric acid, and potash is the average wholesale selling price of these substances in the largest fertilizer markets. Chemists average these prices every year, and publish the figures as the commercial values for that year. Generally the commercial value is about 15 cents per pound of nitrogen, 5 cents per pound of available phosphoric acid, and 5 cents per pound of potash.

How to calculate the commercial value. - Multiply the prices given above by the number of pounds of nitrogen, available phosphoric acid, and potash respectively in a ton 
of the fertilizer. Add the products; the sum is the commercial value of the fertilizer.

ExAmple. - What is the commercial value of one ton of complete fertilizer which the printing on the bags guarantees to contain 1.65 per cent of nitrogen, Io per cent of available phosphoric acid, and 2 per cent of potash?

Plant-food Lbs. Cents $\begin{gathered}\text { Commercial } \\ \text { in one ton }\end{gathered}$
value

Nitrogen $\quad \mathrm{I} .65 \% \times 2000 \mathrm{lbs} .=33$ lbs. $\quad 33 \times 15=\$ 4.95$ Available phos-

phoric acid $10 \% \times 2000 \mathrm{lbs} .=200 \mathrm{lbs} .200 \times 5=10.00$

Potash

$2 \% \times 2000 \mathrm{lbs} .=40 \mathrm{lbs} . \quad 40 \times 5=$

$\frac{2.00}{\$ 16.95}$

The above calculation shows a commercial value of $\$ 16.95$ when nitrogen, phosphoric acid, and potash have the prices of 15,5 , and 5 cents a pound respectively. ${ }^{1}$

If the cash price asked by the dealer is many dollars per ton above the estimated commercial value for that year, a calculation should be made to learn what it would cost for the farmer to make his own fertilizer by mixing together acid phosphate, cotton-seed meal, and kainit, or other chemicals.

EXAMPLE. - What will it cost to make a home-mixed fertilizer, having the same composition as the fertilizer given in the table, with cotton-seed meal at $\$ 22$ per ton, acid phosphate (with 16 per cent available phosphoric acid) at $\$ 15$ per ton, and kainit at $\$ 14$ per ton? The price asked for the ready-mixed fertilizer is $\$ 2 \mathrm{I}$ per ton. How much meal, phosphate, and kainit must be mixed in order to obtain an equivalent, but less expensive, fertilizer?

1 These figures will answer for practice. To get the exact prices of nitrogen, phosphoric acid, and potash for any particular year, write to the State Commissioner of Agriculture at the state capital. 
In one ton

Nitrogen

Available phos-

phoric acid

Potash
1.65 lbs. per cwt. $\times 20$ cwt. $=$

10 lbs. per cwt. $\times 20$ cwt. $=$

2 lbs. per cwt. $\times 20 \mathrm{cwt}$. $=$
Plant-food needed

33 lbs.

200 lbs.

40 lbs.

First find how much cotton-seed meal is needed to afford 33 pounds of nitrogen. The table on page 106 gives the per cent of nitrogen in cotton-seed meal as $6 \frac{1}{2}$; this means that each hundredweight of meal contains $6 \frac{1}{\mathrm{lb}}$. of nitrogen. Evidently to supply $33 \mathrm{lb}$. of nitrogen, as many hundredweight of meal are needed as 61 is contained times in 33 . Thus $33 \div 61=5.07$ cwt., or $507 \mathrm{lbs}$., of cotton-seed meal are needed.

Next find how much phosphoric acid and potash this amount of meal will supply. From the tables below it is seen that 1 cwt. of cotton-seed meal contains $2.8 \mathrm{lbs}$. of phosphoric acid ; therefore, $5.07 \mathrm{cwt}$. contain $(5.07 \times 2.8) 14.196 \mathrm{lbs}$. Likewise for potash, $5.07 \mathrm{cwt}$. cotton-seed meal contain $5.07 \times 1.8=10.126 \mathrm{lbs}$. of potash.

Lbs. phosphoric acid needed 200

Less lbs. phosphoric acid supplied in $507 \mathrm{lbs}$. c.-s. meal Lbs. phosphoric acid to be supplied in phosphate

How many pounds of phosphate containing $16 \%$ of available phosphoric acid are needed to furnish $185.8 \mathrm{lbs}$. of phosphoric acid? Evidently as many hundred as 16 is contained times in 185.8 . Thus, $185.8 \div 16=11.61$ cwt., or 1161 lbs. of acid phosphate are required.

Calculate how many pounds of kainit to use.

Lbs. potash needed

Less lbs. potash in $507 \mathrm{lbs}$. c.-s. meal

Lbs. potash to be supplied in kainit

$\frac{10.2}{29.8}$

To furnish $29.8 \mathrm{lbs}$. of kainit requires as many hundredweight of kainit as 12 (the number of pounds of potash which the table shows is contained in 1 cwt. of kainit) is contained times in 29.8 . Thus $29.8+12=$ $2.46 \mathrm{cwt}$., or $246 \mathrm{lbs}$. of kainit are needed.

Combining these three results :

507 lbs. cotton-seed meal

$\left.\begin{array}{l}507 \text { lbs. cotton-seed meal } \\ 116 \text { t lbs. acid phosphate }(16 \%) \\ 246 \text { lbs. kainit }\end{array}\right\}$ contain $\left\{\begin{array}{l}\text { nitrogen } \\ \text { av. phos. acid } \\ \text { potash }\end{array}\right.$ 
Cost.

507 lbs. cotton-seed meal at $\$ 22.00$ per ton $=$ I 16I lbs. acid phosphate at $\$$ I5.00 per ton $=$ 246 lbs. kainit at $\$ 14.00$ per ton $=$ I914 lbs. mixture $\$ 5.58$ 8.75 $\frac{1.72}{\$ 16.05}$

Price asked for one ton of manufactured fertilizer $\$ 21.00$ Cost of home mixture affording same amounts of plant-food Saved in cash by home-mixing

A slight reduction in the amount saved must be made for the labor used.

Advantage of home-mixing. - By mixing his fertilizers the farmer can usually save several dollars per ton. He

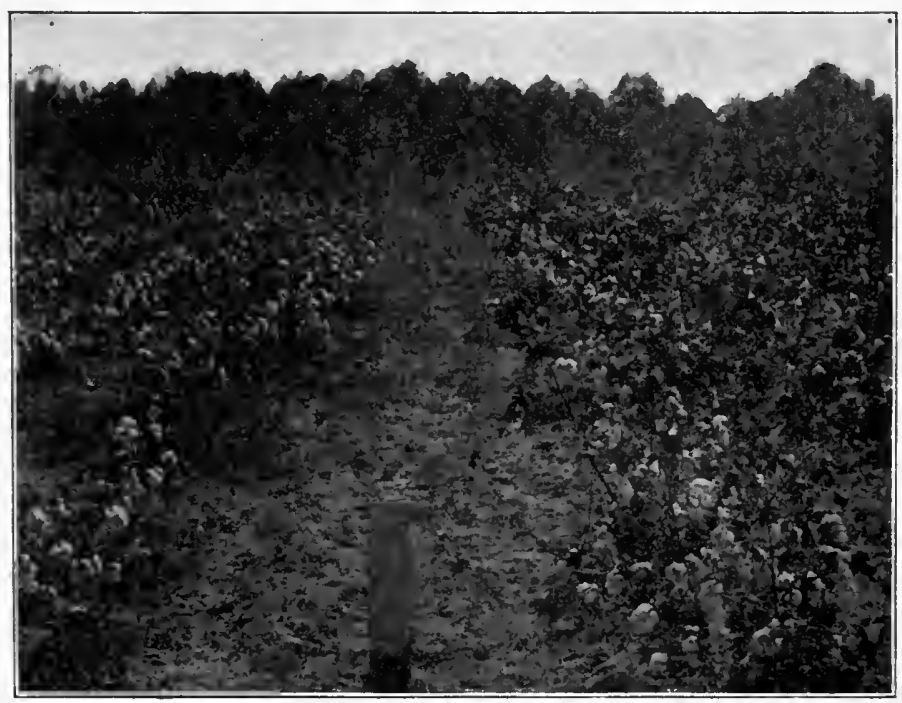

Fig. 66. - ON l.eft, Cotton UNFertilized: on Right, Cotton Supplien with a Complete Home-mixed lertilizer

can also make a varicty of mixtures, adapted to each crop and to each field. 
Fillers in fertilizers. - A full ton of the mixture is not always needed to afford the desired amount of plant-food. If a full ton having the given percentage composition is wanted, add the necessary amount of some worthless material, such as ground stone or cinders. Such worthless additions to fertilizers are called fillers. If manufacturers add them it is for the purpose of making a fertilizer that they can afford to sell at a low price. To avoid buying and hauling useless filler, use only the highest grades of manufactured fertilizers. These are higher in price, but generally furnish nitrogen, phosphoric acid, and potash at a lower cost per pound than do low-grade, cheap fertilizers. In choosing fertilizers, select that one in which a pound of plant-food costs the least.

COMPOSITION OF FERTILIZERS

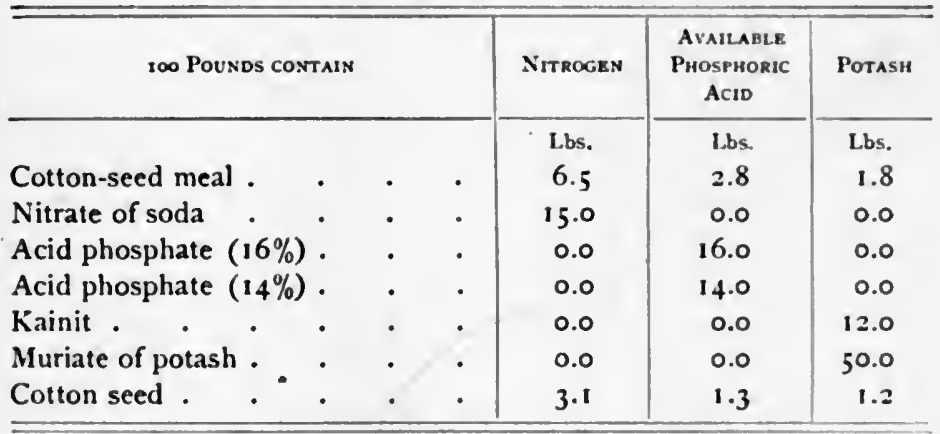

EXERCISE. - Copy in your notebook the two examples given in this section and understand them so that you can work similar examples on the blackboard, or for some farmer.

Note to THE TEACHEK. - If the sixth grade studies agriculture, this section may be omitted. It should be required, together with the additional problems, when the class in agriculture consists of the seventh 
or some higher grade. It is suggested that several problems like the preceding be worked in class, either by dwelling long enough on this lesson, or by substituting this class of problems for the usual lesson in arithmetic.

Addirional Problems:-

(1) What is the commercial value of a ton of complete fertilizer containing $8 \%$ available phosphoric acid, $3 \%$ nitrogen, and $3 \%$ potash?

(2) How much nitrate of soda, kainit, and $16 \%$ phosphate contain the same amounts and kinds of plant-food as the ton of the fertilizer just mentioned?

(3) What would this mixture cost with acid phosphate at $\$ 15$, nitrate of soda at $\$ 55$, and kainit at $\$ 14$ per ton?

(4) How much $16 \%$ phosphate, cotton-seed meal, and muriate of potash would afford the same number of pounds of each plant-food as one ton of the fertilizer mentioned in first problem?

(5) Which should a farmer buy, muriate of potash at $\$ 55$ per ton, or kainit at \$14? What would a pound of potash cost in each?

(6) Which should a farmer buy, acid phosphate containing $16 \%$ available phosphoric acid, costing \$I4 per ton, or a lower grade containing $12 \%$, costing $\$ 12$ per ton? What does a pound of available phosphoric acid in each cost?

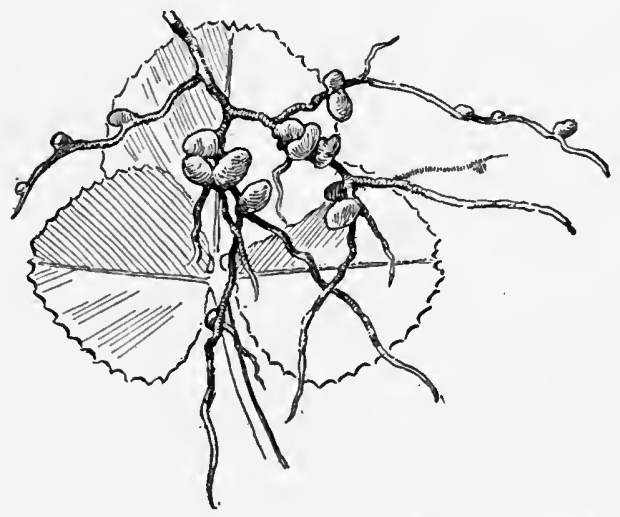

Fig. 67. - Nodules on a Legume, aiding the FARMER TO SECURE NITROGEN 


\section{SECTION XIX. SUITING THE FERTILIZERS TO THE SOIL}

THE amount of fertilizer per acre varies with the land and with the crop. Vegetables and cotton generally pay better for large amounts of fertilizer than does corn. For cotton, many farmers use only 200 pounds per acre. Good farmers often use 400 to 600 pounds. Growers of vegetables increase this to as much as one half or one ton of commercial fertilizer per acre. As labor and land become scarcer or higher it pays to increase the amount of fertilizer. Some land may be too poor for very large amounts of fertilizer to be very profitable. This is because a poor soil may be so shallow or so deficient in vegetable matter that in dry weather it can hold just enough water to make good use of only 300 pounds of fertilizer per acre. When this same soil is made decper and supplied with vegetable matter, it may hold enough moisture to use profitably double this amount.

Experienced farmers often apply more phosphate than the crop will remove from the land because the clay or iron in the soil changes some of it into a form that plants cannot use. This cannot be prevented and fortunately phosphate is not very expensive. Nitrogen, however, is about three times as expensive as phosphoric acid, hence 
more of this than the plant requires is not applied. For fields where soil-improving crops have grown and on stockfarms, often there is no need to buy any nitrogen, or very little at the most.

The agricultural value of a fertilizer. - The agricultural value of a fertilizer is the value of the increase in the crop caused by using the fertilizer.

Suiting the fertilizer to the crop.-Different plants require different kinds of fertilizer. Since leguminous plants get nitrogen from the air by the work of their root tubercles they generally do not need nitrogen. To add a fertilizer containing nitrogen is therefore a useless expense.

Suiting the fertilizer to the soil. - What a soil needs cannot be told by looking at it. There are, however, some helpful.

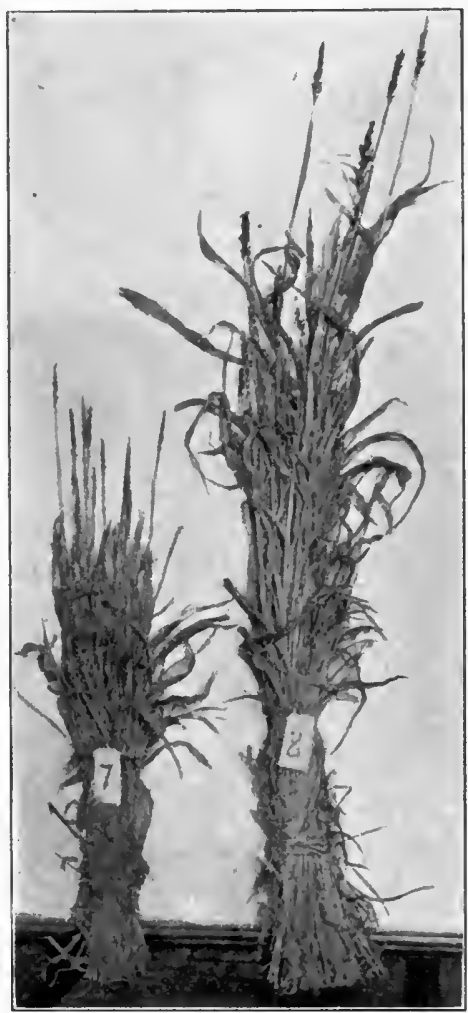

Fig. 68. - Sorghum From Equal Areas On left, no nitrogen in the fertilizer; on right, fertilized with nitrate of soda. rules. Generally, a soil that is black or very dark contains much vegetable matter, which in turn contains much nitrogen. On the other hand, if the stalks of crops cul- 
tivated on a field are small, there is probably need of nitrogen in the soil. A crop of cowpeas or clover usually leaves the soil rich in nitrogen. Clay soils generally contain more potash than sandy soils. Whether a soil is rich in phosphoric acid cannot be told by looking at it.

How to find what fertilizer the soil needs. - Even when a chemist analyzes soil and finds out just what it contains,

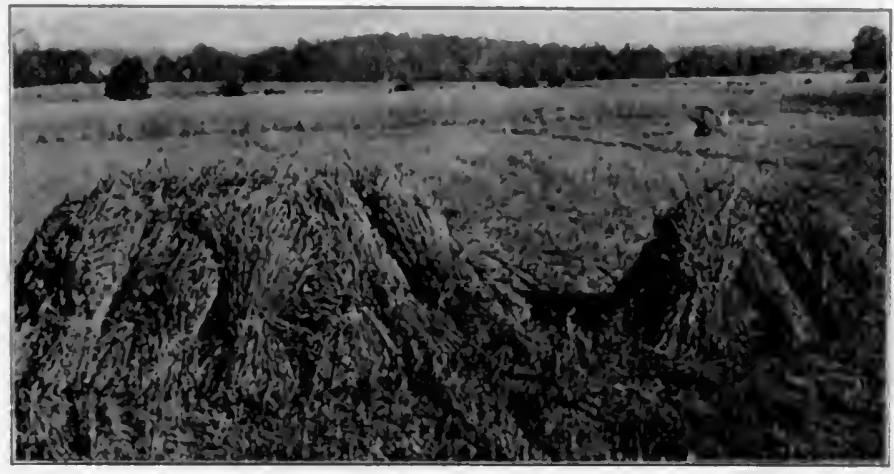

Fig. 69. - Wheat from Equal Areas

On left, fertilized with nitrate of soda; on right, no nitrogen in the fertilizer.

he cannot tell how much of every precious element is in a condition for plants to use. The chemist's analysis does not, therefore, show what fertilizer to apply.

The only way to determine the kind of fertilizer a soil needs is to make an experiment on that soil with different fertilizers.

It will pay to make this experiment with the principal crop of any farm. The following diagram shows how to make such a test. The areas must be of exactly the same 
size, for example, one eighth of an acre. The figures in the table show the number of pounds of fertilizer for one acre :

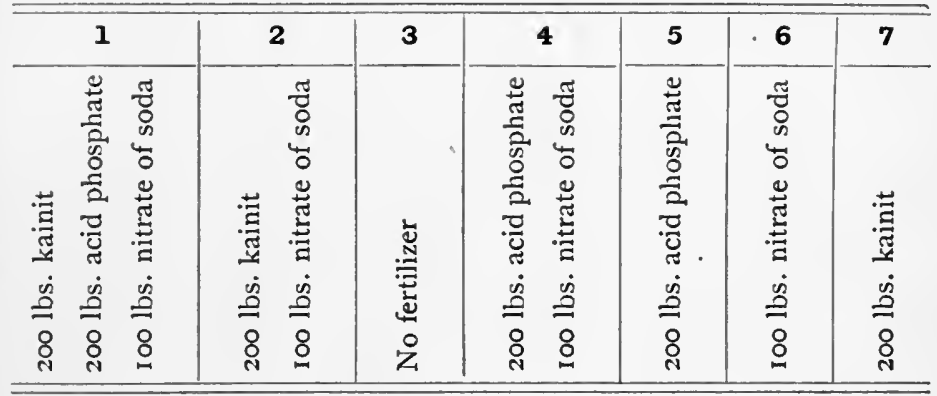

The plots must be on the same kind of soil and equally well drained. If it is not convenient to harvest the crop separately on so many plots, use only plots $\mathrm{I}, 2,3,4$, and 5 .

Fertilizers that do not work well together. - Two fertilizers that must not be mixed are lime and phosphate. The lime changes the phosphate into a less soluble form and thus reduces its value as a fertilizer. Now, ashes contain much lime; therefore ashes and phosphate should not be used together.

EXERCISE. - Learn from a farmer in the neighborhood, or from the printing on fertilizer sacks, the composition of the fertilizer most used in your neighborhood. Is it used on all sorts of soils? If it suits poor clay soils, is it apt to be the best for sandy land? By making the fertilizer experiment described in this Section, you may be able to increase greatly the profits of some farm the next year.

Note to the TEACHER. - The calculation of the commercial values of fertilizers and practice in calculating fertilizer formulas of definite composition should be continued. 


\section{SECTION XX. LIME}

Chalk is one form of lime. Another form is quicklime, which consists of large lumps, from which bricklayers make their mortar. If a bricklayer pours only a small amount of water on a lump of quicklime, the lump absorbs the water and falls into a powder. This lime that has been slacked or changed into a powder by water is the form generally used when the farmer employs lime as a fertilizer. He buys the quicklime and lets it slack or absorb water after it reaches the farm.

Lime overcomes sourness of soils. - All of these forms of lime are alkaline, that is, the opposite of acid. Quicklime is more alkaline than the other kinds of lime and fresh-slacked lime ranks next. If either of these forms of lime is placed in contact with an acid, the lime unites with the acid and by forming a substance different from either, that is, neither alkaline nor acid, it destroys the acidity. If, therefore, lime is put on sour soil, it unites with the acids that made the soil sour, changing them into harmless substances.

How to know that a soil is sour. - A doctor cannot well cure sickness until he determines the nature of the disease. When he has done this, he knows what medicines to give. Likewise it is important for the farmer to know the condition of his soil. If sourness is the principal trouble, lime will aid some crops to grow much better on this soil. To 
test soil for sourness or acidity strips of blue litmus paper are used (purchase at drug store). Acid turns the paper pink or red. Since the acid in a sour soil is weak, it will change the color of blue litmus paper not to red, but to pink.

Cut a slit with a knife in the moist soil to be tested and place the blue paper in this slit. Press the damp soil against both sides of the paper for about two minutes. If the paper becomes pink where it has been moistened by the earth, the soil is acid. The deeper or redder the color, the more acid is the soil.

Large areas of acid soils in the South. - In regions where the long-leaf or yellow pine is the principal forest tree, much acid soil is usually found, especially in the low places. Farther from the coast sandy soils are sometimes found to be acid even on the tops of mountain plateaus. Spots of poorly drained bottom lands, known as "crawfish land," are often sour.

Some plants are able to grow in a slightly acid soil. Fortunately for the farmer who has acid soil, many useful

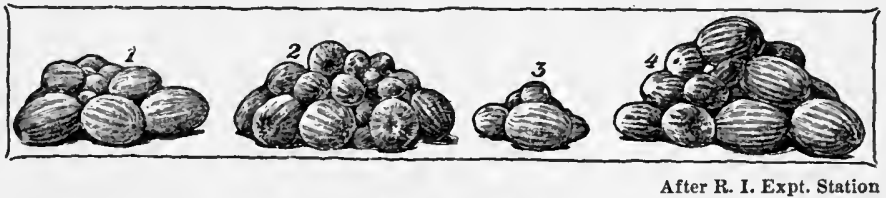

Fig. 70. - Watermelons from Equal Areas

I and 3, limed; 2 and 4, not limed.

plants grow fairly well in such land. Some of the crops that can endure slight acidity of the soil are cotton, corn, cowpeas, and watermelons (Fig. 70). It may not pay to 
buy lime for these. There are other plants, however, which will not thrive on a sour soil until lime is applied as a fertilizing material. Among these are red clover and alfalfa. Wheat, peanuts, sorghum, onions, beets, and cabbages yield much better when lime is used on a soil that previously was acid.

How to use lime as a fertilizer. - Quicklime (or lump lime) must be slacked before being spread. This can be done either by pouring water over it while in boxes or in the wagon body, or by covering piles of a few bushels of quicklime with a layer of damp earth. Within a few days or weeks the water in the earth will reduce the lumps of lime to powder, and it is then ready to be spread broadcast on the plowed ground and harrowed in. From six to twelve barrels of quicklime (which will occupy much more space and weigh more after slacking) are used on one acre. Lime need not be applied oftener than once in three or five years.

Other uses of lime when added to the soil. - Lime is a plant-food. Besides overcoming the acidity of certain soils, lime causes the beneficial nitrate-forming germs to increase. It is useful also in hastening the rotting of vegetable matter, such as leaves or weeds which have been plowed under. This rotting must occur before roots can use such vegetable matter.

Lime makes stiff clay soils more porous, and more easily worked. Like cultivation, it is a stimulant. It changes some of the potash in the soil into a form that plants can use. It may cause a poor, sandy soil to become exhausted rapidly by putting into crops the little fertility 
that was in it. This can be avoided by constantly adding vegetable matter and necessary plant-food.

Do not mix lime with barnyard manure or acid phosphate, nor add it to a manure pile or compost heap. It rots these materials so rapidly that it drives off into the air a part of the nitrogen or ammonia of the manure, the loss of which is made known by the strong smell of the escaping ammonia gas. A covering of soil over the compost pile would absorb and hold the ammonia; hence lime in the soil would not do the harm it might when mixed above the ground with manures or fertilizers.

Exercise. - If possible get a lump of builder's lime; weigh it and notice its size; let water drip slowly on it. Again weigh it and notice its size. What has happened?

At this rate a barrel of quicklime weighing 165 pounds would make how many pounds of slacked lime?

Note to The TeAcher. - It will be worth while to buy from a wholesale druggist a 15 -cent bottle of blue litmus paper. Obtain in addition a bottle of red litmus paper, which is turned blue by lime. Have pupils test a number of soils with the blue litmus paper, afterwards showing to the class the paper used and describing the kind of soil found, acid, neutral, or alkaline. Test with blue and red litmus all obtainable fertilizers, also salt, soda, various well-waters, etc.

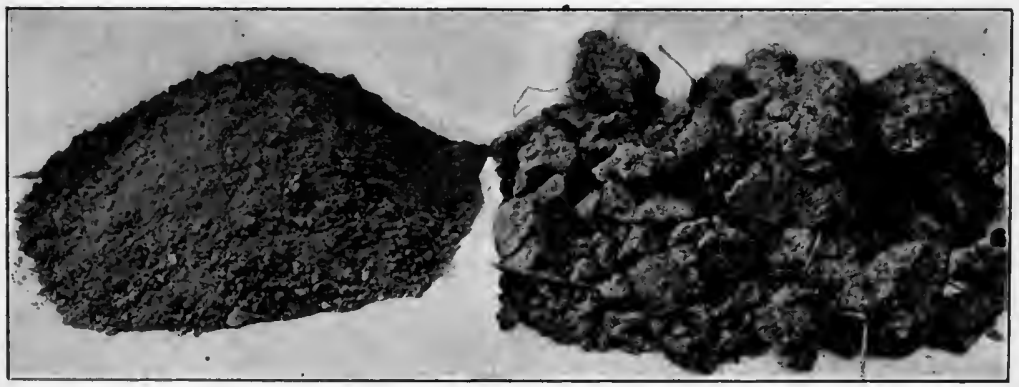

Fig. 71. - Well Cultivated and Poorly Tilled Soils. Much Reduced in Size Lime aids in crumbling clods. 


\section{SECTION XXI. ROTATION OF CROPS}

Rotation means change in some regular order. Rota. tion of crops is the exact opposite of the growth of the same crop year after year on the same land. It has been found that when one kind of plant is grown year after year on the same land, the yield decreases. If a different kind of crop, peanuts or cowpeas for example, comes in between two cotton crops or two wheat crops, the yicld of the cotton or wheat is greatly increased. The different crops ought not only "to take time about" on any one field, but should follow each other in a somewhat definite order. It is impossible in this limited space to arrange tables showing the best order for all crops on the different soils. However, some reasons for rotation are given in the following pages.

Rotation to get rid of weeds. - A corn field generally contains more grass and weeds than a cotton field, because the cultivation of the corn is usually stopped earlier in the summer, thus giving grass a chance to spring up. Cotton is cultivated so late into the summer that in the fall a well-kept cotton field is nearly clean. If a field produces several crops of oats or wheat in succession, it becomes quite weedy. The wise farmer will grow on that field one or two crops of cotton or of some other plant that he cultivates very thoroughly, in order to get rid of the weeds. 
Rotation to add vegetable matter. - No soil can be kept fertile unless vegetable matter is added to it, either by the decay of large amounts of plants grown on the land or by other means. Place must be made in any rotation for an occasional crop that leaves much vegetable matter to be plowed under. Such crops are hay plants, which completely cover the surface and leave a mass of roots and fallen leaves. The stubble of wheat and oats, together with the growth of weeds that usually follows these grains, also affords considerable vegetable matter.

Rotation to add nitrogen. - Plants like cowpeas and clovers get nitrogen from the air. This nitrogen is added to the soil when the growth of cowpeas or clover is plowed into the land. Even the stubble and roots of these crops, when plowed under, increase the nitrogen in the soil. Hence a wisely planned rotation makes room for the growing, as frequently as can well be done,

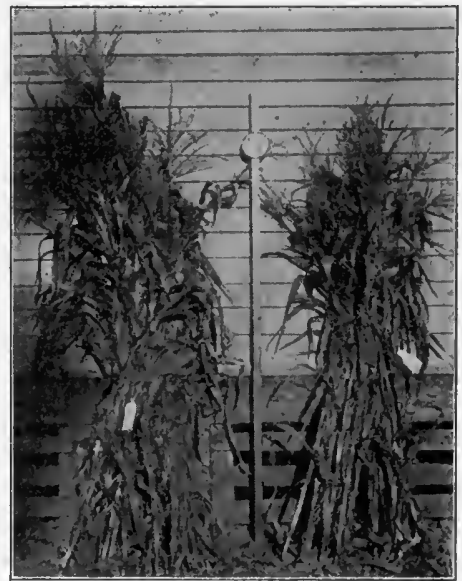

Fig. 72. - Twenty-five Corn Plants IN EACH BUNDLE

On left, grown after plowing under the stubble of mixed vetch and oats; on right, after oat stubble. Weights, 33 and 18 pounds. of some leguminous crop, such as cowpeas, clover, peanuts, or valvet beans. When oats or wheat are grown, cowpeas ought usually to be sown in June after the grain crop is removed. Cowpeas ought generally to be sown among 
the growing corn plants to improve the soil. Figure 72 shows that the nitrogen in the stubble of a previous crop of vetch, a leguminous plant, increased the yield of corn planted as soon as the vetch was cut.

Another reason for rotating crops is to diversify the farm products. The farmer who grows several crops has his labor better distributed over the entire year than the farmer who grows only one or two crops and is less injured if storm, accidents, or low prices cut off his profit on one crop.

Rotation to avoid diseases and insect pests. - Every zultivated plant has its own special diseases and insect enemies that do not attack most other farm crops. Many kinds of disease germs and insects remain alive in the soil for one or more years, ready to do injury when the proper plant is grown on that field. If the plants that would be attacked by these pests are kept away from that field for a few years, all or most of the germs or insects die of starvation. If, however, the plant subject to attack is put on the same land again, the pest increases and does more and more harm.

Examples of rotation. - Rotation must vary with the kinds of crops to be grown and with the number of acres given to each. Here is a rotation in which about one third of the land is to be used for producing cotton:-

Plant one third of the land in cotton; one third in corn, with cowpeas sown later between the corn rows (Fig. 73); and one third in oats or wheat, planting cowpeas in June after the grain is harvested. This is called a threeyear rotation, because at the end of three years each 
field starts over again with the same crop. The cowpeas grown between the corn rows fertilize the oats, which is the next crop. The cowpeas planted just after the oats are cut may be picked or cut for hay or grazed. But no matter what way they are used, they fertilize the succeeding crop of cotton. Of course, phosphate, and sometimes potash, will need to be purchased to help fertilize the crops. Thus cotton following cowpeas on only one third of the cultivated land

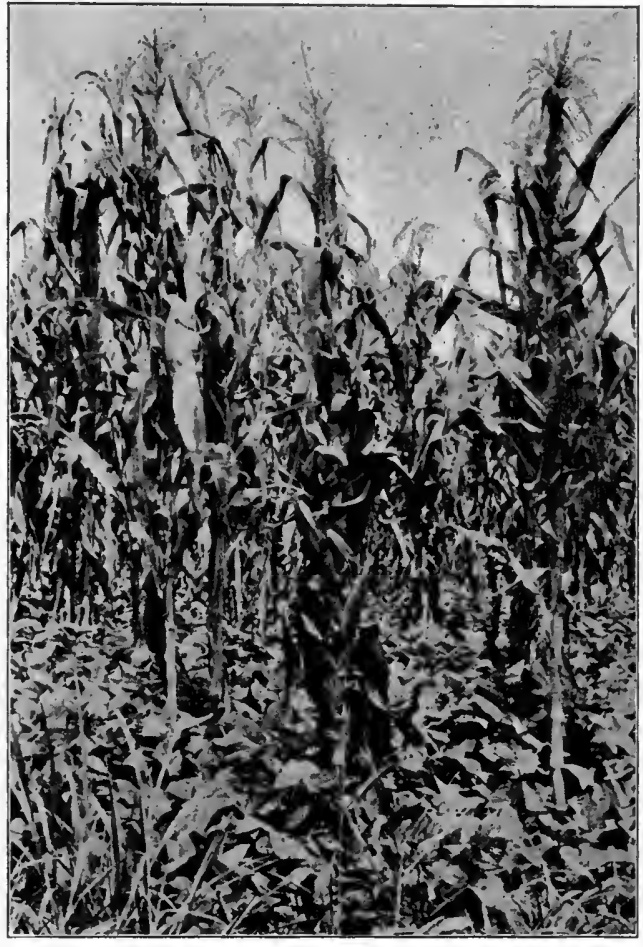

Fig. 73.- COWPEAS SOWN BETWEen the Rows of CORN

will usually produce as many bales as when half or more of the cultivated land is used for cotton and only a few cowpeas grown.

Each year let corn follow cotton; sow oats or wheat on the field that has just borne a crop of corn and cow- 
peas; and plant cotton every year where oats or wheat (and afterwards cowpeas) grew the year before. Study the following diagrams until this order of cropping is understood.

Under this rotation the soil bears a soil-improving crop two years out of every three and the farm becomes richer year by year. A soil-improving crop can be grown every year by sowing crimson clover, vetch, or bur clover in September among the cotton plants.

If a farmer wishes half his cultivated area to be in cotton, he can easily do this by growing cotton two years in succession, changing the three-year to a four-year rotation. In a four-year rotation each field bears the same crop in the fifth year as in the first. The smaller areas used for peanuts, sweet potatoes, vetches, sorghum, watermelons, and other minor crops are rotated on different parts of a single field near the barn, letting crops that add nitrogen to the soil rotate with those that do not have this power.

A good rotation for sugar cane in regions where the cane stubble lives through the winter is:- first year, corn, with cowpeas grown between for fertilizing the cane; second year, sugar cane; third year, or third and fourth years, sugar cane from the stubble. In climates where a good stand of sugar cane does not spring up from the stubble, a rotation for sugar cane is: first year, cowpeas or velvet beans; second year, sugar cane. In the region just north of the cotton-belt a satisfactory rotation is: first year, wheat, among which red clover or grass seeds are sown; second year, clover or timothy hay; 
third year, corn (after clover), or timothy hay ; fourth year, corn or wheat.

\begin{tabular}{|c|c|c|c|}
\hline First yeAR & SECOND YEAR & THIRD YEAR & $\begin{array}{c}\text { FovRTH } \\
\text { YEAR }\end{array}$ \\
\hline $\begin{array}{l}\text { Cons; cowpeas } \\
\text { between rows; in } \\
\text { fali sow in oats or } \\
\text { wheat. }\end{array}$ & $\begin{array}{l}\text { OATs; after cut- } \\
\text { ting oats sow cow- } \\
\text { peas for hay, seed, } \\
\text { or grazing. }\end{array}$ & Cotton. & $\dot{\Xi}$ \\
\hline $\begin{array}{l}\text { OATs; after cut- } \\
\text { ting oats or wheat } \\
\text { sow cowpeas for } \\
\text { hay, seed, or } \\
\text { grazing. }\end{array}$ & Cotton. & $\begin{array}{l}\text { CORN; cowpeas } \\
\text { between rows; in } \\
\text { fall sow in oats or } \\
\text { wheat. }\end{array}$ & 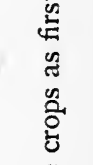 \\
\hline Cotton. & $\begin{array}{l}\text { CoRN; cowpeas } \\
\text { between rows; in } \\
\text { fall sow in oats or } \\
\text { wheat. }\end{array}$ & $\begin{array}{l}\text { OATS; after cut- } \\
\text { ting oats sow cow- } \\
\text { peas for hay, seed, } \\
\text { or grazing. }\end{array}$ & $\tilde{\Xi}$ \\
\hline
\end{tabular}

Fig. 74.- Diagram showing a Simple Three-year Rotation

The soil will be enriched still more rapidly if crimson clover is added to a rotation for a cotton farm. This three-year rotation then takes the following form:-

\begin{tabular}{c|c||c|c||c|c}
\hline \multicolumn{2}{c||}{ First Year } & \multicolumn{2}{|c||}{ Second Year } & \multicolumn{2}{c}{ Third Year } \\
\hline Summer & Winter & Summer & Winter & Summer & Winter \\
\hline $\begin{array}{c}\text { Corn, with } \\
\text { cowpeas }\end{array}$ & $\begin{array}{c}\text { Oats or } \\
\text { Wheat }\end{array}$ & Cowpeas & $\begin{array}{c}\text { Crimson } \\
\text { Clover }\end{array}$ & Cotton & $\begin{array}{c}\text { Crimson } \\
\text { Clover }\end{array}$ \\
\hline
\end{tabular}

Fig. 75. - Diagram showing a Three-year Rotation for Rapidly IMPROVING A COTTON FARM 
In three years under this rotation a field bears three fiber and grain crops (cotton, oats, and corn) and four crops of soil-improving forage plants (cowpeas and crimson clover, each twice).

EXERCISE. - What farm or garden crops, that are extensively grown in your neighborhood, leave the field most free from weeds? Which one permits weeds to grow? Can the corn crop be harvested in time for wheat or fall-sown oats to be sown?

Note to THE TEACHER. - Encourage pupils who have grown up on farms to write on the blackboard a statement of the best rotation in use by any farmer of their acquaintance, and to decide whether any of the teachings of this Section and of Section XXX suggest a possible improvement in the local rotation of crops.

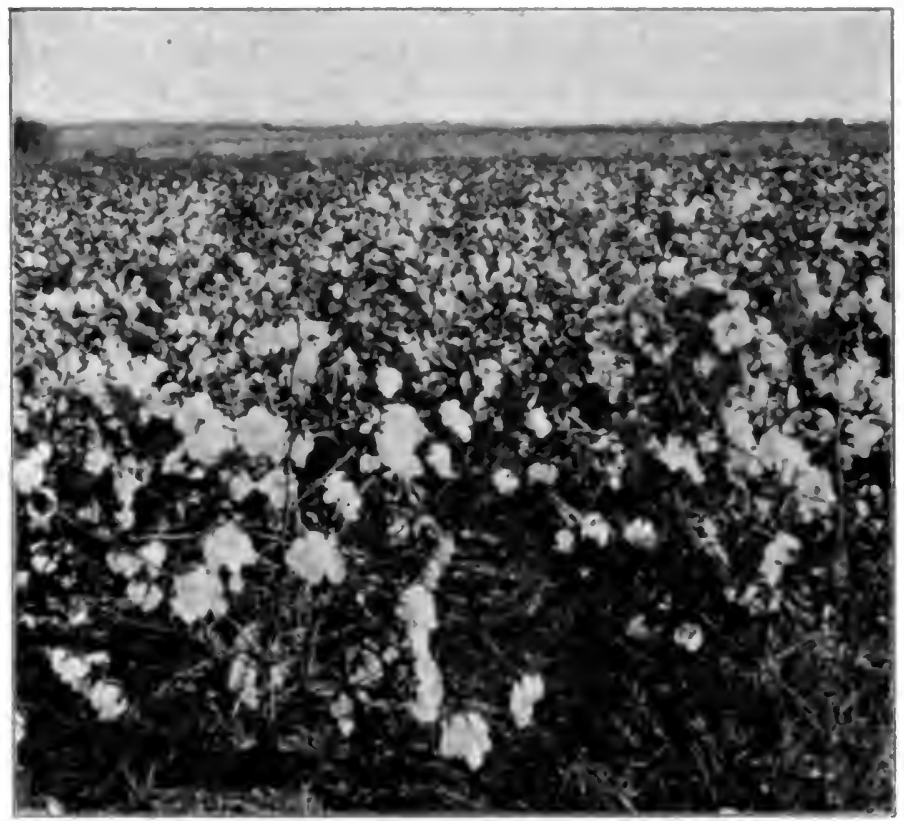

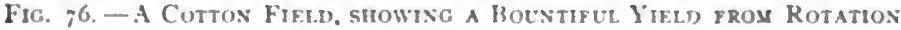
of Croms and Thorovgh Cutthistun 


\section{SECTION XXII. CORN}

Corn belongs to the grass family. Some of the plants to which it is related are all true grasses, as sugar cane, wheat, oats, rye, barley, and rice. Corn differs from most of its relatives in having both a tassel and an ear, and in having these located on different parts of the plant.

A corn plant in full tassel gives off a cloud of dust-like particles when shaken. There are estimated to be about I 8,000,000 tiny pollen grains formed by each tassel. Most of these are wasted, but those that fall on the silks are useful. There are as many silks as spaces for grains of corn on the ear.

Races of corn. - There are only a few races of corn, the most important being pop, sweet, dent (or common), and flint corn. In each race there are many varieties.

Mixing of races of corn. - Some ears of popcorn have some kernels like those of field corn. These have been crossed with common corn. Hence popcorn should not be planted near other kinds that will tassel at the same time. If it is impossible to plant it away from all other kinds, arrange the date of planting so as to have it silk and tassel before the other corn, or after the tassels on the common corn have shed their pollen and dried. Sweet corn readily crosses with field corn, and some of its grains are then smooth instead of wrinkled, as dry kernels of sweet corn ought to be. When these races cross, the 
character of the grain is generally changed the same year that the mixing occurs.

Varieties of field or dent corn. - There are several hun-

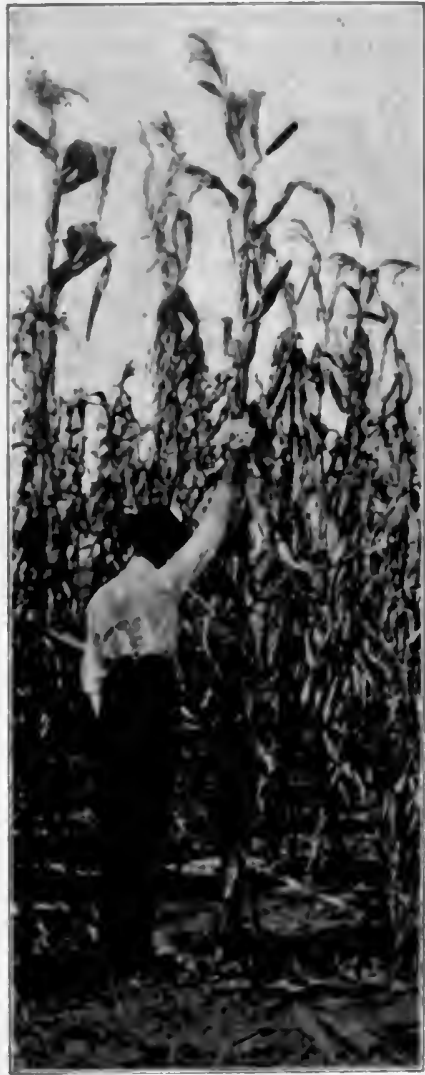

FIG. 77. - A TAll VARIETY OF Corn, Mexican June be no white grains on the yellow cars. This is beMany of them are Northern kinds, too small and carly to yield well in the South. Experiments have shown that the following varicties are often among the most productive for the Gulf states and regions with similar climate: Mosby, Cocke, and Henry Grady. In most experiments in the South varicties with two medium-sized ears have yielded more corn than those having a single large ear per plant.

Mixing may not show the first year. - There may be a large amount of crossing between varieties of common corn, and yet the farmer may be unable to see it by exam. ining the ears. A white varicty may grow beside a yellow variety of dent corn and yet the first year there may dred varietics of field corn. 
cause crossing between two varieties of dent corn does not always change the character of the grains the first year. The growing of two varieties of corn close together (unless they are planted at such dates as to cause them to tassel at different times) should be avoided.

Corn is a plant easily improved by the method given in Section VIII. It is also a plant that quickly becomes mixed, and hence inferior, if great care is not taken in the
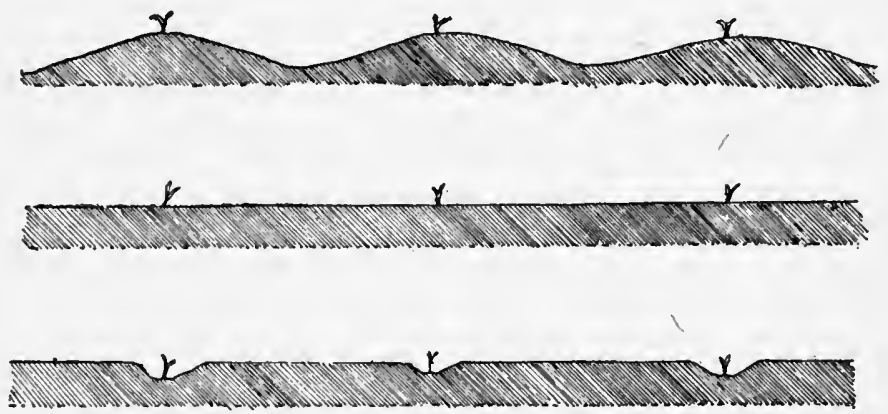

Fig. 78. - Showing Three Methods of planting Corn

selection of seed. Learn the best kind of corn for your soil, then keep it pure and improve it.

Corn roots and the preparation they require. - A corn plant may have 20 to 50 roots, many of them as long as the plant itself. These, with their branches and roothairs, are always busy taking water from the soil. Hence corn yields best on a soil that is always moist (but not wet). It needs land so deeply plowed before planting and so well drained that some of its roots can grow deep down where there is moisture even when the weather is dry. Plow deep in preparing a field, if you can plow early. 
Corn is planted either in elevated ridges or beds, in depressions or water furrows, or in level ground (Fig. 78), according to the soil and the farmer's judgment. Plant corn just deep enough to make sure that it will continually be in moist soil until germinated. Usually a depth between one and three inches is best.

Distance between plants. - The poorer and drier the land, the greater must be the distance between plants. But land on which corn requires more than three feet between plants, in rows five feet apart, is probably too poor and dry for corn. The richer and moister the land, the more the plants can be crowded; the rows on some bottom lands are only three and a half feet apart. In the South, corn is usually planted from the first of March to the middle of June.

Cultivation. - Corn roots are long and near the surface; this shows that cultivation ought to be shallow. Heavy rains after planting make some clay lands very compact. This causes some farmers to give one deep cultivation while the plants are very small. Avoid this unless sure that it is necessary, and then make this deep cultivation only when the plants are very young. A corn plant six inches high may have roots twelve to eighteen inches long. Many of them would be cut by deep cultivation.

It is possible and wise to cultivate corn before it comes up. This is done by running a spike-tooth harrow or a weeder over the field, either across or along the rows. In this way millions of tiny weeds and grass plants are killed just after they have come up. This early cultivation also forms a loose layer of earth all over the field, which holds 
the moisture in the ground, thus making the corn come up more completely and quickly and causing the young plants to grow more rapidly. This cultivation with the weeder can be kept up until the corn plants are several inches or even a foot high. One man with a horse or mule can thus cultivate 10 to 2 acres in a day.

In the cotton belt, upland corn is usually thinned to one plant in a hill. Corn should be cultivated as soon after every rain as the soil is dry enough. A cheap implement much used in the South for cultivating corn is the "heel scrape." Various styles of one-horse and two-horse cultivators are used. Cultivation usually ceases before all the silks appear. In cultivating corn avoid ridging the land very much, because this takes earth from the middle of the row and because ridging increases the amount of surface that evaporates moisture.

Fertilizers. - Corn grows best on rich, moist land, and it pays better to enrich the land by growing cowpeas or other soil-improving plants in previous years than to use large amounts of commercial fertilizers. Manure, applied early, is the best fertilizing material for corn. When this cannot be had, moderate amounts of commercial fertilizers rich in nitrogen may be used on land needing fertilizer. A mixture of 200 pounds of cotton-seed meal and too pounds of acid phosphate per acre is often satisfactory.

Stripping the leaves. - Many farmers in the South strip off the corn leaves to obtain "fodder" with which to feed their teams. When the farmer strips the green leaves from the corn plant he stops the accumulation of carbon, the material of which the corn grain chiefly consists. 
Thus he reduces the yield of corn grain several bushels per acre. The same amount of labor employed in making hay as in "pulling fodder" would produce much more food for stock. The practice of cutting and shocking the corn plants just after most of the shucks have turned brownish does not greatly reduce the yield.

Exercise. - Find ears or even kernels of sweet corn and popcorn, and bring these, as well as dent-corn ears, to the class. Write in your notebook a description of the shape, size, etc., of grains of each. Examine a corn plant and locate the brace roots. Examine ten ears of corn and record in your notebook the number of rows on each. Can you find any ear with fifteen rows? Can you discover any law or rule about the number of rows?

Note to the Teacher. - Helpful object lessons for this chapter are: Dried or fresh corn tassels; unhusked ears of corn with adhering silks ; ears of sweet, pop, flint, and dent corn, and ears of pop or sweet corn with a few dent grains. Corn kernels planted close to the glass side of a box (Fig.22) or near the glass inside of a tumbler permit a study of corn roots. Keep the glass covered with black paper or cloth except when making observations. Washing the soil from the roots of a growing corn plant, by the use of a small stream of water from an elevated barrel or bucket, will reveal the length and position of the roots and thus enforce the lesson of shallow cultivation. 


\section{SECTION XXIII. SELECTING OR JUDGING SEED-CORN}

By careful selection of seed-corn, five bushels or more per acre can be added to the usual yield. It pays well, therefore, to learn to select or judge corn. It is important to select seed from good plants, and also from the best ears.

Selecting the best ear. - On p. I $3 \mathrm{I}$ is the score-card adopted by the corn-growers of one state. It gives all the points to be taken into consideration in judging corn. Experience is needed to bring skill in this.

General Directions. Begin with the second horizontal line in the table, which is for "shape of ear." Carefully examine the ear to discover whether or not the shape is perfect. Among defects may be slight crookedness, too much taper, or rows of kernels twisting around the cob instead of being straight. A shape that is very good may be scored "9"; a perfect shape, 10 , is rare. If there are very great defects in shape, give it some lower number, say " 8 ," if its only weak point is a moderate twisting of the rows of kernels.

After deciding on the score for each quality, write the figure or grade in the proper blank column in the table. When all the other qualities have been noted, score the first one.

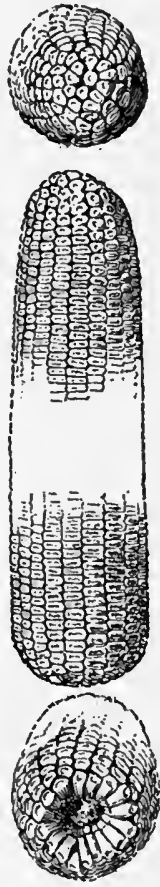

FIG. 79. - TIP, Side View, AND Butt of A PrizeWINNING EAR OF CORN 
Color of grain and cob. - The color of all kernels on the same ear (or on the same set of ears in exhibits at fairs) should be the same.

The color of the cob should not be different from the usual color for that variety. White cobs are preferred if the grain is white, and red cobs if the grain is yellow. The yield, however, is not affected, whether the cob be uniformly white or uniformly red. Cobs of different colors in one varicty indicate impurity or crossing, and such cars should be rejected.

Vitality or seed condition. - A germination test shows the vitality most accurately. However, the appearance of

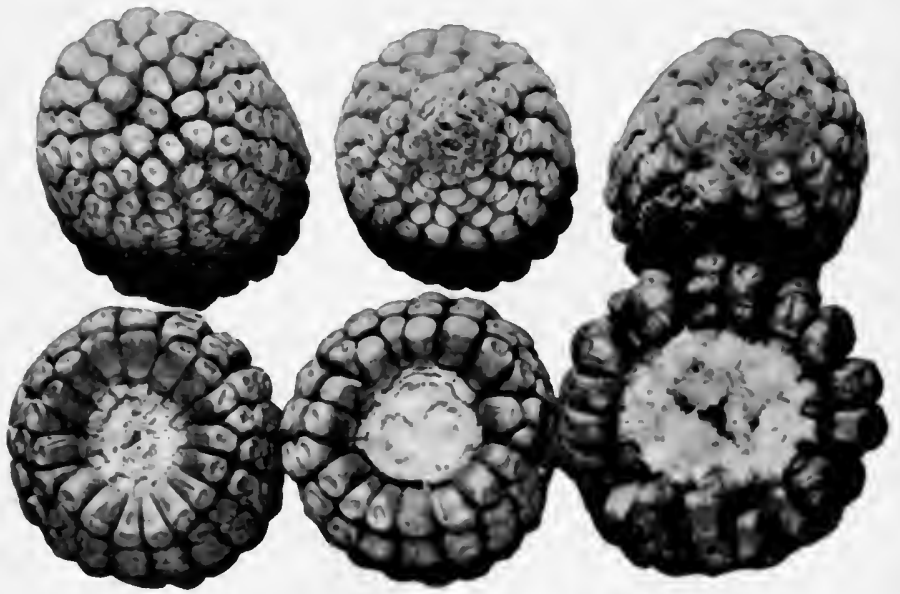

Fig. 80. - Tips and Butts or Corn

On right, poor; in center, better; on left, good.

the tips of the grains often indicates how they may germinate. Poor or low germination results when the tips of the grains are either (1) black or brownish, (2) shriveled, 


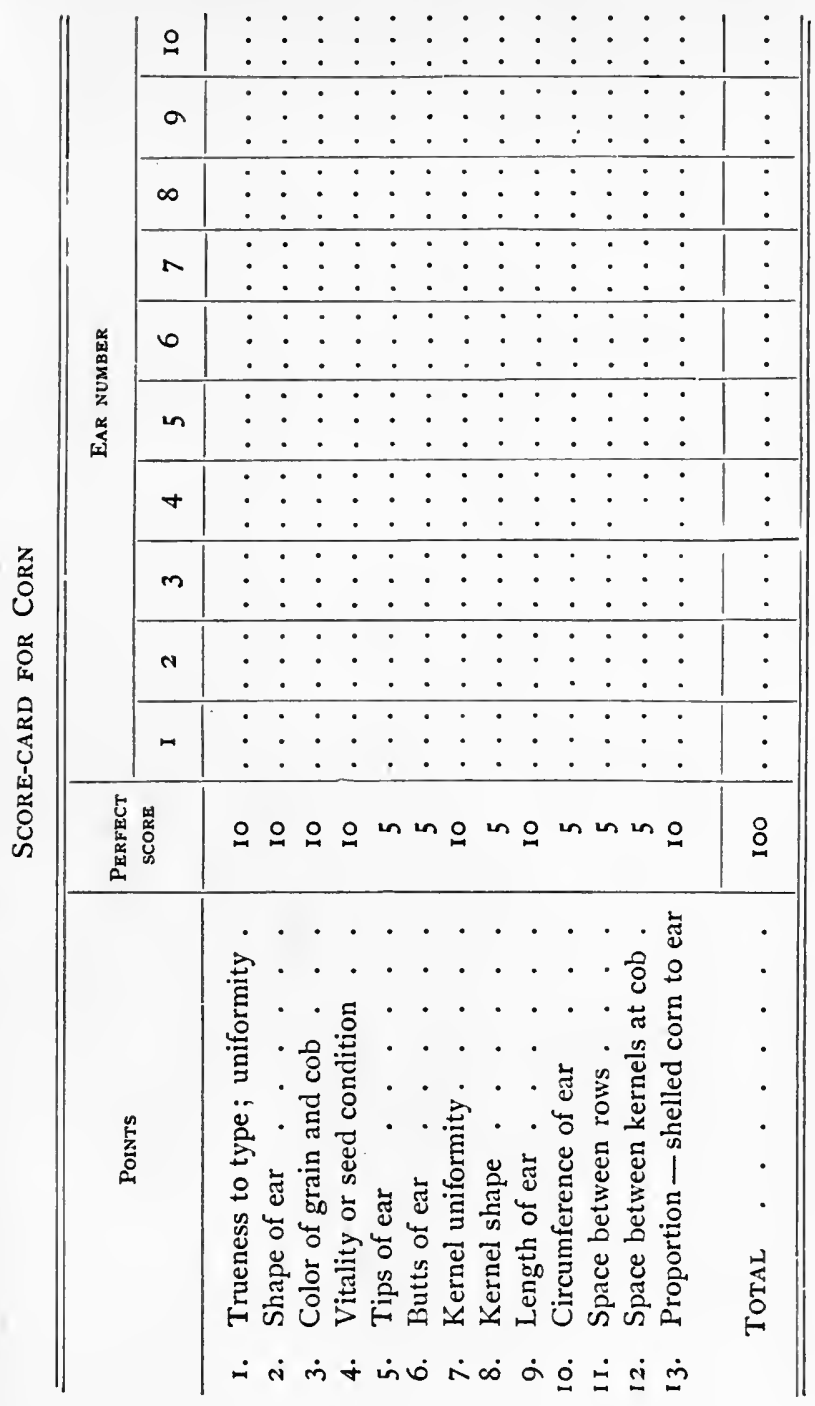


(3) covered after being shelled by small bits of the cob, or (4) very slender and sharp-pointed. Generally a grain with well-filled shoulders next the cob and with a large
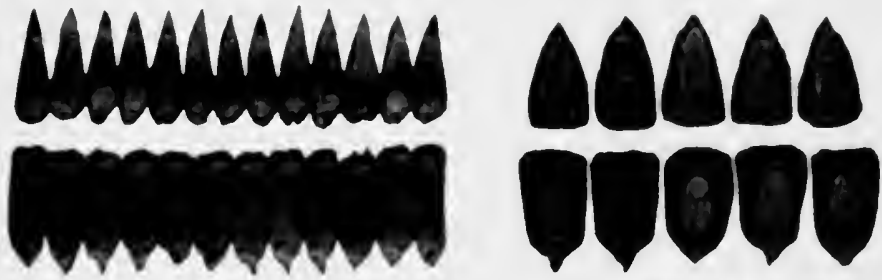

Cuurtegy Iow Eixpt. Statlon.

Fig. 81. - Goud and Poor Silapes of Corn Kernels

germ (Fig. 82 below) affords strong sprouts that make good plants.

Tips of ears. - The grains near the tip of the car should be well shaped and the rows should extend well out to the

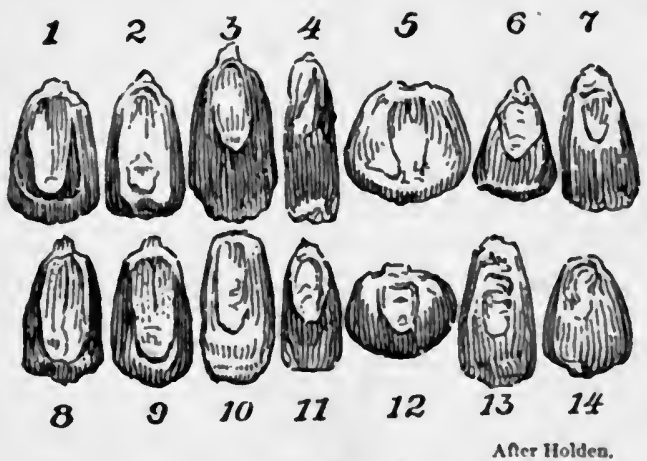

Fig. 82. - Various Siapes of Corn Kernels $x, 2,8$, and 9 are the best. end of the cob. The less cob exposed, the better (Fig. 8o).

Butts of ears. - On the butt, or larger end of the ear, there should be straight rows of grains and very few irregularly shaped kernels. The best butts are those in which the grains extend beyond the end of the cob, leaving a 
medium-sized depression where the ear stalk or shank was attached to the cob. Stand the ear on end. If the butt is even, as it should be, the ear will stand erect or vertical. An ear with butt much larger than the remainder of the ear, or with several extra, short rows of grains, is badly shaped.

Uniformity of kernels. - Except the grains near the ends of the ear, the kernels on one ear and in one variety should be nearly similar in shape, size, and degree of denting on the top. When corn is planted by machinery, it is important for the grains to be of one size, so that the same number may be dropped in each hill.

Shape of kernels. - The grains are most compactly arranged when they are almost square-shouldered, both at the crown or top, and next the cob. A grain rounded at the top wastes space and is apt to be short. A well-shaped kernel is well filled next to the cob, giving room for a large germ. The larger the germ, the better. The grain should be large, and it is best when the shape is like numbers I, 2, 8, 9 (Fig. 82).

Length of ear. - The best length differs for different varieties. If the ears

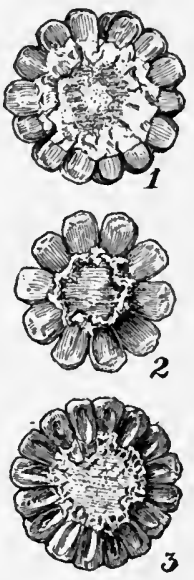

FIg. 83. - $\mathrm{C}_{\mathrm{R} O \mathrm{SS}}$ Sections through EARS OF CORN I, grains too short; 2, too much space between rows and cob too small; 3, good shape of kernels. are short, the yield is reduced. If they are unusually long, there is danger that the ear may not be well covered by the shuck. In varieties bearing only one ear to the plant, the ear should generally be more than nine inches long. 
Circumference of ear. - The measure around an ear is taken with a tape-line a: a point one third the distance from the larger end. The usual rule is for the circumference to be three fourths the length of the same ear. An ear much larger around than this may have too large a cob, and may

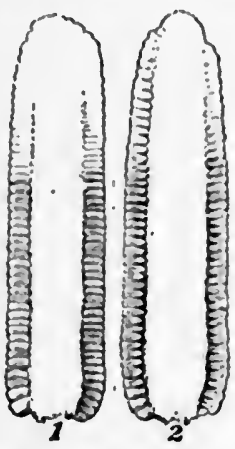

Fig. 84. - Sections THROUG II TWO EARS OF CORN

On right, too much space between kernels at the cob; on left, kernels fitting close together. dry out too slowly. A very slender ear may have too small a cob, and grains that are much too short.

Space between rows. - If these furrows are deep and wide, they indicate a poorly shaped, round-shouldered kernel. Such ears yicld a low percentage of grain (Fig. 83).

Space between kernels at cob. - Spaces between the flat sides of the kernels, near the cob, show that the grains are not occupying all the room they might (Fig. 84). On such ears, the tips of the kernels are apt to be too thin or too flat with a small germ; the grains seem loose when the ear is twisted.

Proportion of corn to cob. - This is determined by shelling the ear (or half the ears in an exhibit of ten ears), and weighing the shelled corn and the cob. The weight of the shelled grain is then divided by the weight of cob and grain. The quotient gives the per cent of grain on the husked ear. With most highly bred varieties the selected ears are expected to show at least 86 or 88 per cent of grain.

Germination test. - Vacant hills, or poor stands, greatly reduce the yield of corn. They are often due to planting 
ears on which the germs in the grains are dead or injured. A very even stand may be obtained by testing between moist blotting-paper six grains from every ear of seedcorn. Do not plant the ears whose grains fail to sprout or that make small, weak sprouts.

EXERCISE. - Every pupil should bring to school at least one ear of corn for use in reciting this lesson. After one ear has been scored under the teacher's direction pupils may by themselves practice scoring or comparing other ears.

Note to THE TEACher. - The first day let every pupil carefully score one ear. Repeat this exercise from two to four times, being careful that each day every pupil scores a different ear or ears. Encourage every one to give the reasons why he scored each quality of a certain ear high or low, and by consensus of opinion try to decide which are really the best ears.

When the class shows some proficiency in scoring single ears, and before interest wanes, endeavor to have every pupil bring from home either five, or better ten, selected ears. Let them first place the ears quickly from left to right in supposed order of merit ; then score every ear, re-arranging the ears according to the scores now given. Two or more days may well be spent on each set of ten ears. Then new sets may be brought or the different sets may be exchanged.

It will stimulate interest and proficiency to promise that when the class has had five to ten days of practice in corn judging, it may give a public exhibition of corn and of corn judging.

The public exercises should consist of (I) the placing in order of merit of five or ten ears, (2) the careful scoring of some of these ears, and (3) in answer to the teacher's questions, a statement of reasons why certain ears are scored or arranged low down.

This may be supplemented by a display of sets of ten ears of corn brought on invitation by neighbors; by the display of the results of a germination test; by the reading of a short composition on some phase of corn growing; and by the reading of extracts from bulletins or corn published by some experiment station. 


\section{SECTION XXIV. WHEAT, OATS, RYE, AND BARLEY}

THESE four crops are called the small-grains. Each one of them is an important human food in some part of the world. Oats and barley are largely used as hay or pasturage. Their straw is fed to live-stock or used for bedding. Wheat makes better bread than any other grain.

Resemblances between the small-grains. - Wheat, oats, ryc, and barley all bear seeds or grains at the top of a hollow stem or straw. Although the walls of the straw are thin, the hollow form gives great strength to a small amount of stem material.

These small-grain plants are alike in having no taproot, but only a great number of fine roots springing from a center or crown. This crown, or starting-place for the permanent roots, is usually about one inch below the surface of the ground, whether the seed be planted deep or shallow. The seeds are sown one to three inches deep.

Some differences between the plants of wheat, oats, rye, and barley. - The heads of oats are branched and open, but those of wheat, rye, and barley have grain clusters or spikelets closely joined to the main stem. The heads of rye are long, somewhat flattened, and have long beards. Common barley and bearded wheat have shorter heads with stiff spreading beards. Some of the best varietics of wheat, however, do not have beards. 
How to recognize the seeds of the small-grains. - The threshed grain of wheat, oats, rye, and barley may be distinguished as follows :-

Oat kernels are wrapped tightly in a long tough hull. Barley grains are covered with a hull that has grown to the kernel, forming an angular grain. Wheat grains have no hull after being threshed, and are short and usually plump. Rye grains, like wheat grains, have no attached hull, but are longer and more wrinkled than those of wheat.

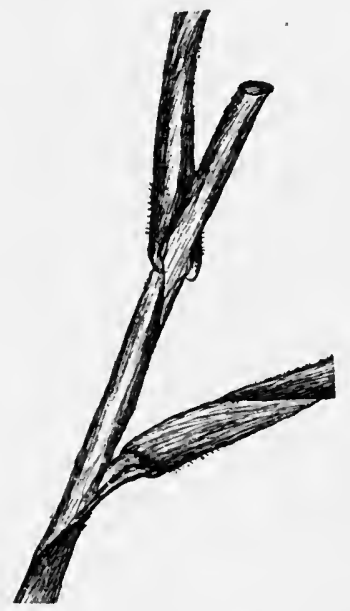

Fig. 86. - Part of A Young Plant of Oats, Showing the AbSence of "Clasps"

How to recognize the young plants. - It is possible to distinguish between fields of these plants when they are small. This can be done by the width of the leaves, and the erect or spreading growth. It is sometimes puzzling to decide whether a single young plant is wheat, oats, rye, or barley. On the leaves of young barley, wheat, and rye plants there are tiny growths like little horns, clasping the stem. These may be called "clasps." They help to identify the plants (Figs. 85 , 86,87 , and 88). Barley has larger clasps than any other kind of small-grain. Wheat has the 
next largest, or medium-sized clasps. They are unlike

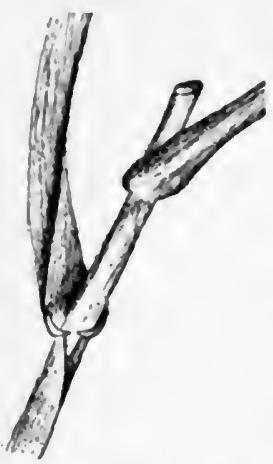

FIG. 87. - PART OF A

Young Rye Plant, SHOWING SעALL "Clasps" those of barley and rye, and bear on their edges a few very fine, short hairs. Rye has smaller clasps than either wheat or barley. The oat plant has no clasps at all.

The flowers of the small-grains. Wherever there is a single grain of oats or wheat, there has once been a flower. It had no brilliant color, but resembled a flower only in that it had the essential parts, that is, stamens and pistils. The green flower of oats, wheat, rye, or barley before the grain has begun to form contains in each grain place three stamens or pollen-cases and two feathery, plume-like stigmas (Fig. 10).

Oats, wheat, and barley do not need bright colors and nectar in their flowers to attract insects, because they are self-pollinated. That is, the pollen in any one flower fertilizes the pistil in that same flower. Self-pollination does not seem to injure plants that are accustomed to it. It keeps varieties of wheat or of oats from mix- Frg. 88. - PART OF A Young ing with each other through the carrying of pollen by wind or in-

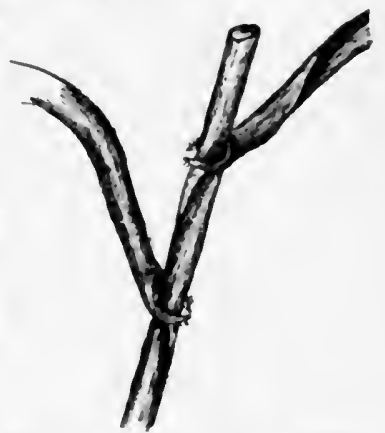
Wheat Plant, showing "Clasts" bordered witu IIAIRS sects. Thus red oats do not naturally cross with Burt or Turf oats. However, rye may be cross-pollinated. 
Preparation of land. - Good preparation should be given to the land intended for wheat. This grain requires a seed-bed that at the time of planting is compact or settled in the lower layers but loose and fine in the upper ones. This is best secured by plowing land for wheat a number of weeks before sowing the seed. Then pulverize the clods with a harrow.

Unfortunately, some farmers seem to think that any kind of preparation or none at all is good enough for oats. An oat seed is well protected by its hull and can lie for weeks uninjured among dry clods. But, nevertheless, oats should not be deeply buried under large clods, for this makes the plants come up at different dates and ripen unevenly, and makes the stand thinner than it would otherwise be.

Thickness of sowing small-grains. - When planted at the usual distance, a wheat or an oat plant generally ripens from two to six heads on an equal number of stems or branches. But a plant well fertilized, planted early, and given abundant space, may form more than a score of stems and heads.

This habit of branching from buds at the crown permits the plants of these crops to occupy as much or more than the usual space. It explains why sometimes just as large a crop comes from sowing two bushels of oats as from sowing three bushels per acre. About five pecks of wheat or rye per acre are generally sown.

Varieties. - Among the standard varieties of wheat for the Southern states are Blue Stem and Fultz, which are beardless or smooth, and Fuicaster, which has beards. Red oats is the standard Southern kind. It is called rustproof because it is less injured by rust than most other 
varieties. The Burt oat is an early Southern variety and is sown after Christmas. Southern rye affords more forage than does rye seed brought south from higher latitudes.

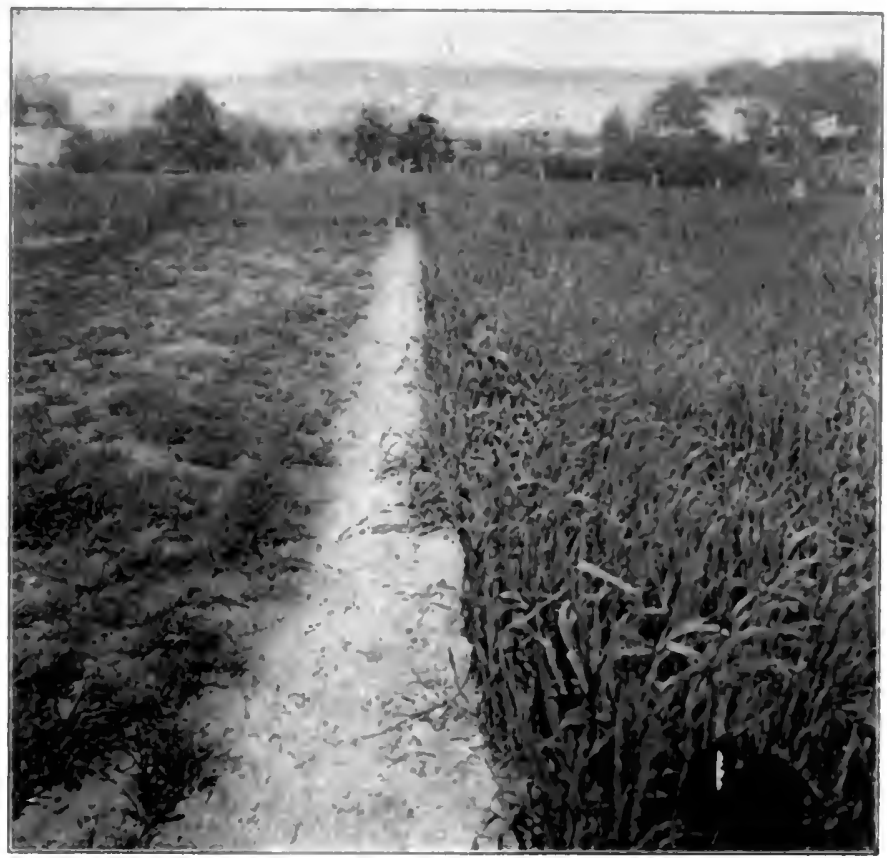

Fig. 89. - Showing the Larger and Eartifer Growth iN Spring amate by OATS SOWN IN THE FAl,L THAN bY tIIOSE SOWN IN FEBRUARY

Time to sow small-grains. - Rye and wheat are usually unhurt by the coldest weather that occurs in the Southern states. Hence they are always sown in the fall. Barley and winter, or Turf, oats are usually sown in the same season. In the southern part of the cotton-belt, Red oats can be sown either in the fall or after Christmas. Wher- 
ever oats can live through the winter, the yield is much larger from sowing the seed in the fall than from sowing oats after Christmas (Fig. 89).

Increasing the resistance of oats to cold. - Fall-sown oats are much more productive than those sown later, and so it pays to help oats live through the winter. Notice young oat plants on a clay soil late in a cold winter, and you may observe that the whitened roots of many young plants are partly above ground. In this position they are easily killed. The repeated frcezing of the water in the soil has lifted them. Water swells in turning to ice, so that the ice is forced up

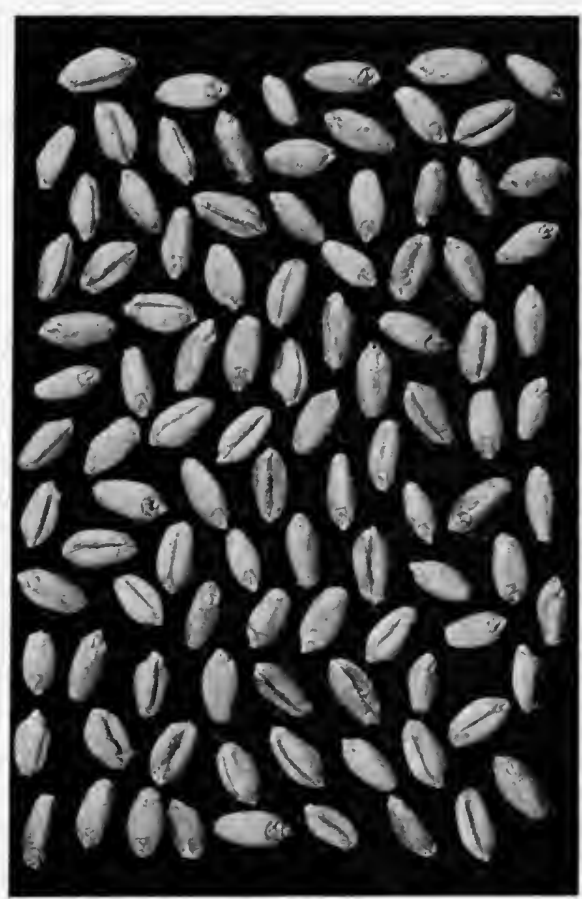

Courtesy Cal. Expt. Station Fig. 90. - A Good Sample of IVheat above ground. In rising it lifts a little earth, and with the earth the young and slightly rooted plant is carried. When the ground thaws, the uplifted earth, being heavy, falls back into place, but the plant remains in its raised position. This heaving may be repeated several times. 
If oats are sown early enough in the tall, they form long. strung roots which tend to anchor them. A more

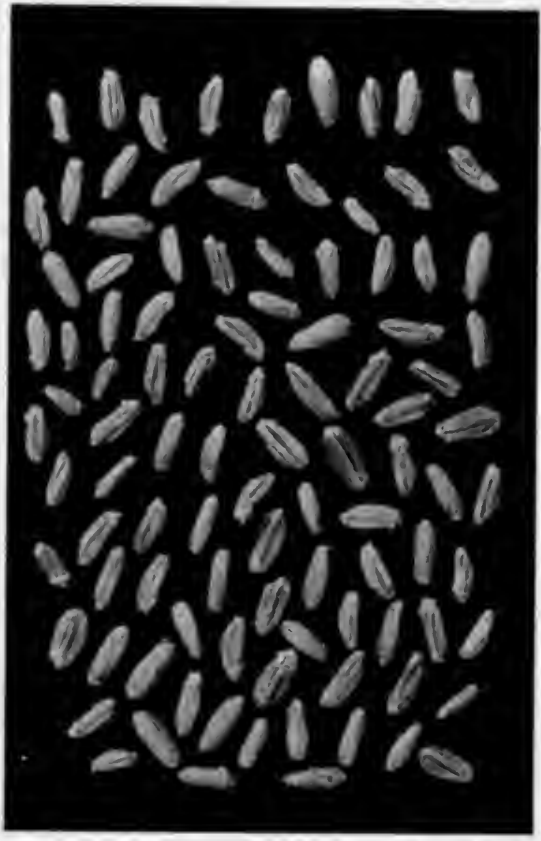

Fig. 9r. - A Poor SaMPle of Wreat; Grains Shriveled
Courtey Cal. Expt. Statton

certain method of protecting them against death from cold consists in planting them in deep furrows that are not entirely filled in. The young plants are safer here because it is more difficult for a plant in a low place to be lifted by a freeze than for one in a higher place. In sowing oats thus in open furrows a one-horse planter is used, run in the bottom of a furrow made with a shovel-plow. The drills are 18 to 24 inches apart.

Improvement of seed. - Large seeds generally produce larger crops than do light seeds (Figs. 90, 91). Both wheat and oats can be greatly improved by selecting the best plants and sowing their seed in a small seed-plot. Any improvement once made is apt to be permanent, because wheat and oats do not cross with inferior kinds. On any farm where oats or wheat mature large, plump grains, it is better to use home-grown seeds than those from other 
parts of the country. When properly cared for, wheat and oats do not "run out" and do not require change of seed.

Fertilizers for small grains. - These plants make much of their growth during the cooler part of the year. Then the vegetable matter in the soil is not then rotting very rapidly so as to furnish the plant with available nitrogen. For this reason the fertilizer for the small grains ought to be rich in nitrogen. Nitrate of soda is especially suited to the small grains. This can be sown on the growing plants in spring and need not be covered. Acid phosphate, applied when the seed are sown, is often a profitable fertilizer for small grains. On very poor soils, it may be necessary to add also some form of potash, making a complete fertilizer.

EXERCISE. - If this chapter is studied just after rye has formed heads, notice the abundance of pollen. What does this suggest? Examine a head of oats to learn how many grains in each spikelet or cluster; which one is the larger; and where the beards, if any, start. In the same way examine a head of wheat. Resolve to save seeds of the best plants of oats or wheat, when ripe, for a seed-row where the seeds can be improved by continued selection of the best plants.

Note to the Teacher. - A comparison of heads (or of grains of young plants) of the four small-grains will suggest many points of similarity and of contrast. Be sure to give practice in identifying the piants by means of the clasps. If any of the small-grains are in bloom, have each pupil examine a flower and describe the stamens and pistils. 


\section{SECTION XXV. COTTON}

EVERY nation depends largely upon the southern part of the United States for cotton. The Chinaman, as well as the Englishman, is clothed in American cotton. All classes of people, from beggars to princes, make use of it, and the world is continually calling for more. Foreign countries send more gold into the United States in payment for our cotton than for any other American crop.

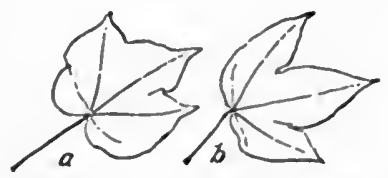

Fig. 92. - Cotton Leaves $a$, upland; $b$, Sea Island.

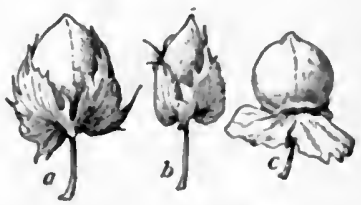

Fig. 93.- Cotron Bolls $a$, upland; $b$, Sea Island ; $c$, Indian.

The cotton crop of the Southern states, which is usually between $11,000,000$ and 13,000,000 bales per year, generally sells for an amount between $\$ 600,000,000$ and $\$ 750,000,000$, including the seed.

The next largest producer of cotton is India. Most Indian cotton, however, is of poorer quality and lower price than the American. Egypt stands third as a cotton-producing country. Its product has a very long staple, and sells for a higher price than American cotton. 
Some of it is imported into the United States for use in making goods where a long staple is required. In length, the staple of Egyptian is between that of American longstaple and Sea Island cotton. Egyptian and Indian cottons are not nearly so productive in America as are the varieties generally grown in the Southern states.

The cotton plant. - Cotton belongs to the Mallow family, which includes not only all kinds of cotton, but also okra, hollyhocks, and a number of common weeds and flowers.

The several kinds of cotton differ greatly in their stalks, leaves, blooms, and lint. In tropical countries, cotton is a tree-like plant, not dying in winter. In the southern part of Texas cotton plants springing from roots that live over winter are troublesome because they give food to the cotton-boll weevil early in the spring.

Why cotton makes strong thread and cloth. - Cotton is popular for making thread, cloth, and rope, in spite of the fact that a single fiber of the common kind is generally not over one inch long. This is because a cotton fiber is a twisted, hollow tube (Fig. 94). The twist makes the separate cotton fibers cling tightly to each other, just as two chains would do if twisted together. The fibers are so small

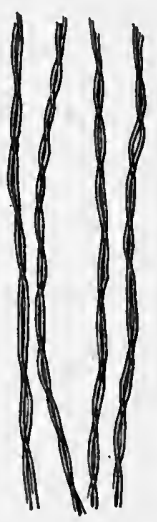

FIG. 94. - FIBERS OR Strands of Cotton, ENLARGED that $\mathbf{2} 200$ to 1500 of them could be laid side by side in the space of one inch.

The kinds of cotton in the United States. - There are only three main kinds of cotton grown in the United 
States. These are, (1) common or short-staple, (2) longstaple upland, and (3) Sea Island cotton. Long-staple upland cotton resembles common cotton very much in appearance and has the same shape of leaf; but its bolls are usually more slender and the lint longer, usually being one and one eighth to one and one half inches

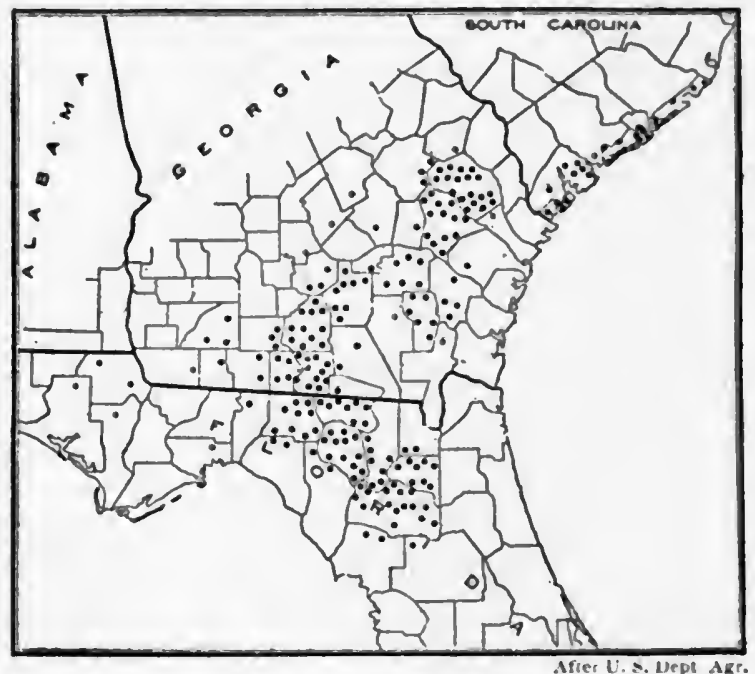

Fig. 95. - Where Sea Island Cotton grows

Each dot stands for an annual yicld of 500 bales.

long. This extra length makes it worth several cents more per pound. However, long-staple cotton is not so productive of lint as the best varieties of short-staple and is a little later in maturing. It prefers bottom land. Among the popular varieties are Allen, Florodora, and Griffin.

Sea Island cotton is a tall, slender plant with branches, leaves, and blossoms different from those of short-staple 
and long-staple upland cotton. The lint is very long and fine, and commands a price more than double that of common cotton. There is, however, much less lint per acre. Sea Island cotton is largely grown on and near the seacoast in South Carolina, Georgia, and Florida, and is not a profitable crop very far from the coast (Fig. 95).

Varieties of short-staple upland cotton. - There are several hundred separate names, but many of these are merely new names for well-known old varieties. The following are the main groups of varieties :-

\section{Cluster.}

II. Semi-cluster.

III. King group.

IV. Peterkin group.

V. Big-boll group.

The cluster varieties bear a part of their bolls in clusters, several bolls being near together, and many near the main stem. The plant is slender and the upper limbs very short. A well-known cluster variety is Jackson. These varieties drop many of the squares or blossoms when weather or cultivation is unfavorable (Fig. 97).

Semi-cluster varieties resemble cluster varieties in shape of plant, but the bolls are not borne in clusters. The middle and upper limbs, though short, are a little longer than in the cluster varieties. A popular semi-cluster cotton is Hawkins (Fig. 98).

The King group consists of low plants with numerous crooked limbs of medium length. On many of the blossoms there is a red spot near the base of each petal and inside 
the flower. The bolls are small. This is the earliest wellknown American kind, and hence has been used as a means of insuring a crop of open cotton against boll weevils, which become numerous late in the season. The lint is short and readily falls from the bolls. The early varieties of cotton, and indeed of most crops, are not usually so productive as those that take a longer time to complete their growth (Fig. 99).

The Pcterkin group consists of varieties having small seed, some of which are black and nearly free from fuzz. A quality much liked about this variety is the fact that there is a greater weight of lint in proportion to seed than usual. For example, sometimes as much as 37 to 40 per cent of the seed-cotton consists of lint, so that a full bale ( 500 pounds) is often made from only 1350 pounds of seedcotton. Among the best-known varieties are Peterkin and Layton. Unfortunately, the bolls are small (Fig. 102).

The big-boll group takes its name from the large size of the bolls. It requires only 45 to 68 of these to yield one pound of seed-cotton. Much more can be picked in a day than from varieties having smaller bolls. Most of the bigboll varieties are late in maturing, but some of them are medium in maturity. This group needs to be improved by being made earlier, and by an increase in the number of bolls per plant. Among the best known and most productive varieties of this group are Russell (which has large green seed), Truitt, Cleveland, and Cook Improved (Fig. IOI).

Desirable qualities. - The ability to yield the greatest number of pounds of lint cotton per acre is the quality most desired. A high percentage of lint is often a means 
of securing this large yield of lint. Large bolls are very desirable, since they make picking easier and quicker. Earliness is needed in the northern part of the cotton belt and is a most important quality wherever the boll weevil is present. The "storm-proof" quality, or ability of the seed-cotton to cling in the boll rather than to fall on the ground, is desirable, if it does not go to the point of making picking very difficult. The fiber must not be very short. In sandy soils, where cotton-wilt is common, ability to live in spite of this disease is an important character that has been developed in some varieties, as Dixie, some strains of Jackson, and certain Sea Island varieties.

Examples of very satisfactory varieties. - There is no one variety best for all soils and seasons. A productive one is Cook Improved. This has rather large bolls, a high percentage of lint, and is rather early for a big-boll kind. Cleveland is another productive kind, with big bolls. Both of these have the disadvantage of easily falling out of the boll. Cook Improved is especially liable to rotting of the bolls. Almost equally productive are Toole and Layton. Both have a high percentage of lint, but small bolls. For earliness, no well-known variety stands ahead of King.

The varieties most extensively grown at present are probably Peterkin, Russell, and Truitt. Triumph is adapted to the western region, where the boll weevil is present. It has a large boll and a high percentage of lint. Generally a storm-proof variety is preferred in Texas.

Improving or breeding cotton. - Even in a pure variety there are poor, medium, good, and very good plants, though 
all may have had an equal chance. Hence, it is very easy to improve cotton by selecting seed from the best plants. The yield of lint and the percentage of lint in the seedcotton can be increased, the bolls made larger, the lint longer, and the plants earlier or shorter-jointed. But all of these cannot be attained at the same time. It is best to start with a pure variety that is satisfactory in all but one

N-1.7-1bs.
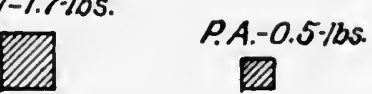

p.-2.3-1bs.
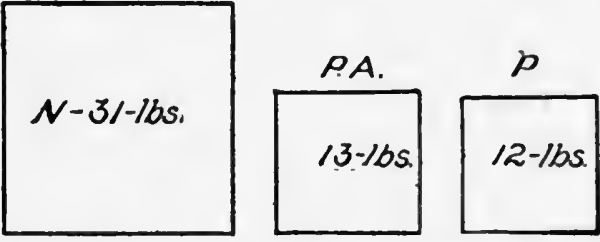

Fig. 96. - Showivg Asounts of Nitrogen, Phosphoric Acid, And Potasi

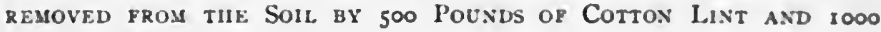
Pounus or SEeD

Shaded squares indicate the small amount of plant-food in the lint; unshaded squares show the large amount in the seed.

quality, and then select from good plants that make the nearest approach to this desired quality. The first rule in cotton-breeding is to select chiefly for one quality at a time and to keep up this selection for the same quality every year. The second rule is to keep separate the seed of each of the best twenty or more mother plants and to grow each in a separate row the next year. The seeds from the best rows should be saved. Always locate the breeding-patch as far from other cotton as possible. Insects carry cotton 


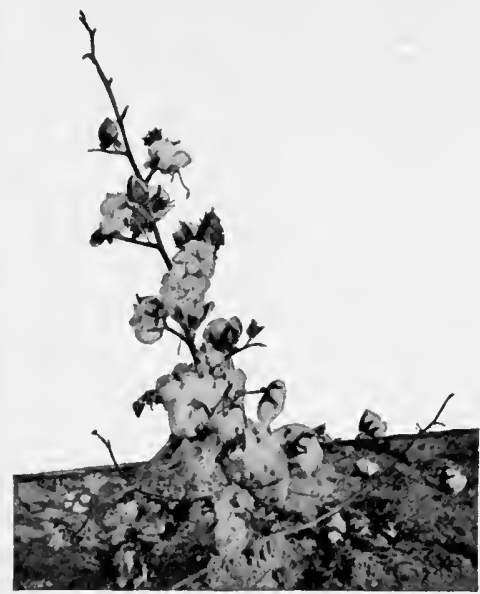

Fig. 97.-A Cluster Cotton Plant

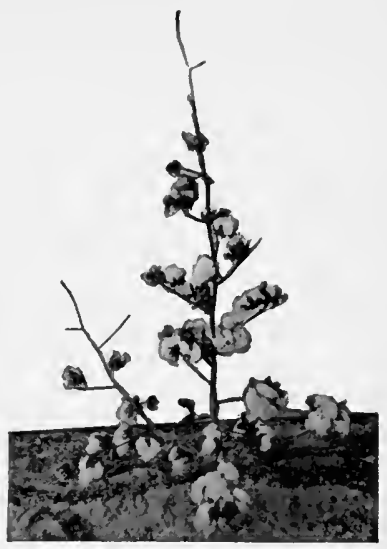

Fig. 98.-A Semi-cluster Cotton Plant

pollen and thus mix varieties, but not to the same extent that the wind causes the mixing of varieties of corn. As the boll weevil spreads over the cotton belt, it becomes more important to select seed from plants that form their bolls early.

Preparation of land and cultivation of cotton. Thorough and deep preparation usually pays. Cotton comes up better if the harrow is used to prevent the formation of a

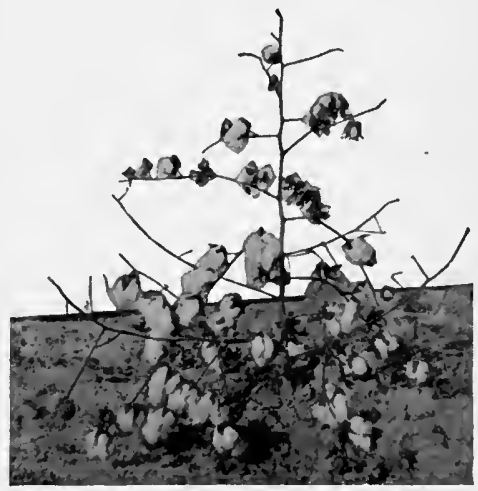

Fig. 99. - A Cotton Plant of the KING TYPE. 
crust and the drying of the land during the few weeks before

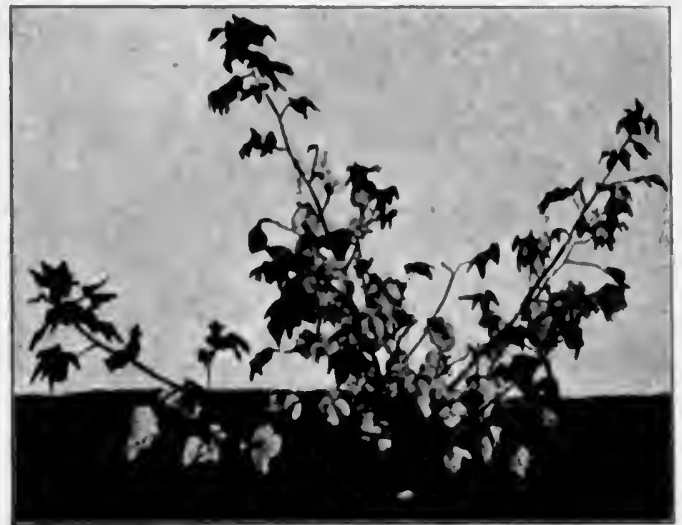

Fig. 100. - A Long-staple UfaAnd Cotton Plant

the seeds are planted. Cotton is planted as soon as danger of frost is past. Cultivation should be shallow and frequent, and if possible after rains and before a crust would form on the soil, rather than at regular intervals. On poor land the rows may be as narrow as three feet and the plants as close as one foot apart. As the land becomes richer or is better fertilized, the space for each plant must be increased, because the limbs grow longer. On rich land the rows may be four feet or more apart and the plants about two feet from each other.

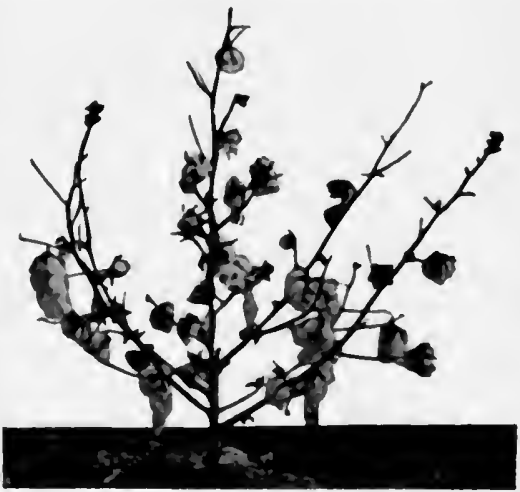

Fig. 108.-A Big-boll Cotton Plant

Planting cotton in checks saves labor, but requires 
good or well-fertilized soil and nearly level, well-drained fields.

\section{The fertilizer for cot-} ton is usually a complete fertilizer (Fig. 96). Generally it should contain two to three times as much phosphoric acid as nitrogen or potash. On soils where cotton rust is usual the proportion of potash may be in-

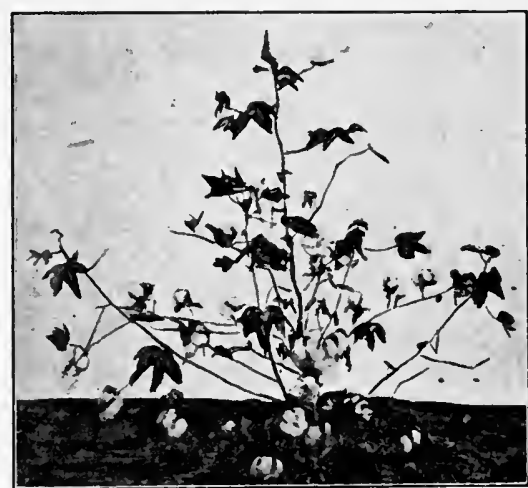

Fig. ro2. - The Peterkin TyPe of Cotton creased. If the plants make a very small growth on any soil, the proportion of nitrogen should be increased.

EXERCISE. - Write in your notebook the names of the varieties of cotton grown in the neighborhood. Which of these have large bolls? Small bolls? Long staple? Very green seed? Partly sleek or very dark seed? Small seed? Examine ten plants or even ten dead cotton stalks and notice how widely they differ. Would there be any advantage in selecting seed from uniform plants? Decide which kind of plant you would select from. Why? When the next cotton crop is mature, begin to select and improve cotton by the method described in this section.

Note to the TEACHer. - If possible, make one or more excursions into the cotton fields. Bend every effort to make the pupil see more in a cotton plant than ever before; for example, variations in leaves and bolls on the same plant, ribs of leaves, the relation between earliness and form of plant, etc. If this lesson is studied after the stalks have been plowed under, let the practice be largely a study of the seed, sizes, colors, fuzz, shape, hull and kernel, germination, etc. Dampen seeds slightly with extremely thin flour paste, stir, then dry. Do the seeds stick together? What is the practical advantage of this treatment in planting? Advise pupils to try it at home on a bushel of seed, using one cup of flour in two quarts of water. 


\section{SECTION XXVI. SUGAR CANE}

Sugar cane and corn both belong to the grass family. Safely hidden under the clasping or tube-like lower portion of each leaf are buds or eyes, one at each joint. These serve instead of seed to multiply the plant.

When a stalk of sugar cane is planted, the moist, warm soil causes the buds to grow into young sprouts, which for a little while feed on the juice of the mother cane.

Roots and suckers. - At each bud or cye and extending entirely around the stalk are several rows of small, whitish dots. If cane is planted and a few weeks later dug up, it will be found that the roots have grown out from these spots.

Unfortunately these dots, especially in some varieties, also throw out roots when the cane is blown down and lies touching the damp ground. Roots from the joints above ground are not wanted. In a row where only one continuous line of cane has been planted, there may be single hills from each of which three or more canes may grow. The first grew from the bud; the others from buds on the base of the young cane. Stalks that grow from a bud on a young plant, rather than directly from a bud on the planted cane, are called suckers. Suckers that start early add to the yield, but those that form late are useless. 
The plant changed by climate. - Sugar cane, like cotton, first grew in countries warmer than the Southern states. Like cotton also, it has greatly changed its habit of growth as it has been carried northward. In the tropics it continues to grow fifteen months or more before being cut.

In Louisiana the tops cannot live through the winter, but the stubble and roots remain alive and furnish a supply of shoots for a second and sometimes for a third crop. Planting, therefore, is necessary only every second or third year. Only once in a number of years is planting necessary in tropical countries. In the central part of the Gulf states, and farther north, the roots usually do not live through the winter, so that stalks of cane have to be planted every year.

Varieties of sugar cane. - Sugar cane forms seeds in very warm countries, but not in the Southern states. The chief use of these seeds is to start new varieties. Plants grown from seeds are more unlike their parents than are plants grown from buds. When a seedling is better than its parent, it is prized as a new variety and is increased by planting canes (Fig. I03).

The variety most generally grown is the red or purple cane, so named from the color of the stem. The striped or ribbon cane that is sometimes grown is so named because it is streaked with irregular stripes of white. Green cane is also grown to some extent. Some of the newer varieties introduced by the Louisiana Experiment Station are proving superior to all of the old varieties and are displacing them in Louisiana. Japanese cane is one of the hardiest varieties and can be grown for syrup farther north 


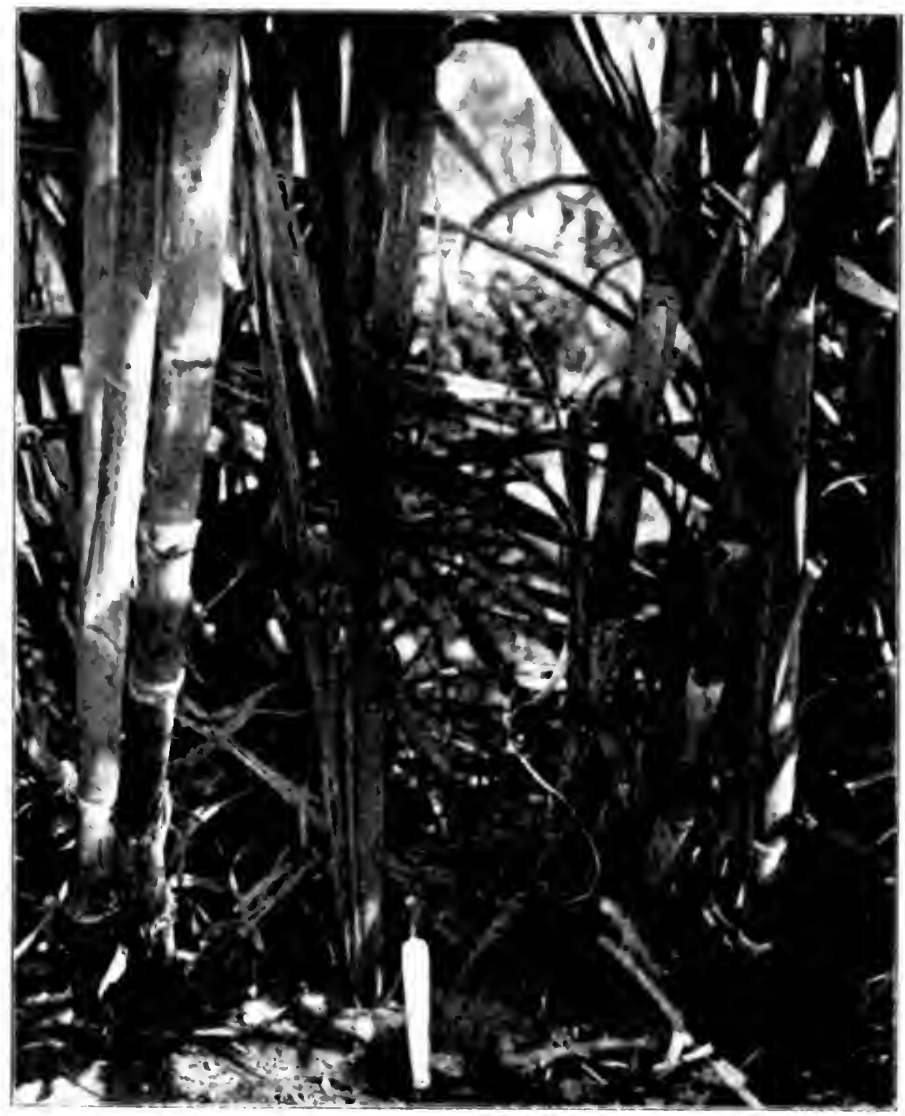

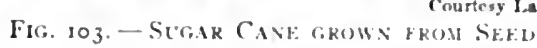

In this way new varieties originate.

than the other kirds. It throws up many slender canes or suckers from every joint. It is sometimes profitably used as a food for hogs and other live-stock.

Since sugar cane grows from the succulent buds on the 
canes planted, these buds must be kept through the winter in such condition that they will neither freeze, dry, nor shrivel. In Louisiana a part of the cane is planted in the fall, the

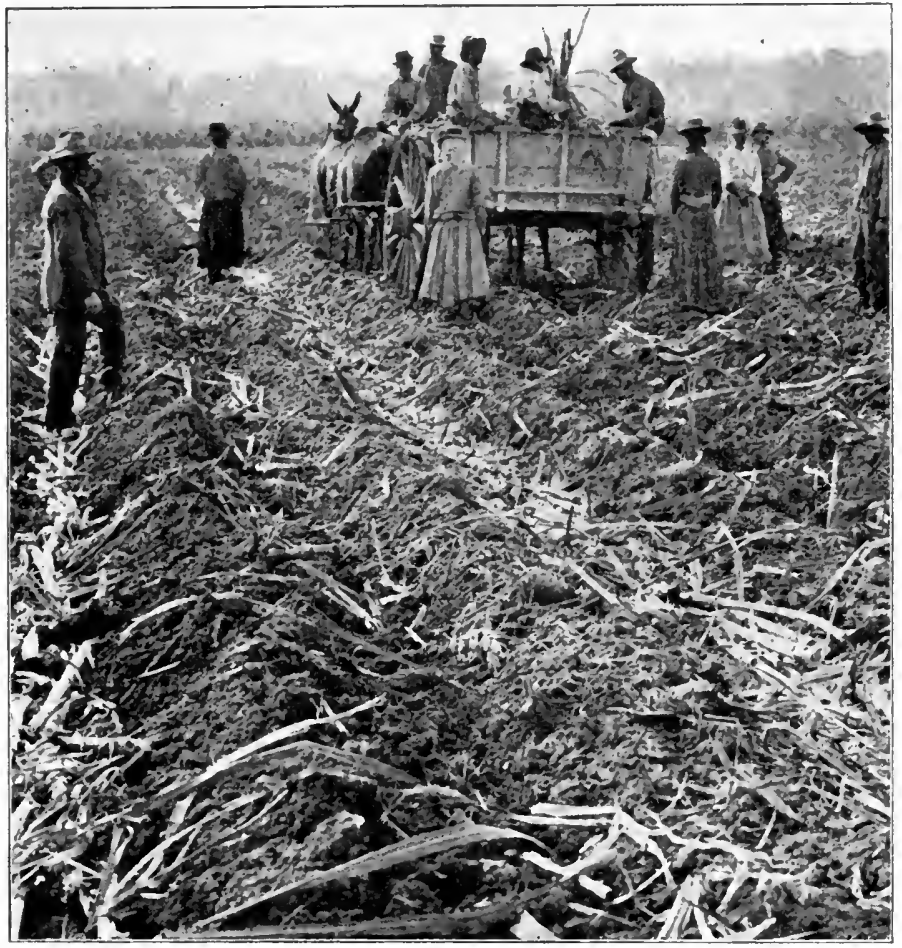

Courtesy La. Agr. Expt. Station

Fig. 104. - Planting Sugar Cane in Louisiana

soil protecting the buds until the warm, growing weather in the spring, when another part of the crop is planted. In the fall the canes intended for planting in the spring are placed with their leaves overlapping like shingles in 
the water furrow of certain rows and covered with earth. In the spring these are taken up and planted (Fig. 104). Farther north cane for planting is kept over winter in beds or heaps covered with earth. In these cooler regions it is usual to dig, rather than to cut, cane intended for planting.

Preparation and cultivation. - In Louisiana a field to be planted in cane the next year is planted this year in corn, and cowpeas are sown thickly among the corn. The entire growth of cowpeas is turned under by the use of immense plows. This enriches the land by furnishing vegetable matter and nitrogen. Sugar cane is then grown on that field two or three years. On the sandy soils of the southern portion of Georgia and Alabama, a crop of velvet bean vines is sometimes plowed under to enrich the soil for the succeeding crop of sugar cane.

On the stiff soils of the sugar cane plantations of Louisiana the main need is drainage. The land there is plowed into high ridges 5 to 6 feet-wide, and rather deep parallel ditches are dug a few rods apart. In other states sugar cane is grown chiefly on sandy bottom land. North of the sugar belt the cane is planted early in spring, using either a single or a double line of canes in each row. Cultivation must be shallow and frequent.

Soils and fertilizers for sugar cane. - Every green leaf throws off into the air moisture brought up from the soil. Hence to supply enough water for such a large leaf surface as a cane field presents, the soil must be well supplied with moisture. No common crop needs more water. Bottom lands, therefore, are generally best for canc. 
They must be naturally rich or made so by plowing under a crop of cowpeas, velvet beans, or other leguminous plant.

On lands not very rich, commercial fertilizers are profitably applied for the growing of sugar cane. A ferti-

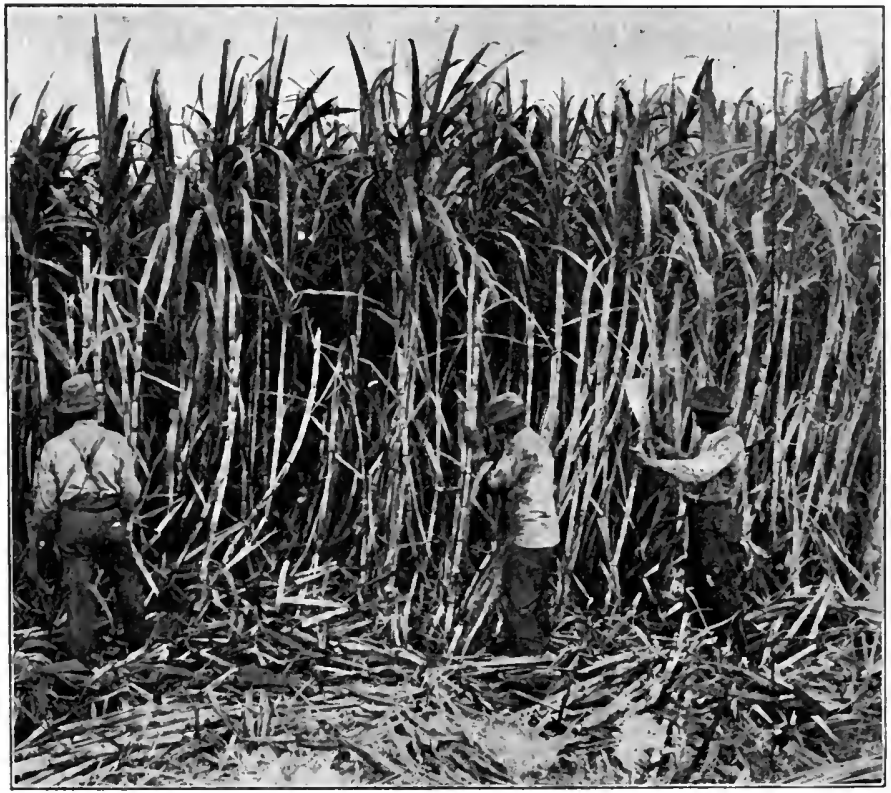

Courtesy La. Agr. Expt. Station

Fig. i05. - Cutting Sugar Cane in Louisiana

lizer for this crop should be rich in nitrogen, and should usually contain also phosphoric acid and potash. Four hundred to seven hundred pounds or more of a complete commercial fertilizer is an ordinary amount for an acre. 
Yields of sugar cane. - In Hawaii, where the canes are allowed to grow much longer than in the United States before being cut, the yield has been as high as 100 tons of cane per acre. Irrigation is largely responsible for the large yields in those islands. This greatly increases the yield on well-drained land in the Southern states. A good average yield for an entire sugar estate in Louisiana is 20 to 30 tons per acre; for sandy pine lands, 15 to 20 tons. A good yield of syrup is from 300 to 600 gallons per acre. Large steam mills press the juice from the cane much more completely than do the small mills worked by horse power. The large plantations are equipped with very large and expensive mills.

Making syrup. - The usual outfit for a small cane mill and evaporator is not expensive. The evaporator is a large shallow pan with a copper bottom. In this the juice is boiled until thick enough for syrup. It is usually placed just above a furnace. Sometimes boiling is done by stcam carried through coils of pipes laid in the bottom of the usual evaporator pan.

Even experienced syrup-makers can make a more uniform article by placing in a bottle of the hot syrup a simple instrument (Baumé hy drŏm'c ter) for showing how thick it is. When this sinks to a point between the marks 34 and 35 degrees on the instrument, the boiling is stopped.

To prevent a part of the syrup turning to sugar, it may be put in cans or jugs while still very hot and tightly sealed to exclude the air. The heat kills the germs and thus keeps the syrup from fermenting. 
EXERCISE. - If growing sugar cane or stubble is available, ask permission to examine it. Notice location of buds, "root dots," point where suckers originate, position of leaves, etc.

Note TO THE TEACHER. - In regions where sugar cane is one of the chief crops, it will be well for the teacher to write for bulletins on sugar cane to Louisiana Experiment Station, Baton Rouge. Selections from these may well be read to the class.

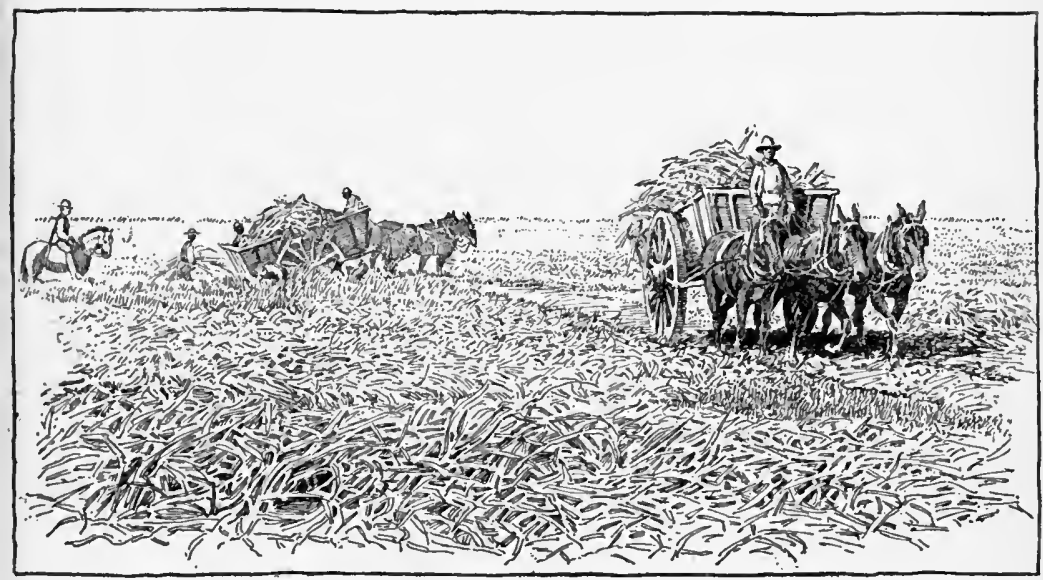

Fig. io6. - Hauling Cane from the Fields

On large plantations, the cane may now be handled largely by machinery. 


\section{SECTION XXVII. SWEET POTATOES}

Sweet potatoes. - This is another of the crops that grow from buds instead of from seeds. These buds can be seen after the potato has been kept moist and warm for a number of days. Sweet potatoes are placed in a potato bed to make the buds grow into shoots, which are called slips. The bed is made warm by spreading a layer of manure on the ground and covering this with a few inches of soil. The potatoes are pressed into the soft earth and covered with another layer of soil. As the manure rots or ferments it forms heat, which warms the soil above.

The bed should be made about six or seven weeks before the time when the slips are to be placed in the field.

Setting the slips. - When there is danger of frost, the bed must be covered. After all danger has passed or after the time when cotton comes up, the slips are gently pulled from the mother potato and transplanted to the field. They are usually placed about two feet apart in rows or beds three to four feet wide. They must be quickly put into the ground so that their roots may not dry.

If the soil is dry, a little water should be poured around each slip, thus settling the earth about its roots. Then be sure to cover the wet spot with a layer of dry soil, so that the water added may not pass off into the air. After the slips have made vines more than two feet long, these may 
be cut off in sections about eight inches long and planted. Press the middle of the cut vine into the soil.

Varieties. - The flowers of the sweet potato are large and pretty, very similar to a morning-glory. They do not often form, however. If perfect seeds develop, these, when planted, start new varieties, some of which may be better than the parent variety.

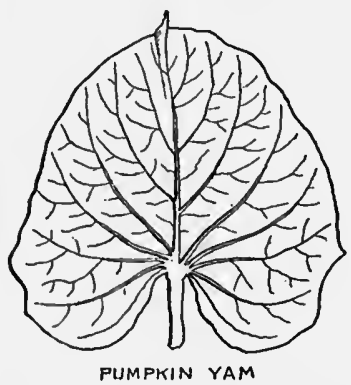

Fig. 107. - ONe Form OF SWEet Potato Leaf

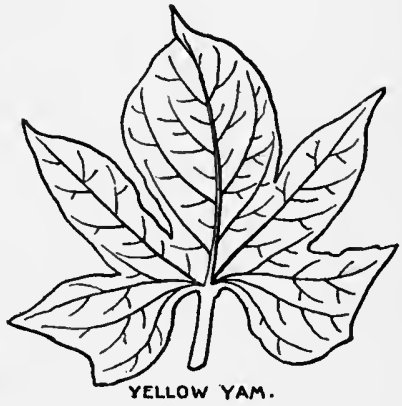

Fig. 108. - ANOTHER ForM OF Sweet Potato Leaf

There are a number of varieties. These differ in flavor, earliness, yield, shape of leaf (Figs. I07, I08), and length of vines. Southern consumers like those which, when cooked, become soft and very sweet. Among such varieties are the Sugar Yam and the Dooley. For shipping to Northern markets a grower must select varieties having a firm and mealy character when cooked.

Fertilizers for sweet potatoes. - The sweet potato needs a complete fertilizer. There is not much danger of having the land too rich, provided. enough phosphate and potash are used to balance the nitrogen that may be in the rich soil. Sweet potatoes need to be cultivated often enough to 
keep down weeds and to check the evaporation of moisture. If the beds are thrown up very high, they dry out rapidly and make the crop smaller. Several diseases attack sweet potatoes, and the germs that cause them remain in the soil. Hence sweet potatoes ought not to be grown on the land where a diseased crop grew the year before.

Storing. - Sweet potatoes must be dug before frost or immediately after the first frost. The utmost care should be taken in handling them to prevent bruises. Cuts and bruises admit germs, which cause rotting.

Sweet potatoes are generally stored in banks under shelter. They are heaped on straw or leaves on a welldrained spot. Straw, hay, or corn stalks are placed in a thin layer around the heap. A covering of earth nearly to the top of the pile is then put on, leaving the extreme top of the pile uncovered with earth for better ventilation. When freezing weather threatens, the top of the pile should be covered more completely.

A house built for the purpose of storing is more satisfactory for large amounts of sweet potatoes. It should have double walls, filled in with sawdust. There should be slatted bins, open on all sides, ventilators for the house, and a stove for heating and drying the air when needed.

Exercise. - Examine an Irish and a sweet potato. Do the roots extend through and beyond the sweet potato? Beyond the Irish potato? Which of these is a true root?

Note to tuE TEAcher. - If this lesson is studied before frost, pupils should bring in sweet potato leaves for comparison and for draiving. If sweet potatoes are extensively grown in your neighborhood, write to Experiment Stations and the Department of Agriculture, Washington, D.C., for bulletins on that crop. 


\section{SECIION XXVIII. PEANUTS AND}

\section{WATERMELONS}

Peanuts. - The soil should be loose, sandy, and well prepared. It need not be very rich, because the peanut is a legume and therefore gets its nitrogen from the air. It must, however, get phosphoric acid and potash from the soil or from fertilizers. If fertilizers are not obtainable, wood ashes may be used. The newly burnt ashes from oak and hickory are richer than those from pine wood. Lime often increases the yield of peanuts and its use is believed to reduce the number of "pops," or empty hulls.

Shell the peanuts without splitting the two halves of the kernel and plant after cotton comes up in a place where the chickens and pigs cannot get them. The plant forms its nuts by sticking its sharp, needle-like pistils into the ground. The seeds are borne underground.

The peanut is an important sale crop in Virginia, North Carolina, and Tennessee. It is grown for home use and for hog food throughout the cotton belt. A good yield is 40 to 60 bushels per acre. Peanuts for planting should be hand-picked, so that only sound seed may be planted.

Peanuts should be dug as soon as mature, and cured in rather tall slender shocks (Fig. I09). The peanut makes the land rich if the vines are allowed to decay in the ground. 
There are two principal kinds of peanuts, the Spanish and the running. The Spanish variety has short, upright stems and small nuts, which are firmly attached to the plant. The running peanuts have larger nuts and require more labor in harvesting.

Watermelons. - Every Southern farm needs its watermelon patch for producing melons for home consumption. The watermelon is also an important sale crop. From some localities thousands of car loads are shipped each year. Varieties for shipping should have a firm rind, which often accompanies rather inferior quality. For home use there are numbers of good varieties.

The watermelon likes a warm, sandy, well-drained soil. If the soil is poor, manure should be freely used. The field should be thoroughly plowed and then marked off into checks 10 by 10 or 10 by 8 feet. Where these check furrows cross, work into the soil one or two shovelfuls of well-rotted compost, made of manure and wood mold or of manure and cotton seed. On the manure, sprinkle a handful of complete commercial fertilizer or guano. With a hoe mark two trenches one inch deep across each hill. Plant at least six seeds in one of the trenches. A week later plant a like number in the other trench in each hill. Thus if frost kills the earlier plants there will be later ones to take their place.

Thin to two plants in a hill and cultivate shallow, frequently, and in both directions. Avoid unnecessary moving of the vines, or cultivation while the leaves are wet. Before cultivation ceases sow a row of cowpeas between the rows of watermelon hills. 
Do not plant watermelons for more than one year on or near the same field. A very fatal disease, watermelon wilt, is especially liable to attack watermelons planted on land on which the same crop has recently grown. Where this disease occurs, it may be necessary to fertilize only with wood mold and commercial fertilizers, omitting the manure. This is because manure frequently contains and carries the germs of the disease. Wilt-resistant varieties of watermelons are now being perfected.

EXERCISE. - When peanuts begin next season to form nuts, examine them carefully and find the flower, the pistil, and the seed. Notice the position of the leaves of peanuts at night. Are there tubercles on the roots of peanuts? Are they as large as those on the roots of cowpeas? Is any of the soil from the field where peanuts last grew brought to the new peanut field?

When watermelons bloom, notice the difference between the pistillate and the staminate flowers.

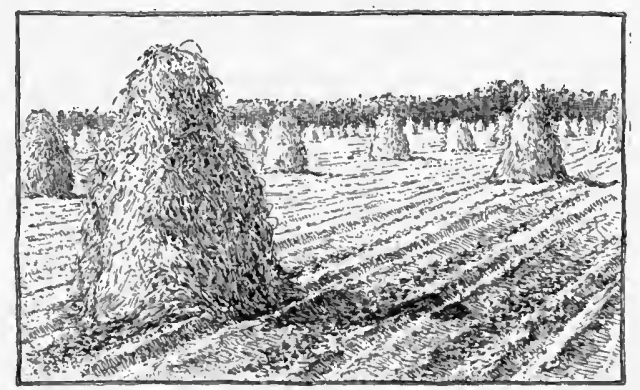

Fig. rog. - Peanuts or Goobers DRying IN Shocks 


\section{SECTION XXIX. LEGUMES AND INOCULATION}

Is former times learned men thought that mankind would finally starve to death because there is not enough nitrogen in the ground to produce food sufficient to feed the growing population of the world. There is no longer any fear of this, for it is known that certain plants called legumes can make use of the limitless amounts of nitrogen in the air. There are about 36,000 tons of this nitrogen gas in the air above every acre. Yet cotton, corn, wheat, and most plants cannot use a pound of this nitrogen gas until legumes have changed it into fertilizer nitrogen. Any of the legumes, for example, the cowpea or clover, by the aid of the tubercles on its roots (Fig. 112), can grow on ground where cotton, corn, or wheat would starve for want of nitrogen. Not only do legumes get from the air enough nitrogen to enable them to make luxuriant growth on a poor field, but they also enrich the soil with a part of this nitrogen. When the roots and fallen leaves decay, the nitrogen in them is added to the soil. Still more is added if the stems and leaves, as well as the roots, are left on the field where the plants grew. That crops often grow much larger after a legume is shown in Fig. 110.

Each germ grows only on the kind of plant to which it is accustomed. - Every tubercle on the roots of legumes is 
inhabited by thousands of useful germs, or plants too small to be seen by the naked eye. When the tubercle decays, these germs are set free, and spread through the

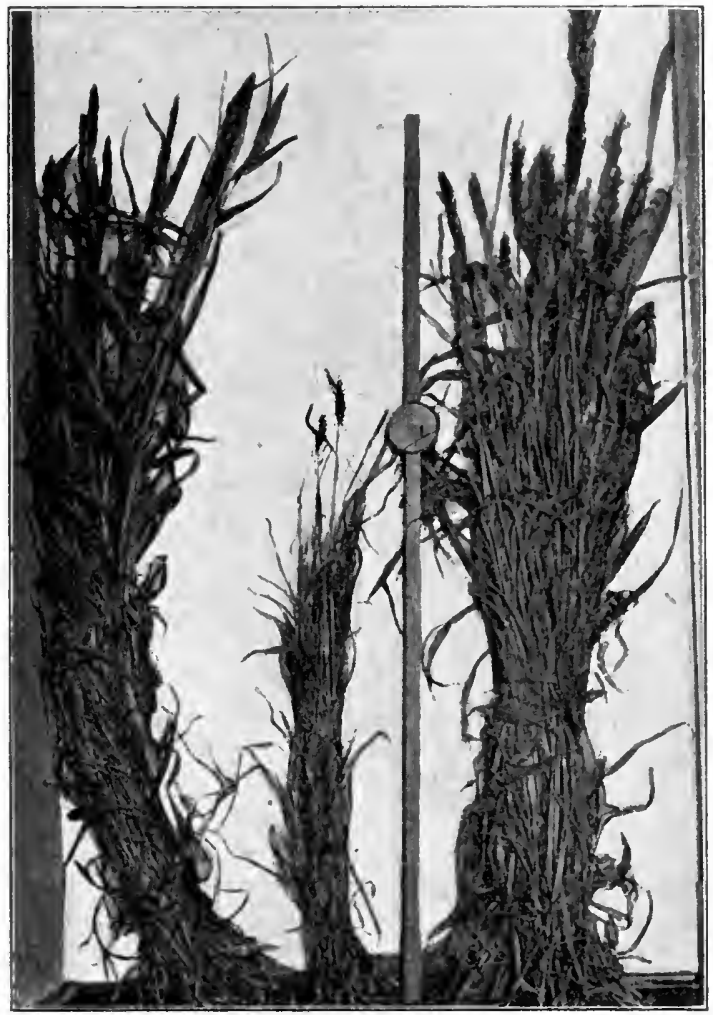

Fig. i io. - Sorghum from Equal Areas

In center, fertilized with rye; on left, with vetch, entire growth; on right, with vetch stubble.

soil by means of water. These little workmen are alive. They must wait until the same kind of legume is planted 
there again. As soon as a clover plant throws nut roots, the clover germs attach themselves to the root, multiply rapidly,

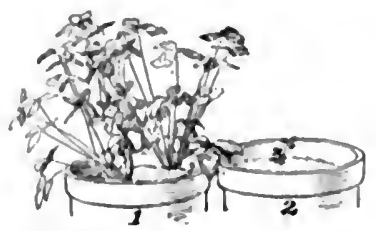

FIg. 11.- RED Clover

I, inoculated; 2 , not inoculated.

become accustomed to living on the special kind of food it finds in clover sap, and perhaps the diet the cowpea or alfalfa offers does not agree with it. If a fertilizer factory is started, it must be by germs accustomed to work on that kind of plant or on one very closely akin to it. Clover germs make tubercles on clover, alfalfa germs cause nodules on alfalfa, vetch germs organize fertilizer factories on the roots of vetch, and so on.

Inoculation of leguminous crops. - If a farmer, therefore, desires to grow clover and form a tubercle. Strange to say, clover germs will not grow on cowpea roots. Perhaps this. is because the clover germ has

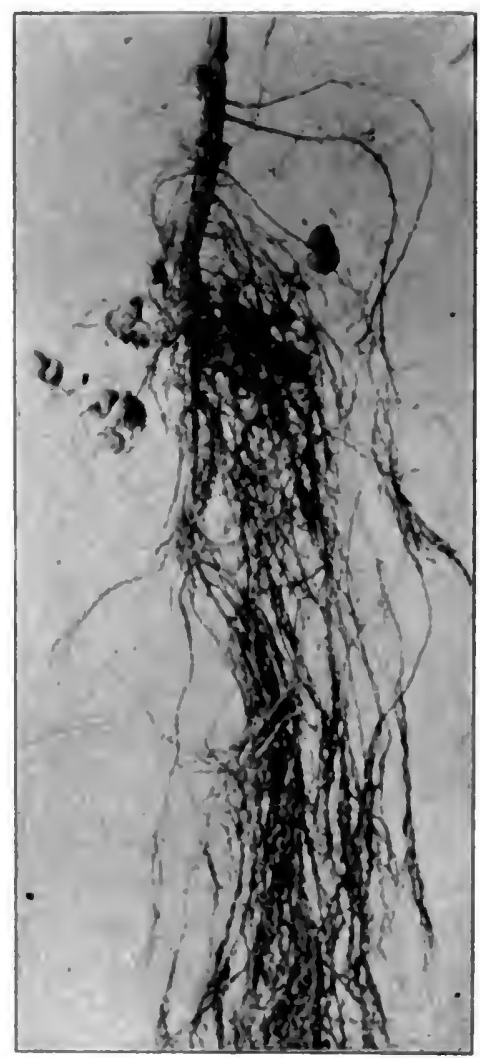

Fig. 112.- ROOTS OP SOY BEAN, INOCULATED 
on a soil where there have been no clover tubercles, he must place the clover germs there (Fig. I I I). He can do this by sowing in that place soil from a field where clover has turned loose its millions of germs. If he wishes to grow alfalfa, he must likewise sow on the new field soil from an old alfalfa field. Inoculation is the name given to this placing of the proper germs where they can form tubercles. To inoculate a legume is to bring the proper germs to its roots (Figs. I I 2, I I 3 , I I4).

How to inoculate legumes. - Legumes can be inoculated in several ways, (I) by sowing soil, (2) by dipping the seed in water mixed with this soil, or (3) by mixing the seed with a special preparation made

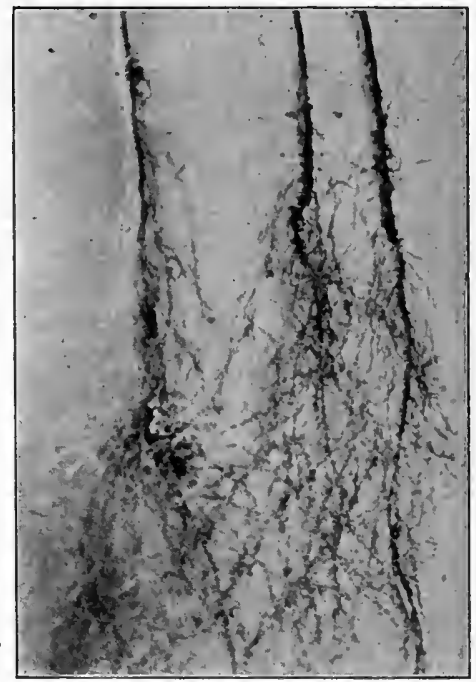

Fig. II 3. - Roots of Soy BeAN, NOT INOCULATED originally from ground-up tubercles of a plant like that to be grown.

Using the proper soil. - This is a reliable method of inoculating the soil. Care must be taken not to use soil that has in it seeds of bad weeds or that contains the germs of serious plant diseases. Promptly cover inoculated seed or soil used for inoculating legumes, for much sunshine will kill the germs. 
Legumes that need inoculation. - There are or have been

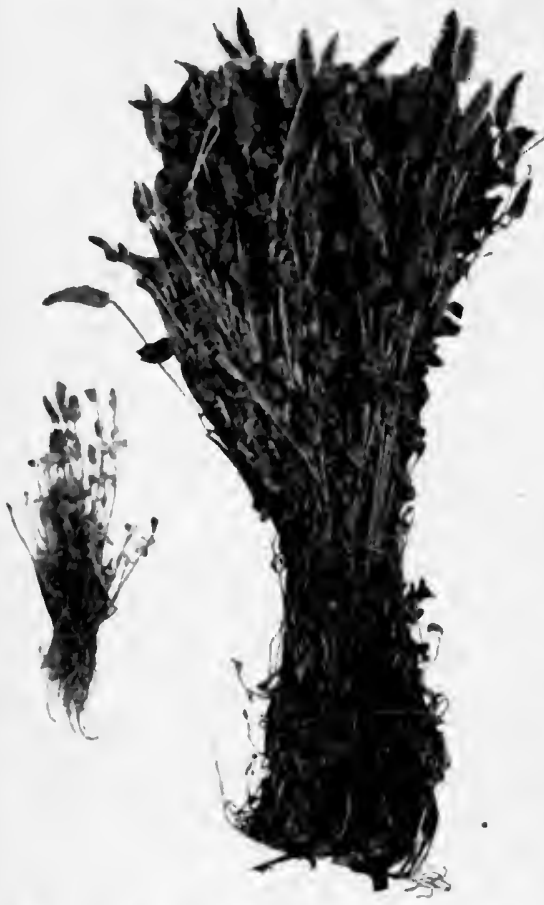

Fig. II4. - Crumson Clover, the SAMr.

Number of l'lants in Each Bunde

On right, inoculated; on left, not inoculated. Grown at Ala. Agr. Expt. Station. tubercles on nearly every cowpea plant found in the region where cotton grows. Cowpea plants in the North, however, have no tubercles where this crop is but little grown. In the Southern states, where cowpeas are generally grown, the wind has blown the germs into almost every field. However, in most sandy soils in the South, where crimson clover, vetch, and alfalfa are seldom grown, the farmer will need to inoculate the seed of these three very useful plants. Figs. III, II4 show how inoculation often helps these rarely grown legumes.

EXERCISES. - Ask your parents to tell you how much their crops are usually increased by a preceding crop of cowpeas or clover.

Examine every leguminous plant you can find. Make drawings of tubercles on some of the leguminous plants you find. 
Note To The TEACher. - Much time can here be given to a study of the tubercles on different plants. Assign drawings from nature of the tubercles on several legumes, as on garden pea, clover, and on any others that may be available. Write to your state Experiment Station and to the United States Department of Agriculture at Washington for any bulletins on soil-improving plants; also ask that the library of your school be put on their permanent mailing lists, so that the school may receive their future publications.

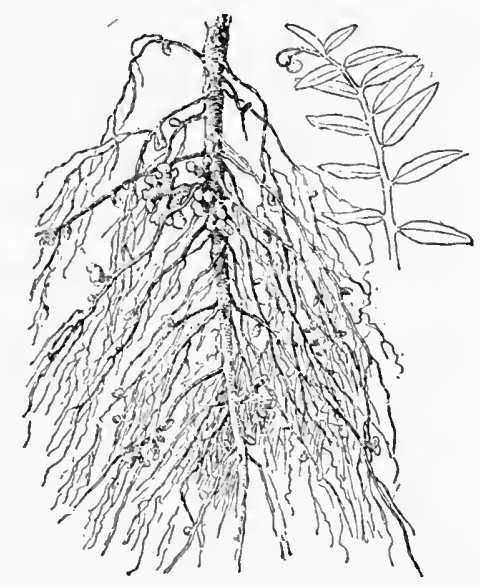

Fig. 115. - Nodules on Winter or Hairy Vetch 


\section{SECTION XXX. SOME FORAGE PLANTS}

Cowpea. - There are more than a score of varietics of cowpeas. Some, like the Speckled, grow almost upright, make a good crop of seed, and are easy to mow. Others make long runners that sometimes lie almost flat on the ground and are hard to mow because they tangle. Still others, like the New Era, make ripe pods so quickly that two crops of them can be made in the Gulf states in one year, by sowing the second crop with seed ripened by the first crop in July. This is helpful when seed for planting is scarce. Bushy, upright cowpeas form "runners" and tangle, if the seed is sown very early. Late sowing, say in July, makes the branches, or "runners," of a running varicty shorter.

Cowpeas may be planted at any time in May or June and even later. Almost every acre of corn ought to have cowpeas sown between the rows, so as to enrich the land. After oats and wheat are cut, cowpeas should be sown on the stubble land either to be used for hay, for grazing, or only for fertilizer. In corn fields and when sown alone, cowpeas may be sown either broadcast or in drills. The fertilizer most frequently needed is acid phosphate, or on some very sandy soils both phosphate and potash.

Crimson clover. - This plant (Fig. 114) is as useful as it is beautiful. It prevents leaching and loss of fertility in winter. It adds to the soil about as much nitrogen as 
does a crop of cowpeas. About the latter part of April, the richest kind of hay can be made from it. This will take the place of part of the corn that so many farmers buy for their teams. As soon as the hay is cut, corn or sorghum or sweet potatoes or other late crop may be planted to fatten on the nitrogen which the clover roots and stubble have added to the soil.

Crimson clover is very easy to grow. Land that has just grown cotton does not even have to be plowed. A little more than a peck of seed per

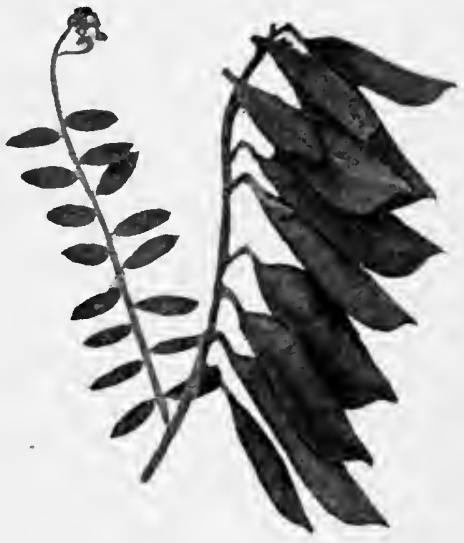

Fig. II6. - HaIRY Vetch acre may be sown broadcast in the cotton in September and covered by passing a one-horse cultivator between each pair of rows. It is easy to fail with crimson clover if the land is not inoculated. To inoculate land for crimson clover, sow with the seed soil from a field where crimson clover, red clover, low white clover, or other true clover has grown.

Vetches. - These plants (Figs. I I 5, I I6) have slender stems or branches, too weak to stand alone. Hence they need to be sown with oats or wheat, so that the weak vines may climb up the grain plants and be high enough for mowing in May. Vetches are useful for hay, for pasturage, and for enriching the soil. Hairy vetch is the most popular kind. The seed should be sown broadcast about Septem. 
ber, 2 to 4 pecks of vetch seed per acre being mixed with the usual amount of seed of wheat or oats. Vetch has an advantage over crimson clover, for, unlike clover, it can re-seed the land. If the farmer will let vetch plants form seed, these seed, dropped in May, will remain sound in the ground all summer while a crop of cowpeas or sorghum is growing on the field. In the fall they sprout and grow without requiring that the land be plowed. To make sure that seeds are dropped on the ground, vetch should not be closely grazed after the middle of April in the Gulf states. If it is mixed with an early variety of beardless wheat, the hay may be mown so early that enough second growth of vetch will afterwards be made to mature seed. Vetch may be inoculated either with soil from a field of any kind of vetch or with soil from a spot where garden peas have grown. This is because vetch and garden peas are very closely related.

Alfalfa. - This is a clover-like legume, the roots of which may live for many years. Alfalfa seed may be sown in the cotton belt either early in the fall or early in the spring. Three to five cuttings of hay can be made each year. It is, therefore, the most valuable of all forage plants for soils that suit it. Unfortunately, it does not generally do well in most sandy soils in the Southern states. Sometimes fertile, sandy land will grow it well if the farmer can get rid of the seeds of crab grass and weeds, and if he uses much lime, besides manure or fertilizer. Favorite soils for alfalfa are the stiff, waxy lime lands of Alabama, Mississippi, and Texas, and stiff, rich, but well-drained river bottom lands. 
One of the worst enemies of alfalfa is love vine or dodder. This is a vine like the one that twines around blackberries and weeds in swampy places. Dodder seeds are bought with the poorer grades of alfalfa seed. It ruins alfalfa

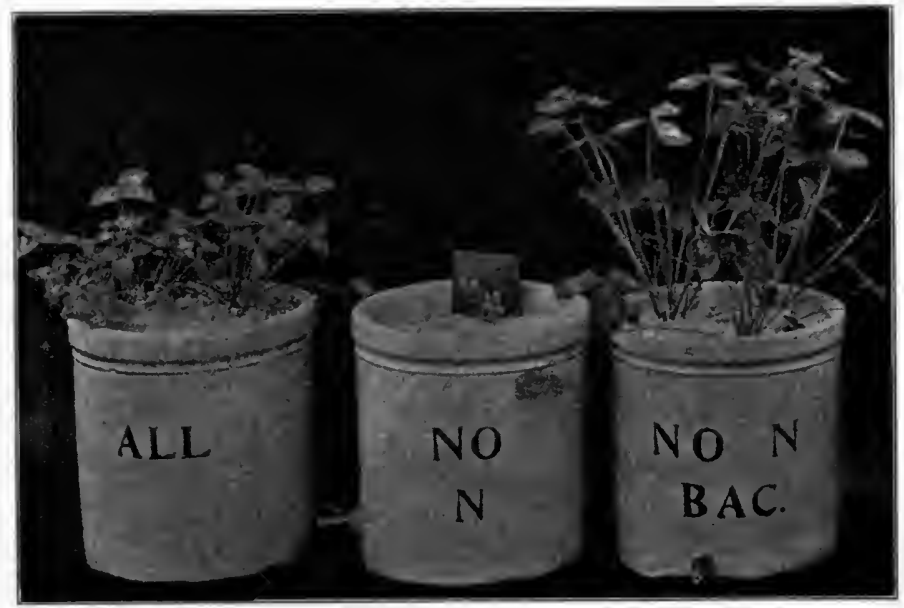

Fig. II7.-RED CLOVER

On the left a complete fertilizer was used, but the plants were not inoculated; on the right clover germs supplied all the nitrogen; in the center the plants received no nitrogen and were not inoculated. (Grown at Ill. Expt. Station.)

by wrapping its small yellow threads around the host plant and sucking its sap. The spots where it appears should be covered with trash and burned.

Red clover (Fig. I I 7). - Except in the extreme Southern and Western states this is the most widely grown legume. It lives for two years, the seed usually being sown in the spring, on growing wheat or grass, or alone. The seed may be sown in the fall. Red clover affords two or more cuttings the second year, sometimes even the first year on 
suitable soil in the extreme Southern states. It requires a lime soil and is unsuited to most of the sandy lands from the Carolinas to Louisiana.

Japan clover. - This is a soil-improving plant, but not a true clover; hence soil from near its roots will not inoculate crimson or red clover. Its true name is Lespedeza. It is the best pasture plant among the legumes for the poorest Southern soils. It grows wild over the greater part of the Southern states. Although an annual, it comes up every spring from seed shed the preceding fall. The seed may be sown in early spring alone or on a field of oats or wheat. On rich, moist land it sometimes grows tall enough to be used for hay. The pasturage and the hay are very nutritious.

Soy bean. - This annual legume (Figs. 118, 119, 120) is used like the cowpea for hay, seed, and soil improvement. It has the advantage over cowpeas that the hay does not tangle and that the seed are threshed out instead of being picked. It is sown in May or early in June in rows about three feet apart.

Grass plants used as food for live-stock. - Common grasses all haveslender, pointed leaves, which wrap partly around the stem. Those that creep along the ground and form roots from the joints, like Bermuda grass and carpet grass, are generally good for pasturage. North of the Gulf states favorite pasture grasses are blue grass, orchard grass, and red-top. Those that stand erect, like Johnson grass, sorghum, and millet, are chiefly useful for hay.

Many pastures are more profitable than any cultivated land on the farm. Any land that has become too poor to 
be worth cultivating should generally be used for pasture. Scatter over it seed of Japan clover (Lespedeza) or ' of

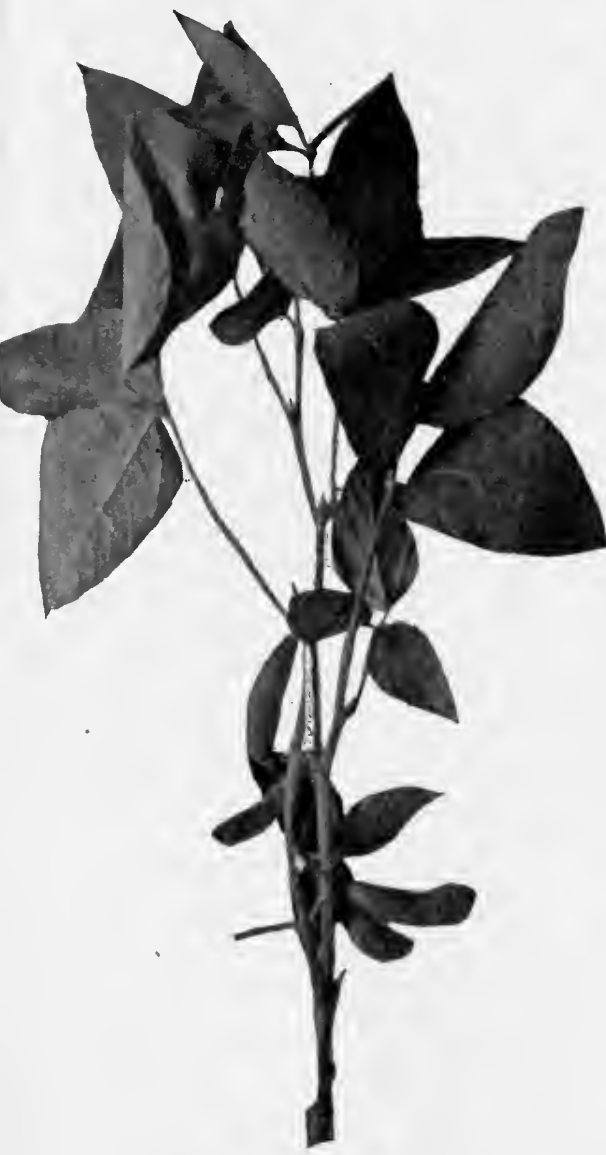

Fig. II 8. - PART OF A

Soy Bean Plant

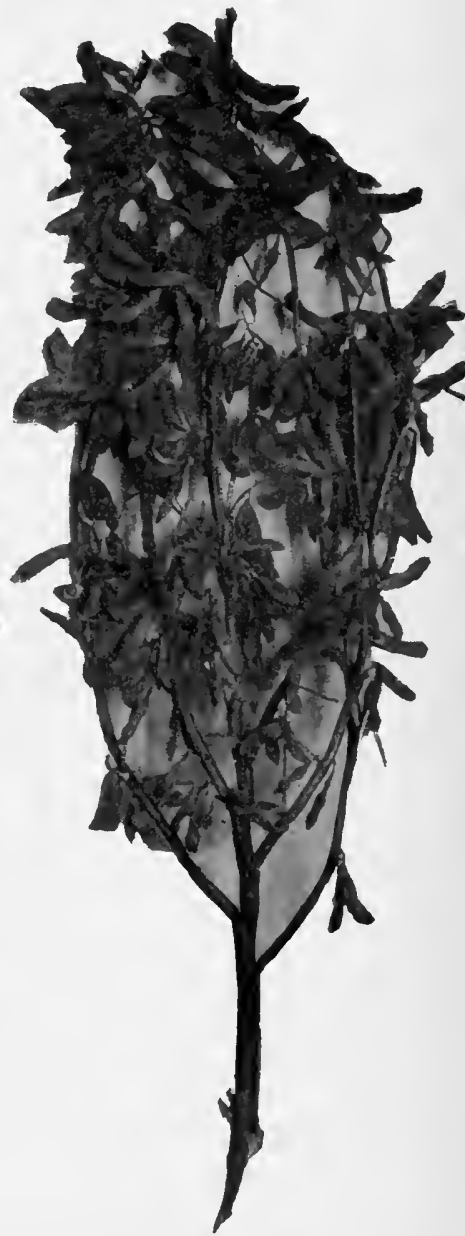

Fig. ilg-A Mature Soy Bean Plant, SHOWING THE PODS 
other suitable forage plants. Land improves while being used for pasture chiefly because much vegetable matter is formed near the surface and because some of the wild

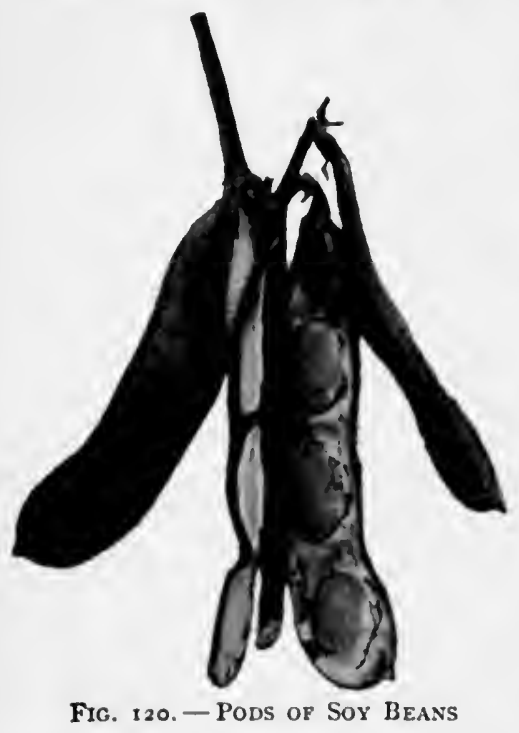

clovers creep in and start the fertilizer factories on their roots.

In the Southern states much more land should be used for pasturing livestock. This becomes doubly necessary where the boll-weevil is, because cotton cannot there be profitably grown on the poorest land. This, however, would yield a fair profit if used for pasture.

Bermuda grass.- Some farmers fear to introduce this grass because it is difficult to destroy. There will seldom be any desire to destroy it if pastures of it are started in the right location. With Bermuda grass may be mixed Japan clover for summer grazing and either bur clover or vetch for winter grazing. Another excellent grass for pasture is carpet grass, which is not difficult to destroy. Portions of the plants or roots must be set, or the seed of carpet grass must be saved from the low spots.

Sorghum. - This annual plant will grow on almost any soil. It is useful for green forage or for hay, and for making syrup. The seed must be sown thick to make good 
hay. Sorghum endures drought better than most annual grasses. It greatly exhausts the soil and hence should generally be followed by a legume.

Kafir. - This plant, also called kafir corn, is a kind of sorghum without sweet juice. It is used in Oklahoma and Texas, both as a grain crop and for forage. It endures drought better than corn, and hence in dry climates it largely takes the place of corn.

Kafir for grain is planted in rows wide enough to permit cultivation. The plants are usually harvested by machinery and cured in shocks.

EXERCISE. - Write in your notebook a list of names of all varieties of cowpeas (southern "field pea") grown near your home. Write a description of the seed of varieties of cowpeas that you know or that you can examine. If you can find specimens of any of the plants mentioned in this section, carry them to the teacher. Would you like to make an acre of land rich by sowing on it inoculated crimson clover seed?

Note to the Teacher. - Most experiment stations, as well as the U. S. Department of Agriculture, have published bulletins on some of these forage plants, and these bulletins are generally sent free to applicants. If you succeed in interesting your pupils in these soilimproving plants, you may be the means of greatly increasing the prosperity of the community. 


\section{SECTION XXXI. WEEDS}

A WEED is simply a plant growing where it is not wanted. Hence a kind of plant that is useful in some fields may be a weed in other fields because it interferes with the growth of some crop. Among the plants that are sometimes weeds and at other times useful are Johnson grass, crab grass, and beggarweed.

How weeds injure the farmer. - Weeds are injurious because (I) they use plant-food and fertilizer needed by the more valuable crop plants; (2) they rob the cultivated plants of water by taking up the moisture of the soil for their own use; (3) they greatly increase the expense of cultivating the crops. Weeds are robber plants and must not be allowed to become large and strong, for then the crop will be ruined. Poor farmers cultivate their crops only as much as weeds compel them to, but good farmers cultivate the ground when there are no weeds, so as to keep the lower layers of the soil moist.

Study the habits of weeds. - To get rid of weeds in the easiest and cheapest way, study their habits. First make sure whether they are annuals. If they are annuals, such as crab grass, foxtail, ragweeds, and bitterweed, all that has to be done is to keep them from maturing seed. If they are biennials, like sweet clover, no seeds should be allowed to form for two years. If they are perennials, ' like Johnson grass, nut grass, thistles, and dock, the forma- 
tion of seeds should be prevented by cutting the tops down for a number of years. Even if the growth of seed is prevented, there is still more work to be done to rid the land of the roots of these long-lived. robbers.

The vigorous growth and abundant formation of seed by some weeds are shown in Figs. I 2 I and $\mathbf{I} 22$.

Killing perennial weeds. - Weeds that come up year after year from the roots are usually not easy to kill.

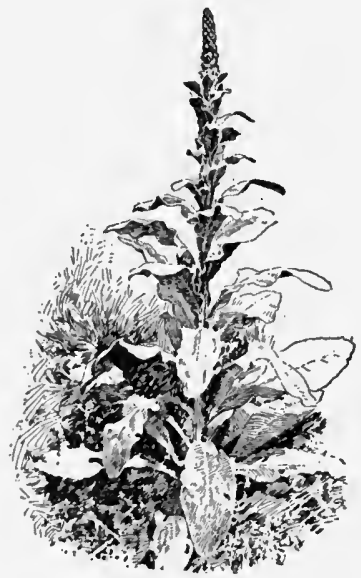

Fig. I 2 I. - MUllein

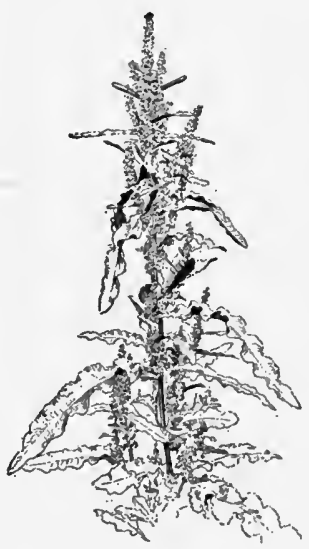

Fig. I 22. - NARROW-LEAVED Dock

Plowing them with a sharp plow sometimes destroys them if the roots are all brought to the surface and thus dried. This is one of the easiest ways to kill Bermuda grass. Shallow plowing is best for killing this grass because the shallow furrow-slice dries out more completely than a thicker layer of upturned soil. Any plant is more easily killed late in its growing season, for then it cannot so easily 


\section{SECTION XXXII. THE VEGETABLE GARDEN}

THE products that a half-acre garden affords are generally worth more than those produced on several acres of common field. From a half acre of land a man whose business is gardening sometimes sells enough vegetables to bring him $\$ 100$ to $\$ 200$ or more. To make a garden productive, treat it as follows :-

(I) Manure it heavily, using 20 to 40 wagon loads of compost or manure per acre each year. (2) Keep every part of it busy, growing two or three crops a year on the same rows. (3) Plant such vegetables as will furnish something for the table every week in the year. (4) Plow the garden deep in the late fall or winter and keep it always so clean that a crop of rank weeds and weed seeds will not need to be plowed under. The garden will pay well for all the manure put on it. Vegetables are more tender and better, as well as earlier and more abundant, when grown on rich land.

Planting seed. - In planting garden seed, cover the large seeds, like beans and peas, with several inches of earth. The small seeds must be covered very lightly. Seeds will not readily germinate in rather dry, loose soil unless it be pressed closely against them, so that it may bring up moisture, just as a wick brings oil to the lamp flame. Many gardeners tread on nearly every seed they plant, walking on the open drill on top of the seeds. The 
same packing of the seeds against the soil in the bottom of the furrow can be secured by rolling an empty wheel. barrow over them before they are covered. The ground must not be wet when packed. Loose soil should cover the footprints or the track of the wheelbarrow. This loose layer of soil keeps the moisture from rising above the seeds and evaporating.

How to set a young plant. - Many kinds of vegetable seeds, such as those of cabbage and tomatoes, are sown in boxes or hotbeds before they are safely planted out of doors. In these boxes or hotbeds the seeds should be planted thickly in tiny trenches several inches apart. If possible, the plants should be thinned as soon as they show the first well-developed true leaf. The surplus plants should be transplanted to other boxes or to other parts of the coldframe. Plants that have been moved once while still in boxes or coldframes are stronger, better shaped, have a better ront system, and grow better when placed in the garden. Let the plant grow several inches high in the seed-box if it must be transplanted directly from the box to the garden.

In transplanting, avoid doubling the roots. If the ground is so dry that the young plants must be watered when transplanted, first punch the hole; next insert the plant; then pour in a cupful of water, which will settle the soil snugly around the roots. Last and most important of all, draw up loose, drier soil around the plant and over the wet spot. Every time a young plant is watered, the wet spot should afterwards be covered with loose, dry soil to hold the moisture and to keep a crust from forming. When rather large plants are transplanted, it is best to 
pinch off some of the leaves so that they may not evaporate water faster than the broken roots can supply it.

A succession of vegetables. - A little work and a little planning every week are worth more to a garden than twice as much work every two weeks. By thus planning, it is possible to have vegetables every week in the year. Most well-cultivated gardens in the Southern states afford an abundance of vegetables during May, June, and July. To be sure of a continuous supply through August, September, and October, make late plantings of tomatoes, butter beans, okra, corn, eggplants, and other vegetables that thrive in hot weather.

The period when fresh vegetables are scarce is from November to March. During this time, there should be a stored-up supply of sweet potatoes, fall-grown Irish potatoes, cushaws, pumpkins, dried beans, dried sliced okra, and ruta-baga turnips. Fresh vegetables can also be had during most of this time by planting in July, August, or September seeds of collards, cabbage, rutabaga turnips, beets, beans, and turnips. The planting of onion sets in the fall and the sowing of seed of kale and spinach for winter "greens" should not be forgotten. Salsify is a delicious vegetable available for fall use.

Hotbed or coldframe. - To obtain early vegetables a hotbed or coldframe will be helpful, because under this the young plants can be started during the winter. The frame is made as shown in Figure 125. It has no bottom, but rests over a shallow pit into which a layer of damp manure has been placed, and covered with several inches of soil. The purpose of this manure is to afford, by 
fermentation, heat to warm the soil in which the seeds are to be planted. Place the seeds in drills a few inches apart. When the frame is placed over such a layer of heating manure, the whole is called a hotbed. A similar frame is called a coldframe if no manure is used under it. The cover usually consists of several glass sashes. On a coldf rame the cover may be of white cloth.

To make a small hotbed or coldframe to be covered by a single sash construct a wooden frame six feet long and at least three feet wide. The back should be twelve inches high and the front eight inches. It is better to make it at least six feet wide, thus requiring two sashes. The glass sashes slide on strips nailed to the sides or on crosspieces, as shown in Fig. 125. The earth should be banked around the outside of the frame.

The slope of the glass sash should be towards the south. The sun's rays strike through the glass, which serves as a trap for the heat. In this heated air and soil young cabbage, tomatoes, and other plants grow rapidly. On mild days, the glass must be lifted so as to prevent disease and to accustom the plants to cool weather. A box kept near a window indoors, or covered with a few panes of glass, may take the place of a hotbed.

Vegetables that may be planted in cool weather. Among the plants of the garden that can endure rather cold weather are peas, kale, mustard, radish, spinach, and lettuce. The seeds of these plants are therefore usually the first to be planted, in February or earlier. Young cabbage plants endure much cold. In the central part of the Gulf states they often live through the winter 
when set on the south side of a high ridge or bed. Irish potatoes are planted while the weather is still cold.

Among the vegetables that are not entirely killed by slight frosts are beets. Asparagus is one of the earliest

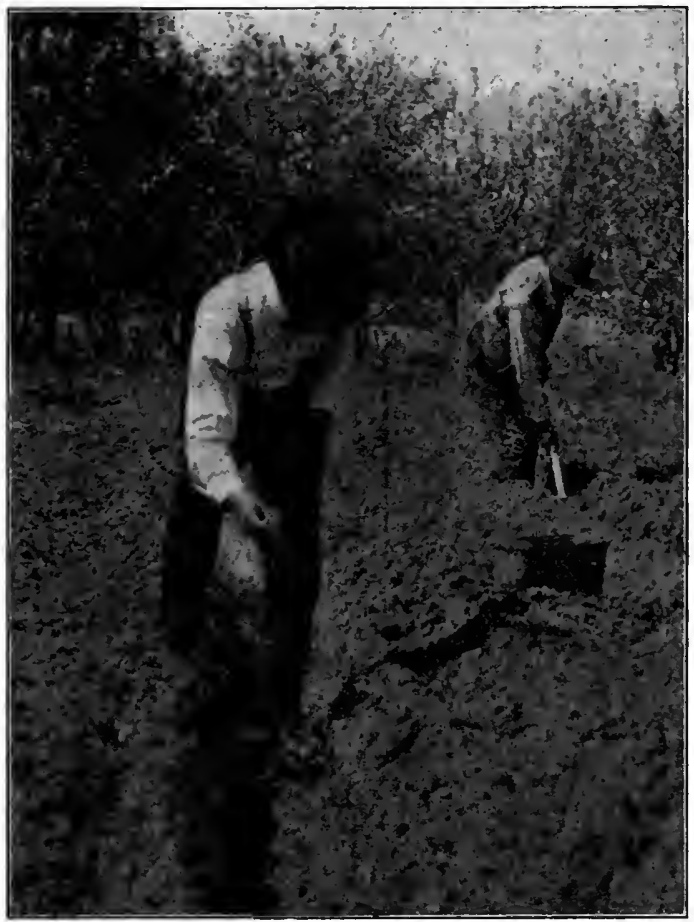

Photograph by R. S. Mackintosh

Fig. 124.-Planting Asparagus Roots

of the season and comes each spring from the old roots. It may be grown from seed sown in early spring. The next winter the roots of the young plants are transplanted (Fig. 124) to rows that have been plowed very 
deep and made very rich with well-rotted manure. A quicker crop is secured by buying the roots instead of growing them. Onions are among the hardiest of vegetables. Onion sets are placed in the ground in the fall, or in January or February. Some varieties of onions grow well from seeds planted in the fall or late winter, the young plants being afterwards transplanted. Garden peas are planted three or four inches deep, usually in January, February, and March.

Tender vegetables. - Among the plants easily killed by frost are beans, tomatoes, eggplants, squash, and all the other members of the gourd or melon family. These cannot safely show above ground until danger of frost is past; so they are usually planted about the same time as the earliest cotton. Tomatoes are generally started under glass and transplanted as soon as the danger of frost is past.

Vegetables that suffer from hot weather. - Peas and lettuce do not thrive during hot weather. Cabbages and turnips are usually ruined by the harlequin cabbage-bug and by other insects after midsummer; they should, therefore, be grown either as very early crops or in the fall.

ExErcise. - Write the names of all plants the leaves of which you know to be cooked for "greens." During what months can each one be used? Make a list of all the vegetables you have ever seen growing in your home garden. What vegetables besides these have you seen growing elsewhere? If you have never grown any plants that were really your own, ask at home if you may not have one row in the garden for yourself. Among the plants that can be most quickly grown in it tre radishes, turnips, lettuce, and in warm weather, bunch snap beans.

Note to THE. TEACHER. - Let the pupils examine and compare alt obtainable garden seeds, as to size, color, germination, etc. Write to the Department of Agriculture, Washington. D.C., for Farmers' Bulletin 
No. 255 on vegetables, also for publications on school-gardens, and consider whether your school should have one, or whether pupils should be encouraged to have their own small gardens at home. In any way get every pupil to grow some useful or ornamental plants that shall really be his own. By questions draw out from the oldest members of the class the month in which every vegetable mentioned in this chapter is usually planted. Similarly secure a statement of the months during which each is eaten. Write for similar bulletins to the Experiment Station in your own state; use the seed catalogues also.

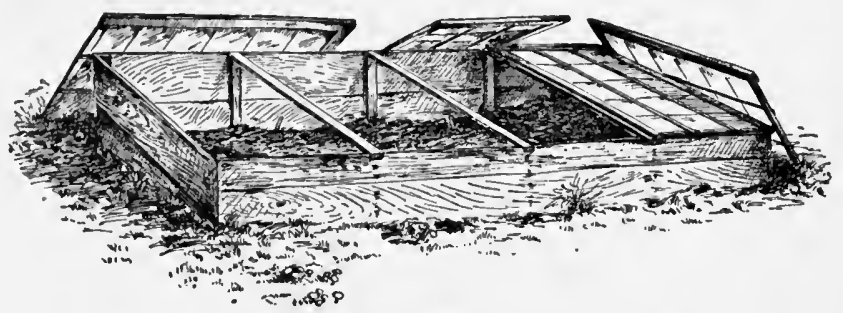

Fig. 125. - A Coldframe of Four Sashes 


\title{
SECTION XXXIII. PLANNING THE FLOWER GARDEN
}

\author{
BY MisS F. E. ANDREWS
}

NATURE's adornment of shrubs and flowers is more beautiful than the most costly paintings. Yet flowers may be had at very slight expense. The care of a small

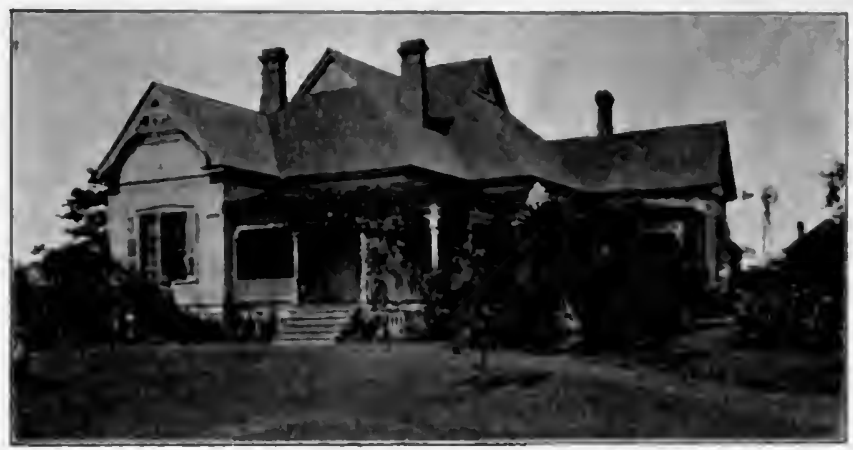

Jhotograph by R. S. Mackintosh

Fig. 126. - Plant Flowers and Shrubs near the House, LEAVING THE LAWN OPEN

flower garden, all one's own, is a perpetual delight, especially to a young person.

In general, the best way to lay off a flower garden is not to lay it off at all. It should not be cut up into stiff beds. The space directly in front of the house should be left open (Fig. 126). Bermuda grass makes the best summer covering for Southern lawns. By sowing white clover 
seed on it in early fall, the lawn will gladden the eye with its carpet of green before winter has wholly passed.

There may be a border of low flowering plants on each side of the walk, while against the walls of the house may be grouped taller plants and shrubs as a background for beds of smaller, bright-blooming flowers. The colors of flowers

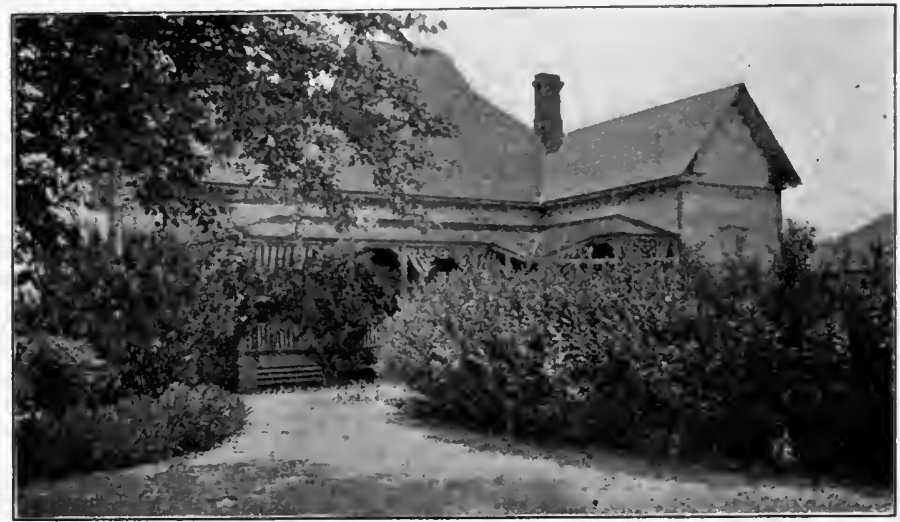

Photograph by R. S. Mackíntosh

Fig. 127. - A Back Yard screened by a Hedge of Privet

show better if many of the same kind are massed together.

The place for shrubs. - Against the fence on either side, and in the corners by the steps, may be planted shrubs, while between the front and back yards, and wherever there is any unsightly object in view, there should be a screen of tall shrubs or vines. The Japan honeysuckle and the Cherokee rose are good evergreen vines for this purpose. The purple wistaria is a hardy climbing shrub that quickly covers unsightly objects or shades sunny porches. For ornamental hedges, privet and pomegranate are good 
(lig. 127). Some of the many beatutul native wild shrubs serve well as screens.

What to plant in the garden. - In the first place, hardy.

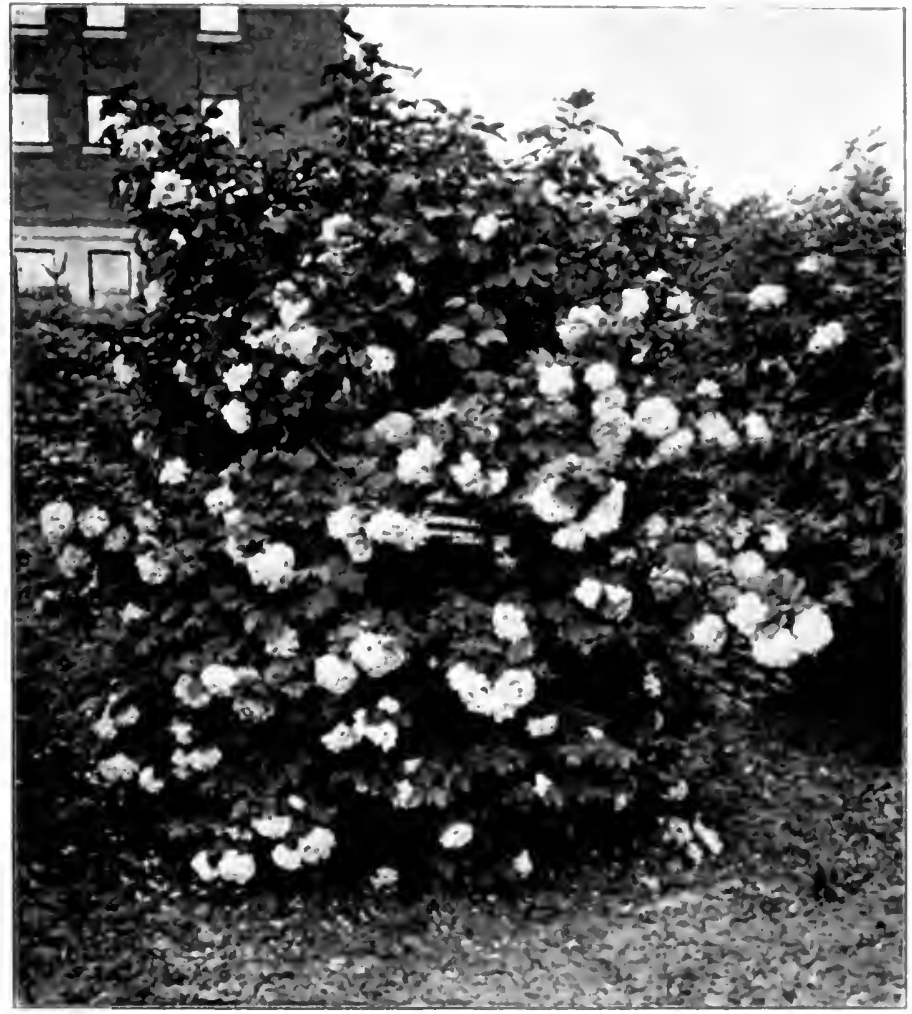

Fig, 1 28, - SNowball

self-reliant plants are needed. Choose bouncing clusters of phlox and sweet william, and ever-blooming roses, sturdy ranks of sunflowers, hollyhocks, and prince's feather, that 
do not surrender to heat or drought, and smiling beds of pinks and verbenas.

In the next place, select plants so as to have a constant succession of flowers all the year round.

Winter and early spring flowers. - White hyacinths, jonquils, sweet violets, and Japan quince bloom early in the year. Then, when the red maple begins to glow in the woods, come the periwinkles, the early narcissus, daffodils, spireas (bridal wreaths), and the blue hyacinths. With March, the early lilacs and the late spireas begin to open their eyes. April brings, along with dogwood, redbud, and haw blossoms and wild azaleas in the woods, a troop of early roses, the wistaria, snowball (Fig. I28), white iris or flag, and some of the lilies. On through May and June the bright throng comes trooping by.

Flowers for the hot dry season. - During the hot months of midsummer and early autum, nature generally calls a halt to this gay procession, and so the gardens must be provided with plants that are hardy to sun and drought. For this purpose choice lies between ever blooming roses, hollyhocks, larkspurs and mallows, four-o'clocks, phlox, "snowon-the-mountain," bear's grass, Spanish bayonet, "old maids" and "bachelor's buttons," "black-eyed Susans," and the whole great sunflower family.

Fall and winter bloomers. - In our climate, many of the summer flowers linger into late fall and early winter. This is especially true of the roses. The chrys ăn'thē mŭms, too, linger till long after frost; the verbenas and scarlet sage and the canna last late into the year. The fall months are brightened by the yellow and brown of the 
marigolds and by the varied colors of cosmos, conspicuous above its fringe-like foliage.

Beautifying the school grounds. - The same principles, in the main, will apply to the school as to the home garden. As a general thing, more hardy plants should be chosen for the school grounds for the reason that during the part of the year when the school is not in session they will probably receive no attention whatever. Hence it is well to choose native shrubs and flowers for planting around the schoolhouse. Many wild plants grown in the woods are quite as beautiful as the most expensive productions of the florist. An ideal location for a schoolhouse is in a grove, for then there is no need for flowers, except, perhaps, in a special school garden beyond the shade of the trees. The school garden should be a plot of ground near the school, in which each pupil has his own little collection of flowers, vegetables, and crop plants.

EXERCISE. - Write in your notebook the common names of all the wild or cultivated shrubs that you think would make the school grounds look better. Think about the best place to plant them. Do you know where they could be obtained without cost?

Note to THE Teacher. - This section affords an opportunity to impress the advantages of improving the school grounds, as does also the section on trees. Could not some of the pupils, working together, make a map of the school grounds, showing location of buildings, fences, trees, shrubs, etc.? Let other pupils copy this. Then let each, after a few days, hand in his or her map, indicating on it where a hedge or screen of vines should be located and where trees and shrubs ought to be planted. Tell them to keep these maps. After they have studied the sections on trees let them write on the maps the kinds of trees that they would choose for any spot needing trees. 


\section{SECTION XXXIV. GROWING FLOWERS}

Most of the plants found in the flower garden may be classed either as (I) shrubs, (2) bulbs and tubers, or (3) herbs. The shrubs are all perennial and so are most of the plants growing from bulbs and tubers. Flowering herbs may be either annual, biennial, or perennial. As a rule perennial plants furnish the earliest flowers, for they have laid up in their roots, stems, or bulbs a supply of food intended to hasten the growth of the new flowers.

Shrubs. - Most cultivated shrubs can be increased by means of cuttings or by suckers

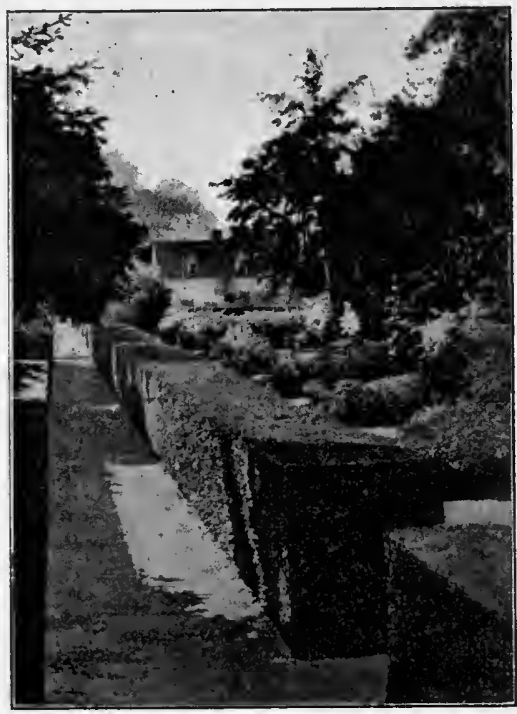

Courtesy Minn. Expt. Station FIg. I29. - WASHINGTON'S FloWER Garden at MT. Vernon from the old roots. Shrubs require less care than smaller plants and endure for many years.

There are roses of very many colors, and they are among the most beautiful of cultivated flowers. Roses are grown from cuttings, which are started either out of 
doors or under glass, depending on the kind of rose, the climate, and the soil. On these points you will need the advice of those neighbors who grow roses. Where practicable to start your rose out of doors proceed as follows: during the winter take a portion of a slender rose branch less than one year old on which the wood has recently become firm. Cut this six to eight inches long and remove the leaves. Be sure that a smooth cut is made. If the cuttings are to be started in moist sand under glass, they may be much shorter and of younger wood. Part of the upper leaf may be left. Place the longer cuttings in a sloping position in a trench in the flower garden and cover them up to the top bud with earth. Where the winters are cold a thin layer of leaves may be added. Roots may form in four to six weeks. When one year old or less, the plants may be transplanted to the place where they are to remain. Roses like good soil, and the ground around them ought each year to receive a coating of manure, which serves as fertilizer and a mulch. On sour soils a little lime is helpful.

There are a number of classes of roses, some blooming almost continuously and others only once or twice during the year.

Bulbs, tubers, etc. - The onion and the lily are examples of bulbs. A bulb consists of a number of thickened, tightly wrapped leaves. Bulbs that grow form new bulbs, and by planting these the plant is multiplied. Plants grown from bulbs need rich soil. Most of them afford very early flowers. In cold climates bulbs are dug, dried, and stored indoors during the winter. 
The canna affords a wealth of blooms - red, pink, yellow, and other gay colors - during the heat of summer. It is increased by planting portions of the roots. In the Gulf states no winter protection is needed except to cut off the tops as soon as frost occurs and to place these over the roots, covering all with a light coat of earth. Violets for winter and early spring, and hardy chrysanthemums for late fall flowering, are increased by dividing the roots of old clusters of plants.

Flowers easily grown from seed. - Most of these are annual plants, living less than one year. Some are longerlived, for example, the foxglove, the hollyhock, and the larkspur.

The California poppy is a fine-leaved plant, with large, brilliant flowers. The seeds of this plant, and also of the common poppies, are sown as soon as danger of severe freezes is past. At the same time the seeds of pinks or carnations are sown.

The sweet zilliam is closely related to the pink. The flowers are showy and beautiful. The plant is rather hardy towards heat.

The annual phloxes are among the best flowers for children to grow, because they afford such a mass of varied and bright colors so soon after the seeds are sown in early spring. They need good soil and abundance of water.

Pansies are general favorites for early flowers. They combine two or more rich colors in the same flower. Among the most beautiful of all are the shades of purple. The pansy, and, indeed, most of these very early annuals, can be sown in boxes indoors (Fig. I30), and transplanted to 
the flower garden as soon as freezing has ceased. Pansies, like sweet peas, are cool-weather bloomers; both require moist soil and are unable to withstand much heat.

Verbenas are the favorite flowers of many children and of many grown people as well. They grow either from seed or cuttings. There are few more beautiful sights in

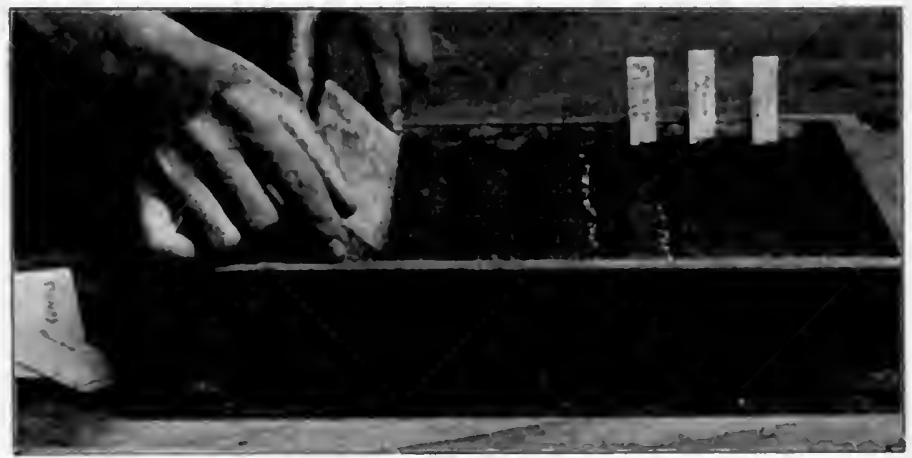

Courtesy Minn. Expt. Station

Fig. 130. - One Method of planting Syall Seed in Boxes

the flower garden than a border thickly bedecked with the purple and crimson or other various colors of the verbena.

Among the annuals most able to continue blooming during the heat of summer are the petunia and the nasturtium. There are both dwarf and climbing nasturtiums, all having large, bright flowers. The seeds of petunias are so small that, like many other flower seeds, they need either the shallowest possible covering, or none. A good way to plant such seeds is to sow them, and then with a board press them against the surface; sprinkle over them the thinnest possible layer of very fine sifted forest soil. This holds moisture and does not easily form a crust. 
Among the plants that do not need to be sown until the weather becomes warm are the marigolds and cosmos. Their blooms are wanted in late summer and fall, after most flowers have ceased blooming. Scarlet sage is also one of the most brilliant of the autumn flowering plants, its tall stems being crowded with bright red flowers. Hollyhocks are tall plants grown from seed, but not showing their large, gaudy flowers until the second year.

Window gardens. - Many persons who have not room for an outdoor flower garden find pleasure in a little window garden. The flowers may be grown in pots or boxes, inside a sunny window or on a shelf outside (Fig. I3I). Most of the smaller outdoor flowering plants may be thus grown from seeds, bulbs, roots, and cuttings, and in addition, many less hardy plants, such as begonias, crab cactus, and geraniums. To start geraniums or other softwood cuttings, place the lower portions of the cuttings in clean sand kept constantly wet, and in a sunny window. If necessary, a pane of glass can be placed over them to retain the heat, and thus make a tiny greenhouse.

EXERCISE. - Ask some grower of flowers whether the present is a suitable time to start cuttings of roses and other flowers. If so, make some cuttings and set them. Ask at home or at some neighbor's if there is any flower from which you can get a start of bulbs, roots, or cuttings. Before using them make sure they are free from disease or insect injury. Write in your notebook a list of five of your favorite flowers.

Note to THE TEACHER. - Catalogues are sent free by most seedsmen. The illustrations in them and their descriptions of varieties will be of greatest service to you in enlisting the pupil's interest in flowers. An especially helpful publication is Farmers' Bulletin No. 195, United States Department of Agriculture on Annual Flowering Plants. If not already obtained, write to the United States Department of Agriculture for bul- 
letins on school gardens, and consider whether your school can longer afford to do without one. See also note to Section XXXII and Appendix. In city schools or elsewhere, boxes of flowers in the windows serve a useful purpose. Let the main aim be to make the pupils closer observers and more appreciative of flowers. Urge them to bring flowers to the class now and later to be used as object lessons. Familiarize the pupils with the foliage as well as with the blooms of the flowers that can be inspected. Is an excursion to some greenhouse or flower pit practicable?

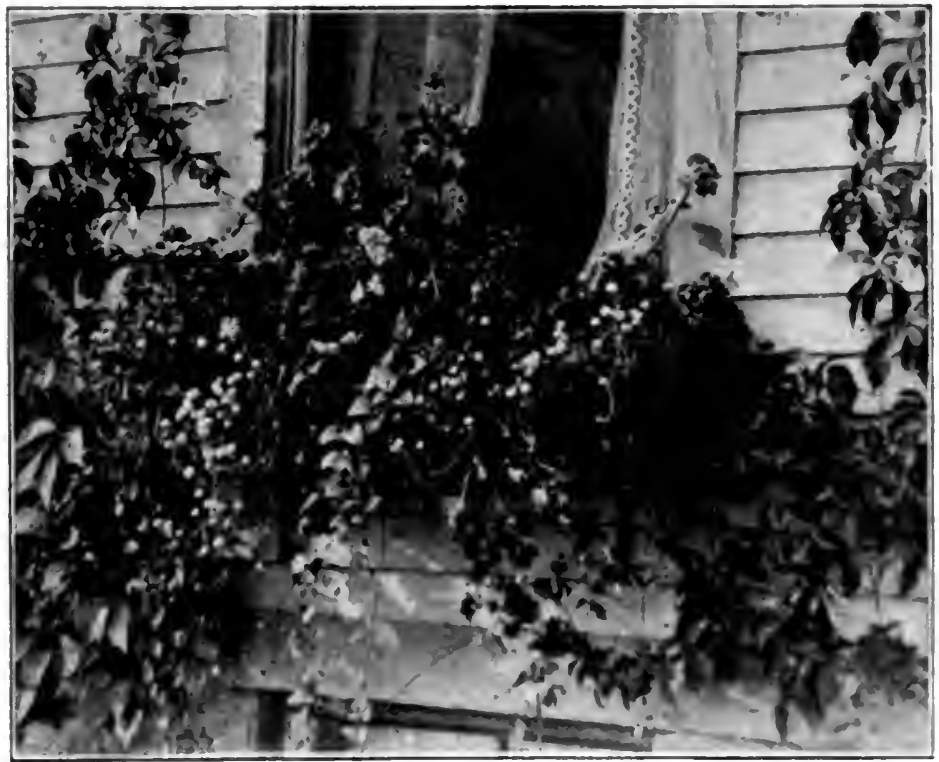

FIC. I31.-A WindoW-Box GARDEN 


\section{SECTION XXXV. FOREST TREES •}

THE true value of trees is scarcely realized until we consider the sufferings of people who live in countries that are almost without trees. Parts of India, Egypt, China, and Korea are in this treeless condition. In winter the people suffer intensely from cold and have to work very hard to supply themselves with even a little fuel. A day's hard work may be rewarded with only a basket of the roots of shrubs. Every bit of refuse in the streets and stables is collected and dried for fuel.

Rapid destruction of the forest. - Our own country is in danger of becoming a country that will lack trees enough to furnish lumber for our homes and to supply our factories. Those who have studied the matter state that in the United States each year three times as much wood is cousumed as is supplied by one year's growth of all the trees in the country. Some even declare that unless this waste is promptly stopped, in twenty-five years there will be practically no forests east of the Mississippi River. This misfortune can be prevented by every one's quickly realizing the true value of a tree. There is no time to be lost, for it takes most kinds of trees 50 to 100 years to grow large enough to make the best lumber.

The tree lives longer than any other form of vegetable 
life. It is the patriarch among plants. The life of a young tree ought not to be taken except for good cause. The farmer who makes firewood out of saplings is destroying the property of his children. When trees mature or reach the point where their growth is very slow, they should be cut and used, so that they may yield a profit and make room for younger and more rapid-growing trees. Saplings or young trees should be removed only where the growth is too thick.

Forest fires. - The long-leaf or yellow pine tree may be six years old before it becomes one foot high. A single fire,

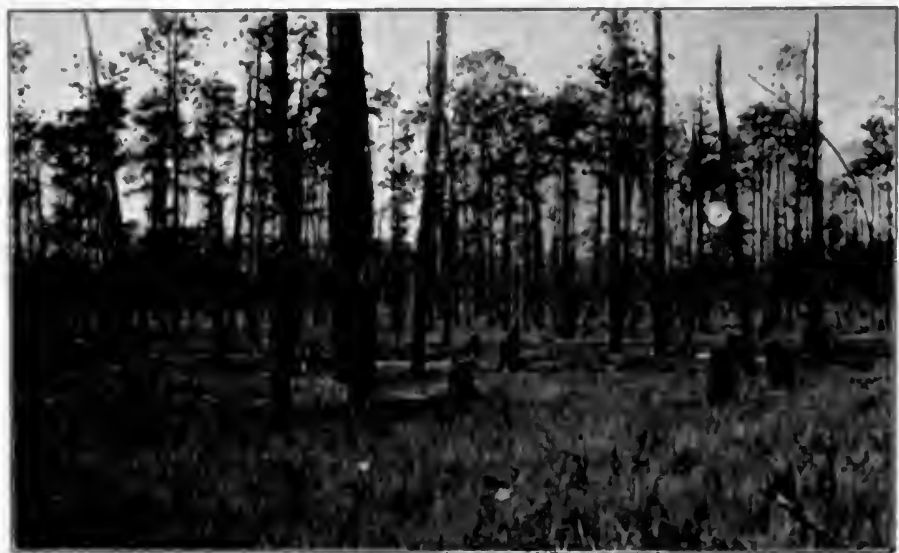

Courtesy Foreat Service, U. 8. Ilept. Agr.

Fig. 132. - Destructive Effects of Fire in a Forest of Losg-leay Pine

started by some careless hunter or other thoughtless person "to burn off the grass," may kill a thousand of these and other valuable kinds of trees on every acre that it invades (Fig. 132). Besides this, fires make the soil of 
the forest poorer by destroying the vegetable matter and thus retard the growth of the surviving trees. The old method of boxing young pine trees in order to make turpentine (as in Fig. I33) causes them to catch fire more easily than they otherwise would. The new method of collecting sap for turpentine, using cups and metal gutters, is much better for the tree (Fig. 134).

Uses of forests. - Forests not only furnish lumber, material for paper, and scores of useful articles, but they decrease floods. When rain falls on the soil of a forest that has never been burnt over, it sinks into the mellow soil and slowly drains away to the creeks, which carry off the water without overflowing. When the trees are cut, the surface loses its layer

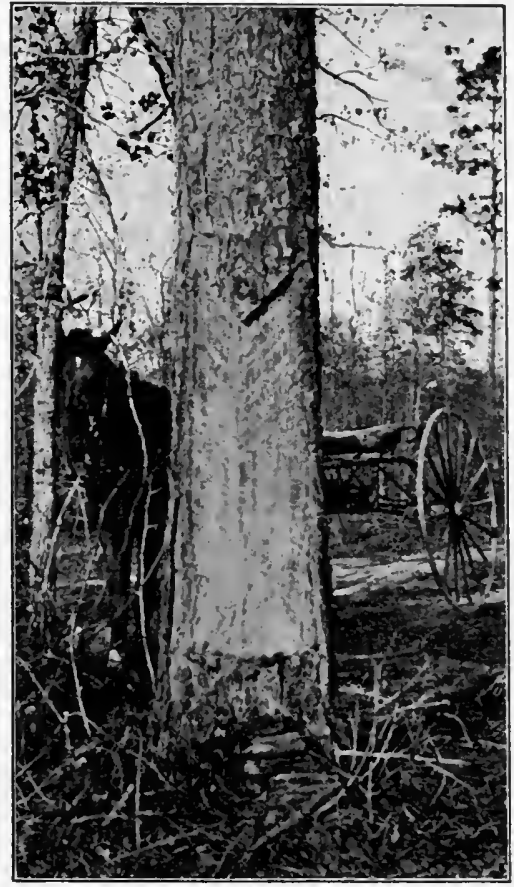

Fig. 133. - The Old Method of boxing Pine Trees for TURPentine of leaves and becomes hard, so that when heavy rains occur, the water rushes rapidly down the slope, washes sand and soil into the creeks, and overflows the bottom lands. 


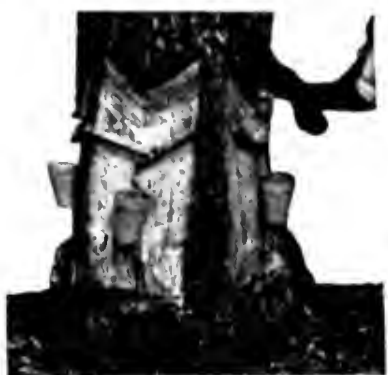

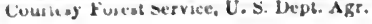

Fic, 13 4 - - THE CUP AND GUtTER

SYSTRM OF hoxing l'INE T'ReEs FOR 'TURPF.STRE

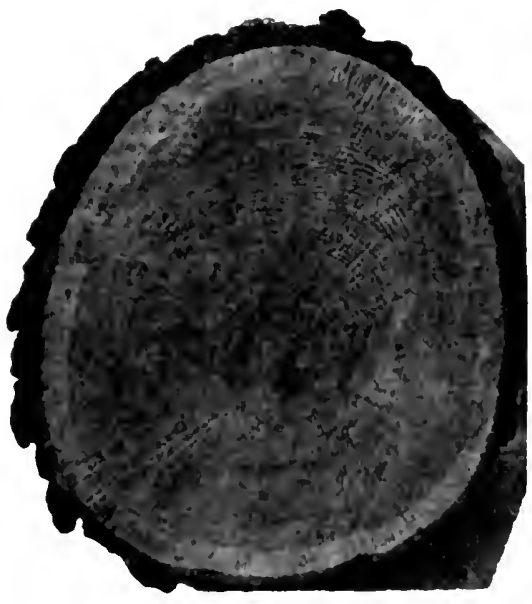

After Forest Service, I', S I Jept. Agr.

Fig. 135. - A Cross-SpCTION OF AN UAK L.og, showise Avvedi. Rivgs

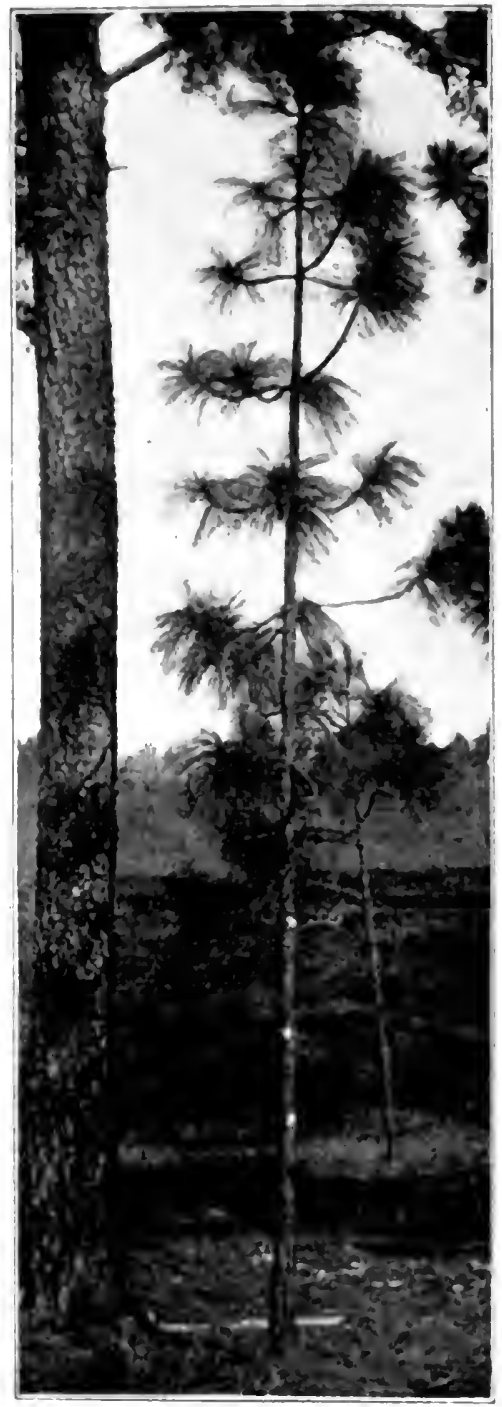

Mooso by tuncan

FIG. 136. - A Yot.Ne I ONG-1.AP I'INE

The sets of branches indicate the age of the top 
Telling the age of a tree. - The age of a tree may be discovered by examining the log or the stump left after it has been felled. On the smoothly cut end of the log there are a number of light-colored rings with layers of darker color between (Fig. I35). Gencrally one lightcolored ring and one dark-colored layer were formed each year. The number of light rings tells in years the age of that part of the body of the tree. The age of each limb is told in the same way.

There is another way to tell how long it has been since the pine and some other trees were only as high as their lowest limbs now are. This is done by counting the number of sets of limbs or sets of knots where limbs once grew. Every set of limbs, growing out of the trunk at about the same place, means one year; for each set represents the buds or young branches which form on the twig near the place where the new and the old growth join (Fig. 136).

EXERCISE. - Report to the teacher the age of the following by counting the annual rings: (I) a log, or stump, or piece of firewood, all from an old-field pine, (2) a similar piece from a long-leaf pine, (3) a branch of either old-field or long-leaf pine. Which has the thicker annual rings? Judging by this, which tree grows more rapidly? Select a pine tree to to 20 feet high and, without cutting it, count the sets of limbs and tell how long it has been since that tree was only as high as its lowest limb now is. Think about this subject for your next composition, "How Much Harm One Forest Fire Did." Is the heartwood or the sapwood the best for lumber? 


\section{SECTION XXXVI. FOREST TREES (Continued)}

If a wire is stapled to a tree, it will not be pushed outwards as the tree grows larger, but will be buried under the new layer of wood (Fig. I37). It thus cuts into and injures the lumber. Fig. 138 shows a better way to attach a fence wire to a tree.

Planting trees on the school grounds. - When the school ground needs shade and beauty, plant trees and pretty shrubs taken from the woods. Set aside one day as "Arbor Day" for the planting of these trees. In the Southern states a good time for this is in December, January, and February. Plan what kinds of trees and shrubs to plant and where to put every one in order to make the school grounds as beautiful as possible. They will live better if not planted on the playground, where the shaking will dry the roots. If planted there, they should be protected by strong stakes until the trees are several years old. The directions given in Section XXXVII for setting fruit trees will help in setting shade trees.

Choose some of the following for planting on the school grounds : the water or willow-leaved oak as a round-topped shade tree, suited even to poor, dry .soils; the sweet gum, for its rapid growth, graceful shape, its willingness to grow on almost any soil, and for its red and purple leaves in autumn; the mulberry for its rapid growth, good 
shade, and sweet fruits; the elm for its rapid growth, great size, and graceful shape; the hackberry for its ability to grow on stiff, wet soils; the black gum for its thick

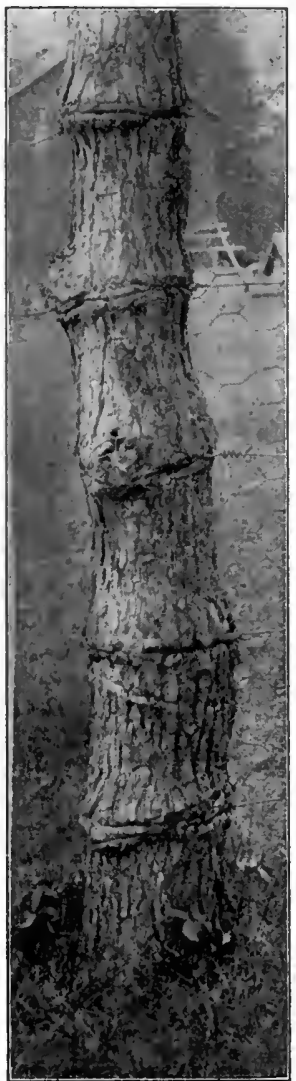

Fig. I 37.- The Wrong Method of attaching Fence Wire to A TREE

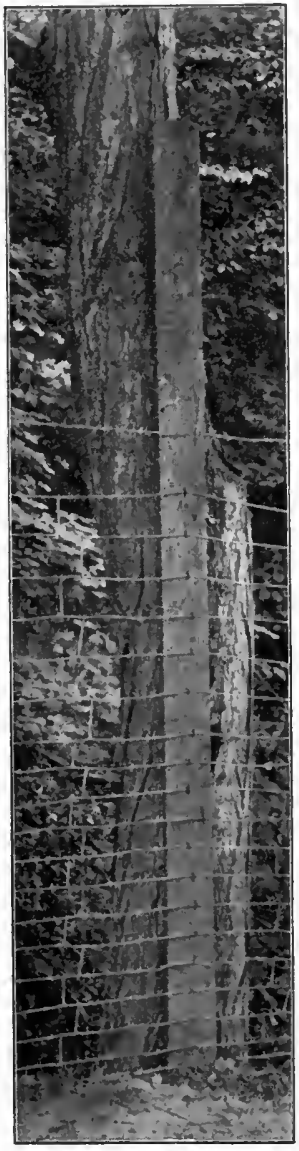

Frg. I38. - The Proper Method of ATtACHINg Fence Wire 


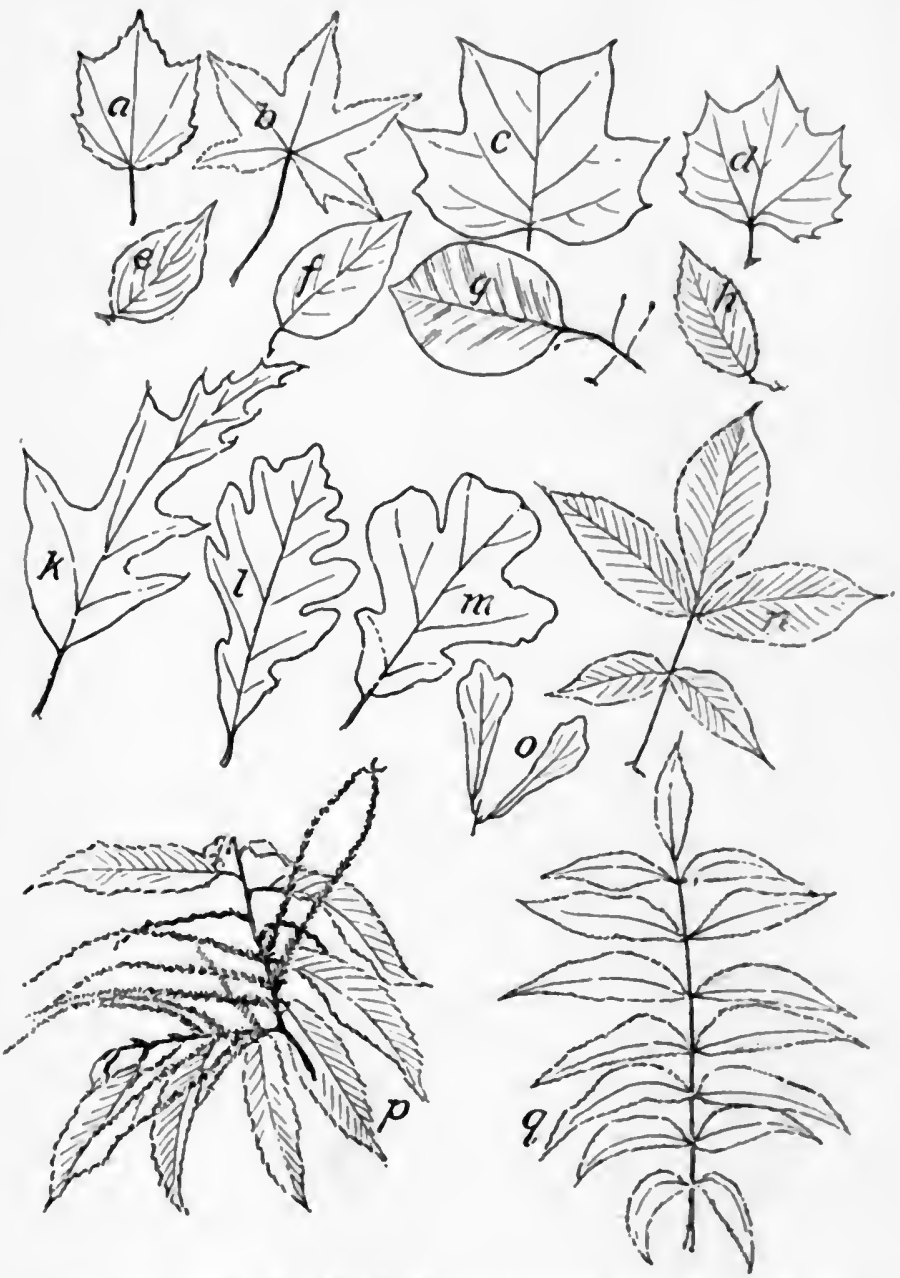

Fig. 339. - Find n the Arove Figures the Following leaves

White oak, hickory, pecan, red oak, black gum, sweet gum, chinquepin, water oak, sycamore, maple, "yellow poplas" (tulip tree), dogwood, elm, jersimmon, post oak. 
rounded top and the beautiful color of its leaves in autumn; the red maple for its red flowers and seeds and its brightly colored leaves in the fall. These trees and many other

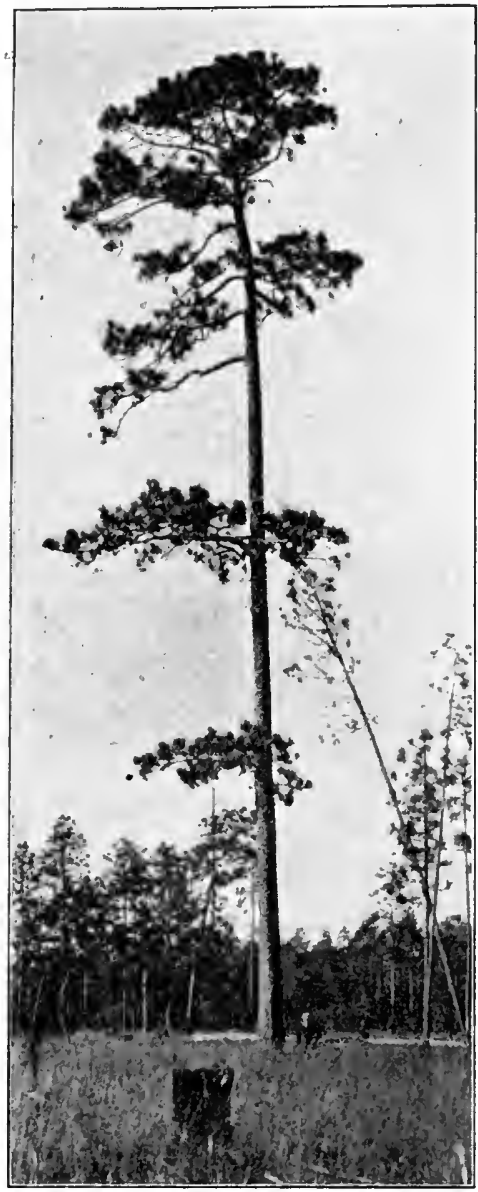

Fig. 140. - A Long-Leaf Pine

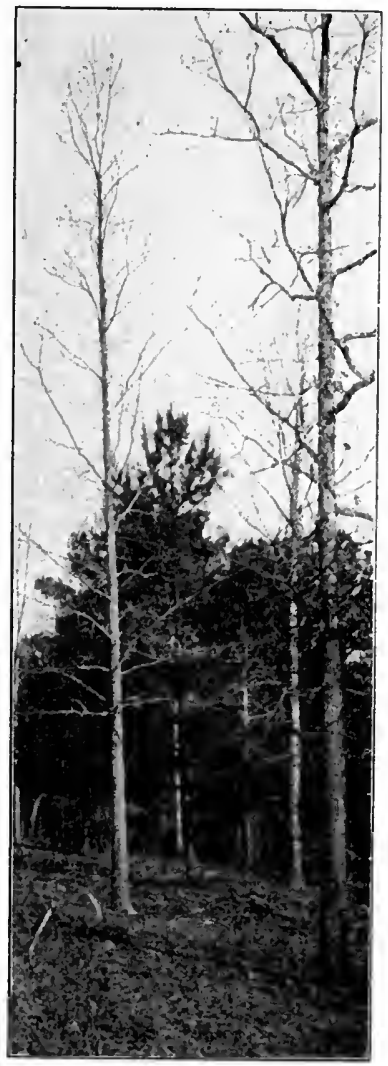

FIG. I4I. - YOUNG HICKORIES 
kinds may so change the school yard that it will become one of the most attractive spots in the neighborhood.

Trees for posts and other farm uses. - In planting young trees on the farm for fence posts choose between

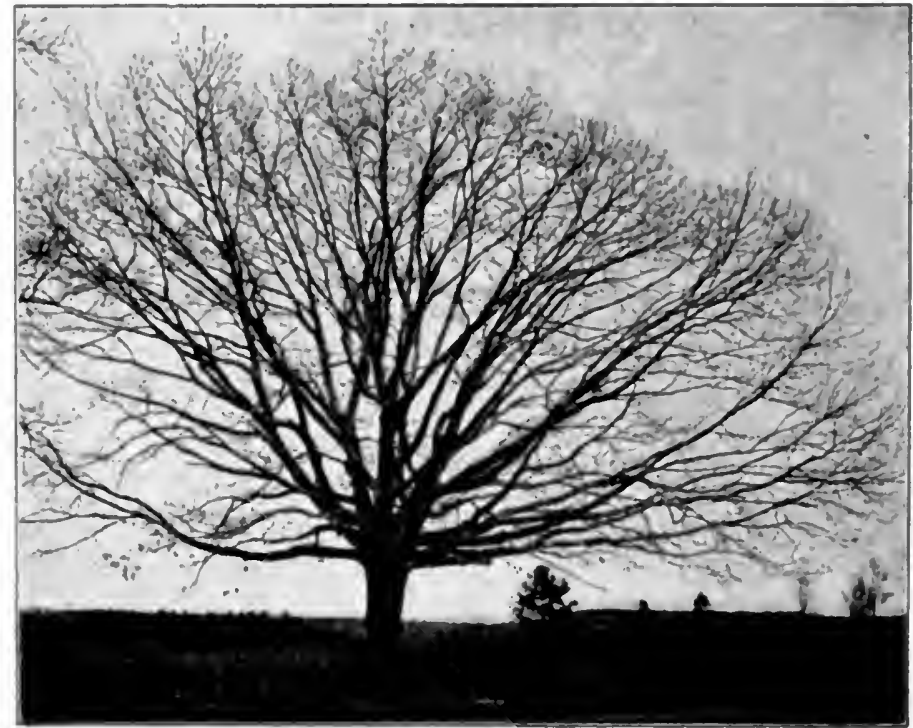

Fig. I $\$ 2 .-$ Showing Spreading Form of SOME OAKS When Not crowded

catalpa, black locust, osage orange, and mulberry. Posts made from these trees last for a long time. Cedar makes excellent posts and is very valuable for making pencils. It grows slowly and should not be set out on a farm where apples are grown. The wood of the walnut is very valuable for furniture. To make shade quickly in the pastures, where beauty is not important, the cottonwood, chinaberry, and catalpa are suitable. 
The trees as friends. - To get all the pleasure possible out of life in the country, know and love the trees. Know

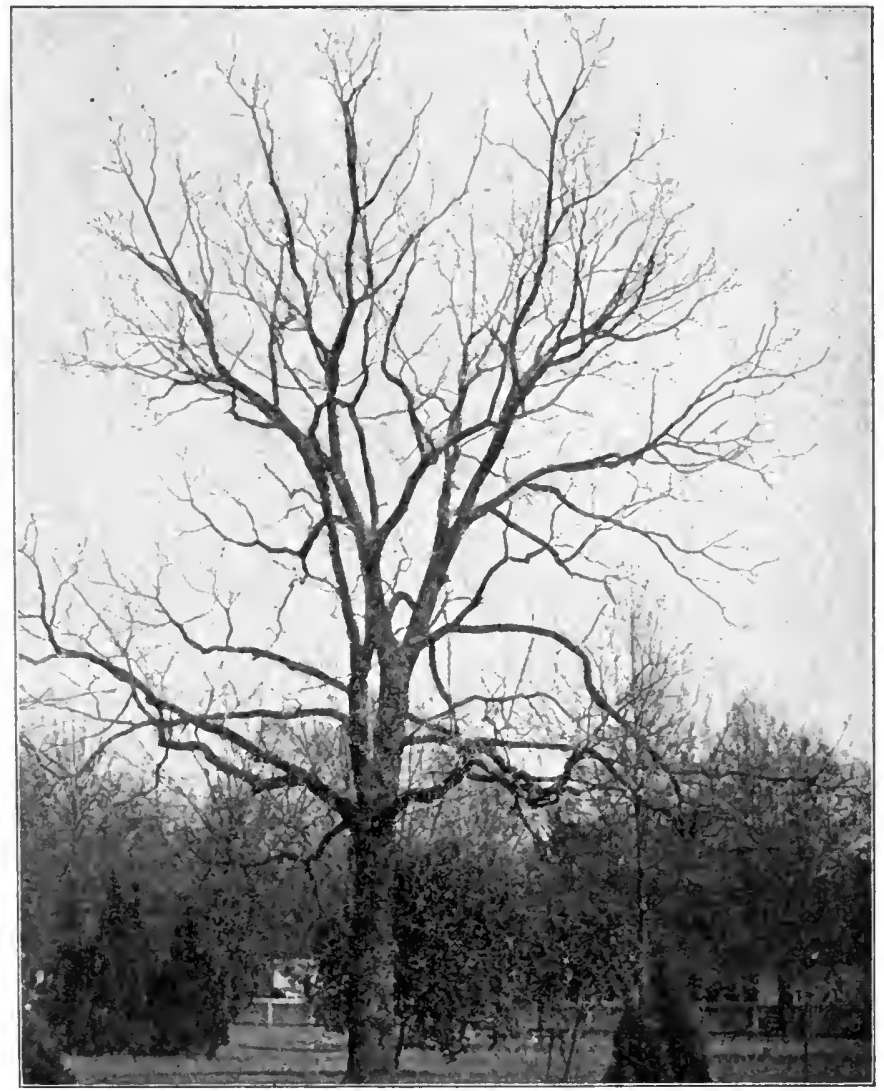

Fig. 143.-A Walnut Tree

them by their leaves (Fig. I39), their branches, their bark, and their seeds. Notice which kinds are found on the dry 
hills and which in the wet bottoms. Observe how they struggle up toward the light. Notice the difference in the forms of those that stand alone, flooded with sunshine (Fig. 142), and those starved for light in the deep shadow of the crowded forest. Even in winter the trees are interesting. The different trees may be recognized in the distance by the differences in their habits of branching. For example, notice the continuous central stem in the pine and hickory (Figs. 140 and 141 ), and observe that in the walnut (Fig. 143) and elm this is usually lost.

EXERcise. - Compare the leaves in Fig. 139 with the leaves found in the woods, and write in your notebook the name that corresponds to each letter. You will find it interesting and instructive to make a map of the trees growing on a small area of woodland, representing the position of each tree by a figure on the map; then on the next page of your notebook write the name of the tree corresponding to each number. You may be surprised to find which pupil knows the greatest number of trees in such a contest.

Note to the TEACHER. - Strive to inculcate in the pupils the habit of carefully observing trees. Among the means to this end are the collecting and identifying of the leaves of trees, excursions to the woods, and recognition of trees by their bark. The mode of branching of different kinds and with different surroundings may be taught by requiring pupils to draw outlines of trees. A drawing exercise may take the place of a recitation. Let the pupils complete the maps of the school grounds begun as an exercise in Section XXXIII and write on it, on each spot where a tree is needed, the kind of tree that each pupil prefers. 


\section{SECTION XXXVII. FRUITS}

IT is possible to have a constant succession of fruit at very little expense by taking the best possible care of a few rows of strawberries, grapes, and a small orchard of

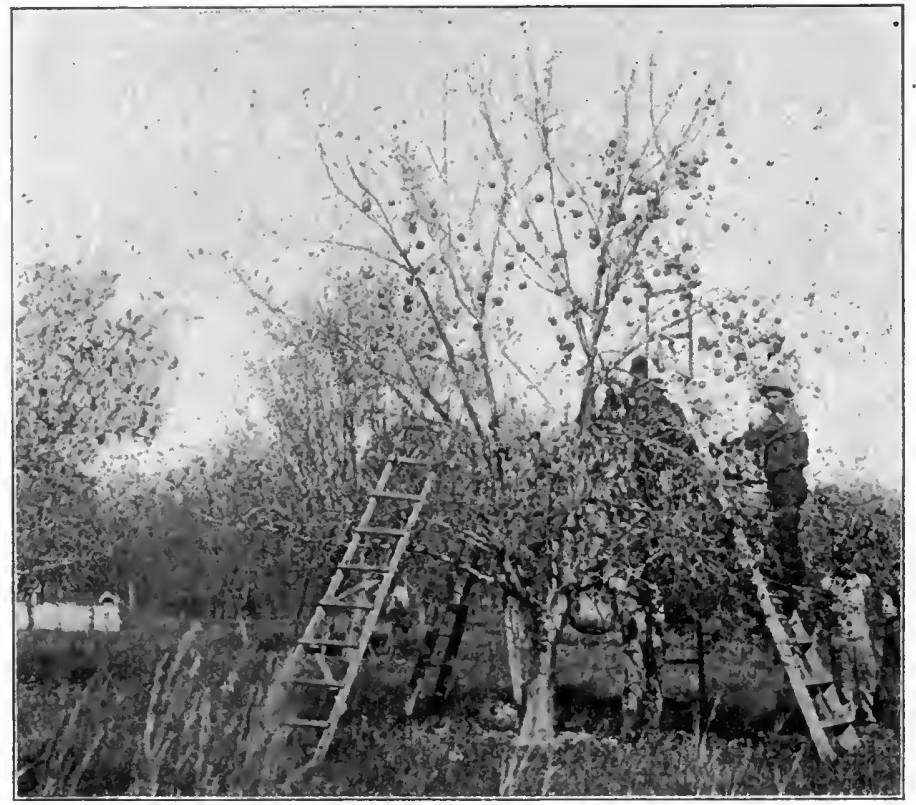

Fig. 144. - Picking Apples in Arkansas

fruit trees. In the collection of fruits there could be strawberries, raspberries, grapes, scuppernong grapes, peaches, plums, apples, pears, Japanese persimmons, 
pomegranates, and pecans. It costs but little to buy the trees and other plants needed. Make selections from the catalogues of reliable nurserymen, not too far away.

For success in fruit growing there must be (I) wise selection of suitable varieties, (2) careful planting, (3) regular

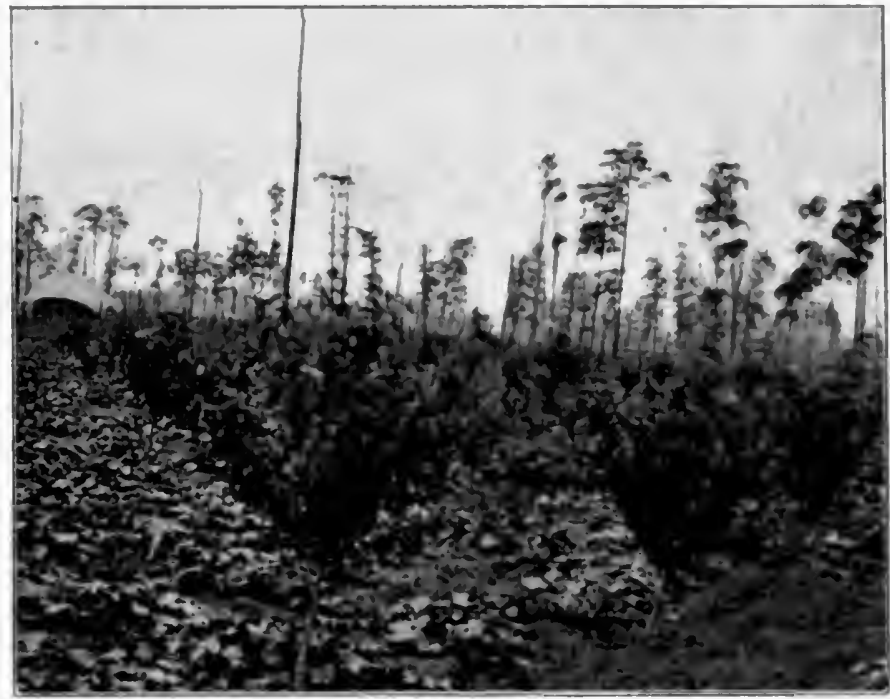

Photugraph by K. \$. Mackintoch

Fig. 145. - Young Peach Orchard witu Cucumbers between the Rows

and intelligent pruning, (4) cultivation and fertilization, and (5) spraying to destroy injurious insects and plant diseases. A small orchard for home use should contain a number of varieties, so that there may be early, medium, and late fruit.

Cultivation and fertilization. - Before planting fruit trees the land must be deeply plowed and well harrowed. Peach trees are generally set about 16 feet apart each 
way and apple trees 25 to 40 feet. On rather poor land fruit trees ought to be fertilized when set and each year afterwards. For young trees a complete fertilizer is best. In later years a mixture of phosphate and some form of potash may be sufficient. Nitrogen should then be supplied by cowpeas or some other "catch crop" grown as a fertilizer between the trees. Scatter the fertilizer as far out as the limbs extend and work it in with a cultivator or harrow. For a few years a low-growing, cultivated crop, for example, cotton or vegetables, may be grown between the rows of trees (Fig. 145). When, however, the trees get

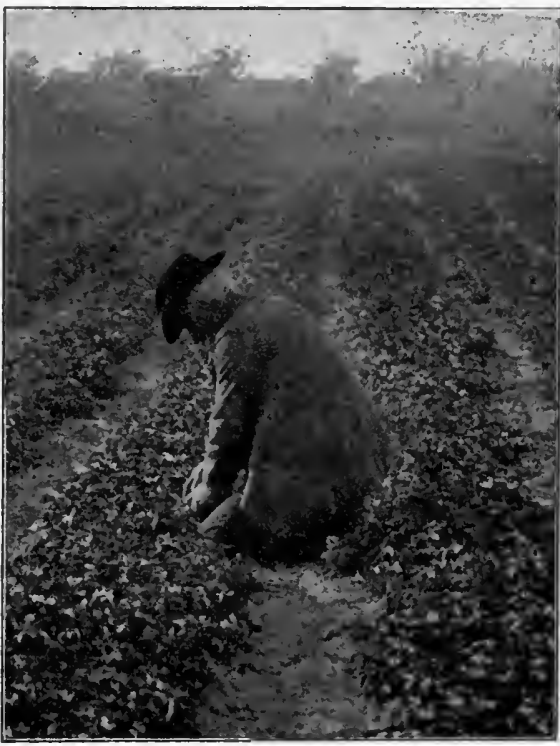

Photograph by R. S. Mackintosh Fig. 146. - A Field of Strawberries in SoutheRN Alabama larger, they need all the space; and the orchard should be kept well cultivated until July, when Iron cowpeas may be sown as a fertilizing crop to be plowed under the next spring.

Strawberries. - The strawberry is the earliest fruit, some varieties ripening in April in the central part of the 
Gulf states. Strawberry plants are increased by means of runners which take root near the end. These rooted

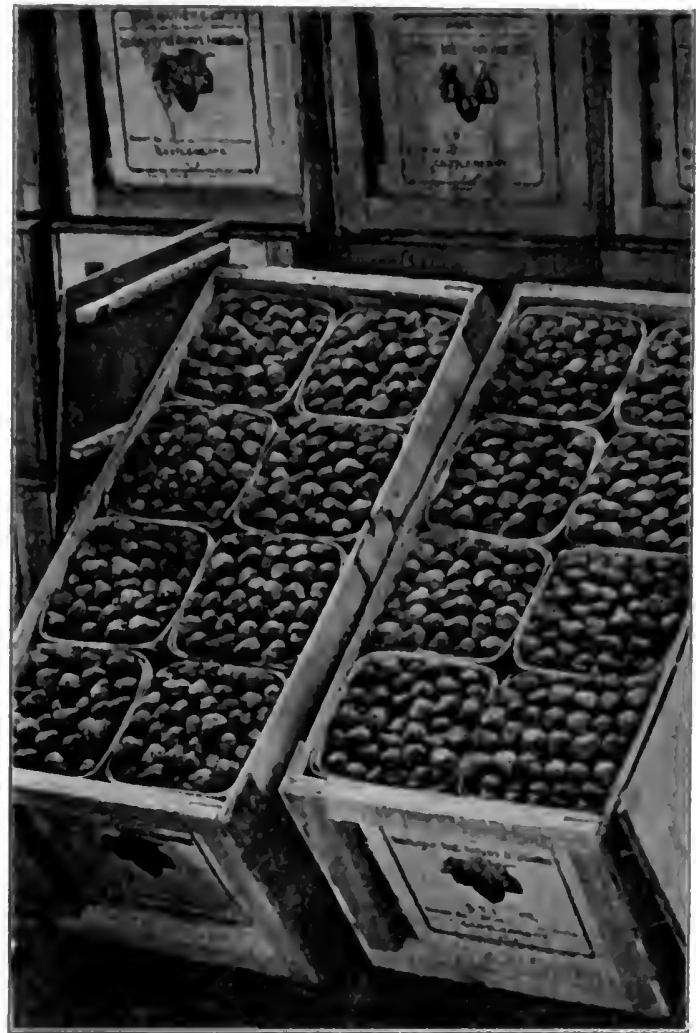

Photograph by $\mathrm{K}$ S. Mackiutouh

Fig. 147 - - Strawberries crated for Surping

young plants are set about two feet apart, in rows about three feet apart. They may be set in the Southern states any time between November and the last of February. Those set after Christmas make only a few berries the 
first year. Those set in the fall bear a few more berries, but there is only a fraction of a crop the first spring. The main crop is borne the second year.

Some varieties of strawberries produce flowers containing pistils, but no perfect stamens. Among these imperfect or pistiliate varieties, every third or fourth row should be planted with perfect kinds to furnish pollen. Perfect varieties are marked in most catalogues with the letter " $s$," meaning that the variety bears stamens as well as pistils, or by the letter " $b$," meaning bi-sexual, or having two sexes. The names of the imperfect varieties are followed by the letter " $p$," which here stands for the word "pistillate." For home use there should be both early and late varieties. The following are all among the staminate or perfect varieties: Excelsior (early), Lady Thompson and Klondike (rather early and hardy), Gandy (large and late).

Strawberry plants need to be well fertilized with a complete fertilizer. The bed should be renewed every few years because young plants bear more fruit than old ones. To start'a new bed set the young plants that form where the runners take root.

When a fruit tree is old enough to transplant. - A nurseryman does not count the age of a tree from the time the seed is planted, but from the time of budding or grafting it. Peach trees are ready to transplant one year after the budding has been done. The apple tree is transplanted when either one, two, or three years old.

Setting a fruit tree. - The time to set a fruit tree is after the leaves fall and before the buds swell in the 
spring to form new leaves. The period from November to February is the usual time for setting fruit trees in the Southern states. The holes should be so dug that the

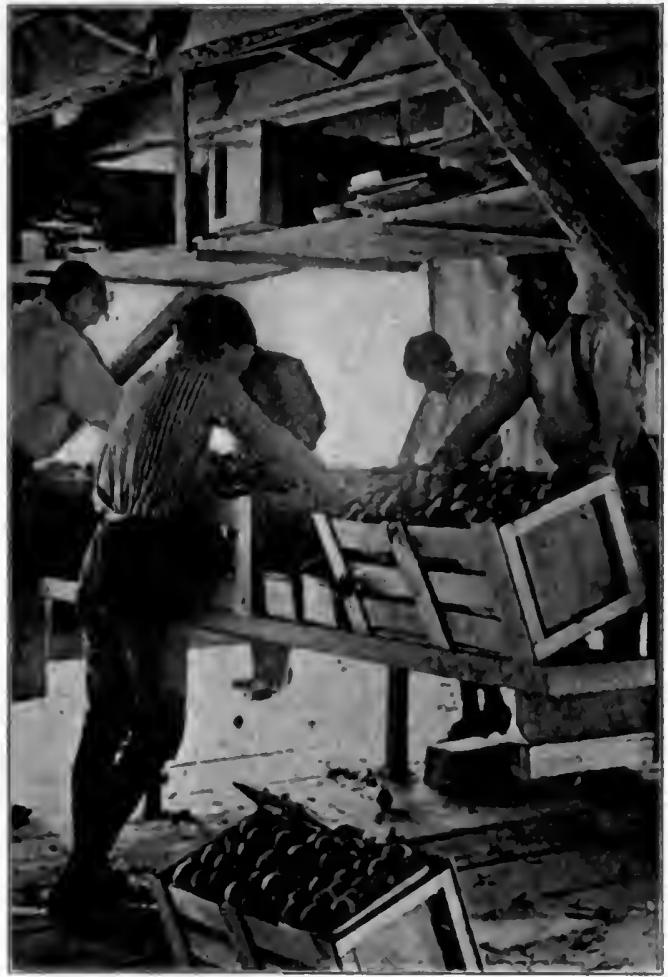

Photograph by R. S. Mackintouh

Fig. 148. - Packing Peaches in Bullock County, Ala.

roots will not need to be bent. All bruised or broken roots should be cut off with a smooth cut, which heals more quickly than a ragged break. 
The very long roots may also be cut back. In setting trees keep all roots straight. The earth taken from near the top of the hole is generally the richest; so this soil should be placed near the roots. The earth must be firmly packed around the roots so as to keep them thoroughly moist. If the soil were put in without packing, air-spaces would be left and the roots would become dry. The upper layer of soil, however, must be left loose as a mulch to retain the water in the lower layers. If a tree is loosened before it has formed a full set of roots, it is apt to die because the shaking causes air-spaces to be left around the roots instead of moist soil. The tree ought to be set in the ground at least as deep as it grew in the nursery row.

Pruning at the time of transplanting. - When a young tree is dug up, a large proportion of its fine roots and root-hairs are broken or stripped off. When it is transplanted, there will not be at first enough feeding roots to supply food and water to all the leaves. The top of the tree should, therefore, be cut back to balance the loss of roots. The cutting off of some of the limbs is called pruning. Most fruit trees at the time of transplanting have to be severely pruned in order (I) to keep the leaf surface balanced with the feeding roots, and (2) to cause the tree to grow in the desired shape.

Shaping the young tree.-When young apple and peach trees are not pruned the central shoot grows more rapidly than the side branches. This forms a tall, slender tree, with few limbs, which bend and break when heavily loaded with fruit. Much of the fruit on unpruned trees is borne too high to be easily gathered. To prevent these troubles, 
the young apple or peach tree is cut off at a height of 16 to 24 inches above the ground. The cutting of the central shoot makes the side branches grow more rapidly and nearer to the ground. The lower limbs should be close to the ground in order to shade the body or trunk.

If the tree is very young and small when transplanted, all the side branches are also cut off close to the main stem (Fig. 149). The buds near the top of this stub or

Fig. 149. - Crose whip will soon grow out and Prunivg take the places of the side branches that were cut off. The number of

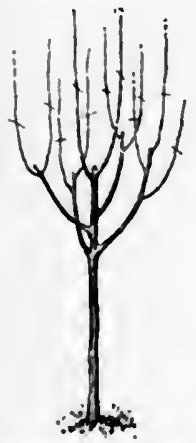

FIG. 151. - ONE YEAR AFTER SETTING

To be pruned as shown by the marks. limbs can be controlled by rubbing off all the buds except the number desired. In pruning a young tree, three,

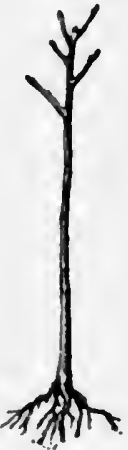
four, or five of these buds Fig. 150.-StuB should be allowed to grow Prunisg into limbs. The buds selected to grow should be evenly distributed around the stem. If the young tree is well grown when transplanted, its branches are cut off six to eight inches from the main stem (Fig. 150).

Later pruning. - The usual time to prune fruit trees is during the latter part of the winter. After the transplanted trees have been growing for about one year in the orchard, they usually need to be pruned again. All of the 
three to five side branches already selected for growth should be cut back until only about eight to twelve inches of their new growth is left (Fig. I 5I). At the end of each year the new peach twigs, if they have made much growth, will need to be cut back to about half their length. Every winter cut out from any kind of fruit tree all the branches that are partly broken, too close together, or growing across the center of the tree, and all twigs that are diseased.

The later pruning of trees is chiefly (1) to regulate the shape, (2) to make the center of the tree open enough to admit the light, and (3) to thin the fruit. Wherever a branch is removed, the cut surface must be left smooth and as close to the parent branch as possible. No projection or stub must be left. A smooth, close wound is soon healed and covered over; but a stub is not easily covered, and decay starts in such a wound (Fig. I 52). When a large branch is cut off, the wound should be covered with thick white lead paint, to keep the germs of decay from getting into the tree.

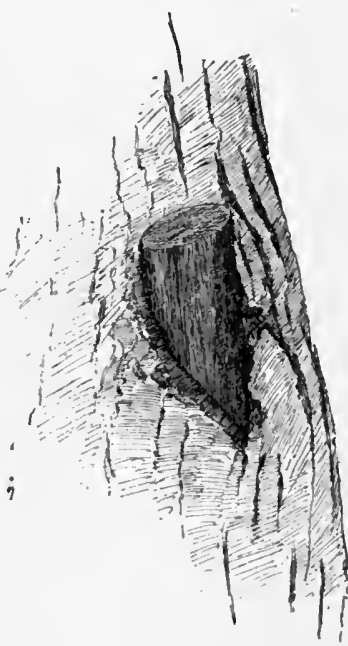

Fig. 152. - Poor Pruning

In pruning a fruit tree the bud left farthest out on the branch is the one that will grow most rapidly and become the leader. The limbs can be made to bend downward more than they naturally would by making the cut just beyond a bud which points downward. Likewise the growth can be 
made more upright by cutting so as to leave as the last remaining bud one that points upward (Fig. 153). In the

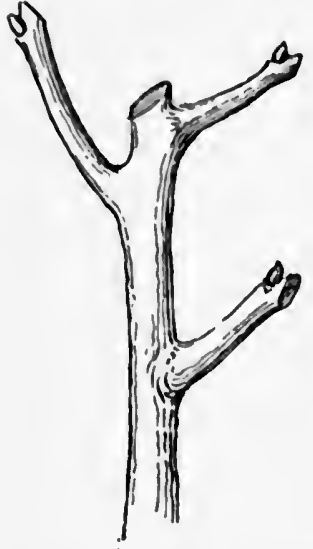

Fig. 153. - Prunivg To DIRECT TIIE GROWTH

On right, pruned for upward growth; on left, pruned for outward growth. same way you can often fill in an unoccupied space on one side of a tree by selecting for leaders the buds that point towards that space.

Fruits that most need pruning. Peach trees, grapevines, raspberries, and cultivated blackberries need pruning every year. Apple trees need less after the first few years, and shade and nut trees require very little pruning.

Exercise. - Perhaps you can find a young peach tree growing wild and can practice pruning on this. Ask some one at home to show you how to prune the trees and graperines in the home orchard. Ask why they prune in a certain way; also when they prune, and why.

Note to the. Teacher. - If there is near the school a carefully pruned orchard, it may be well worth an excursion to see it, and doubtless its owner will give an exhibition of pruning. Farmers' Bulletin No. 181 of the United States Department of Agriculture, on pruning, will be useful to the teacher and to any pupils who desire to improve the orchard at home. 


\section{SECTION XXXVIII. THE CAUSES OF DISEASES OF PLANTS ${ }^{1}$}

Most plants have a green color and thrive in the light. Certain very' small plants, called fŭn'gìi, however, have no green color. Among them are the tiny plants that cause rotting of fruit, spotting and dying of leaves, rust, and smut of grain. Since they have no green substance enabling them to use the carbon from the air, they cannot make their own living. Instead they draw their nourishment from the sap and substances already made by green plants. Therefore they rob the plants on which they grow and cause various diseases, which may affect the leaves, stems, or fruits of useful plants.

Molds. - Among the fungi are certain molds. Fruit mold, or bread mold, is made up of a mass of fine white threads, some of the short branches of which bear tiny black heads. These contain the spores, dust-like bodies from which another crop of fungi grows. Spores are to fungi what seeds are to plants. The spores of mold and of most fungi are so small and light that they are blown everywhere by the wind. This explains why plant diseases are so "catching," or contagious.

Some fungi cannot grow through the skin of fruits, but need to have their spores planted in cuts or bruises. Other kinds are able to force their way through the skin. Very often they push in through the "gateways" or

${ }^{1}$ The five sections on plant diseases were written by Dr. B. M. Duggar of the faculty of Cornell University. 
pores in the leares of plants. Once inside the fruit or leaf, they nrow and nourish themselves by absorb-

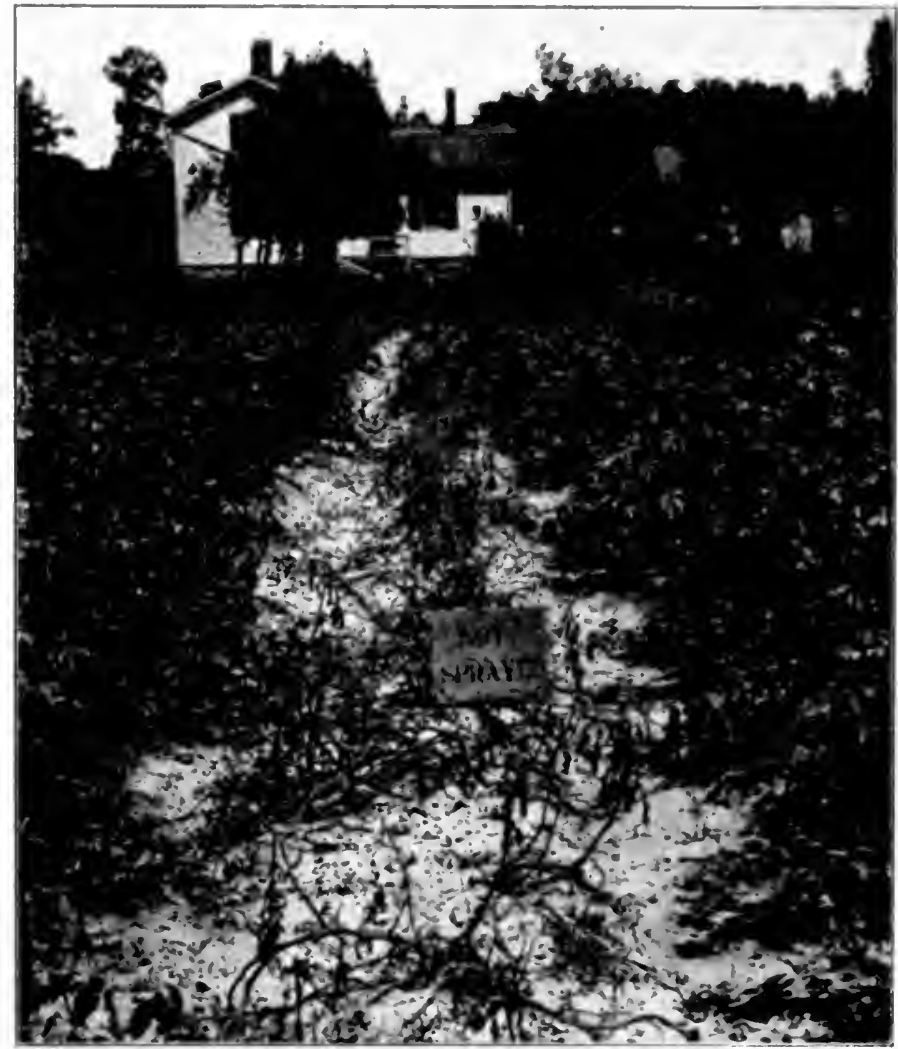

Fig. 154- - Resctits of Spraytivg for I.ate: Blight of Irish Potatoes The plants in the center were not sprayed; those on both sides were sprayed. ing the food material formed by the green plant. They steal the food which the plant had prepared for its own use. 
Killing fungi with poisons. - Fortunately the spores of most kinds of plant diseases will not grow in contact with certain substances. Two of the best of these chemicals used to destroy fungus spores are bluestone (copper sulfate) and formalin. The buds, the fruit, or the leaves are sprayed with a mixture containing bluestone. If this is done before the fungus plant has passed through the skin of the fruit, the crop is often saved. Seeds of oats from a smutty crop are dampened with formalin to kill the spores on the seed. The white mildew on the leaves of the rose is easily killed by sprinkling on it a solution of one ounce of liver of sulfur to two gallons of water.

Prevention of plant diseases easier than cure. - In most cases, however, it is useless to try to cure plant diseases by treatment after the fungi have entered the green plant, where no poisons can reach them. Spraying fruit trees is done to prevent, and not to cure, diseases. The poison generally used to ward off diseases of fruit trees, Irish potatoes, and others is Bordeaux mixture, which contains bluestone (see Appendix).

Weak plants become diseased. - Plants that are thrifty and well nourished are less apt to catch certain plant diseases than those that are weak, starved, or unwisely fertilized. There are many diseases of plants that are not due to germs. These are generally due to poor drainage or other unfavorable conditions of soil or climate. Such diseases are not contagious.

Fungous diseases spread rapidly because of the light spores, which are blown or carried great distances. Nearly all the peaches in an orchard may be ruined by rot 
during a few weeks of damp weather, which makes most germs of plant diseases grow more rapidly. No matter how damp the weather, there will be no peach-rot unless the spores or seed bodies are first sown. A few fungi are useful. Some kinds sour milk so that it can be churned into butter; others, called yeasts, cause flour bread to rise ; while still other kinds are necessary in making vinegar.

EXERCISE. - Secure some half-ripe sound peaches and place two or threc of these under tumblers. At the same time find one which is decayed and shows upon the surface tufts of a gray mold. Now with a pocket knife touch the mold tufts of the diseased fruit and make cuts in the healthy peaches. Wrap the scratched peaches in a damp newspaper and put them under a can or cup in a warm place. Do they rot?

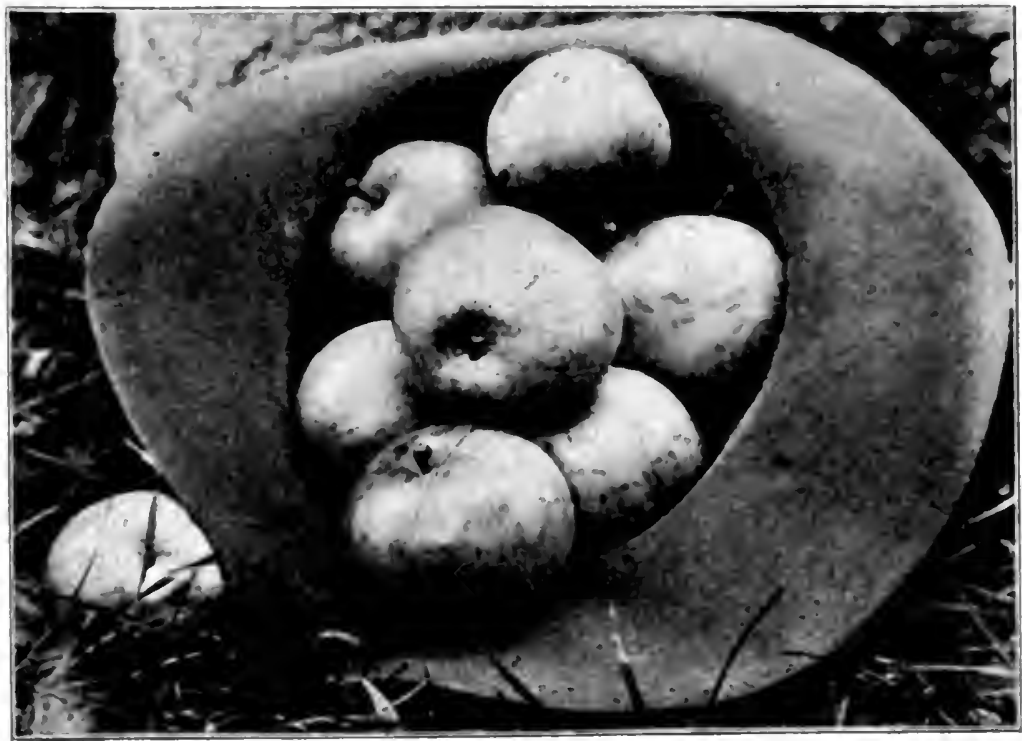

Fsg. 155. - Scabless Apples, the Resur.t of Thorougu Spraying 


\section{SECTION XXXIX. SOME DISEASES OF FRUITS}

ONE day a brown spot may appear on a fruit, and the next the whole fruit may be browned and decayed. Meantime there may appear on the surface numerous gray tufts of the mold-like fungus spores (Fig. 156). These light spores are carried by wind and insects to adjacent healthy fruits or even to fruits of distant trees.

Brown-rot. - The spores spread the disease, and during a week of sultry weather the peach crop may be ruined by this disease, called brown-rot.

With age a diseased fruit shrivels and becomes what is termed a "mummy." These mummies hang on

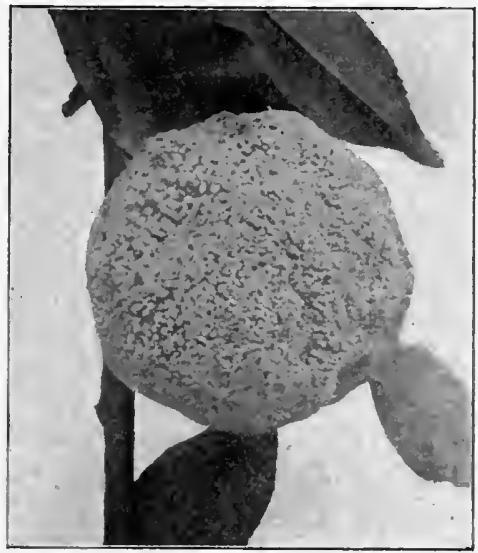

After Ga. Agr. Expt. Station Fig. 156. - Brown-Rot on a PeACH the tree and there the fungus remains until the next season, ready then to start a new outbreak of the disease. In controlling this malady, therefore, first remove and destroy or cover up by plowing all mummied fruits. Then spray the trees carefully with Bordeaux mixture before the buds open, to kill all germs. Finally, spray during the growing season. 
Peaches and other stone fruits are of ten injured by spraying when leaies are on the trecs.

Peach leaf-curl. - This disease can be recognized by the curling and arching of the leaves, which later turn dark and fall. The fruit shrivels and becomes almost

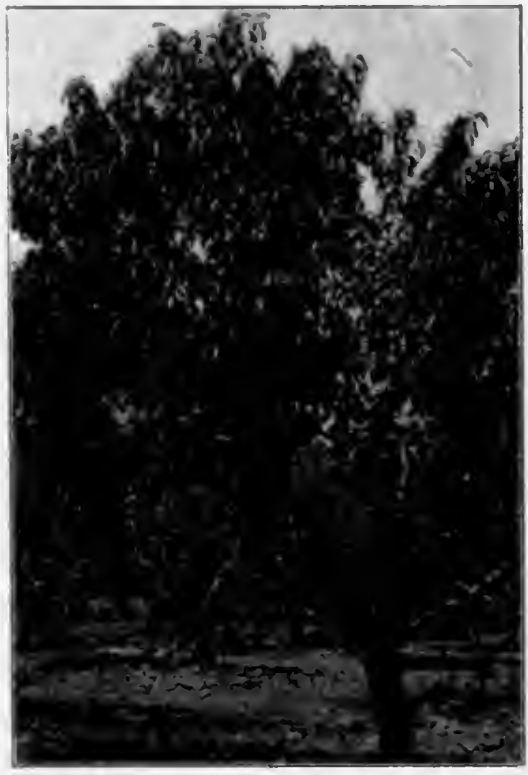

Fig. 157.-A Peach Tree protected against Leaf-CurL by Spraying worthless. The young shoots also may become diseased. This fungus establishes itself at the time the fruit buds are opening. It may be prevented by spraying the trees with Bordeaux mixture just before the buds open (Figs. I 57 , I 58)!

Apple-scab. - Applescab is very common throughout the country during moist seasons. Examine the fruit carefully during July and August, and the presence of this disease will be shown by the scabby spots that do not resemble rot. There is an olive-colored growth around these. Scabby spots may also occur on the leaves. The apple-scab causes an enormous loss, making the apples misshaped and dwarfed and often reducing their selling price by half. When the scab begins, it may kill the bloom or 
it may cause the little apples to fall. In ordinary seasons this disease is well controlled by spraying at intervals of two weeks with Bordeaux mixture.

Bitter-rot of the apple. - As the name implies, an apple attacked by this disease has a bitter taste. Bitter-rot is worst in moist, warm weather. It begins as a small spot and rapidly spreads from fruit to fruit. Later the affected area becomes flattened or sunken. A few days after the rot has begun, there are little circles of black dots beginning to appear at the center of the diseased spot. These little dots contain the spores which will spread the disease. This fungus also makes injuries, called cankers,

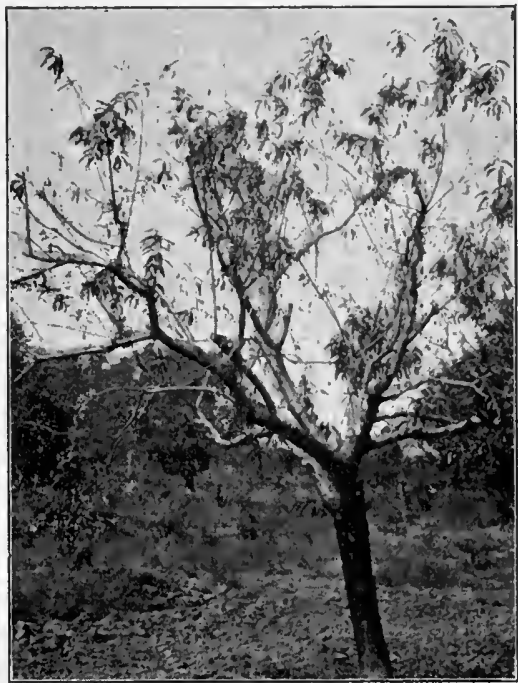

Fig. 158. - Peach Tree not Sprayed Injured by leaf-curl. on the branches of the apple tree.

It is estimated that bitter-rot of apples has repeatedly caused damage to the extent of ten million dollars a year. It may be controlled by the use of Bordeaux mixture.

Fire-blight of the pear and apple tree. - The common blight of pear and apple trees, which kills and blackens the leaves and sometimes kills the pear tree, is caused by germs, called bacteria. This disease also kills the blos- 
soms. The germ is usually carried by bees from a diseased tree to a healthy flower of pear or apple. The fungus grows into the flower and on into the twigs. The diseased twigs die. Pear-blight, unlike most diseases, does least harm to trees that are growing slowly and thus forming tough, short twigs. Hence, when a grown pear tree is attacked, cultivation may be stopped, and no fertilizer rich in nitrogen should then be used.

Spraying is not a cure, but cutting in winter and throughout the growing season all the diseased twigs helps to control the disease. Cut the twigs about one foot below the diseased portion. After making each cut kill any germs that may have lodged on the blade of the pruning shears or knife. Do this by dipping the blade into a solution of formalin or of carbolic acid or by wiping it on a cloth dampened in a poisonous solution. Thus you will avoid spreading the disease.

EXERCISE. - Find, examine, and show to your classmates specimens of peach " mummies," rotting peaches or plums, diseased apples, curled peach leaves, or spotted leaves of any fruit tree. Do the appearances suggest that you are looking at the diseases here described?

Note To THE TEACHER. - Most State Experiment Stations will identify diseased leaves or other specimens addressed to their botanists and will furnish bulletins on plant diseases or tell you where to get the bulletins that you may desire. 


\section{SECTION XL. DISEASES OF OATS AND WHEAT}

IN a field of ripening oats we can generally find some blackened smutty heads. The black dust which flies when these are touched consists of spores, whose only business is to cause more smut in next year's crop. They lodge on healthy oat grains in the field or while the crop is being thrashed. Healthy grains on which smut spores lodge do not become unhealthy, but when planted they carry the smut spores close to the sprouting plants.

Oat-smut. - The only time when the smut fungus of oats can enter into the oat plant is just at the time of sprouting. If the smut spores can be destroyed on the seed to be planted, not a single head of smut will appear in the field, and the yield of oats will be increased six to twenty-five per cent. These germs on the seed can be killed either with scalding water or with formalin. Do this by. soaking the seed for ten minutes in hot water that a thermometer shows to be between 132 and 135 degrees. Or smut may be entirely prevented by thoroughly wetting the seed oats in water to which one ounce of formalin has been added for every three gallons of water. After treating seeds with formalin keep them moist and covered with cloth for about two hours, so that gases from the formalin 
may better kill the smut spores. This treatment costs only a cent or two for each bushel of seed. Oat-smut is shown in Fig. 159.

Concealed smut of wheat. - The wheat smut which is

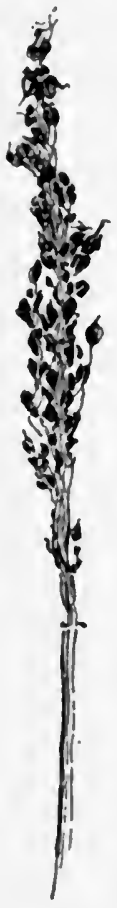
most injurious is not readily observed. Here, too, the spores of the fungus replace the kernel, but the seed-coats, or kernel coverings, conceal the disease. On crushing one of the diseased "kernels" the spores will be found and the unpleasant odor that arises will not be forgotten. Concealed smut may be prevented by dipping or soaking the seeds in a solution of bluestone.

Other diseases. - Among other diseases of wheat and oats are several forms of rust, also due to fungi. You may be able to find specimens of rust and to compare them with the smuts.

No treatment has been found to prevent the rusts of grain. Some varieties are more injured by rust than others. Those that ripen early oftenest escape severe injury. If you should find a wheat or oat plant that is free from rust while all others around it are diseased, your

Fic. 159 . discovery may give rise to a genuine rust-proof SAUTTY OATS variety.

EXERCISE. - When wheat or oats have formed heads, count the number of smutted heads on a square foot or square yard of surface. Estimate how much the yield will probably be reduced by smut. Are the other stems ever stunted on a plant having one diseased head? Look for rusted leaves or stems of wheat or oats. 
NOTE TO THE TEACHER. - If you can get the promise of some farmer to sow half an acre of smutty oat seed and an acre alongside with seeds that have been treated for smut, your State Experiment Station may possibly be able to send you the necessary formalin. Or you can ask certain pupils simply with the aid of a borrowed thermometer to scald the seed for this test. If you have a school garden, plant in it treated and untreated oat seed. Let different pupils plant the two kinds of seed, so that disease germs may not be carried from the untreated to the treated seed. 


\section{SECTION XLI. DISEASES OF IRISH AND SWEET POTATOES}

The scab of Irish potatoes. - Irish potatoes of ten have a surface covered with rough scabs. This is a fungous disease. If a scabby potato is planted, both fungus and potato are sown and the harvest will consist of both. Moreover, the fungus spores are apt to be present in a soil which has recently produced scabby potatoes, ready to injure the next crop of potatoes. Fortunately this disease is easily prevented. A sound crop comes from smooth, healthy potatoes in a soil where scabby potatoes have never grown. For safety treat seed potatoes by soaking them two hours in a formalin solution containing one ounce of formalin to two gallons of water.

The early blight. - This is a common disease of the leaves of the Irish potato. Round brown spots appear upon the leaves, or irregular spots show on the margins. This disease is readily prevented by spraying the foliage with Bordeaux mixture. Paris green may be added to the mixture so as to poison the potato beetle at the same time.

The soft-rot of sweet potatoes. - Sweet potatoes in storage are sometimes injured by the same little black mold often found growing on bread or on preserves. When the potatoes are stored where it is too moist and warm, this fungus grows upon them and produces what is known as 
the soft-rot, which has an unpleasant odor. This fungus takes advantage of the so-called sweating period, which occurs a short time after the sweet potatoes are dug. It then finds an easy entrance through the injuries on the surface or through the broken end of the root. From a single diseased or bruised spot it may spread with alarming rapidity. This disease is readily prevented by proper drying of the potatoes for a few days after they are dug, before placing them in the lower temperature at which they are to be stored. Infected potatoes should be destroyed.

The black-rot of sweet potatoes. - This disease is really a soil rot. The fungus doubtless enters through the young rootlets of the growing plant. It finally becomes established in the potatoes themselves, producing circular black patches. The disease may even extend its injuries after the potatoes are stored. Black-rot is the most destructive fungous enemy of the sweet potato, but fortunately it has not been found in all localities. In order to control it, the potatoes should not be grown on any field where sweet potatoes grew for one or two years before. Moreover, the seed or slip bed should be carefully watched, for this disease may make its appearance there, producing upon the shoots dark-colored spots known as "black shank." Set out no slips from a badly diseased seed-bed.

ExERCiSE. - Find Irish and sweet potatoes. Search them for any unhealthy appearance. If any disease is found, does it seem to be one of those described above? 


\section{SECTION XLII. DISEASES OF COTTON}

Cotton wilt. - Cotton wilt, often called black rot, causes the plant to drop its leaves or wilt and then dry up. Most

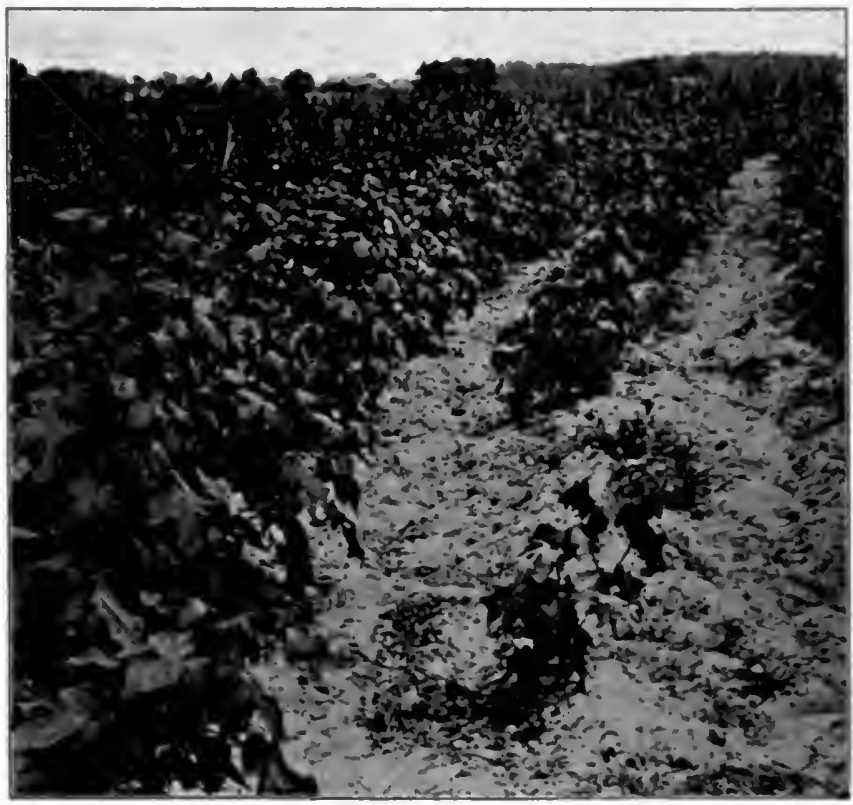

Photograph by U.S. Irept. of Azrieulture

Fig. 160. - ON LeFt, a VARIETy of Cotton Resistant to Wilt; on Rigut, Ordinary Cotton

Many of the plants killed or stunted by wilt.

plants die when bearing a full load of blooms and bolls. The discase occurs chiefly in the southern half of the cotton belt, and as far west as Louisiana. It is very common on certain 
of the islands on the South Atlantic coast where Sea Island cotton is produced.

The first year that wilt occurs on a field it attacks only a single plant or a small spot here and there. The next year the spots where the plants die are larger. In a very few years the fungus may become so very widespread as to make it impossible to maintain a stand of cotton on any part of the field (Fig. 160).

In the stem of a cotton plant that has been attacked by wilt, the woody portion is darkened or streaked with very fine black lines. These black lines are the water-carrying vessels that have become stopped up by the growth of the fungus. Their stoppage causes the plant to wilt for lack of water. A dark layer occurs just under the bark (Fig. I6I). The germs of the disease enter the plant through the roots. Cotton wilt is generally considered worse on land where the tiny worms that produce knots on the roots are present. The germs probably enter more readily through the wounds made by these root-knot worms on the roots of the plant.

In some of the affected areas in the field there may be a few stalks which do not contract the disease. If so, they are resistant and their seeds may transmit this
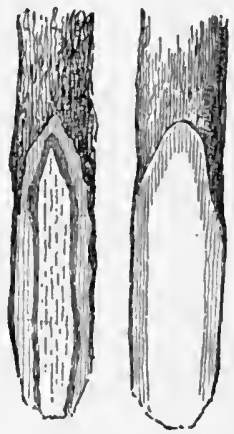

Fig. I6r.- Diagonal SECTION THROUGH Cotton Stalks

On right, healthy plant; on left, blackened by cotton wilt. natural resistance. Mark them and very carefully preserve their seeds for planting purposes. Different varieties of cotton show marked differences in their ability to 
withstand the attacks of this fungus. The Dixic (Fig. 162), some strains of the Jackson variety, and some varieties of Sea Island cotton have been made quite resistant to cotton wilt by years of selection.

Rotation of crops is generally the way to decrease

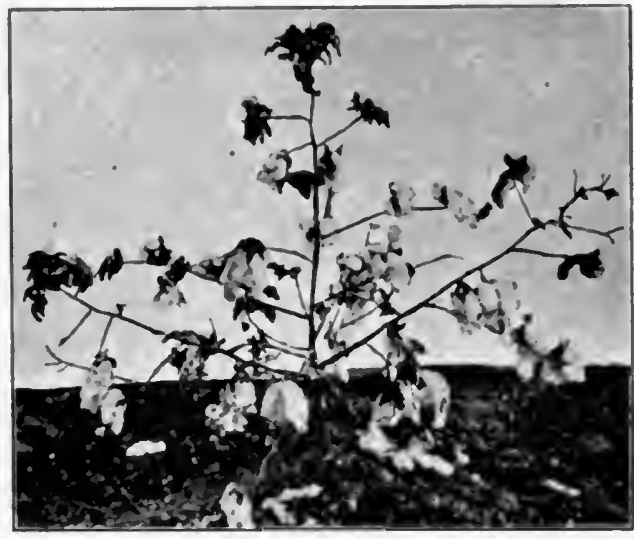

Fig. 162. - Dixie, A Wilt-Resistant Variety or Cotton the damage from wilt. However, the germs of wilt live in the soil for several years. Hence, in a rotation for land where this disease occurs, cotton must not be grown of tener than once in three or four years. Nejther should the ordi-

nary varieties of cowpeas be grown in such a rotation, for the root-knot worms, if present, increase rapidly on the cowpea roots. This increases the number of wounds on the cotton roots the next year, and hence probably the number of wilt fungi entering the cotton plant. But in a rotation of crops on such a field, the variety of cowpeas called Iron, and also the velvet bean, may well be grown, because the root-knot worms do not rapidly increase on the roots of these plants.

Cotton root rot. - The farmers of Texas and Oklahoma are not troubled with cotton wilt. Instead, their cotton 
often suffers from another disease, which, in appearance, is very similar to the wilt. This is the well-known root rot, or "dying" of cotton. The symptoms of this disease also are sudden wilting followed by the death and browning of the whole stalk. Plants die from this disease about the time that the first bolls begin to open. It seems to be most common in the blackwaxy, and other stiff soils.

The method of its attack is very different from that of the cotton wilt. Over the whole root system, and particularly covering the larger roots, are found brownish yellow threads, or a fuzzy growth of the fungus. The threads of the

fungus penetrate the Fig. 163.-Roots of A Cotros Plant bark and even extend

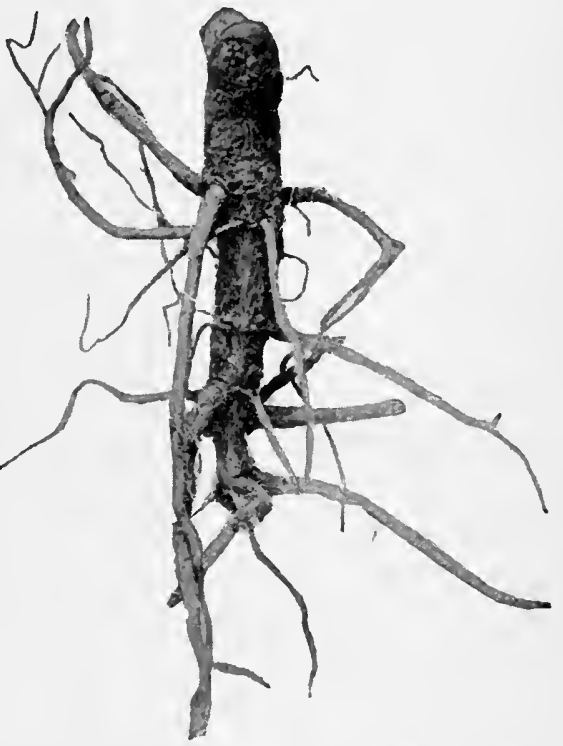
ATTACKED BY RoOT Rot into the wood of the roots; the younger roots are promptly killed (Fig. I63). Wilting is due to the failure of the roots to furnish the usual supply of water.

The fungus has been found on practically all varieties of cotton, but methods have heen discovered for lessening the loss. It grows best and injures cotton most 
where the soil contains little air, that is, where the soil packs down heavily, or where the land has been poorly prepared for the growth of cotton. Therefore, better circulation of air in the soil is needed. This can be attained by deep plowing, thorough cultivation, and the addition of stable manure or vegetable matter. Rotation of crops is necessary. Such a rotation should not include alfalfa, sweet potatoes, or other plants on which this fungus can live. On land where cotton root rot occurs, corn, the small grains, sorghum, the true grasses, and many other similar crops may be grown.

Cotton boll rot. - The boll rot is a very common disease in moist seasons. It is most severe in moist bottom lands where the large plants shade the ground and the bolls. The careful observer will notice first upon the boll small water-soaked spots, and as these spots increase in size they become gray at the center and finally pink, with a purple border. The pink or gray coating is evidence of the abundant production of fungus spores. These spores are blown about, or spread by insects, thus planting the disease wherever they fall upon cotton bolls surrounded by sufficient moisture and warmth to make the spores develop. The boll rots and the contents are ruined. Varieties differ somewhat in the extent to which they take the disease. Wide spaces between rows may decrease boll rot by letting in more sunlight.

Black rust. - This is the disease that so generally causes the cotton plant gradually to drop its leaves. The leaves turn pale or yellow, and then blacken and die. Black rust is not started by germs. After a plant 
has been made weak and unhealthy by unfavorable soil or other surroundings, the rust fungus enters the leaves and completes their destruction. Rust is largely a disease of poor land, and can be prevented on some soils by adding vegetable matter or potash.

EXERCISE. - Ask your parents which of these diseases occur near your home. On what kinds of soil is each one worst? If diseased plants are found, examine them in the field where they grow. Do not take them to school for fear of spreading the disease. 


\section{SECTION XLIII. GERMS IN THE SOIL}

THE farmer could not grow profitable crops without the help of several kinds of germs that live in the soil. Some of these live in the tubercles on the roots of leguminous plants and change the nitrogen of the air into fertilizer nitrogen. These might be called the nitrogen-trapping germs because they catch or trap the nitrogen gas.

Nitrate-forming germs. - Other kinds of bacteria that work faithfully for the farmer may be called the nitrateforming germs. These finally change certain compounds in vegetable matter in the soil into nitrates, the only form in which most plants can use nitrogen. The heaviest growth of cowpeas or clover might be plowed under as fertilizer, and the plants growing on that field the next season could not use a pound of its nitrogen if there were no nitrate-forming germs. These germs are too small to see, so small indeed that many millions have been found in a thimbleful of soil. The farmer should care for these tiny useful plants that are helping him to grow larger crops.

Helping our friends in the soil.-Men who have spent their lives in studying these tiny plants under powerful microscopes have found that what the nitrate-forming germs need in order to increase rapidly and to help the soil and the crop are the following:- 
(I) An abundance of vegetable matter for the germs to feed on and to change into fertilizer.

(2) A soil that is always moist, but well drained.

(3) A soil kept so loose and well drained that air can circulate in it.

(4) An abundance of lime to keep the soil from becoming sour.

(5) A warm temperature.

Germ enemies in the soil. - The soil is not dead. It swarms with living creatures. Some are friends, some foes. If the farmer helps the friendly germs, they rapidly increase and almost drive out some of the harmful germs. But if he allows his land to remain long very wet or very compact or very deficient in vegetable matter, his enemies in the soil will increase to enormous numbers and his friends will be banished.

Nitrate destroyers. - For example, there are germs that are harmful because they change the valuable nitrates into useless nitrogen gas. Thus they undo the good work that the nitrate-forming germs have done. These harmful kinds, or nitrate destroyers, do not thrive in a soil where there is plenty of air. The farmer must fight these by the means that help the friendly germs, by drainage, plowing, cultivation, and by the addition of vegetable matter. 


\section{SECTION XLIV. WHAT AN INSECT IS 1}

MANY persons regard insects only as troublesome pests, always to be considered as enemies. To the farmer, however, a large majority of the insects are really not enemies. Many of them are his friends, although others are serious enemies of health and crops. All of them are interesting, and some of them very beautiful. A few general facts about aiding our insect friends and destroying our insect enemies will be of value.

What an insect is. - Three great divisions are made to include all natural things, that is, the animal, the regetable, and the mincral kingdoms. All insects belong to the animal kingdom. They are, therefore, animals, of which class they form much the largest group. In fact, there are more kinds of insects than of all other animals and of all plants put together. It is the abundance of insects and their close relationship to our health and welfare that make it so important for us to study them.

Insects are never very large and rarely exceed a few inches in length or breadth. Many of them are so small that a magnifying glass or lens is needed to see them clearly. Most insects have wings when they are in the full-grown or adult stage, but some never have these in any

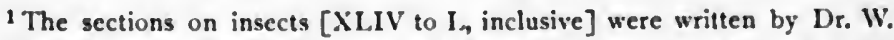
E. Hinds, Professor of Entomology in Alabama Polytechnic Institute. 
stage of their existence. When wings are present, there may be either one or two pairs. Nearly all insects have legs; six is the usual number. These two characteristics, the presence of wings and of six legs, are sufficient to identify an insect. There are insects, however, that lack wings and legs.

Spiders and mites not insects. - The only creatures likely to be mistaken for insects are the spiders and mites. These never have wings and always have eight legs. By simply counting legs, then, spiders may be separated from the wingless insects.

The principal parts of an insect. - The body is divided into three parts: the head, the thorax, and the abdo'men (Fig. I64). The head bears the eyes, the antěn'na, or feelers, and the mouth parts. To the tho' rax, or chest, of the insect are attached the wings and the legs, but both wings and legs are entirely wanting in some insects.

The eyes and antennæ. - The eye is made up of a large number of simple eyes, so closely crowded together that they form what is called a compound

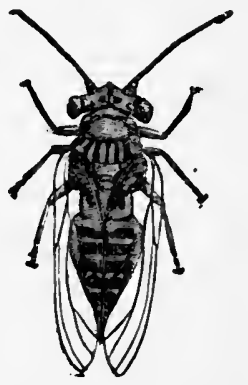

Fig. I64. - THE PARTS OF AN INSECT eye. As a whole it is shaped somewhat like half a raspberry, dewberry, or blackberry. The shape of each part of the eye is something like that of a cell in honeycomb.

The antennæe bear the sense organs, which correspond to our touch, smell, and probably hearing also. One reason why the name "feelers" is often applied to these organs is 
because the insects really seem to use them in that way. Insects do not have a nose or ears as we have, but some of them have the sense of smell very wonderfully developed, and doubtless they hear many sounds that never reach our ears. There are many interesting differences in the form of the antenna in different insects.

Wings and legs. - The wings serve to carry their owners over long distances. They are very important aids in enabling insects to find their food. A bee could not get enough to eat if it had no wings to carry it from flower to flower. The legs are arranged so as to balance the body in walking. Having six legs, the insect always has three on the ground while it is moving the other three forward.

EXERCISE. - Catch a fly and see whether you find all of the parts of the body which have been mentioned. How nany pairs of wings has it? If you can get a magnifying glass examine the eye, antenna, mouth, and feet. Describe what you see.

Note to the Teacher. - The United States Department of Agriculture and most of the experiment stations have issued bulletins on injurious insects. 'The text and illustrations in these will be useful to you in teaching the sections on insects. 


\section{SECTION XLV. HOW INSECTS GROW}

ONE difference between the structure of insects and four-legged animals is that the insects have their skeleton or bones, as we may call them, on the outside of their bodies. This is what makes an insect hard. For this reason, insects cannot grow slowly and steadily, as animals do that have their skeletons inside and covered with the soft and easily stretched muscles and skin. When insects grow they do so by sudden jumps, as it were. When they have grown so that they fill their outside skins very tightly, a new skeleton is formed inside of the old; the old skeleton bursts and is shed by the insect. While the new skeleton is yet soft it allows a considerable growth of the insect. This process is repeated several times in the life of every insect before it becomes fully grown. Having the skeleton on the outside is a great protection to the insect.

With some insects these changes of skeleton are accompanied only by a change in the size from the newly hatched form to the adult; but with others there are great changes in structure and appearance during the last two changes of skin. We must know something of these changes in order to recognize the different stages in the life of the same insect.

Immature and adult forms of insects. - Among the insects that change but little with their development are 
the grasshoppers and the true bugs. Those who study insects use the name "bug" only for a certain large group of insects, just as one would speak of the "flies," "bees," and "grasshoppers." Grasshoppers and bugs have the same general form of body when young, but acquire wings as they become adult. Most of the other common insects undergo very remarkable changes. It is important to know this, since it may be very difficult to destroy an insect in one stage, but very easy to do so in another. Among those that make great changes in form are all of the caterpillars, which become butterfies or moths when full grown; the maggots, which become flies; the griabs, which become beetles. You will find it exceedingly interesting to watch a caterpillar change its skin or the butterfly emerge from its chrysalis or pupal case.
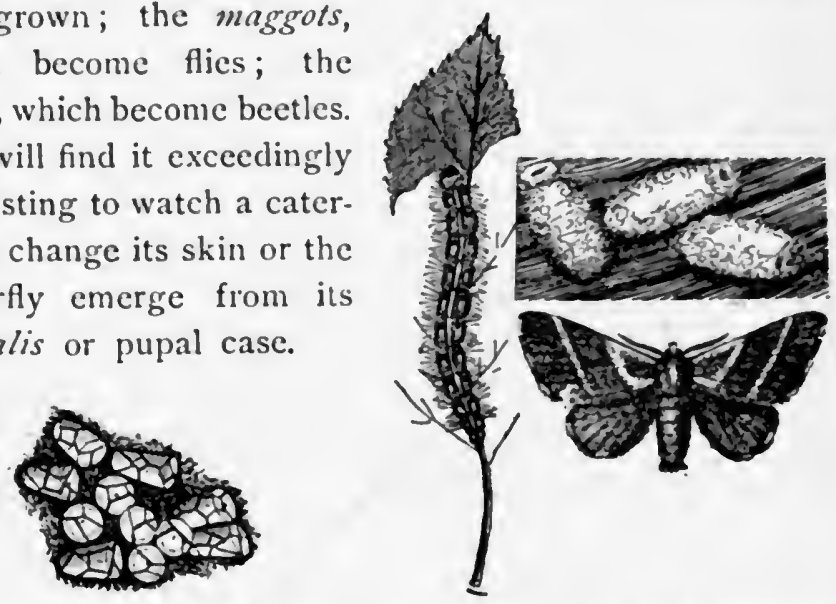

Fig. 165. - Four Stages or insect (Tent Caterithlar). Egcs separated AND MAGNIFED

Larva; cocoons; moth.

Stages in an insect's life. - In the life of most insects there are four well-defined stages. The first is the egg, the second is the larra, the third is the pupa, and the fourth 
stage is the adult (Figs. 165, 171). With a few insects there is no visible egg stage, as the young are born alive. This is the case with the plant-lice. The larval stage is the growing stage in every insect's life. If it is not well fed, the adult insect coming from it will be smaller in size than usual. The pupa, or pupal stage, occurs only among insects in which the larva is very different from the adult. It is purely a transformation stage, and is one of the most wonderful facts in the life of any animal.

Transformation from caterpillar to butterfly. - When the butterfly caterpillar has become fully grown, it ceases to feed and seeks some protected spot in which to transform. For a time it seems to shrink or shrivel as though about to die. The most wonderful thing, perhaps, is that through all the vital changes that take place within its body during this period it does not die. After a few days, the caterpillar sheds

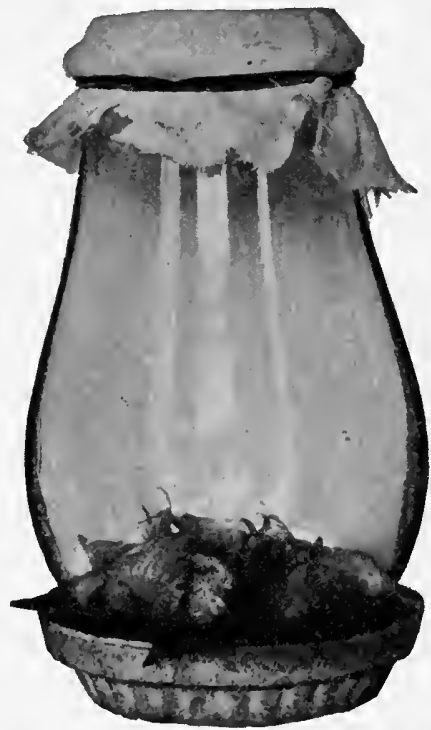

Courtesy U. 8. Bur. Entomology

FIG. I 66. - BREEDING CAGE its larval skin and becomes the pretty, shining chrysalis, or pupal case, of the butterfly. This is generally attached to some twig or stem. The surface is marked with delicate lines which really indicate the outlines of the 
slicaths within which the wings, legs, and antenne are developing. The body of the caterpillar is made over into an entirely new set of structures especially fitted for the different life the adult will lead. A wonderful change takes place in both the structure and the habits during the two stages of these insects' lives. A new butterfly is formed out of the body of the old caterpillar without destroying its life. This is just what happens with most insects. With moths the changes are very similar, only they are hidden from view by the cocoon, or silken case, that the caterpillar spins around itself for protection during this critical time of life. The change with wasps and bees and beetles is just as great as with butterflies and moths.

EXERCISE. - Bring some potato beetles to the school and confine them in a cage such as shown in Fig. 166, with some of the potato vines. Watch the adult beetles lay their eggs and the young hatch and grow. Have some earth in the bottom of the cage for the larvar to enter when they are ready to transform. After a few days dig out some of the pupa and see how differently they are formed from the mature insects that were put in. 


\section{SECTION XLVI. HOW INSECTS FEED}

How insects feed. - Insect mouth-parts are fitted for either biting or for sucking food.

Insects have a number of parts to their jaws, and these are so arranged that they work sidewise against each other. The biting insects consume the entire substance of the leaves, flowers, fruit, or wood on which they feed. This is the reason that it is possible to kill such insects by applying some poison to the plants on which they are feeding.

Some biting insects, however, feed in protected places where it is impossible to reach their food with a poison application. This is the case with the wood-boring insects as a rule and with the cotton-boll weevil. Many of the leaf-feeding insects, even, feed in the buds or some other protected position that makes it hard to control them. It is, therefore, necessary to know both the structure of the mouth and something of the general feeding habits of each insect before it can be destroyed.

Different uses of biting mouth-parts. - Among the biting insects the jaws are arranged in two principal positions, either pointing downward toward the surface upon which the insect rests, or forward, straight ahead of the insect. These positions indicate a different use. When the jaws point downward it means, as a rule, that the insect feeds 
upon the surface or substance upon which it rests. This is the case with the grasshoppers, caterpillars, and most other leaf-feeding insects. Where the jaws point forward, it indicates that they are used for catching prey or for boring into wood. Those insects which catch others are as a rule uscful and should not be destroyed. The tiger bcctles and the ladybirds are two important groups of such useful insects.

Sucking insects. - In the second large group are included all insects that take their food by sucking. The mosquitoes, flies, butterflies, moths, and bugs are insects of this class. The food of sucking insects is generally either plant sap or animal blood. The butterflies and moths, however, use neither of these foods, but live on the nectar, or sweet liquid, which is formed in flowers. Some adult insects never feed at all. The larva from which they are developed have stored up so much strength and a surplus of food materials in their body tissucs that the adult simply lives upon that reserve. In such cases the adult may have entirely lost the use of its mouth and the parts may not be developed. Such insects are usually short-lived while in the adult stage. Among the mosquitoes only the females suck blood. It is possible for them to live on some other food as well as upon blood.

Perhaps the most interesting form of sucking mouth is that of the butterflies and moths. All caterpillars have biting mouths. The tongue of the butterfly is often longer than its body. It would be very much in the way if it were not possible for its owner to coil it up like a watchspring and carry it closely packed away under its head. 
There is a narrow channel extending through the entire length of this tongue through which the butterfly sucks the liquids that serve it as food.

With most sucking insects the mouth-parts are strong enough to enable them to pierce the tissues of plants, animals, or other insects, so that their food is obtained entirely from beneath the surface. This is the reason that it is impossible to kill sucking insects by applying poisons to the plants on which they are feeding.

Different treatments for biting and for sucking insects. - These types of mouth-parts must be well understood in deciding just what treatment should be given for any insect pest. With the biting leaf-eating insects, any poison spread on the surface of the leaves will be taken into the insect's stomach with its food and cause its death. Paris green is the principal poison that is used in this way. It is generally mixed with water and the poisoned solution sprayed all over the trees or plants on which leaf-eating insects are feeding. Other poisons may be used in the same way. Such a treatment will have no effect upon the sap-sucking insects that take nothing from the surface of the leaves. It has never been found possible to introduce any poison into the sap of a plant so as to destroy the sucking insects upon it. The principal thing that can be done to destroy such insects is to apply something which will not injure the plant, but which, coming into contact with the insect's body, will cause its death. There are two kinds of such treatment that can be used. The first kind includes many substances which cause death by covering with soap or with oil the openings through which 
the insect breathes, which keep out the air and really suffocate it. These are called contact insecticides. Kerosene emulsion is one of the most common of such substances. (See Appendix.) The second class includes those gases that are either poisonous in themselves or cause the death of the insect by replacing the air and thus causing suffocation.

ExERcist. - Watch caterpillars feeding on foliage, and mosquitoes and flies sucking blood or swects, and describe what you see them do.

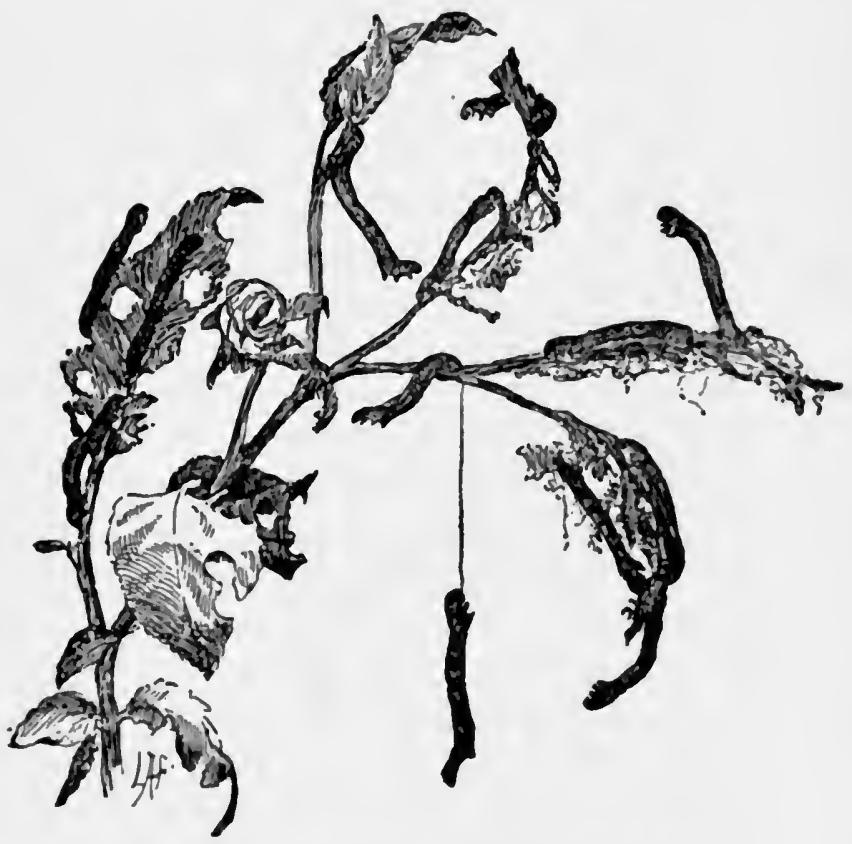

Fig. 16\%. - Leap-eatiNg Caterplliars at Worz 


\section{SECTION XLVII. INSECT ENEMIES OF THE}

\section{FARMER}

WHILE the injurious kinds number but a very small fraction of the great group of insects, they are exceedingly important both to our wealth and health. Perhaps more than a tenth of all the crops raised each year in our entire country is eaten or destroyed by insects. This clamage amounts to a direct cost of about ten dollars for every man, woman, and child in the United States.

The Hessian fly.- Perhaps the most injurious species of all is the Hessian fly, a minute insect which lives on the stems of wheat and other grains. In some places wheat cannot be grown because of the presence of this insect and the injury it causes. The only remedy consists in burning over the stubble after the crop has been harvested and in delaying the planting of the fall wheat until after frosts have occurred.

The chinch-bug. - This is another very important insect that attacks grains. It is especially injurious to wheat and corn. It is a true bug and hardly more than a fifth of an inch long. Chinch-bugs often occur in such numbers as to cause the death of the plants because of the enormous amount of sap they withdraw. After the crops of smallgrain are harvested, these bugs move on foot in countless numbers to the corn-fields. The fields can be protected 
by running a deep furrow across the path of the bugs and destroying them as they fall into it. The fields should be cleaned by burning all rubbish which can shelter the adult bugs through the winter. With many such pests, it is advisable to change the crop on a field each year, so that the pests may not so readily find an abundance of their food.

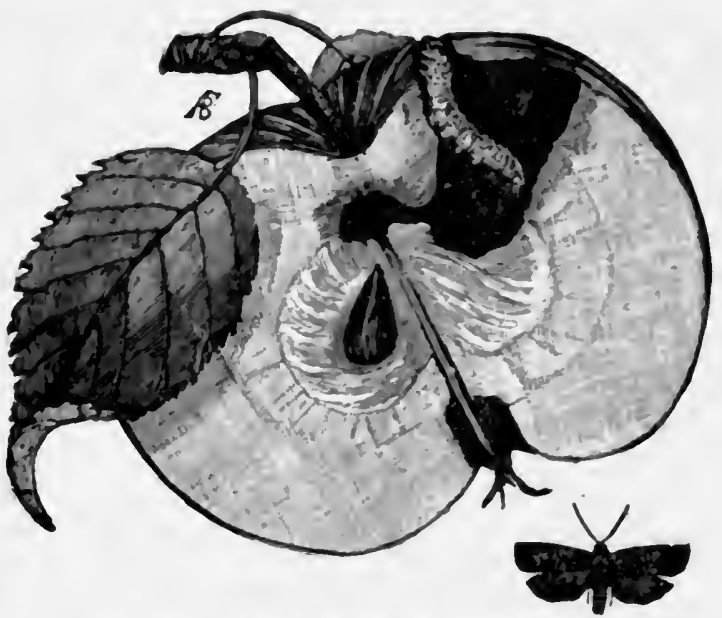

Frg. I68. - Apple Wory or Codling-Moti

The moth or miller lays the egg, from which hatches the larva or worm.

The apple worm or codling-moth. - A widespread pest of apples is the worm (Fig. 168) that works into the core and makes the fruit "wormy." This is the larva of a pretty moth that lays its eggs on the leaves of the apple soon after the blossoming time. The young larva feed on the leaves before they enter the fruit, into which they bore their way. This is the reason why it is possible to kill nearly all of the young worms by applying a poisonous 
spray, which usually contains Paris green, at about the time that the petals drop from the blossoms. A second spraying in from ten days to three weeks after the first is an almost complete remedy for this pest. The expense is very slight in comparison with the value of the crop saved.

The peach borer. - One of the most important peach insects is the peach borer, which works, not upon the fruit, but in the trees. If constant care be not taken, these borers may destroy a valuable orchard in a few years. The adult is a beautiful little moth, resembling some of the wasps in its appearance. The eggs are laid by the parent moths during the summer upon the bark near the surface of the ground. After hatching, the larva begins to bore into the bark, working downward a little below the surface. It lives thereafter in the sap-carrying layers just under the bark. Its presence is marked by an abundant formation of gum. The usual and best remedy is to dig around the base of each tree early in the fall or winter, and if any signs of gum are found, to dig out and destroy the larvæ or worms. This must be done carefully so as not to miss any of the worms or injure the trees more by digging than the worms would do if left alone.

The San José scale. - This is one of the most important enemies of all fruit trees that shed their leaves. It is called the San José $\left(\mathrm{Ho}^{\prime} \mathrm{s} \overline{\mathrm{a}}\right)$ scale because it was first found in the United States near a place in California by that name. The scale insects are true bugs and suck the sap from the trees. The adult female scales are hardly as large as pin heads, but they may occur so abundantly as to cover the bark completely, and to cause the death of large trees in a 
few years (Fig. 169). The best treatment is to spray the trees thoroughly just before the leaves start in the spring

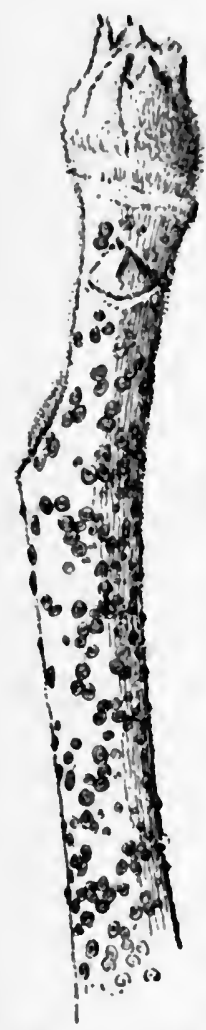

Fig. $169 .-S_{\Lambda N}$

José SCAles, ENLARGED

with a solution made by boiling lime and sulfur together. This is known as the lime. sulfur wash. (See Appendix.)

The potato beetle. - This insect occurs so commonly that it is probably well known to all of you. The adult beetle is marked with ten light and dark stripes. The young are thick-bodied, soft, red grubs. They eat the vines of the Irish potato and the mature beetles do likewise. The beetle lives over winter and lays its eggs upon the potato plants early in the season. The eggs hatch into small reddish grubs and in a few weeks the vines may be eaten bare. The remedy for this pest is Paris green, sprayed or dusted on the leaves. Lime should generally be used with Paris green to prevent its injuring the leaves.

The plum curculio. - This is another beetle that does great damage to the plum and peach crops. The adult is one of the snout beetles, or weevils. After the fruit has set, the mother weevil lays her eggs in it and then eats a crescent-shaped cut half around each egg in order that the growth of the fruit may not crush the egg before it hatches. This always marks the location of the egg. The larva eats its way into the fruit and around the stone. When fully 
grown, it leaves the fruit and goes into the ground to transform. The adult weevil comes out early in the spring and feeds for a time on the buds before the fruit is set. During this period it may be destroyed by spraying the opening buds with poison. If sprayed just after blos-. soming, many weevils will be killed before they injure the fruit.

Another method of destroying the weevils depends upon their habit of dropping to the ground for protection if anything disturbs the tree. A cloth-covered frame is placed under the tree, which is then jarred vigorously, causing most of the weevils to drop into the cloth, from which they may easily be collected and destroyed (Fig. I 70).

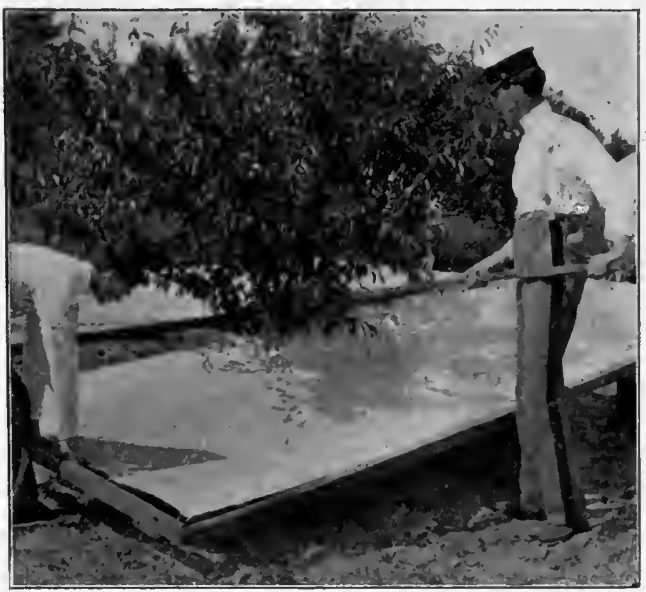

Photograph by R. S. Mackintosh

Fig. r7o. - Jarring Peach Trees to catch Curculios on the SCREFN Below

The cotton-boll worm (Fig. I7I). - These worms prefer corn ears to cotton bolls. That is, if corn that has not become hard or mature is near, the boll worm moths will place nearly all of their eggs on the corn. By planting a few rows of corn at intervals of two weeks it is 
possible to have the corn silking and in condition to attract the moths when they are most abundant in July and August. The cotton is left almost uninjured. This practice is in addition to that of plowing the ground early in

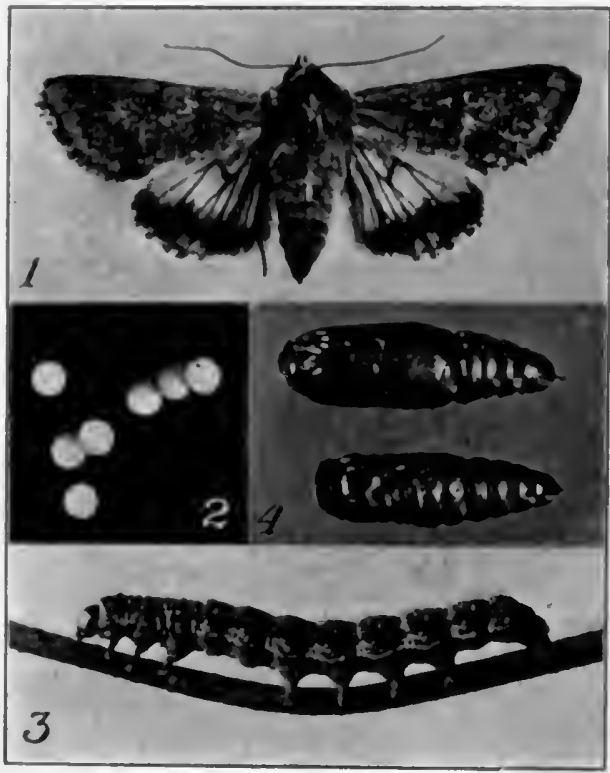

Courlous C.S. Bur. Entomology

Fig. 171. - Four Stages of the CottonBOLLL WORY, ALL ENLARGED the winter:o break up the cells in which the pupse are passing the winter.

\section{The cotton worm.}

- A number of years ago this was the most serious enemy of cotton, but more recently it has been less injurious. The caterpillars be. come abundant rather late in the season and may strip all of the foliage from the plants. They may quite easily be reduced in numbers by dusting the cotton plants with Paris green mixed with flour. Strange as it may seem, this worm has recently come to be considered as beneficial to those sections of the cotton belt where the boll weevil occurs. It deprives the boll weevil of food by practically killing the cotton plant. 
ExERCISE. - Ask the owner's permission to examine the roots of peach trees for borers. In your notebook write a description of what you find. If specimens of the other insects mentioned in this section can be found, place them in bottles and present them to the teacher for examination by the class.

Note to THE TEACHER. - Bulletins on each of these separate insects have been issued by the United States Department of Agriculture and by many of the experiment stations. You may render a great service in preventing the destruction of fruit trees by obtaining one or more of these bulletins and, with its help, collecting twigs that seem to be attacked by scale insects. Specimens forwarded to the entomologist at your state experiment station will generally be identified without charge and detailed information will be furnished for the treatment of the insect found. 


\section{SECTION XLVIII. THE MEXICAN COTTON- BOL.L WEEVIL}

In the Southern states where cotton is grown, the nost important insect for you to know about is the Mexican cot-

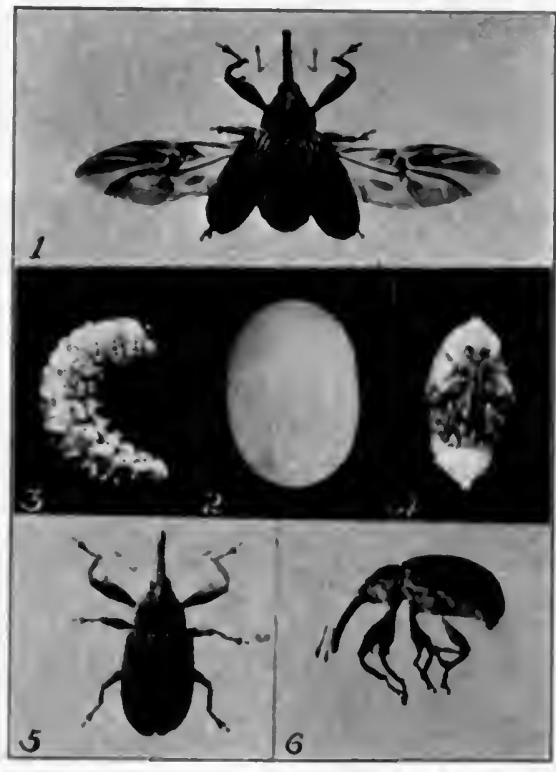

Courtesy U. S. Bur. Enwarology Fig. 872.- THe Cotton-Boll Weevil,

(x) adult; (2) egg, much enlarged; (3) larva; (4) pupa; (5) adult, back view; (6) side view, all enlarged. ton-boll auccrit. This insect (Fig. I 72) feeds only upon cotton, but its injury to this is very serious.

It came into the United States from Mexico about I892, and has since spread throughout most of the cotton-growing portions of Texas and Louisiana, and over the southern parts of Oklahoma and Arkansas. During the fall of 1907 it crossed the Mississippi River into a few of the southwestern coun. ties of Mississippi. It is very certain to continue its spread throughout the other cotton-growing states. The injury 
that it is doing now can scarcely be estimated at less than twenty-five million dollars a year.

The egg. - The adult weevils that have lived through

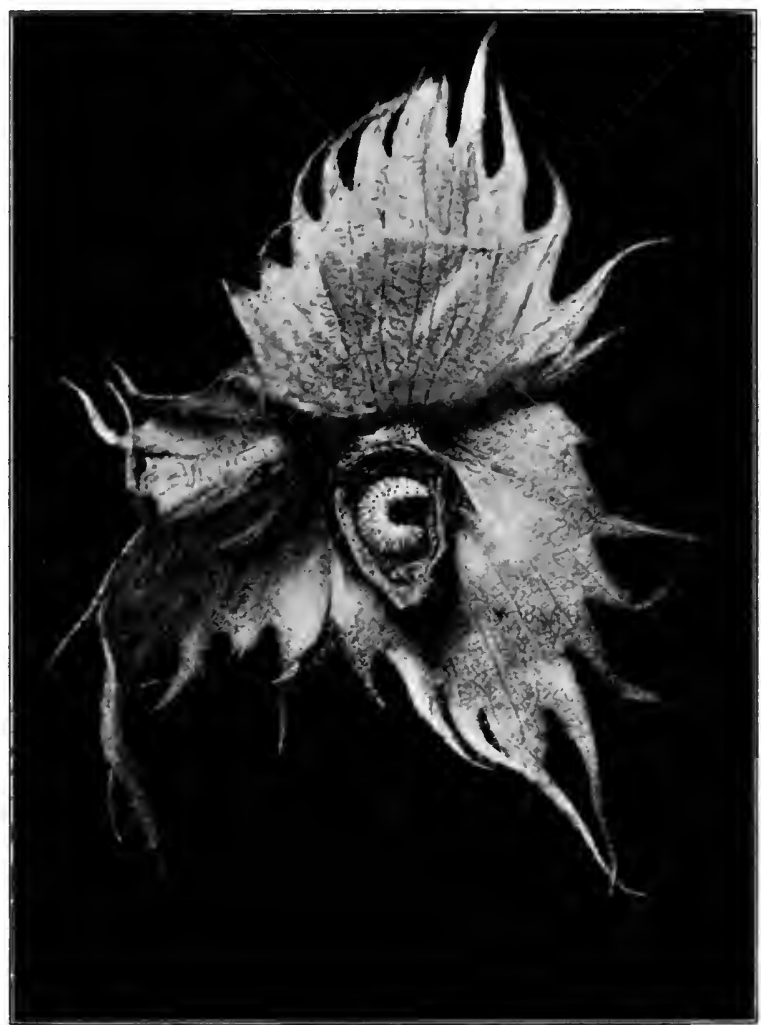

Courtesy U. S. Bur. Entomology

Fig. I73. - Larva of Boll Weevil in a SQuare of Cotton

the winter are ready to attack cotton as soon as the first squares are formed in the spring. The eggs are very 
small, and are laid in a hole which the female eats in the square or boll. After placing the egg at the bottom of the hole, the opening to it is sealed air-tight by the mother weevil so that the egg will not dry up and fail to laatch. Fach female may lay more than a hundred and some even

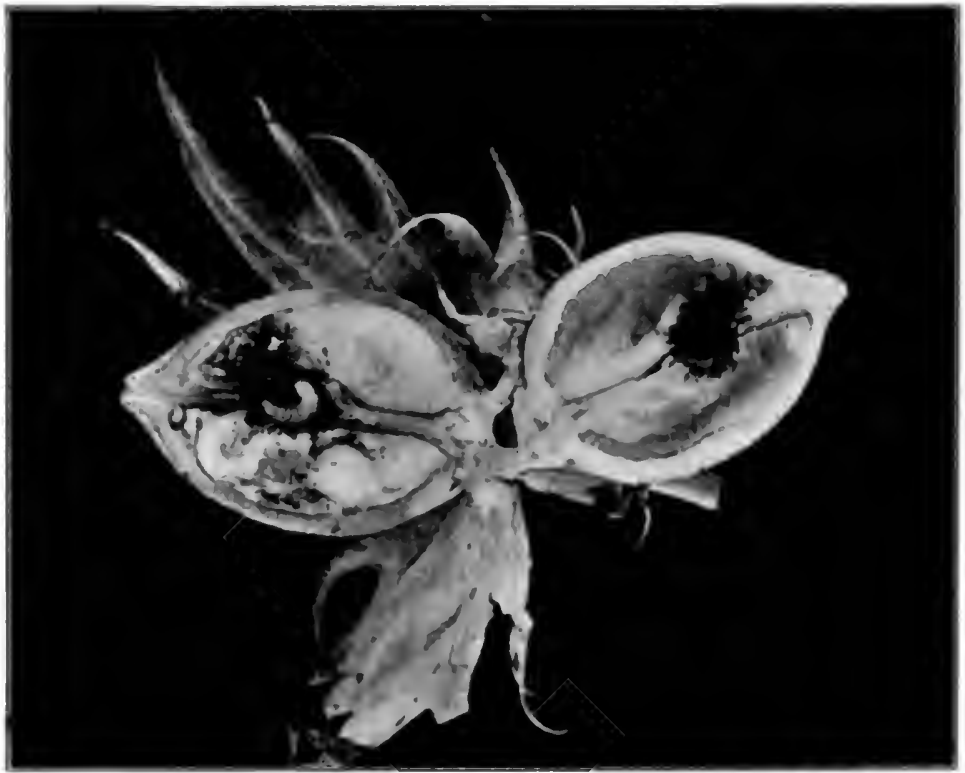

Courtes U. 8. Bur. Eotomolocy Fig. 174.- LARva of Bot.t. WeEvil in the Boll more than two hundred eggs. Only a few days are re. quired for these to hatch.

The larva. - Upon hatching, the little larva, or grub, finds itself surrounded by the tender parts of the bud or boll and then proceeds to feed and grow. When the larva 
has become about half grown, the injury to the square is usually so severe that the little leaf-like parts surrounding the bud spread outward and the square turns yellow. In about ten days from the time the egg is laid the square usually falls to the ground, where the larva continues to

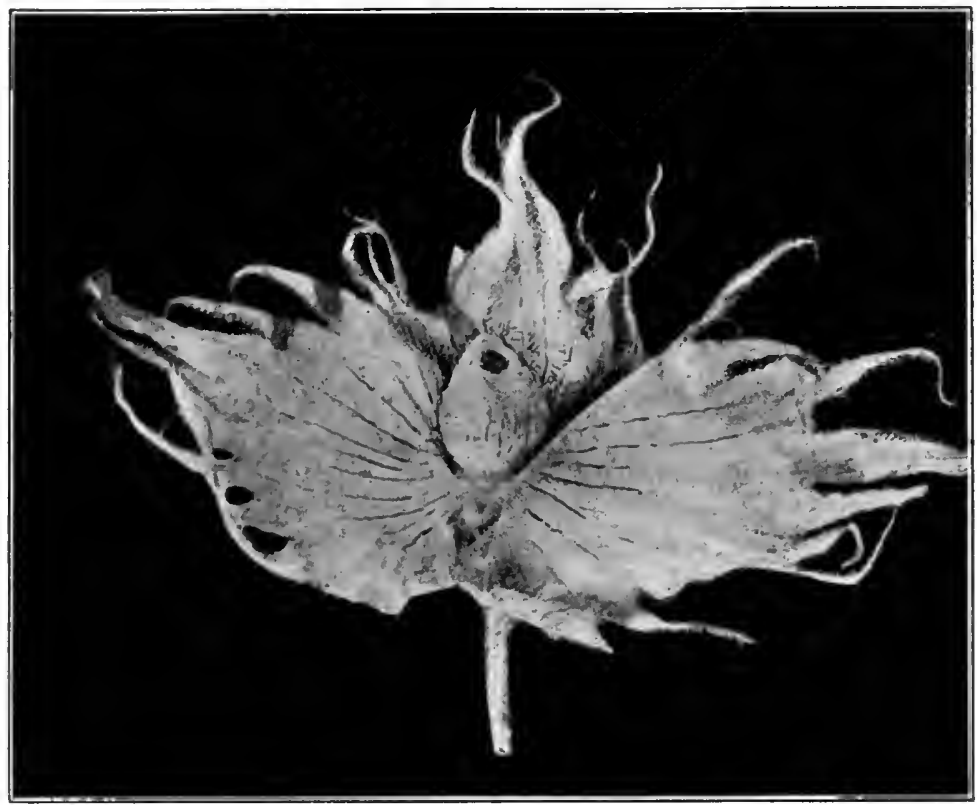

Courtesy U. S. Bur. ELtumong

Fig. I75.- Square from which aN Adult Boll Weevil has emerged

feed within it until fully grown (Fig. I73). This requires only about ten to fifteen days. Dry, hot weather may kill the insects within the fallen squares, especially if the rows of cotton be far enough apart to let in the sunshine.

The pupa. - Within the shelter of the walls of the fallen 
bud or square, or within the boll (which is more likely to remain hanging upon the plant), the larva changes to a pupa. After only about three days more it becomes a fullgrown weevil. The weevil then cuts a hole in the surrounding walls that is just the size of its body, and through this makes its escape to the outsicle world (Fig. 175). All of its life fron the time the egg is laid until the mature weevil comes forth is passed in the interior of the square or boll. This fact makes it impossible to apply any poisons so as to destroy the insect in its early stages.

The adult. - The mature weevil (Fig. I72) is a gray or reddish brown insect about a quarter of an inch long, not including the long snout. The mouth-parts are very small and are at the extreme tip of the long snout. This enables the weevil to bore deep into the squares and bolls. Squares, blooms, and bolls are destroyed by the attacks of the mature weevils, by the injury caused by the growing grub, and by the decay which starts in such wounds. The adults, or weevils, may live for a number of months. The development is so rapid that fully five generations may reach maturity in a season. Hence the insects are most abundant in the late summer and in the fall. The only check to the increase of weevils is the absence of squares, blooms, and bolls. When the weevils are very numerous, they destroy the squares so completely that no blooms are formed.

Spread. - The weevils may be spread in a number of ways, especially by seed carried from the gins on the border of the region where the weevil is present. To prevent 
this, strict rules have been made against the shipment of cotton seed or other materials that might carry the weevils.

The boll weevil spreads chiefly by flying. This flight and rapid spread occur during the fall months. In this way, the weevil spreads into about fifty miles of new territory each season. It is expected to spread over the entire cotton belt within a comparatively few years.

How it passes the winter. - The weevils which reach maturity late in the fall are the ones that are most likely to live through the winter. Fortunately, only from one to ten weevils live through the winter out of every hundred that attempt to do so. The weevils that mature in the late fall find shelter in the old cotton bolls on the stalk, or under any rubbish in or around the fields. The few that survive the winter leave their places of shelter gradually during a period of from ten to fourteen weeks, as a rule between the last of March and the first of July. This gradual coming out from winter quarters makes it very difficult to do much to control the weevil early in the spring.

Treatment for the weevil. - This has proved to be a very difficult insect to control. No poisons have proved of much value in fighting it. It has been found that the direct rays of the sun will destroy large numbers of the insects while in the immature stages in the fallen squares, when they are exposed to it. Some of our native ants, which occur all through the cotton-growing area, are very valuable helps, because they destroy large numbers of the pest in its immature stages. A number of other insects attack the immature insects in the squares and bolls and destroy them. More than forty species of birds are known 
to destroy boll weevils. The most important of these are the swallows and orioles in summer and blackbirds and meadow larks in winter.

The best way to fight the boll weevil is to make certain improvements in farm practice. The most important step is to hasten the cotton plant to early maturity, so that the bolls formed early in the summer may become well grown by the time the weevils become very numerous, - the middle of July or first of August. The boll weevil does not do much damage to well-grown bolls while there is an abundance of squares in which eggs have not already been laid.

The maturity of cotton may be hastened -

(I) By planting varieties or selections that mature early, or that form bolls early in the summer.

(2) By early planting and frequent and thorough cultivation.

(3) By the liberal use of fertilizers. Generally acid phosphate hastens the maturing of cotton.

The farmer who adopts the intensive system of cotton culture and who produces two thirds of a bale or more of cotton to the acre before the boll weevil reaches him will probably be able to grow cotton profitably after this insect comes. But the farmer, who before the coming of the boll weevil gets only a third of a bale or less from an acre, will scarcely be able to continue to grow cotton in the old way after the pest reaches him.

The second step in fighting the boll weevil consists in destroying the green parts of the plants or in plowing under the cotton stalks as early as possible in the fall. This 
is done in order to deprive the weevils of their only foodsupply, to stop their increase, and to reduce the number of hiding places in which they may spend the winter. The best preparation for farmers to make for the coming of the boll weevil is ( $\mathrm{I}$ ) to become accustomed to growing a greater variety of crops and more live-stock, and (2) to practice intensive cultivation of cotton, that is, to cultivate fewer acres of cotton so thoroughly as to make them produce as many bales as were grown on the larger area. The only safety lies in diversified farming and intensive cotton culture.

Exercise. - Let those who live outside of the region already invaded by the boll weevil try to estimate by the aid of the maps in some geography, how many years will probably pass before the boll weevil will reach their county, if it moves forward about fifty miles each year, assuming that it starts eastward from the Mississippi River in 1908. Do you think that farmers living near you realize that the boll weevil is certainly coming? Are any of them making preparations for its coming by raising a variety of farm products, - live-stock, truck crops, fruit, etc., - and by raising cotton under the intensive system? Ask your parents what additional crops or live-stock, or live-stock products, could be produced to advantage in your own neighborhood. 


\section{SECTION XLIX. INSECTS AND HEALTH}

DURisg the past few years much has been learned about the part that insects play in the spread of various diseases.

Flies carry disease. - It has been found that flies are frequently very important agents in the spreading of typhoid fever. They do this by carrying to human food on their feet or mouth-parts the germs that cause the disease. These germs are brought from the infected matter which flies visit. This has been proved by allowing a fly which had been on diseased matter to walk across the surface of a specially prepared material in which the germs of the disease could live. In a few days it was found that the typhoid germs were multiplying at every spot the fly had touched. The danger of the spread of such a disease by flies can be decreased as follows: (1) the frequent use of lime where needed about the premises, so as to reduce the number of flies and thus protect food; (2) frequently cleaning stables and lots to keep flies from breeding there; and (3) thorough screening oi houses.

Mosquitoes and yellow fever. - It has been proved very positively that a certain kind of mosquito is the agent in carrying this disease from one person to another. It is probable that it is spread in no other way. This mosquito is the common black-and-white-banded day mosquito of the Southern states. Before the connection of the mosquito with the spread of this disease became known, 
frightful outbreaks of the fever sometimes occurred in the South. In Havana, Cuba, it was always present. Even there the disease has been stamped out by destroying the mosquitoes (Fig. I 78).

As these mosquitoes breed very extensively in the cisterns, rain barrels, or other water-holding vessels, the remedy evidently consists in removing every unnecessary water vessel and in screening those which must remain with wire screening or cheese cloth so tightly that the mosquitoes cannot get to the water to breed.

Mosquitoes and malaria. - More important than either of the cases which have been mentioned is the relation of mosquitoes to the spreading of malaria. That they do this has been most positively proved, and it is certain that malaria is never spread in any other way. The females alone do all of this deadly work, as the males never suck blood.

How malaria is spread. - Malaria is caused by a very minute animal that lives as a parasite in the red blood cells of man. When a mosquito sucks blood from a person who has the disease, the parasites are taken with the blood. In the body of the mosquito certain of them undergo a development which they never do in man. After about ten or twelve days in the mosquito these parasites pass through the stomach walls and gather in its throat. At any time after this occurs, when this mosquito bites a well person, she is likely to force some of the parasites into the person's body along with the saliva which she injects into the wound. In this way, after a few days or weeks, a new case of malaria develops. This is considered as one of the most important recent discoveries in medicine. 
Knowing how the disease is spread, it becomes possible to prevent it entirely. The malarial regions are simply those where the malarial mosquitoes are abunclant. It has been positively proved that it is possible for people to live even in the worst of such regions and yet to keep entirely well by guarding against being bitten by the mosquitoes. Their bites can be escaped, for the malarial mosquitoes are active only between sunset and sunrise.

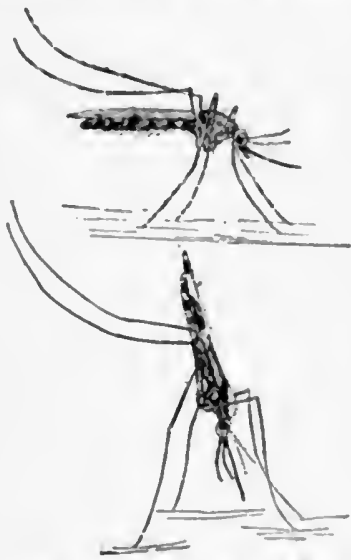

FL. 176- MAlarial MosQUito Below; CoMmon Mosquito ABove The thorough screening of the houses is the most certain means of preventing the spread of the disease. In addition the draining or filling of the standing water pools in which the mosquitoes breed should be done. Small fish live on mosquito wigglers and, hence, fish should be kept in ponds that cannot be drained or filled.

How to know the malarial mosquitoes. - Whether we desire to destroy or to avoid these mosquitoes, we should know how to tell them from harmless kinds and also be able to tell the larvae or wigglers, in their breeding places. All of the mosquitoes that are concerned in spreading this disease belong to a single group and are closely related. The adults are rather long-legged as compared with other kinds; when at rest, they stand with their bodies pointing head first to the surface to which they are clinging (Fig. 176). Other mosquitoes 
rest with the body parallel to the surface upon which they touch.

Among the larvæ, or wigglers, these positions are quite reversed, as the malarial kinds are usually found with their bodies just under the surface of the water and parallel to it, while the other kinds hang, head downward, nearly at right angles to the surface (Fig. I77). Green scum is usually present where malarial mosquitoes abound.

The remedies. - These mosquitoes do not fly far from the places where they breed. It is only necessary to thoroughly screen the houses, to avoid being bitten by the mosquitoes, and to fill or drain the places where they

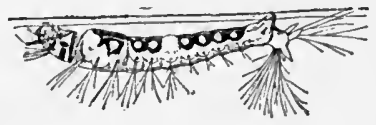
breed to stop completely the spread of this disease. Care should be taken to empty the water at least once a week from drinking troughs, barrels, etc., where the mosquitoes might breed. Tin cans, or similar water holders, should be buried or placed so that they cannot hold water. Cisterns and wells should be covered and everything possible done to prevent the multiplication of mosquitoes of any kind. The reward for such work will be a largely increased measure of comfort and health.

Note to the Teacher. - Bulletins on mosquitoes have been published especially by the United States Department of Agriculture and the state experiment stations at the following post offices: Berkeley, Cal.; Lexington, Ky.; College Park, Md.; Agricultural College Post Office, Miss., and New Brunswick, N. J. 
ExERCisE. - Catch some of the mosquito wigglers which you may fund in standing water and keep them in a glass partly filled with water, under a lantern glolse covered with cheese cloth. Watch the habits of the larvix and pupae. If you can find any of the boat-shaped egg masses of the common house mosquito or the single eggs of the malarial mosyuito, put them into a tumbler of water by themselves and watch them until they become full-grown mosquitoes.

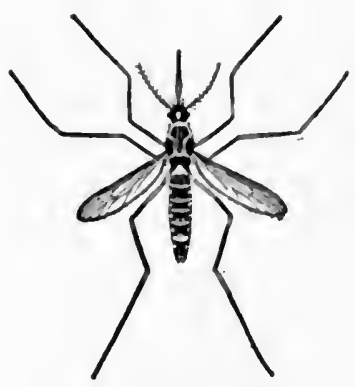

Fig. 178. - Mosquito that carries tile Yeliow Fever Gerd 


\section{SECTION L. THE HONEYBEE}

THE keeping of bees for the production of honey is an important industry in many sections of the country and is practiced to some extent nearly everywhere. The occurrence of nectar in flowers and the visits of the bees and other insects to the flowers to secure it are well-known facts. Many wild bees store honey, but the few kinds kept and cared for by man have developed FIG. I79. - Worker a wonderful ability to do this. Bees are
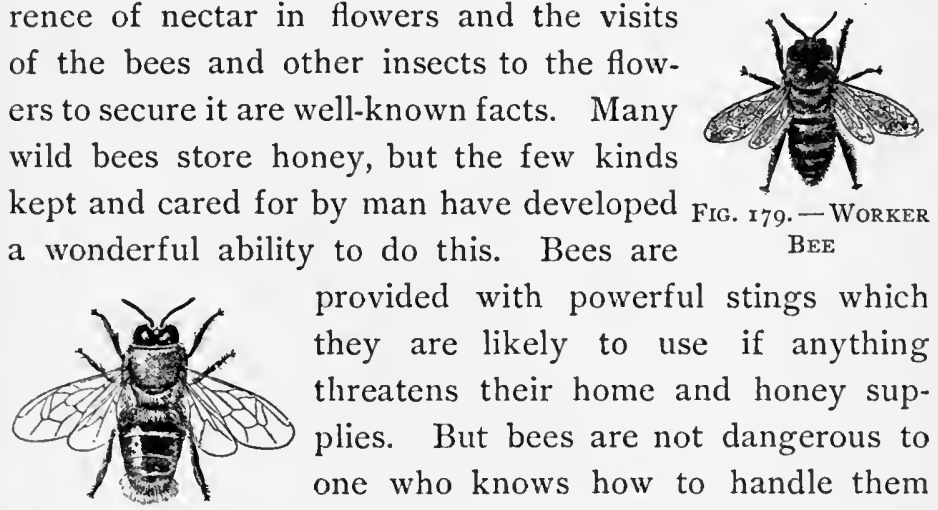

provided with powerful stings which they are likely to use if anything threatens their home and honey supplies. But bees are not dangerous to one who knows how to handle them Fig. r8o. - Drone BeE properly.

The members of a colony. - The workers number from 25,000 to 35,000 in a hive. These do all of the work of collecting and storing the honey and all of the housekeeping in the hive. Besides the workers there are a few male bees or drones, and usually only one queen (Figs. I79, I80, I 8I). If more than one queen is present, there will be warfare

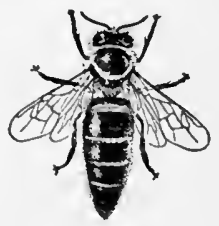
between the two until one is killed; or if the colony is strong and the honey supply abundant, part of the 
workers may leave the old hive with the new queen and found another colony. This is called swarming.

The work of the queen. - The queen bee is very carefully cared for by the workers, for upon her depends the very life of the colony. They feed her and do everything else possible for her comfort and safety. The reason for all of this anxiety about the queen is that she alone lays all of the many thousands of eggs for the colony. Her strength is saved for that work.

The bee nursery. - The worker bees build the honeycomb in which the honey is stored and in which the young bees are reared. Separate combs are used for these two purposes. While the honey is stored for food, the young bees are not fed upon it directly. They are not brought up in the cells with the honey. This is how it is possible to have the fine solid combs of pure honey.

When a comb is prepared for the rearing of the young, the queen is taken to it by the workers. She places one egg in the bottom, or rather in the inner end, of each cell. With that her work is done. But during the summer time, she may have to lay several hundreds or even thousands of eggs every day. Whether the young bee is to become a worker, a drone, or a queen depends largely upon the kind of cell in which the egg is placed and also upon the kind of food that the young bee is fed. The workers are developed in the ordinary sized, horizontal cells. The drone cells are much larger, but also horizontal, and the eggs deposited in these are supposed to be infertile. The workers can produce a queen when they desire by forming a larger vertical cell, placing in it an 
ordinary worker egg, and then feeding the young larva upon a special kind of food which is called royal jelly.

The bee larvæ are little legless creatures and are fed and cared for entirely by the workers. Their food is a mixture of honey with pollen. After they become adult they do not leave the hive for some days, but serve as nurses for the larvæ still in the cells. In about two weeks they also begin the collection of honey.

How honey is made. - When collecting honey, a bee usually visits only one kind of flower on a trip. The sweet nectar is carried in a special stomach from which the bee is able to expel it again for storage in the honeycomb. Upon its legs and body the bee carries pollen from the flowers it has visited. Bees really gather nectar, not honey. After the nectar has been stored in the comb, the bees fan it with their wings and dry out much of the water, and in due time it ripens into real honey.

There are so many things to be known in order to manage bees successfully that it has become a special business to which many people give all of their time. Upon the amount of honey produced each year depends the value of a colony of bees. From well-managed hives of selected bees and during seasons favorable for the growth of the honey-producing plants as much as several hundred pounds of honey may be stored by a single hive.

Length of life of bees. - The life of a colony of bees may be continued indefinitely, but the life of the individual workers is short in the summer time when they are flying a great deal. They wear their wings out and thus really work themselves to death, in a few weeks. The drones 
never live over winter and are usually killed by the workers during the fall. But the queen may live for several years. When a queen becomes old or exhausted, a new one takes her place and the life of the colony goes on steadily.

Producing select hives of bees. - The best kinds of bees have been developed in Italy. Among these are the Italian and the Carniolan bees. In some respects the latter are the best bees known. By placing a single fertile queen of one of these choice kinds in a hive of common bees, it will happen that in a few weeks or months all of the bees in the hive will be of her kind because she lays all of the eggs. This is the way colonies of choice bees are produced. Such queens are raised for sale by some beekeepers and can be sent long distances by mail.

Honey-producing plants. - For the best results with bees it is important that there be an abundance of good honeyproducing plants in the vicinity of the hives. Among the best plants for this are some of the clovers, alfalfa, vetches, and many of the common fruit trees. Sweet clover, which grows wild and which is also cultivated on lime soils in the Southern states, is an excellent bee plant. Many of the wild flowers and weeds are sources of abundant honey. supply. Cotton, cowpeas, and buckwheat are good. The magnolia, palmetto, tulip or yellow poplar, and sourwood are valuable sources of supply. Before undertaking beekeeping on a large scale the surrounding plant life should be carefully studied. Desirable honey-producing crops may be grown to help out the natural sources of supply. 


\section{SECTION LI. IMPROVEMENT OF LIVE-STOCK}

THE principal animals that add to farmers' profits are horses, mules, cattle, sheep, and swine. All of these animals have been greatly changed by man in order that they may better serve his uses. The active, slender, longlegged wild hog has been changed into the round-bodied, short-legged Berkshire or Poland-China. The angular, long-horned wild cattle of earlier days have been transformed into immense masses of flesh.

The changes that have occurred in domestic animals have been brought about chiefly by selection of the ones best suited to their owner's main purpose. Improvement in the kind and amount of food has also helped to make these changes.

Improving common or scrub live-stock. - A breed is a large group of animals that resemble each other and whose offspring inherit the same qualities. A pure-bred animal is one both of whose parents belong to the same breed. Scrubs or natives are animals having no ancestors that belonged to any distinct breed. Grades are animals descended from both pure-bred and scrub ancestors.

Fortunately for the farmer, the pure-bred parent has more influence than the scrub parent in determining the form, color, and useful qualities of the grade offspring. 
Hence, the best way to improve cattle or other live-stock cheaply is to purchase pure-bred sires, or males, and to use cheaper females. Starting with a pure-bred sire and scrub females the first generation are half-bloods. The second generation (or the offspring of these half-blood females and of a pure-bred sire) are three quarters pure; the members of the fourth generation are seven eighths pure, or high grades. The process of improving inferior animals by the use of pure-bred sires is called grading $u p$. It is the cheapest way for most farmers to improve their herds. The cheaper females intended as a foundation for the herd or flock ought to be selected from the best of their kind.

The high grades may be just as good for butter or beef or other special use as are the pure-bred animals, but for purposes of increase they are less valuable. This is because some of their offspring may resemble their scmb ancestors. It is unwise, therefore, to use either a grade or a scrub sire. A cross-bred animal is one having one parent belonging to one breed and the other parent to another. When the parents are thus widely unlike, the character of the offspring is uncertain. Such violent crosses are generally unwise.

Advantages of raising live-stock. - There are advantages in raising some live-stock even on farms devoted chiefly to cotton, sugar cane, tobacco, or grain. Some of the main reasons why live-stock ought to be raised on most farms are:-

(I) Because they make profitable use of much grass and other coarse food that would otherwise be wasted. 
(2) Because they enrich the farm directly, by converting most of their food into fertilizing material.

(3) Because they enrich the farm indirectly, by causing the farmer to grow more cowpeas, clover, and other soilimproving forage plants.

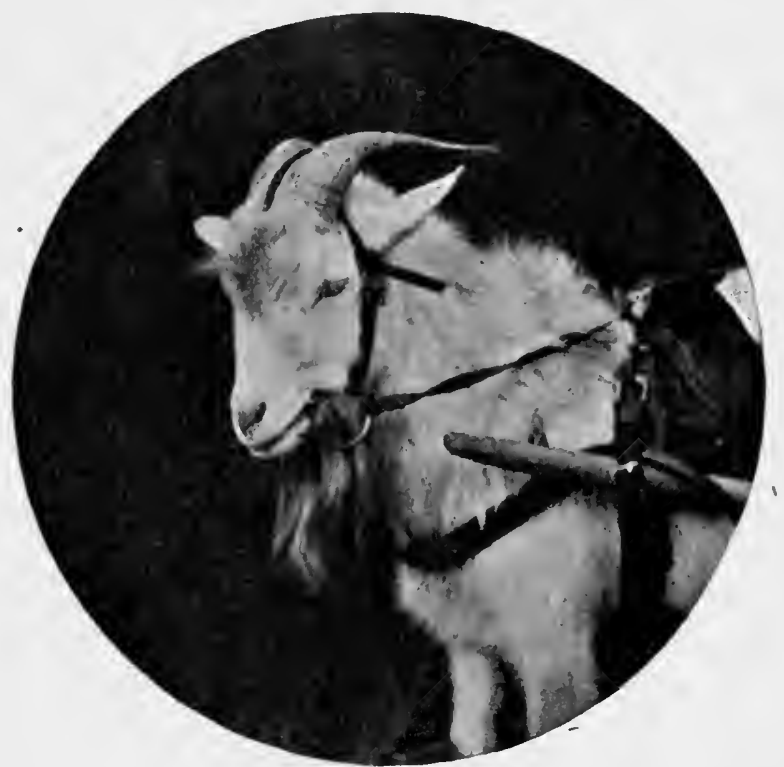

Fig. 182. - A TYPe OP Live-STOCK OFTEN RAISED IN Europe, but less Popular iN this Country

The picture shows a goat harnessed to a small cart, for children's amusement. 


\section{SECTION LII. HORSES}

THE three principal classes of horses are (I) draft horses, (2) coach or carriage horses, and (3) light riding and driving horses.

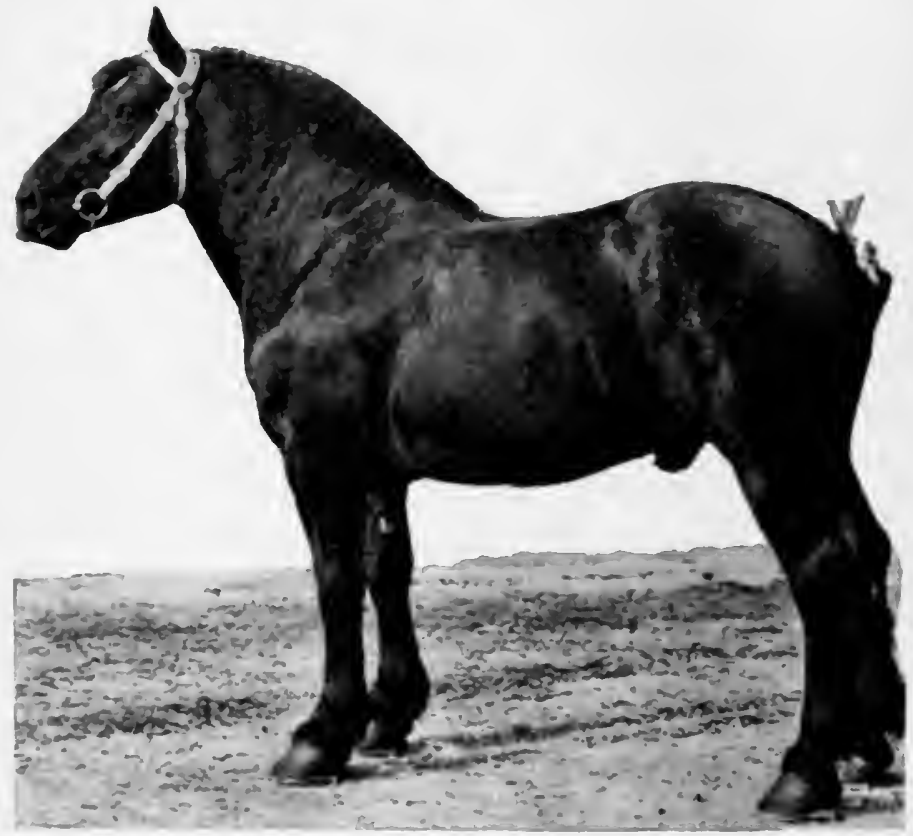

Fig. 183. - A Draft Horse; Percherox 1

Draft horses. - There are many breeds of draft horses, most of them coming from France, Belgium, England, and

1 All figures of horses and also Figs. 193, 194, 197, 199, and 200 are used by permission of The Breeder's Gazette, Chicago. 
Scotland. Draft horses are immense animals, generally weighing from 1500 to 2000 pounds. Their legs are rather short, very strong, and placed wide apart. Their bodies are rounded; their backs are broad, showing great development of muscles. Their shoulders are rather upright instead of sloping. This upright position enables them to

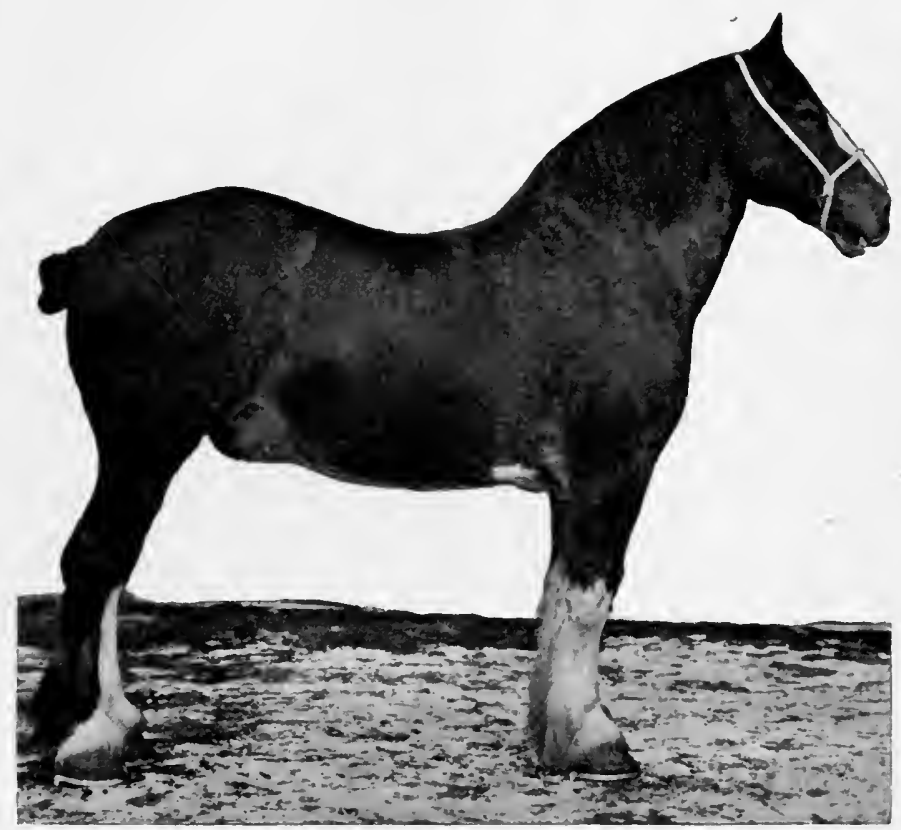

Fig. I84.-A Draft Horse; Clydesdale

throw their weight and strength squarely against the collar. Their feet are large. In the Southern states where the mule is a favorite work animal on the farm, the draft horses are used much less on the farms than in the cities. 
Percherons. - The Përch'e ron breed originated in France. It has become very popular in the United States. The colors that most frequently occur are black and all shades of gray. The Percheron horse is a very heavy, compactly built animal, with short legs free from long hairs (Fig.

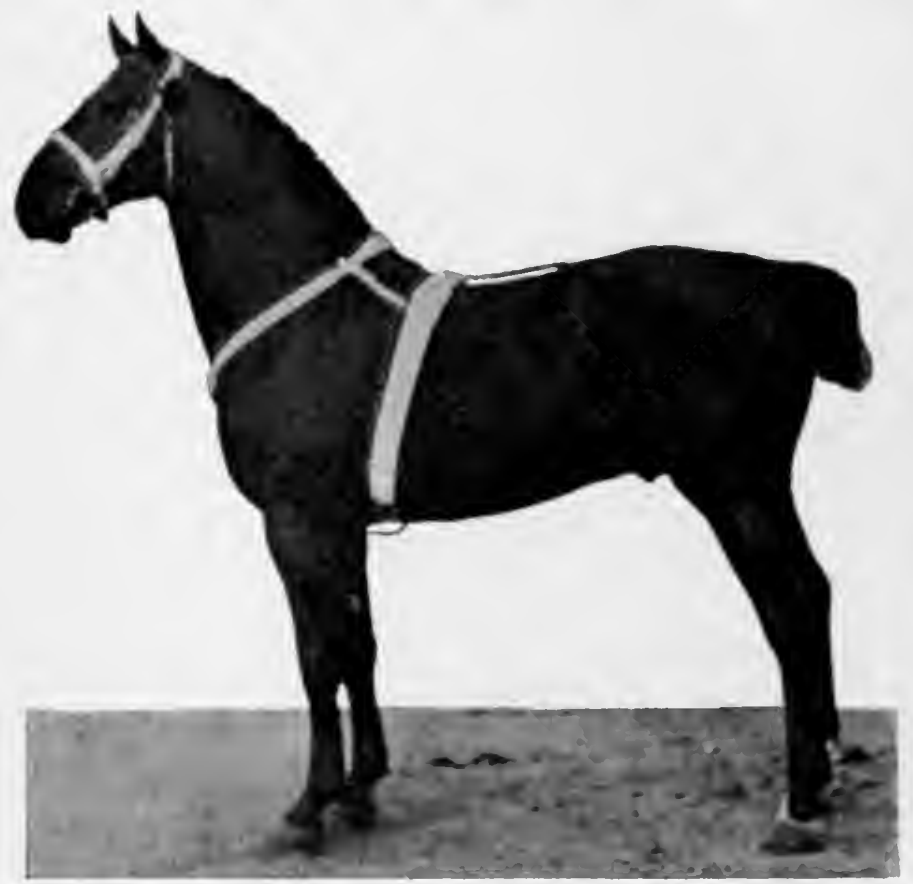

Fig. 185. - A CoAch Horse

183). A good Percheron shows style in form and movement, and in the proudly arched neck.

Clydesdales. - The Clydes'dale breed originated in Scotland. The colors are bay, brown, chestnut, or black; often 
there is white on the face and feet (Fig. 184). A fringe of long hair grows out behind the lower portion of each leg.

Coach or carriage horses. - A coach horse is a large, stylish animal, lighter and more active than the draft horse, but larger than light riding and driving horses (Fig. I85).

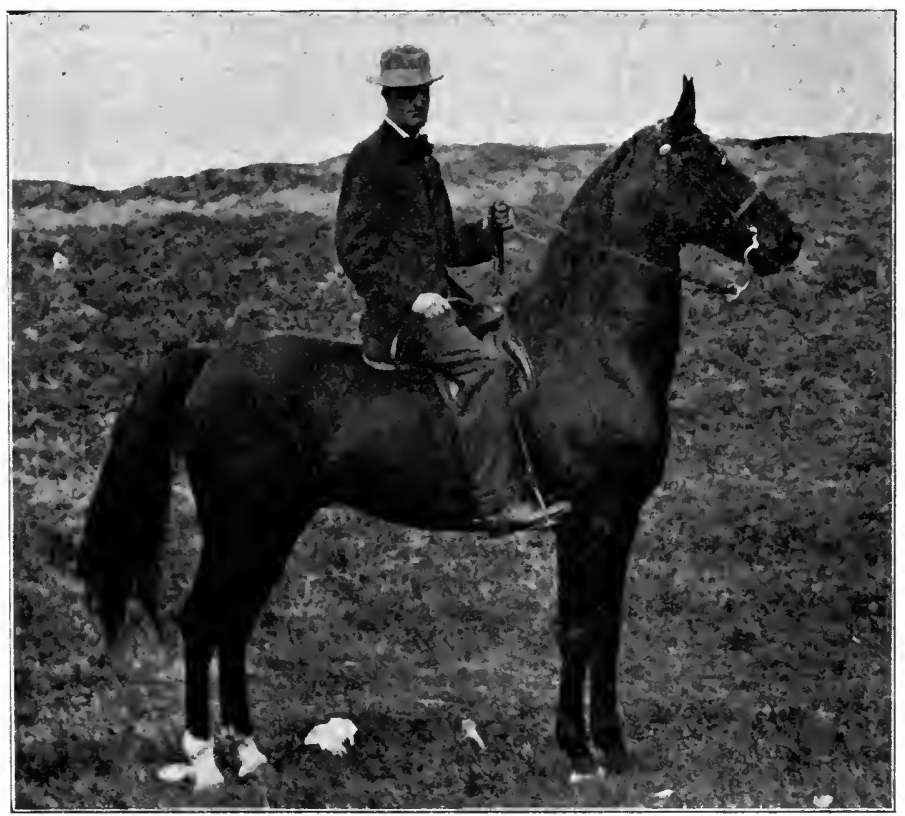

Fig. I 86. - AMERICAN SADDLE HoRSE

Light driving and riding horses. - These are formed for speed and hence have slender bodies, sloping shoulders, and long legs with sloping pasterns. Thoroughbred is the name of a breed of horses that are very speedy at the running gait. Thoroughbreds have been useful in giving 
speed, endurance, and other qualities to driving and riding horses descended from them.

Amcrican trottcrs owe their speed largely to their thoroughbred or running ancestors. They are largely used as buggy horses. The colors are various.

The Amcrican saddle horse is prized for its easy riding gaits. The best saddle horses are expected to have five gaits; namely, (I) walk, (2) trot, (3) canter, (4) rack (another name for single foot), and (5) either the running walk

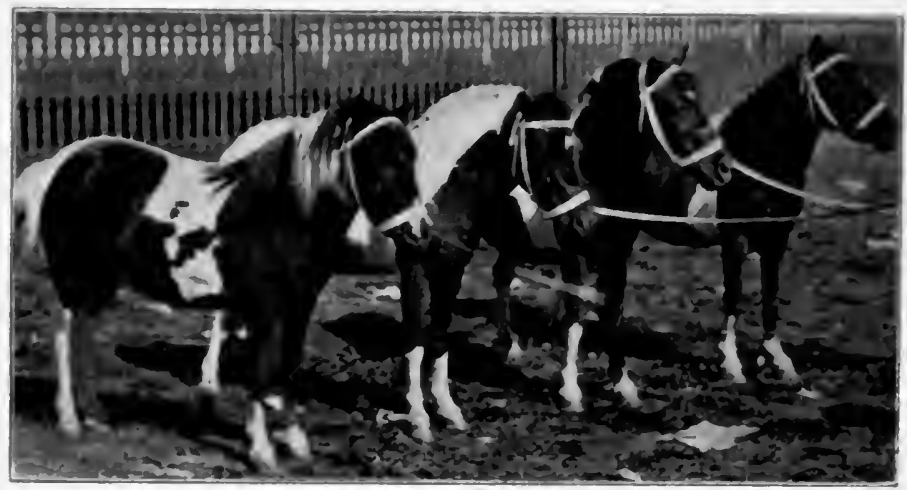

Fig. 187. - Siletland Ponies

or slow pace or fox trot. The saddle horse should be of medium size, graceful proportions, and should have stylish action and a good disposition (Fig. 186).

Shetland ponies. - These very small ponies are useful for children to ride and drive. They are usually gentle and make delightful pets. The height is oftenest from 36 to 42 inches (Fig. 187). Some ponies have been only 30 inches high. Most Shetland ponies are compact or "blocky" in 
form and stronger than their small size would suggest. Common colors are black, bay, and brown; grays, chestnuts, roans, and spotted ponies are not unusual.

Mules. - Mules are preferred to horses on Southern farms. They pull more steadily, are less high-spirited, and are put to work at an earlier age. Southern farmers can easily and profitably raise their own mules.

Care of horses and mules. - Some of the most important points in the care of horses and mules are these:-

(I) An abundant but not excessive supply of food, containing an ample amount of nitrogen.

(2) Clean, dry stables, so that the feet may not become diseased.

(3) Frequent watering, best before meals.

(4) Regular exercise.

(5) Careful shoeing.

EXERCISE. - Compare several horses with regard to the following points : slope of shoulders; slope of pasterns (the part of the leg just above the foot); size or fineness of the bones in the lower part of the leg.

Have you read "Black Beauty," a book that tells a very interesting tale about a horse? In reading it you will find not only pleasure, but also many useful hints about the proper management of horses. 


\section{SECTION LIII. BEEF CATTLE}

The beef type. - The chief use of the beef breeds is to furnish meat. The form that is desirable in a beef animal is one that affords the largest proportion of valuable meat and the smallest proportion of inferior meat and waste. Hence, the neck and legs should be short and the body full, deep, and rounded. The shape of a beef animal's body is "blocky"
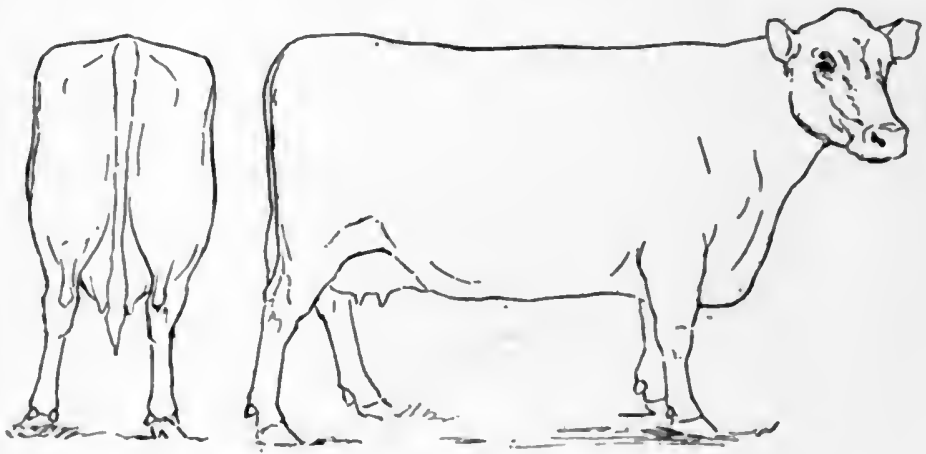

Fig. 888, - SHowing the Bref ForM

Vicws from behind and from the side.

and somewhat like that of a brick set on edge with the edges and corners rounded off (Fig. 188). The best cuts are those from the upper part of the body, especially in the region of the loins. The back and loins of a beef animal, therefore, should be broad and deeply covered with flesh. 
The hind quarters must be fleshy. Cows of .. the beef breeds usually give only enough milk for their calves.

Most beef breeds that are popular in the United States originated in England and Scotland. A mature cow of the beef breeds often weighs 1500 pounds or more, or nearly twice the weight of a scrub or Jersey cow. The males sometimes weigh more than 2500 pounds.

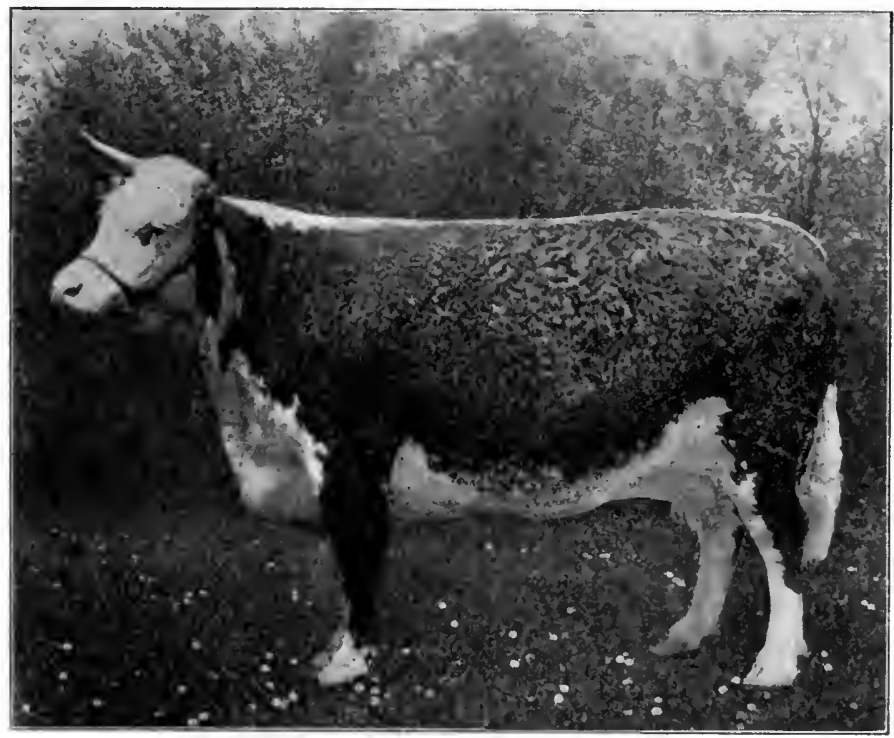

FIG. 189. - A HEREFORD

Even grade animals of the beef breeds are better than scrubs because they grow larger, mature earlier, and afford a larger proportion of valuable meat. All these advantages can be obtained by the purchase of a pure-bred sire. 


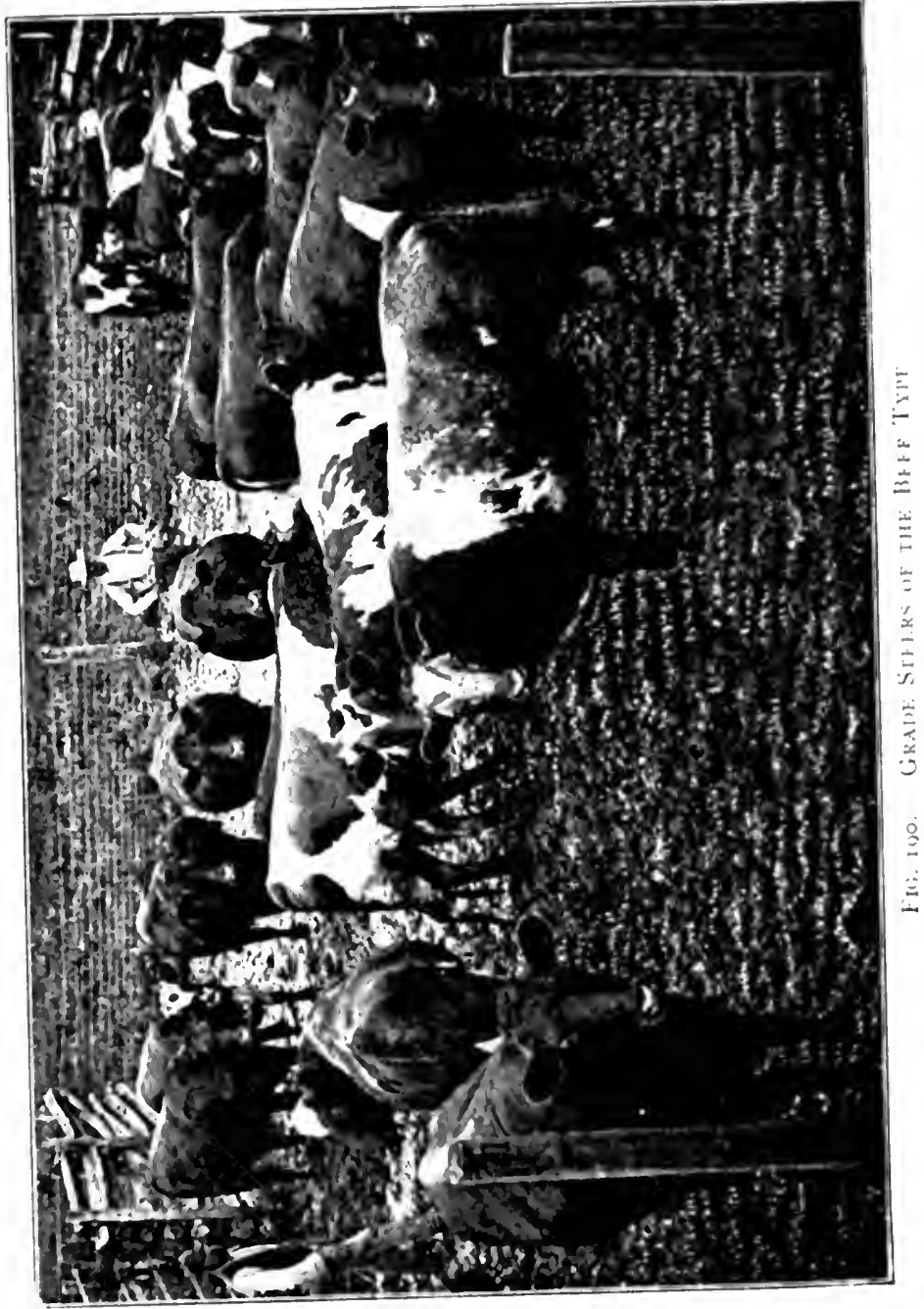


The Hereford breed. - These cattle are sometimes called "White Faces" (Fig. 189). The face, breast, legs, underportion, and part of the neck are white; most of the body is red. The Hereford is a very valuable and popular breed and has been found especially satisfactory for the Western ranges.

The Aberdeen-Angus breed. - Other popular names for this breed are Polled Angus and Black Polled. The color is black over the entire body. There are no horns; even among the half-blood Angus grades very few animals have horns. In size, the Angus is slightly below the Hereford and Shorthorn. It has a very blocky, rounded body. The Galloway (Fig. I9I) is another black, hornless breed.

The Shorthorn breed. - The horns are short, and in the cow they are gracefully curved. The principal colors are (1) solid red, (2) red and white mixed, and (3) roan, that is, a mottling of red and white. The Shorthorns are widely distributed over the United States. They are most valuable for beef, but in some families of Shorthorns the milkproducing quality has been maintained.

The Red Polled breed. - These hornless red cattle stand between the beef breeds and the dairy breeds. Red Polled cattle are smaller and generally less "blocky" than the beef breeds mentioned above. Their bodies, however, are rounded and plump. The breed includes many excellent milkers, and also many animals of the beef type.

EXERCISE. - At home or on the farms of neighbors select the most "blocky" cow you can find. Compare every part of her body with that of some more angular animal; also compare her shape with those shown in the pictures of the beef breeds. If especially interested in beef 
cattle, write to the Agricultural College of your state for score-card or publication showing how to judge beef cattle.

Note to THE TEACHER. - Encourage pupils to describe specimens of any of these beef breeds that they have seen. If the class can inspect some animal of the beef type, whether pure-bred, grade, or native, require them to locate the parts of the body where the greatest amounts of valuable meat are found. Compare the shape of this animal with the shapes shown in the pictures of beef cattle.

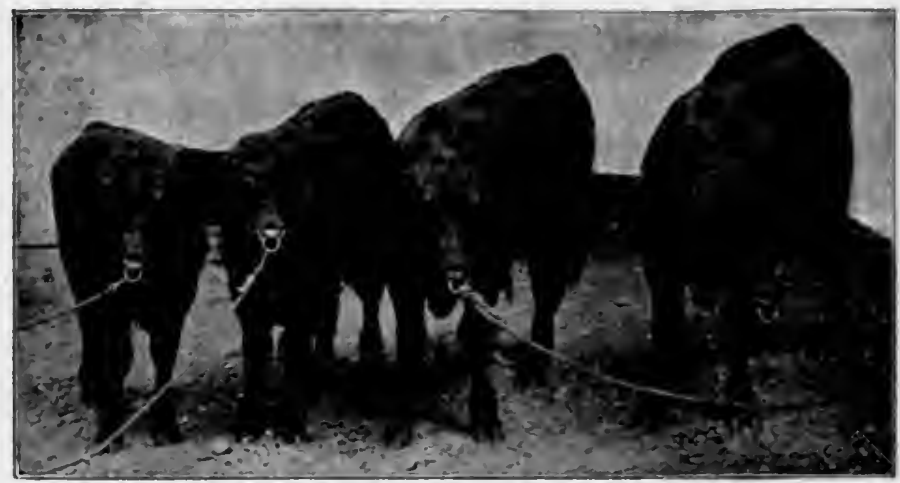

Fig. 191. - A Bunch of Galloway Steers 


\section{SECTION LIV. DAIRY CATTLE}

The dairy type of cattle. - The form of a good dairy cow should be almost the opposite to that of a good beef cow. She should have a thin back, wide, prominent, bony hips, and lean hind-quarters (Fig. 192). If there is much flesh on the back, loins, and hind-quarters of a dairy cow,
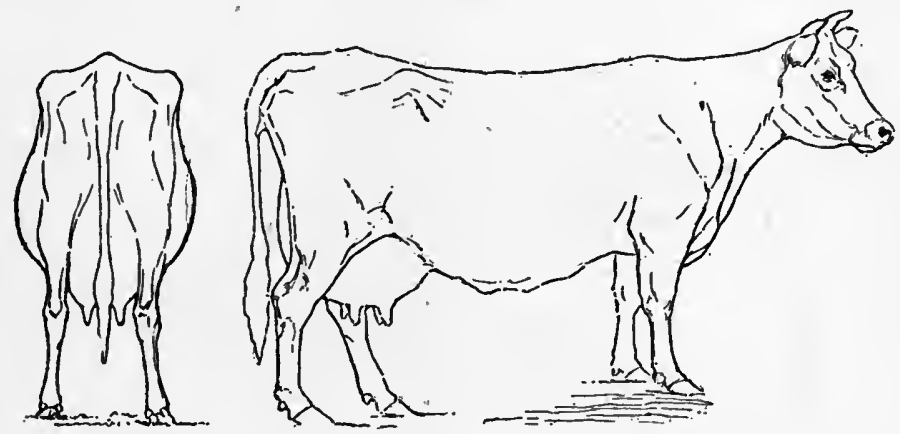

FIg. 192. - SHOWINg THE DAIRY FORM

Views from behind and from the side.

she has made wrong use of her food, which should have been changed into milk or butter.

The barrel, or rear portion of the body, must be large, so that in it she may store away much food while converting it into milk and butter. Viewed from the side, her body should be deeper at the hind flank than at the fore flank, giving a wedge-shaped appearance. Viewed from above, the dairy cow should also be wedge-shaped, having the narrow part at the withers on top of the shoulder blades and the wide part at the hips. 
The udder should be large and should extend well forward. The loose skin forming its rear portion should extend as high as possible. The milk veins in front of the udder should be large and crooked, and the "milk well" where they enter the chest cavity should be large.

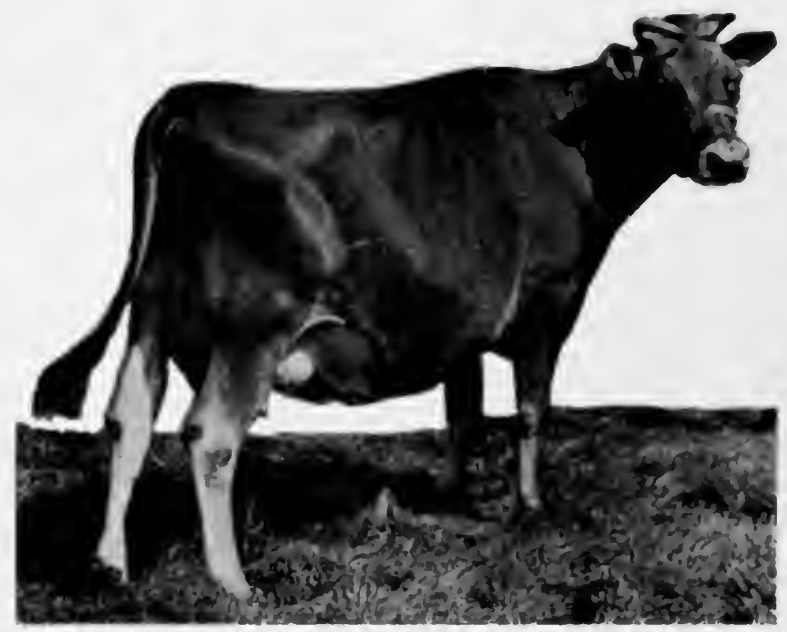

F1G. 193.-A JeRSEY Cow

The milk veins carry blood from the udder where it has helped make milk. If they are large, it shows that much blood flows past the udder for use in making milk.

The Jersey breed. - This breed originated on the little island of Jersey between England and France (Fig. 193). The laws of that island do not permit any other breed to be introduced. The Jersey is now the most popular dairy breed in the United States. This is because its milk is so rich. A Jersey cow often produces more than 
400 pounds of butter in a year, and some of them have records of more than twice that amount.

The Jersey cow has a small, angular, lean body, a fine and beautiful head with short crumpled horns, and usually a rich, yellowish skin. Common colors among Jerseys

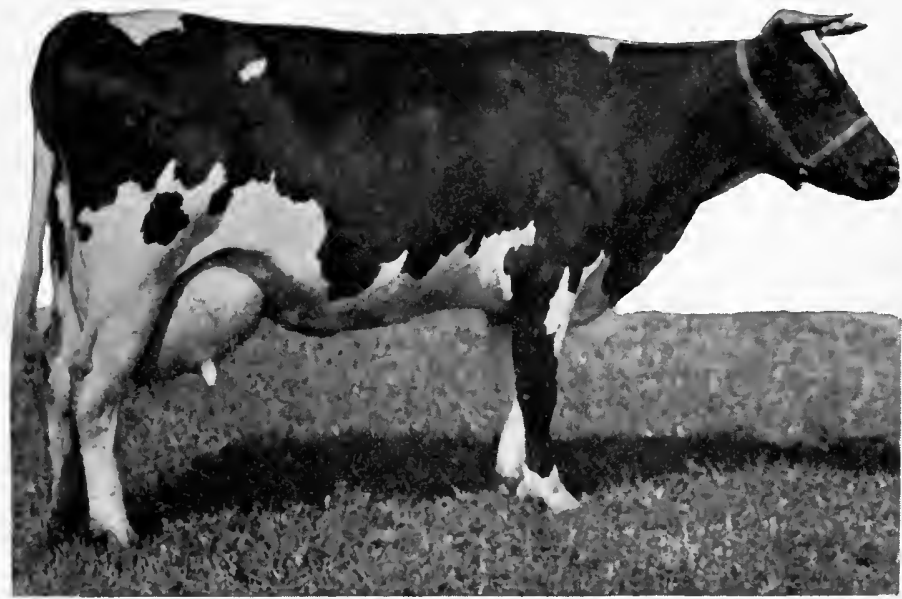

FIg. I94. - A Holstein Cow

are silver-gray and fawn color. White markings are frequent. The legs and nose are often black. A Jersey or even a Jersey grade can generally be distinguished from most other cattle by the "mustache." This is a ring of light-colored hair around the muzzle or nose.

The Guernsey breed. - This breed is very similar to the Jersey, but the form is somewhat larger and coarser, and light colors are less common. Guernsey milk is quite as rich as Jersey. These two breeds are entitled to be called the two principal butter breeds. The Guernsey 
originated on the island of Guernsey, which is near the island of Jersey.

The Holstein-Friesian breed. - These cattle (pronounced Hōl' stīne Frēz' yăn) originated on the rich land near the

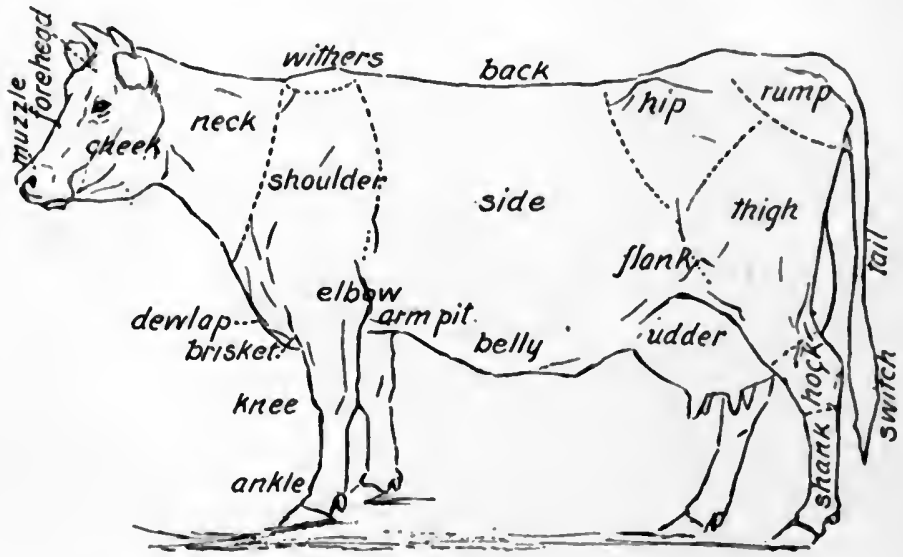

Fig. 195. - PARTS of the Cow

sea-coast in Holland (Fig. 194). They are large, angular, black-and-white cattle, and give larger amounts of milk than any other breed. Some cows have given more than Io gallons of milk in one day. However, the milk is not rich.

EXERCiSE. - Select some good milch cow of the dairy type. Make a drawing of the outer line of her udder. Locate the parts of her body, using Fig. 195.

Note to the TeACuer. - Doublless a good dairy cow an be inspected by teacher and class. If so, instruct pupils in locating parts of body and in noting their correspondence with the "dairy shape," as suggested in text and illustrations. This exercise will bear frequent repetition. Then compare, in all points, any two cows placed together. 


\section{SECTION LV. SHEEP}

LoNG before cotton was known, men and women wore garments made of wool. The sheep still furnishes a large part of our clothing. This animal is as useful for its flesh, called mutton, as for its wool.

Sheep are more easily kept than almost any other ani-

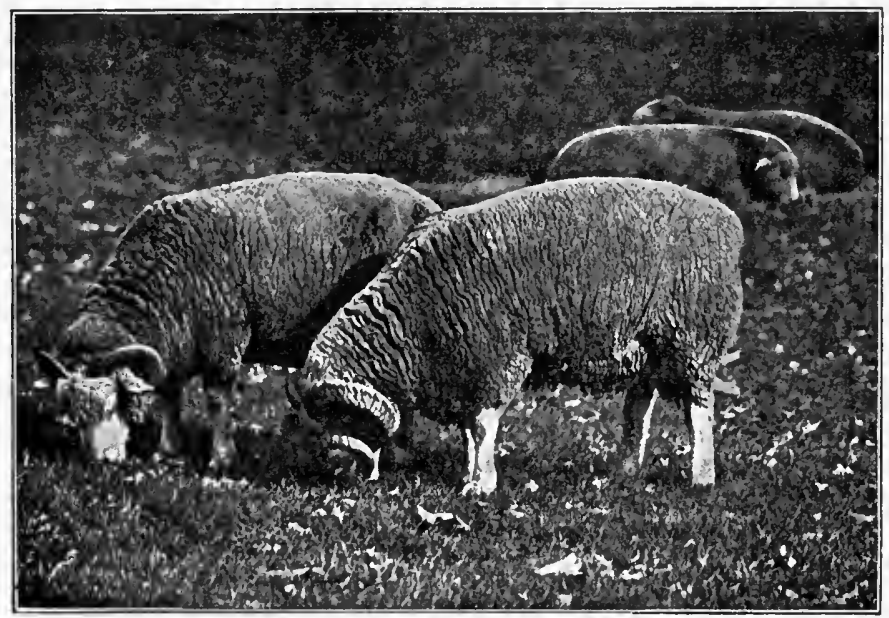

Fig. I96. - DORSET SHeEP

mal. They live chiefly on coarse feed that would otherwise be wasted and eat weeds which horses, cattle, and hogs will not touch. Thus they help to keep the farm clean and neat and improve the land on which they pasture. This explains the true proverb that "The hoof of the sheep 
is golden." Every farm ought to have its flock of sheep. The wool generally pays the cost of keeping them. The lambs are clear profit, and usually a flock produces more lambs than there are ewes. A lamb will often sell when a few months old for as much or more than its mother.

Unfortunately, sheep are subject to injury and death

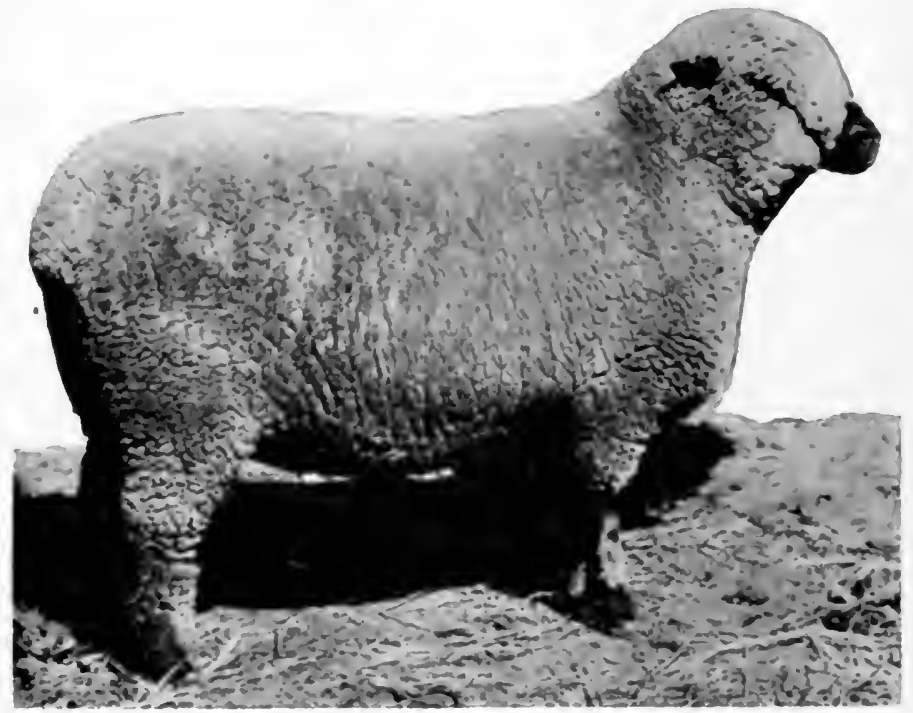

Fig. 197. - SHRophine SHefp

from worms in the stomach and intestines. Change of pasture at brief intervals is the best means of avoiding these troubles.

There are three types of sheep, fine-wool, mediumwool, and long-wool. The long-wool breeds, which are used both for mutton and wool, have not been extensively raised in warm climates. 
Medium-wool breeds. - The medium-wool breeds include the Dorset, Shropshire, Southdown, and others. They afford good mutton and a fair amount of wool.

The Dorset is a sheep of medium size. Both sexes have horns. Dorsets are prized for the early date at which their lambs come and for the frequent occurrence of twin lambs (Fig. 196).

The Shropshire (Fig. 197) is of medium size or above.

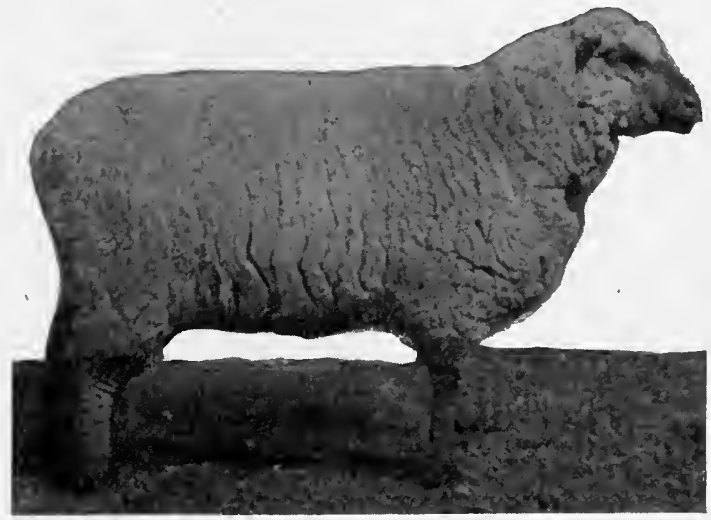

F1G. I98. - A Southdown

It is a popular breed in all parts of the United States. The color of the face, ears, and legs is very dark brown or black. The Shropshire has no horns.

The Southdown (Fig. 198) is a favorite mutton breed over almost the whole world. Its face, ears, and legs are of a brownish color, but of a lighter shade than those of the Shropshire. The Southdown is a little smaller than the Shropshire and affords somewhat less wool. 
The fine-wool breeds. - These include several breeds of Merinos (Fig. 199). Merinos are most valuable for the

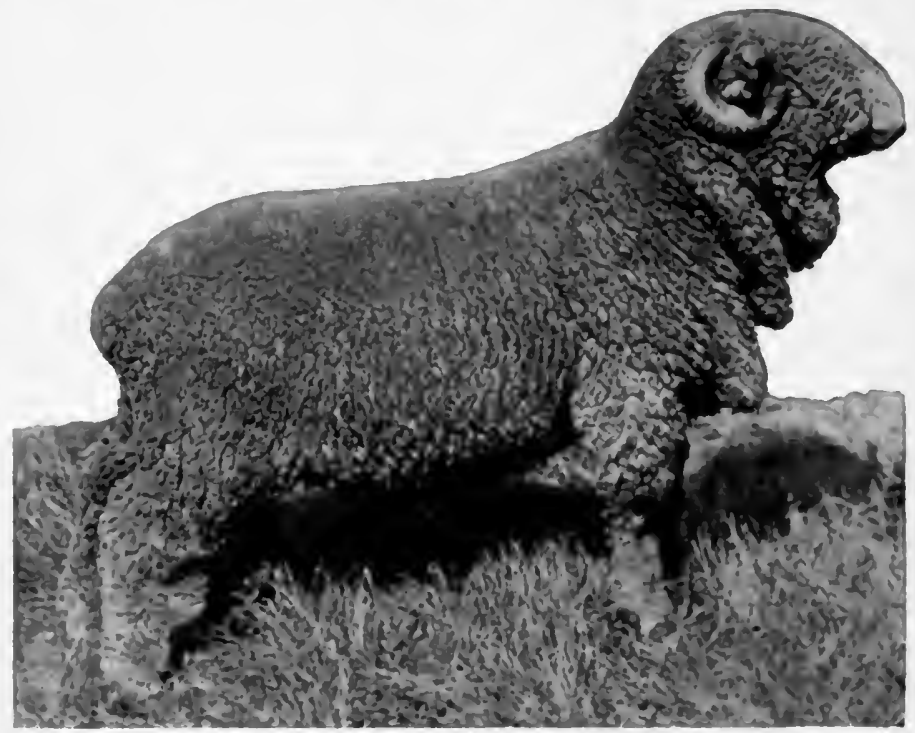

Fig. 199. - A MERINO

production of wool, but are not the best for mutton. The wool is much greater in amount and contains more grease than that of other breeds.

EXERCISE. - Write in your notebook the month in which shearing is done, asking older persons if you do not know. If any member of the class has seen sheep sheared by machinery, he should be prepared to tell how it was done. If there is a flock of sheep near you, watch them while grazing and notice the weeds that they consume which other live-stock would not eat. 


\section{SECTION LVI. SWINE}

IT costs so little to make a start in improving the hogs on any farm that scrubs, or razorbacks, ought soon to disappear. Pure-bred hogs and grades mature at a much earlier age than scrubs and grow to a much larger size.

Hogs are healthier and much more profitable when they live partly on pasturage. But even with the best pastures of grass or clover, it pays to feed them some grain. In the Southern states, hogs can be raised on very little corn by growing artichokes, chufas, vetches, clovers, and alfalfa for them to eat in cool weather. When the weather becomes warm, there should be ready for them fields of sorghum, cowpeas, peanuts, and soy beans, besides pastures.

It costs less to put a pound of flesh on a young hog than on one more than a year old. It is generally more profitable, therefore, to make a pig grow large enough to be made into pork when ten to twelve months old than to feed it longer.

Hog cholera and swine plague destroy great numbers of hogs every year. They are due to germs that have been brought from other places where the diseases have occurred. They are carried by means of running water, by loose animals, by buzzards, and even by the shoes of men. These diseases can generally be prevented by not allowing the hogs to range outside of their pasture, and by keeping out of the hog pasture and lots everything that has been 
on a farm where these troubles have recently occurred. It is safest for hogs not to drink water from a stream that originates beyond one's own property.

Breeds of hogs. - There are many breeds of hogs. Among the most popular are the Berkshire, Poland-China, Duroc-Jersey, and Chester White.

The Berkshire is a large or medium black hog with white

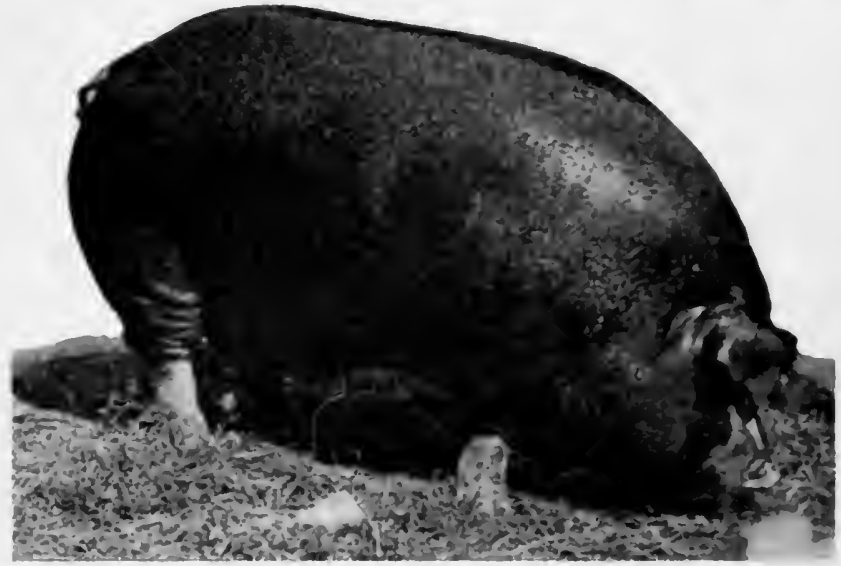

Fig. 200. - A Poland-China

markings on the face, feet, and legs. The face is short and sharply dished. The ears are held stiff or rigid.

The Poland-China is a large or medium black hog with slight white markings on the face and feet. The face is not sharply dished. The tips of the ears droop (Fig. 200).

The Duroc-Jersey is a large reddish hog with shape of face and ears like the Poland-China. There are many pigs in a litter. 
The Chester White is a large white hog with drooping ears. White hogs are regarded as less hardy in the South than those of other colors.

EXERCISE. - Compare a pure-bred or good grade hog with a razorback, noting especially differences in nose, neck, back, and hams.

Note to the Teacher. - Write to the Agricultural College in your state for score-card for judging hogs. These sheets contain sufficient directions. It is instructive and interesting, after some practice in judging fairly good hogs, to have pupils engage in a judging contest.

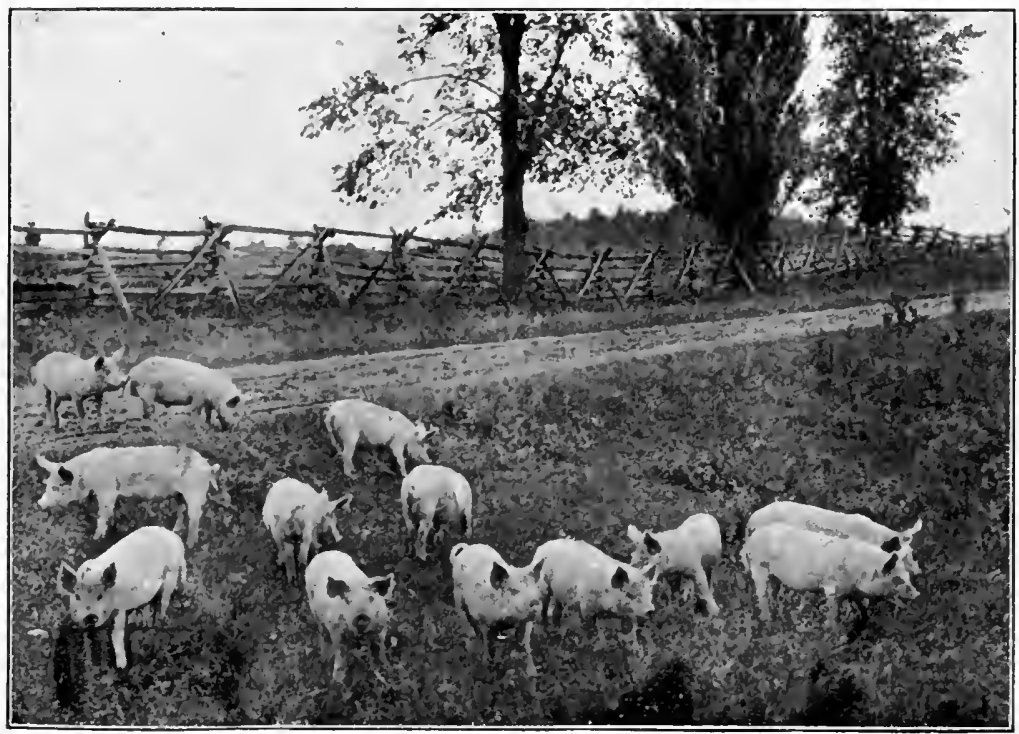

F1G. 2OI. - SHOATS ON PASTURE

Can you expect the same plumpness in young shoats living largely on pasturage as in older fattening hogs? 


\section{SECTION LVII. THE MANAGEMENT OF POULTRY}

THE poultry products of the United States are estimated to be worth about five hundred million dollars each year. The hen has even a stronger claim than this on our care. In her eggs and in the flesh of her chickens she furnishes the most nutritious kind of human food. Fowls are still further useful on the farm because of the large numbers of injurious insects that they destroy. They also make profitable use of waste material, such as grass, surplus vegetables, bruised fruit, and spilled grain. Some kinds of fowls afford valuable feathers.

Improving the flock. - By saving eggs from only the best layers for hatching there will be every year an increase in the number of eggs laid by the flock. Hens have been raised that produced more than two hundred eggs in a year (Fig. 202). This was done by selecting through several generations the best layers and the roosters hatched from eggs laid by the best hens. Those who cannot at once have pure-bred fowls should improve the flock by using only pure-bred cocks.

Food for poultry. - Fowls lay best and grow best when allowed some exercise. The insects that they catch while ranging in orchard or pasture or field form a mos: nutritious diet. When fowls are not permitted to range, 
the food given them must be rich in nitrogen. Foods suitable for supplying nitrogen to poultry are the seeds of cowpeas and soy beans, leaves of clover and of all legumes,

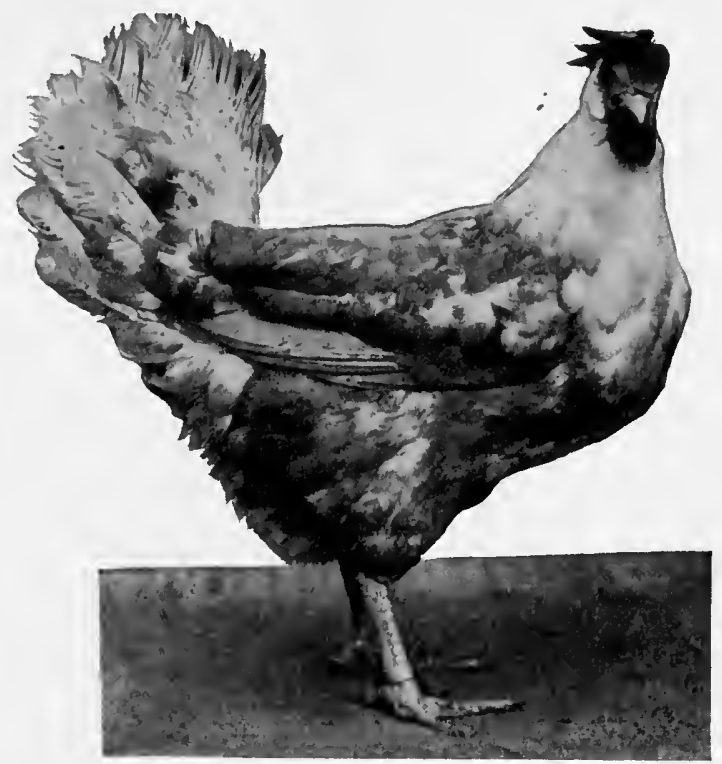

Fig. 202. - A Waite LeghorN HeN that Laid 216 Eggs in TEN MONTHS

meat scraps, skimmed milk, and fresh, ground bones. These should be fed mixed with the usual daily supply of corn, wheat, or oats.

Poultry thrives best when furnished with a variety of food and when constantly supplied with green food. A field of rape, alfalfa, or clover should be grown especially for poultry. When fowls are confined, green food ought to furnish part of the daily ration. 
Grit. - Fowls prepare their food, not by chewing it like larger animals, but by grinding it against grit in the giz. zard. Hence, fowls must have an abundance of grit, which may be sand, gravel, cinders, pounded glass or oyster shells, or any finely divided hard substance. If they range, fowls can pick up enough of this. If confined, they should be supplied with some form of grit, as clean sand or crushed oyster shells. The oyster shells are especially useful to laying hens because, besides serving in the gizzard to grind the food, they furnish lime. Much lime is needed to form the shell of the egg.

Destroying vermin. - The profits from poultry are much reduced by the discomfort caused by lice and mites. When fowls can scratch and roll in the dust, the dust of ten suffocates the lice. A box of fine dry road-dust, or sifted ashes, should be kept in the poultry-house so that the fowls can regularly take their dust baths and thus destroy many vermin. Chicken mites are not all thus killed. Many leave the fowls after tormenting them all night, and spend the daytime on the roosts and walls of the poultry-house. Hence, the house ought to be whitewashed frequently with a lime wash to which crude carbolic acid has been added. The orchard spray pump may be used and the walls and roosts sprayed either with this kind of whitewash or with kerosene emulsion. Directions for making this mixture, so useful for killing insects, are given in the Appendix.

By having the nests movable, these can be brought out of the hen-house at frequent intervals and the straw burned, thus ridding them of vermin. Some poultrymen dip their 
fowls in a mixture made of fifty parts water to one part of chlō' rō năph thō' lē um.

Water. - Chickens need a constant supply of clean water. A good way to keep it clean is to buy a water fountain in which they cannot make the water unclean.

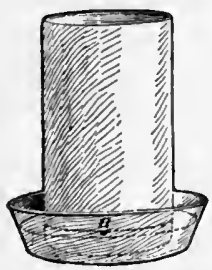

FIg. 203.- A Hоме-

MADE DRINKING Fountain $a$, hole in inner tin can A home-made drinking fountain can be made as follows : with a nail make a hole in a can about half an inch from the open end. Fill the can full of water and over it place a pan about two inches deep. Quickly invert both. The water will stand in the pan as high as the hole in the can (Fig. 203). Poultry-houses, incubators, and brooders. - A good poultry-house should be ventilated, but not crossed by draughts of air. Sunshine should be let in to keep it dry and to destroy germs of certain diseases. The roosts should be movable and smooth, so as not to afford hiding places for vermin. Some careful poultry-breeders build a platform under the roost and a foot or two below. This keeps the floor clean and saves all the manure, which is much richer than that from the larger farm animals.

EXERCISE. - Weigh a dozen eggs; write the weight in your notebnok. Are they all of the same size? Of the same color? Try to think why eggs that have become greasy do not hatch well.

Note to The TEACHer. - Encourage statements from pupils about familiar facts connected with the management of poultry, kinds of foods used, best location of nests for different fowls, etc. If any one can find an old can and pan, let him or her make a drinking fountain, and show in class how it operates. See whether any pupil would like to make one for use at home. Parents would appreciate one. 


\section{SECTION LVIII. BREEDS AND VARIETIES OF CHICKENS}

Ir has been found easy to create new breeds of chickens by selection and by crossing. As a result, there are now more than one hundred varieties of chickens. These may be divided into four general classes, according to the use to which each is best suited. These classes are :-
(I) The egg breeds.
(2) The egg-and-meat breeds.
(3) The meat breeds.
(4) The fancy or ornamental breeds.

The egg breeds. - The breeds of this class are so named because they lay more eggs than those of the other classes. The fowls are small and active. They are poor sitters. Among the leading egg breeds are the Leghorns, Minorcas, Spanish, Red Caps, Andalusians, and the Hamburgs. They mature early, pullets beginning to lay before they are five months old. The eggs of this class are generally pure white.

Most breeds of each class are again subdivided into varieties named according to color of plumage or shape of comb. In other respects, these varieties of each breed are alike. The Leghorns include eight varieties; among them are the White, Brown, and Buff Leghorns. A Leghorn hen should lay between 150 and 200 eggs in a year (Fig. 


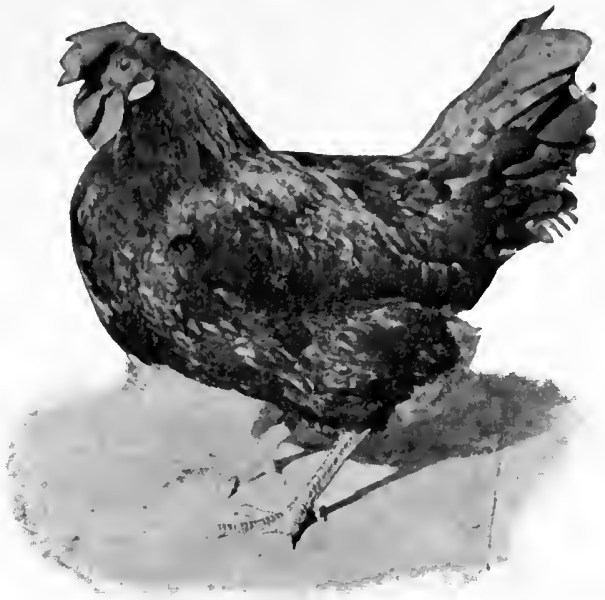

FIG. 204. - Black Minorca HeN

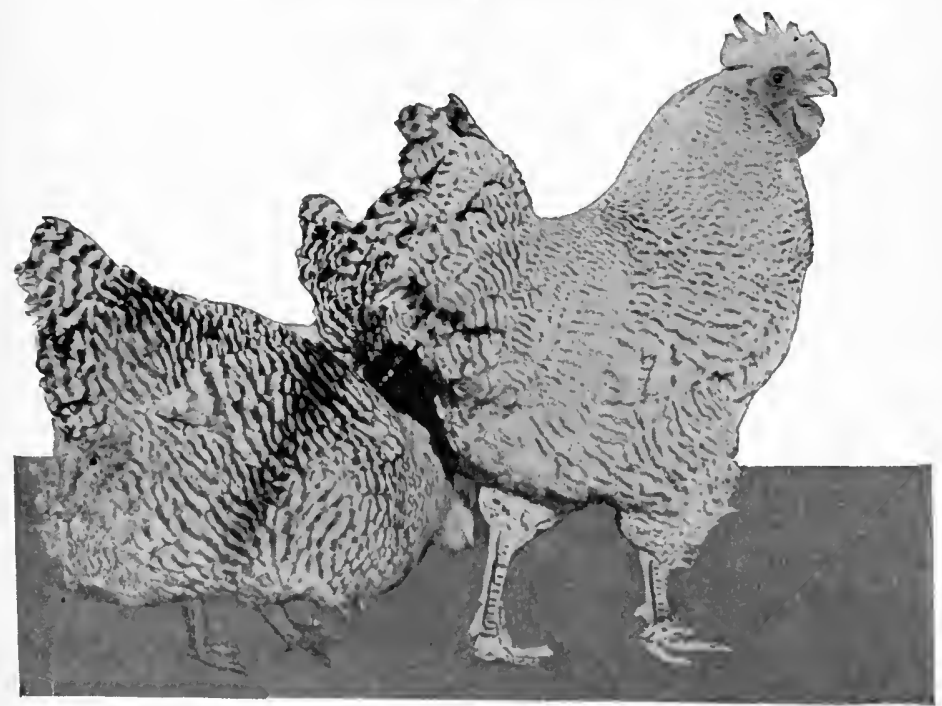

Fig. 205.- Barred Plymouth Rocks 
202). Minorcas (Fig. 204) include both black and white varieties. Their eggs are larger, but not so numerous as

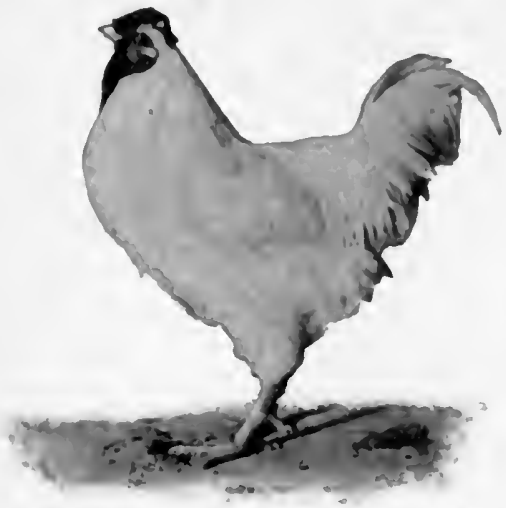

FIG. 206. - WHITE WYANDOTTE those of the Leghorn.

Egg-and-meat breeds. - Hens of this class are of medium to large size. They are good layers, though not equal in this respect to the egg breeds. They are good sitters and mothers. Their eggs are usually of a brownish shade of white, and so are those of the meat breeds. Among the most popular breeds of this class are the Plymouth Rocks (Fig. 205), Wyandottes, Rhode Island

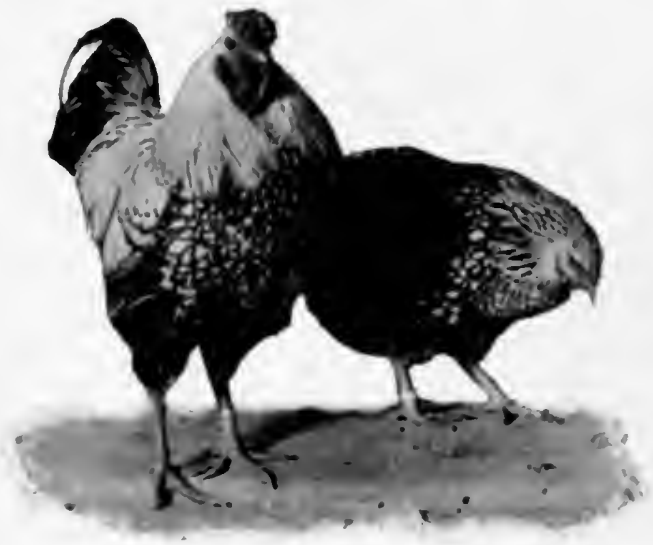

Fig. 20\%. - SiLVER-LACED Wyandotte 
Reds, and Orpingtons. There are three varieties or colors of Plymouth Rocks, Barred (Fig. 205), White, and Buff. Wyandottes are divided into eight varieties, including the White (Fig. 206) and the Silver-laced (Fig. 207).

Meat breeds. - These include the largest fowls. The hens lay fewer eggs than do the hens of either of the other classes. These fowls are gentle and good sitters. Their large size renders them less active and less able to search for food than the smaller breeds. Hence, they require more care and food.

The principal meat breeds are the Brahma (Fig. 208), Cochin, and Langshan. Each is subdivided into varieties of different colors. The Light

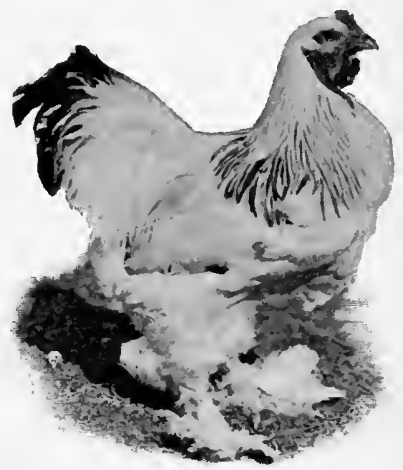

Fig. 208. - Light Brahma Rooster Brahma is the largest of all chickens. All three breeds have feathers on the leg or shank.

EXERCISE. - Write in your notebook the names of all the breeds of chickens you know. What is the color of each ? What is the color of the leg or shank? How many toes have chickens? Why are the feet of ducks and geese different from those of chickens and turkeys?

Note to THE TEACHER. - For fuller description of each breed and variety of chickens, write to United States Department of Agriculture for Farmers' Bulletin No. 51. 


\section{SECTION LIX. PRINCIPLES OF FEEDING ANIMALS}

Animals cannot feed on the minerals in the soil nor on the carbon dioxid in the air. The plant lives upon both. The chief use of the plant to man is in chang. ing the minerals from the soil and the carbon dioxid from the air into substances fit to nourish man and his servants, the domestic animals. Plants form the natural food of the animals of the farm.

The same classes of substances are found in the bodies of plants and animals. These are water, ash, and protein (that is, materials containing nitrogen). Each of these substances in the plant goes to form somewhat similar matter in the animal body. But plants contain substances not found in the flesh of animals; these are starch and sugar. Yet starch and sugar are among the most important foods of animals. Instead of adding these to its own body unchanged, the animal converts starch and sugar into animal fat, or uses them as fuel.

Ash. - This is the part of the dry matter of plants or animals that will not burn. There is generally an abundance of ash in the common foods to supply all that animals need. But pigs fed on corn alone without any pasturage may be helped by giving them wood ashes, which aid in the formation of their bones and in other ways. Fowls 
too, when confined and fed on corn, need ash, in the form of ground bone and the like.

Protein. - In plants and animals most substances con-

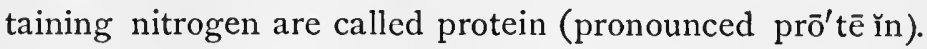
Forms of protein are the white of eggs and the curd in soured milk. The protein of plants is used by the animal to make lean meat, muscles, blood, and curd in milk. Men or farm animals doing heavy work require an abundance of this substance. So do cows when giving much milk. Among the foods richest in protein are cotton-seed meal and both the hay and the seeds of leguminous plants. Indeed, seeds of all kinds contain a considerable proportion of protein.

Fuel for heat and force. - The animal body is a machine with much work to do. Even an idle horse expends some force or work in the circulation of the blood and the digestion of food. All the work the horse has to do increases the force or energy he must expend. Hence, the horse needs to use a part of his food to produce force or motion just as much as a steam engine needs burning coal to furnish power. An animal needs some food to serve as fuel to keep the body warm. Thus a part of the food is consumed, or slowly "burned," in the body in order to be changed into heat and force. Among the substances that serve as fuel to produce heat and force are starch and sugar. Starch, sugar, and the coarse fiber of plants are called cär bō hy $\bar{y}^{\prime}$ drātes. This is because they consist of carbon and hydrogen, in addition to oxygen.

Fattening. - An animal that digests more carbohydrates than it needs for heat and force changes the surplus into 
fat, which it stores in its body, or adds to its milk. No fattening can occur until after all food necessary to do the work of the animal's body has first been provided.

Fat. - Fat or oil is abundant in the seeds of some plants, as in cotton seed, flaxseed, soy beans, and peanuts. The fat of plants can be used by the animal to make fat in the

HOW THE ANIMAL USES THE FOOD IT GETS FROM THE PLANT. KIND OF FOOD

USED IN

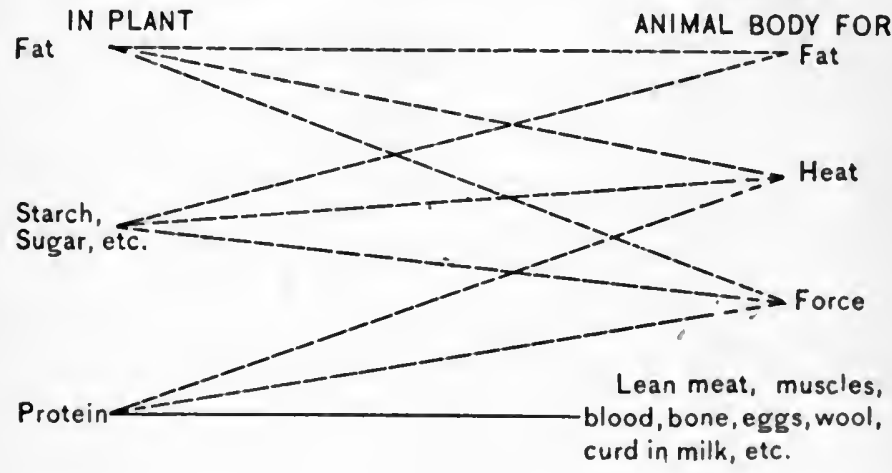

Ash

Bones, eggshells, ash in lean meat, milk, etc.

animal body. Fat in the food is also used for fuel to produce heat and force. Indeed, one pound of fat when burned makes about two and one fourth times as much heat as one pound of carbohydrates.

If it does not have enough protein, the animal will suffer, because nothing else can take the place of protein in making lean meat, muscles, blood, bone, eggs, wool, and curd in milk. However, if fats or carbohydrates are omitted 
entirely, the other substances can take their place. But the omission or insufficient supply of any of these is unwise and unprofitable.

Animals differ in the use of food. - Young animals require less food than older ones to increase their weights equally. It is much more profitable to fatten a hog less than a year old than one nearly two years old.

Hogs and chickens require most of their food in condensed or concentrated form. Horses need about half concentrated food and half bulky food, like hay. Cattle and sheep may do well on a ration that consists chiefly of bulky foods.

Animals of the same breed differ greatly in the use they make of their food. One fattens on much less food than another does. Experience and study enable good judges of animals to select those that fatten most readily.

Exercise. - Weigh an exact quart or gallon of corn, corn meal, wheat bran, cotton-seed meal, and any other common "grain feeds" that are convenient. Write the weights in your notebook and compare them with the weights that your classmates find. Ask your parents what are the cheapest foods for feeding cows.

Note to THE TEAcher. - No portion of the tables following is to be memorized. They are for reference in working problems suggested in the next section. In case the sixth grade studies this book, or in case the class is backward in arithmetic, the whole of the next section may be omitted. Do not, however, omit Section LIX. If the class has studied an elementary book on physiology, require the pupils to read now those parts of it bearing on digestion and food. 


\section{SECTION LX. CALCULATING RATIONS FOR LIVE-STOCK}

A RATION is a supply of food for an animal for one day. It is called a balanced ration when it contains just the proportion of digestible protein to the carbohydrates and fat that tests have shown to be best for that particular kind of animal. A balanced ration for most animals contains five or six times as much digestible carbohydrates and fat as digestible protein. The proportion between digestible protein and carbohydrates and fat is called the nutritice ratio. It is obtained by multiplying the fat by 21 , adding this product to the carbohydrates, and dividing the sum by the quantity of protein.

The table on page $32 \mathrm{I}$ shows what amounts of each of these substances have been found best for different kinds of animals. The longer table on page 322 shows how many pounds of digestible substances there are in 100 pounds of the most common foods. From these two tables can be calculated a ration that is best for a cow giving milk, for a work horse, or for other animals.

Examine both tables to learn whether a ration for a horse at medium work could be made from corn and oat straw. The shorter table shows that a ration for a horse ought to contain about 6.2 times as many pounds of di- 
gestible carbohydrates and fat as of protein. The longer table shows that corn has 9.8 and oat straw 33.8 times as much carbohydrates and fat as protein. Evidently a mixture of corn and oat straw contains too large a proportion of carbohydrates, which means that it contains too little protein. This protein can be supplied by using cowpea or clover hay in place of the straw.

In feeding animals first be sure that enough protein and carbohydrates are supplied. It may be proper to give a slight excess of protein if this does not increase the cost. The more protein fed, the richer is the fertilizer.

Example. - Calculate a ration for a cow producing 22 pounds of milk per day, using grass hay, cotton-seed meal, and corn. The table on page 321 shows that a cow needs 2.5 pounds digestible protein, 13 pounds of carbohydrates, and .5 of a pound of fat. Start by guessing how much of each food might perhaps serve. Take 15 pounds of hay, 5 pounds of corn or corn meal, and 3 pounds of cotton-seed meal. By dividing the figures in the table on page 322 by 100 so as to find the weight of protein, fat, etc., in every pound of grass hay, cotton-seed meal, and corn respectively, the calculations in the first table can be made. (See page 320.)

The ration is thus figured to be 15 pounds grass hay, 8 pounds corn meal, and 3 pounds cotton-seed meal.

The calculated ration contains more than enough protein and fat, but lacks about one pound of carbohydrates. Its excess of fat, .31 of a pound (after being multiplied by $2 \frac{1}{4}$ ) makes up most of this deficiency. The calculated ration need not contain the exact amounts required in the standard rations in the short table.

ExERcise. - In preparing this lesson pupils should rule their notebooks as in the next table; copy the example; understand how every figure is obtained; and perform the suggested multiplications. To work the optional problems, the notebook should be ruled in the same way as in the example worked. 


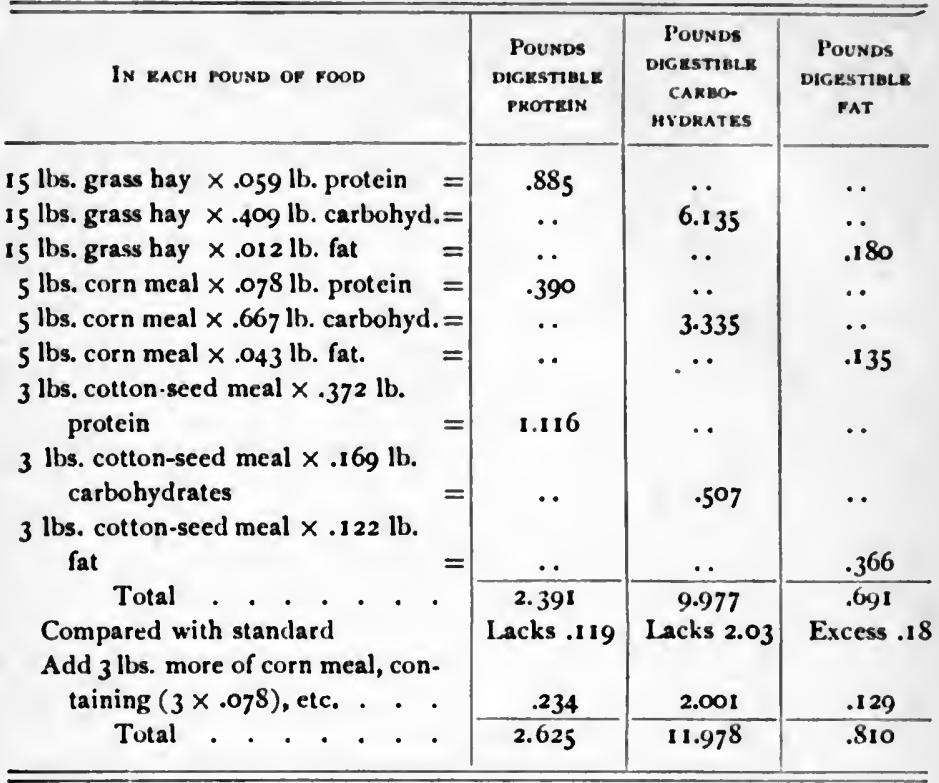

Note to THE TEACHER. - The following problems are optional, and, if assigned, they should be divided into several lessons. They are solved in the same way as the example just given, and may be supplemented by original problems requiring calculations of rations for any class of animals, using the foods most common in any locality. Rations consisting largely of cotton seed and cotton-seed meal cannot be made to approach very closely to the standards. They will contain an excess of protein and fat and not enough carbohydrates. But they are satisfactory in the South, where the extra protein is cheap.

If it should be desired to increase the number of problems and to make them apply to larger or smaller animals, the proportions of protein, fat, etc., would be unchanged, but the total amount of each food would be, for example, four fifths as much for an animal weighing $\$ 00$ pounds as for one weighing 1000 pounds.

Helps in teaching feeding and in working such problems may be had from bulletins from your state experiment station, or from those of the 
United States Department of Agriculture, especially from Farmers' Bulletin No. 22. You may expect the figures in different books showing the composition of foods to vary slightly.

Problem I. How many pounds of corn will be required to supply enough carbohydrates for a fattening pig, weighing 200 pounds?

Problem 2. How much soy-bean seed should be added to the amount of corn just found to supply the deficiency in nitrogen.

Problem 3. Calculate a ration of corn and cowpea seed for this pig.

Problem 4. Calculate a ration for a horse at heavy work, using cowpea hay and corn.

Problem 5. What would the ration in Problem 4 cost at local prices?

Problem 6. Find in the table on page 322 all the kinds of hay that could be substituted for cowpea hay, that is, all those having a nutritive ratio between 3 and 6 .

Problem 7. Calculate the composition of the following Southern ration and compare it with standard for a cow giving milk: 6 pounds cotton seed, 5 pounds corn meal, 15 pounds cowpea hay.

Problem 8. Calculate the composition and compare with the standard a ration of 6 pounds cotton seed, 7 pounds wheat bran, i 5 pounds mixed grass hay.

Standard Daily Rations needed by Different Animals (FOR REFERENCE)

\begin{tabular}{|c|c|c|c|c|c|c|}
\hline \multirow[b]{2}{*}{ NEEDED DAILy BY - } & \multirow[b]{2}{*}{$\begin{array}{c}\text { WEIGHT OF } \\
\text { ANIMAL }\end{array}$} & \multicolumn{4}{|c|}{ Digestible matter } & \multirow[b]{2}{*}{$\begin{array}{l}\text { Nutritive } \\
\text { RATIO }\end{array}$} \\
\hline & & 点 & 点 & 官 & 䏒 & \\
\hline & $L b s$. & Lbs. & Lbs. & Lbs. & Lbs. & \\
\hline milk per day . & I000 & 29.0 & 2.5 & 13.0 & 0.5 & I to $5 \cdot 7$ \\
\hline Horse at light work . & 1000 & 20.0 & I. 5 & $9 \cdot 5$ & 0.4 & I to 7 \\
\hline Horse at medium work & 1000 & 24.0 & 2.0 & 11.0 & 0.6 & I to 6.2 \\
\hline Horse at heavy work & 1000 & 26.0 & 2.5 & $13 \cdot 3$ & 0.8 & I to 6 \\
\hline Growing swine & 100 & $3 \cdot 5$ & 0.5 & $2 \cdot 3$ & $0 . I$ & I to 5 \\
\hline Fattening swine. & 200 & 6.0 & 0.7 & 4.1 & 0.1 & I to 6 \\
\hline Fattening cattle & 1000 & 30.0 & $2 \cdot 5$ & 15.0 & 0.5 & I to 6.5 \\
\hline
\end{tabular}


Average Digestible Matter in Feeding Stuffs

\begin{tabular}{|c|c|c|c|c|c|c|c|}
\hline \multirow{2}{*}{\multicolumn{3}{|c|}{ FEEDING sturts }} & \multirow{2}{*}{$\begin{array}{l}\text { DeY MATtek } \\
\text { IN } 200 \text { POUNDS }\end{array}$} & \multicolumn{3}{|c|}{$\begin{array}{c}\text { Digestible MATtex iN } \\
\text { 100 pounds }\end{array}$} & \multirow{2}{*}{$\begin{array}{l}\text { Nutкitive } \\
\text { KATIO }\end{array}$} \\
\hline & & & & Protein & $\begin{array}{l}\text { Carbo. } \\
\text { hydrates }\end{array}$ & Fat & \\
\hline $100 \mathrm{kss}$. of & & & Lbs. & L.bs. & Lbs. & LSs. & \\
\hline Corn or corn $n$ & teal & & 89.4 & 7.8 & 66.7 & $4 \cdot 3$ & 9.8 \\
\hline Corn and cob & meal & & 84.9 & $4 \cdot 4$ & 60.0 & 2.9 & 15.1 \\
\hline Oats . . & $\cdot$ & & 89.0 & 9.2 & $47 \cdot 3$ & 4.2 & 6.2 \\
\hline Wheat . . & . & & 89.5 & 10.2 & 69.2 & 1.7 & 7.2 \\
\hline Wheat bran & - & & 88.1 & 12.2 & 39.2 & 2.7 & 3.7 \\
\hline Wheat shorts & . & & 88.2 & 12.2 & 50.0 & 3.8 & 4.7 \\
\hline Cotton seed & . & & 89.7 & 12.5 & 30.0 & $17 \cdot 3$ & 5.5 \\
\hline Cotton-seed me & eal & . & 91.8 & 37.2 & 16.9 & 12.2 & 1.2 \\
\hline Rice, rough. . & $\cdot$ & & 87.6 & 4.8 & 72.2 & 0.3 & 16.4 \\
\hline Rice polish . & $\cdot$ & & 90.0 & 9.0 & 56.4 & 6.5 & 7.9 \\
\hline Rice bran & $\cdot \cdot$ & - & 90.3 & $5 \cdot 3$ & 45.1 & $7 \cdot 3$ & 13.5 \\
\hline Kafir corn . & . & & 84.8 & 7.8 & 57.1 & 2.1 & 8.1 \\
\hline Peanut meal & $\cdot \cdot$ & . & $89 \cdot 3$ & 42.9 & 22.8 & 6.9 & 0.9 \\
\hline Cowpeas (seed & ) & - & 85.2 & 18.3 & 54.2 & I.I & 3.1 \\
\hline Soy beans (see & d) & . & 89.2 & 29.6 & 22.3 & 14.4 & 1.8 \\
\hline Cowpea hay & $\cdot \cdot$ & - & 89.3 & 10.8 & $3^{84}$ & 1.5 & 3.9 \\
\hline Soy-bean hay & $\cdot \cdot$ & . & 88.7 & 10.8 & $3^{8.7}$ & 1.5 & 3.9 \\
\hline Red-clover hay & . & - & $84 \cdot 7$ & 6.8 & 35.8 & 1.7 & 5.8 \\
\hline Alfalfa hay & $\cdot$ & . & 91.6 & 11.0 & 39.6 & 1.2 & 3.8 \\
\hline Crimson-clover & - hay & . & 90.4 & 10.5 & 34.9 & 1.2 & 3.6 \\
\hline Grass hay (mi & xed) & . & 87.1 & 5.9 & 40.9 & .1 .2 & $7 \cdot 3$ \\
\hline Oat hay . . & $\cdot$ & & 91.1 & $4 \cdot 3$ & 46.4 & 1.5 & 6.2 \\
\hline Timothy hay & $\cdot \cdot$ & & 86.8 & 2.8 & $43 \cdot 4$ & 1.4 & 16.6 \\
\hline Corn stover & $\cdot$. & - & 59.5 & 1.7 & 32.4 & 0.7 & 19.3 \\
\hline Kafir-corn stove & er. & . & 86.5 & $2 \cdot 3$ & 44.8 & 0.8 & 20.0 \\
\hline Cotton-seed hu & & & 88.9 & 0.3 & 33.1 & 1.7 & 123.0 \\
\hline Corn silage. & $\cdot \cdot$ & & 20.9 & 0.9 & 11.3 & 0.7 & 14.2 \\
\hline Cow's milk . & . & • & 12.8 & 3.6 & 4.9 & $3 \cdot 7$ & 3.7 \\
\hline Skimmed milk & (gra & & & & & & \\
\hline $\begin{array}{c}\text { ity) } \\
\text { Linseed meal }\end{array}$ & $\cdot \cdot$ & & 9.6 & 3.1 & $4 \cdot 7$ & $\begin{array}{l}0.8 \\
2.8\end{array}$ & 2.1 \\
\hline $\begin{array}{l}\text { Linseed meal ( } \\
\text { Pumpkins }\end{array}$ & new) & & $\begin{array}{r}89.9 \\
9.1\end{array}$ & $\begin{array}{r}20.2 \\
1.0\end{array}$ & $\begin{array}{r}40.1 \\
5.8\end{array}$ & $\begin{array}{l}2.0 \\
0.3\end{array}$ & 6.3 \\
\hline Oat straw & . . & • & 90.8 & 0.8 & 38.0 & 0.5 & 33.8 \\
\hline Wheat straw & • . & - & 90.4 & 1.6 & 41.6 & 0.7 & 93.0 \\
\hline
\end{tabular}




\section{SECTION LXI. THE PRODUCTION AND CARE OF MILK}

Cows of the same breed differ greatly in the amount and richness of their milk. The most accurate way to decide which are the best among a number of cows is to weigh the milk at regular intervals, once or twice a month, and then to test its richness. By using a Babcock milk-tester (Fig. 209), it is possible to tell just how much fat or butter-making material there is in the milk of any cow. Dairymen who try this plan sometimes find that half the cows in their herd are not paying for their food. By selling the inferior cows for beef and keeping only those that

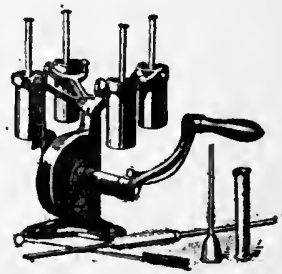

Fig. 209. - A S MALX BabCOCK MilK-TEstER AND OUTFIT make a large yield of butter fat, a dairyman sometimes doubles his net profits.

Milking time. - Avoid exciting a cow at milking time. Fear and excitement check the formation and flow of milk. Be regular and milk at the same time every day. Feed at regular hours also.

Keeping the milk pure. - Milk is formed from the blood which circulates through the udder in exceedingly small blood vessels. While forming in the udder, milk of a healthy cow contains no germs. But as soon as it is drawn, 
germs fall into it. A dirty udder, a dusty stable, dirty hands, and poorly cleaned milk vessels are the most common means of adding unwelcome germs to milk.

Before milking, the dust and loose hairs on and around the udder should be removed by wiping with a damp cloth. The stables must be kept clean and well littered so that the cow's udder and body may not be soiled. To avoid getting dust and germs in the milk, it is better to feed hay or other dusty food after milking or else a long time before.

The milk pails, strainers, and all other vessels must be kept clean by careful washing and the use of scalding water or steam after each milking. Be sure to clean thoroughly the seams and rough places in metal milkvessels. These hiding places may be crowded with germs if any of the dried milk is allowed to adhere. Sunning helps to clean milk-vessels, for sunshine is a great enemy of germs. Neither milk nor empty milk-vessels should ever be left in a room where there is sickness. Germs of human diseases sometimes enter milk by this means or by the use of impure water used in washing the milk-vessels. If the milk pails have partially covered tops and are held in a slanting position, much of the germ-laden dust will be excluded (Fig. 210).

Cooling. - Milk or cream should be cooled as soon as possible, for germs do not multiply so rapidly in a cold temperature as in a warm one. One means of quickly cooling milk or cream consists in putting it in tall slender cans and placing these in cold water. Because these cans are deep, this method is called the deep-setting system of 
raising cream. The most common method in Southern homes where only one or two cows are kept is to pour the milk as soon as drawn into shallow pans.

Note to THE Teacher. - Let pupils test with blue litmus paper samples of buttermilk and whole milk of various ages or kept 12 to 30 hours at different temperatures. If any dairyman near you has a Babcock milk-tester, try to plan a trip with the class to see it in operation. Samples of first-and last-drawn milk, and of milk from several cows, - can be prepared in advance for testing. If a very small amount of formalin or other disinfectant is added, the samples can be kept for a number of days. If there is any money for school equipment, consider the purchase of a Babcock milk-tester, costing $\$ 4.00$ or more. Write the Agricultural College of your state, asking which pattern to buy and from whom to order. Farmers will be pleased to have pupils test their cows.

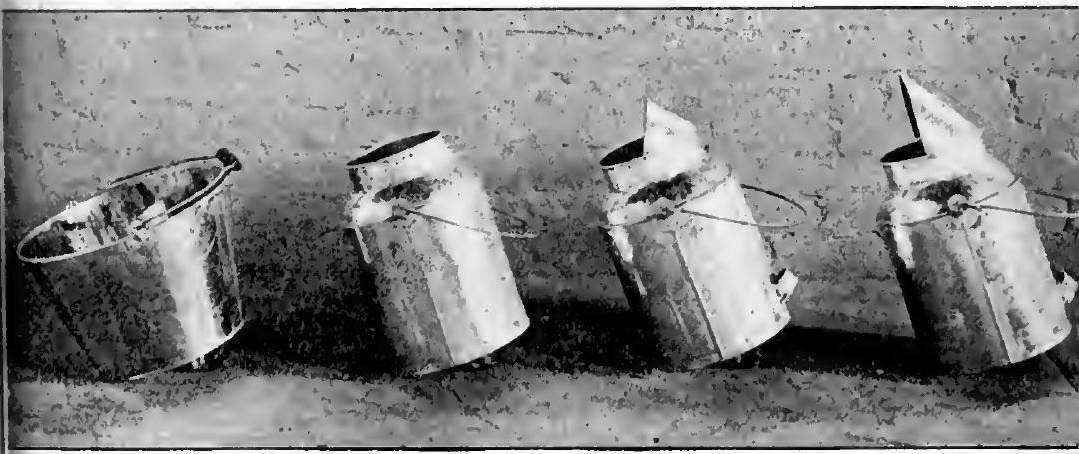

Fig, 210.-Modern Milk Pails, to keEp out Germs and Dust 


\section{SECTION LXII. MAKING BUTTER}

THE fat in milk is in the form of very small, round particles, called globules. Since fat is lighter than milk, the fat globules rise to the surface, forming the cream. They rise more completely if the milk is cooled promptly after milking. Hence, milk is generally promptly poured into shallow pans, or quickly cooled in deep cans placed in cold water. But any method of removing the fat globules that depends upon their rising to the surface leaves many

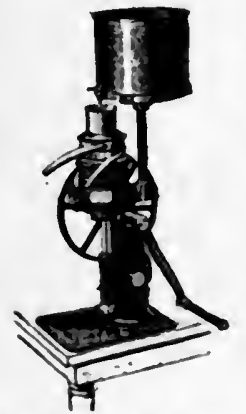

Fig. ari. - A IIAND

Creas Separator of them entangled in the skimmed milk. When shallow pans are used, about one fourth of the fat may be lost in the skimmed milk. However, the cream separator (Fig. 2 I ) removes nearly all of the fat. It does this by the rapid revolution of the metal bowl through which the milk is passing. The bowl revolves six thousand times or more per minute. The rapid motion throws the heavier part of milk to the outer edge of the bowl, from which it runs out as skimmed milk. The cream, being lighter, collects nearer the center of the bowl, and overflows.

Ripening cream for churning. - While many kinds of germs are harmful to milk, there is one kind of germ which the dairyman needs in milk or cream intended for 
making butter. This is the lactic germ, or the one that produces the ordinary souring of milk or cream. When numbers of these germs get into milk kept at a mild temperature, they change the sugar in it into a pleasant acid, called lactic acid, the flavor of which is found in buttermilk. This acid changes that part of the milk which contains nitrogen into the somewhat solid curd, and makes it easier for the churn to separate the fat. Cream is soured or ripened before it is churned.

If the milk or cream is kept too cold before churning, other germs that can endure more cold increase more rapidly than the helpful lactic germs, thus giving an unpleasant flavor to the butter and buttermilk. On the other hand, if the cream is kept very warm, souring occurs very quickly and the butter is soft and inferior. A good temperature at which to ripen or sour cream at home is 60 to 70 degrees Fahrenheit. This is a little cooler than the air of a comfortably heated living room in winter. In some dairies, the cream is cooled to about 50 degrees. Since the lactic germs multiply slowly in cold milk or cream, it may be necessary in cold weather to add an extra supply of these germs. The addition of a little well-flavored buttermilk from a previous churning is one way to hasten the ripening of milk or cream in cold weather.

The flavor of butter is chiefly due to the kind of germs in the ripening cream. To make sure that every lot of butter shall have a good, uniform flavor, some dairymen add a prepared starter, containing the particular germs that will produce the desired flavor. 
Churning. - A good temperature for the cream in the churn is about 60 degrees Fahrenheit if the cows are fresh in milk and are not fed on cotton seed or cotton-seed meal. If these foods are fed, raise the temperature within the churn to some point between 63 and 68 degrees. Much warmer cream can be churned, but the butter is then soft and mixed with the curd of the milk. Such butter sells for a very low price and soon becomes rancid. Moreover, if the cream is warm when churned, much of the fat is left in the buttermilk. A dairy thermometer costs little and often saves many an hour of work and many a pound of butter.

Sometimes, when butter will not come, it is because the cream is not sour enough, or because the churn is too full. The best churns are those that revolve, and these should not be more than one-third or one-half full. Green feed for the cows makes the cream easier to churn and gives to the butter an attractive yellow color. Sometimes, when the butter comes but will not gather, churning can be hastened; but the buttermilk ruined, by adding a little salt.

Handling the butter. - The churn should be stopped when the grains of butter are about as large as kernels of wheat. Then draw off most of the buttermilk and add cold water to harden the butter. Later, wash the grains of butter thoroughly in cold water. Add fine dairy salt while working it on the butter-worker. It is generally best to work it twice. When coloring is added, it should be placed in the churn before churning begins. A uniform color, neat prints, and careful wrapping in special oiled paper greatly increase the selling price. 
ExERCISE. - Who has seen and can describe a cream separator? Obtain two small clean bottles of the same size and shape and fill both with milk as soon as it comes from the cow. Shake one of them about every half hour. Leave the other perfectly still. On which does the cream rise best? Another day fill one of the these same bottles with the milk first drawn from the udder and the other with strippings. After the cream rises, try to estimate how much more cream there is in strippings.

Note to the TEACHER. - Ask the pupils to take the temperature of the well or spring water at home and of the contents of the churn. Could a can of milk be kept advantageously in water of this temperature? Would such water chill and harden butter? Ask for experiences in churning when the butter would not come. What were the conditions?

Optional Problems in Dairying. - ( 1 ) In one year cow A gives 4000 pounds of milk and cow B gives 5000 pounds; the Babcock test shows that A's milk contains 4.5 per cent of butter fat and B's milk 3.5 per cent; how many pounds of butter fat are produced by each in a year?

(2) Assuming that one pound of butter fat is mixed with enough water, curd, and salt to make $\mathbf{I}_{6}^{\frac{1}{6}}$ pounds of butter, what is the number of pounds of butter produced annually by each cow? What is the value of the yearly butter product of each cow, with butter at 25 cents per pound?

(3) How many more pounds of butter fat would cow A produce in a year (see problem I) if the cream from her milk were separated in a cream separator than if it were raised in shallow pans, assuming that there is left in the skim milk from the separator $\frac{1}{3^{3}}$ of the fat in the whole milk and in the skimmed milk $\frac{1}{5}$ of the fat that was present in the whole milk?

(4) What would be the value of this increased production of butter fat in problem 3, at 25 cents per pound of butter, assuming that each pound of butter fat would thake ${ }^{1}{ }^{1}$ pounds of butter?

(5) Use the answer to problem 4 to determine how many months or years it would require for the extra amount or butter made by the sepa1 rator from a herd of 6 cows like A to pay for a small hand-power separator costing $\$ 75$. Can any one point out an additional saving (in feeding the calves) when a separator is used? 


\section{SECTION LXIII. THE CATTLE TICK}

IN somewhat the same way that the mosquito spreads malaria among mankind, the cattle tick spreads a very fatal disease among cattle. This is the tick fever, which causes more deaths and other losses among Southern cattle than all other diseases combined. It has been estimated that in this and in other ways the cattle tick causes a loss every year of more than $\$ 40,000,000$ to the South. The government maintains a quarantine line to prevent the spread of ticks and tick fever.

The cause of tick fever is a tiny parasite, or harmful living thing, that can be seen only by the use of a good miscroscope. It destroys the red blood-cells of the diseased animals.

In the blood that the tick sucks from Southern or other cattle that have once had the disease are the parasites. The mother tick conveys these to her eggs, and these pass them on to the young ticks. When these latter insert their mouth-parts into a cow that has not had tick fever, the parasites pass from the tick into the animal, and cause it to sicken and often to die. Hence cattle brought south from north of the quarantine line often die with this disease, which is carried to them by ticks. Experiments have recently shown that the cattle tick can be entirely destroyed over large areas of country.

The life of a tick. - To learn to fight any pest, first 
learn how it lives. A large tick on a cow drops to the ground when too full of blood to suck more, and there lays as many as 3000 eggs. In warm weather these eggs soon hatch into tiny ticks, each about the size of a chicken mite. They crawl up on tall grass or bushes, waiting for a cow to rub them off. Neither old nor young ticks can live on anything but blood. Hence, if no animal comes along, the young ticks starve. But they do not starve quickly. Without food they may live as long as three months in summer and much longer in cool weather.

Destroying ticks on cattle. - Ticks are killed by grease, kerosene, crude petroleum, and other poisons. These substances are applied to cattle either by hand, by spraying, or by dipping the cattle.

Starving the ticks in fields, pastures, and woodlands. When the owner has cleared his cattle of ticks, he can get entirely and permanently rid of ticks on his whole farm. He can starve the ticks in his fields, pastures, or woodlands by keeping cattle, horses, and sheep out of them for a time. The time to starve all the ticks is the period from May I to about September Io. In cool weather the ticks must be starved for a longer period, from September until April.

Land is generally free from ticks where no cattle have been during the months of hot weather. Thus most cultivated fields are free from ticks. By having two pastures, one used only during the hot season, and the other during the other part of the year, both can be kept free from the ticks. The cultivated fields, after the crops are harvested, may be used as the cool-weather pastures. Of course, it is necessary, in changing the cattle from one pasture to 
another, to rid them of ticks. No cattle bearing ticks should be brought in from other farms without first cleaning them.
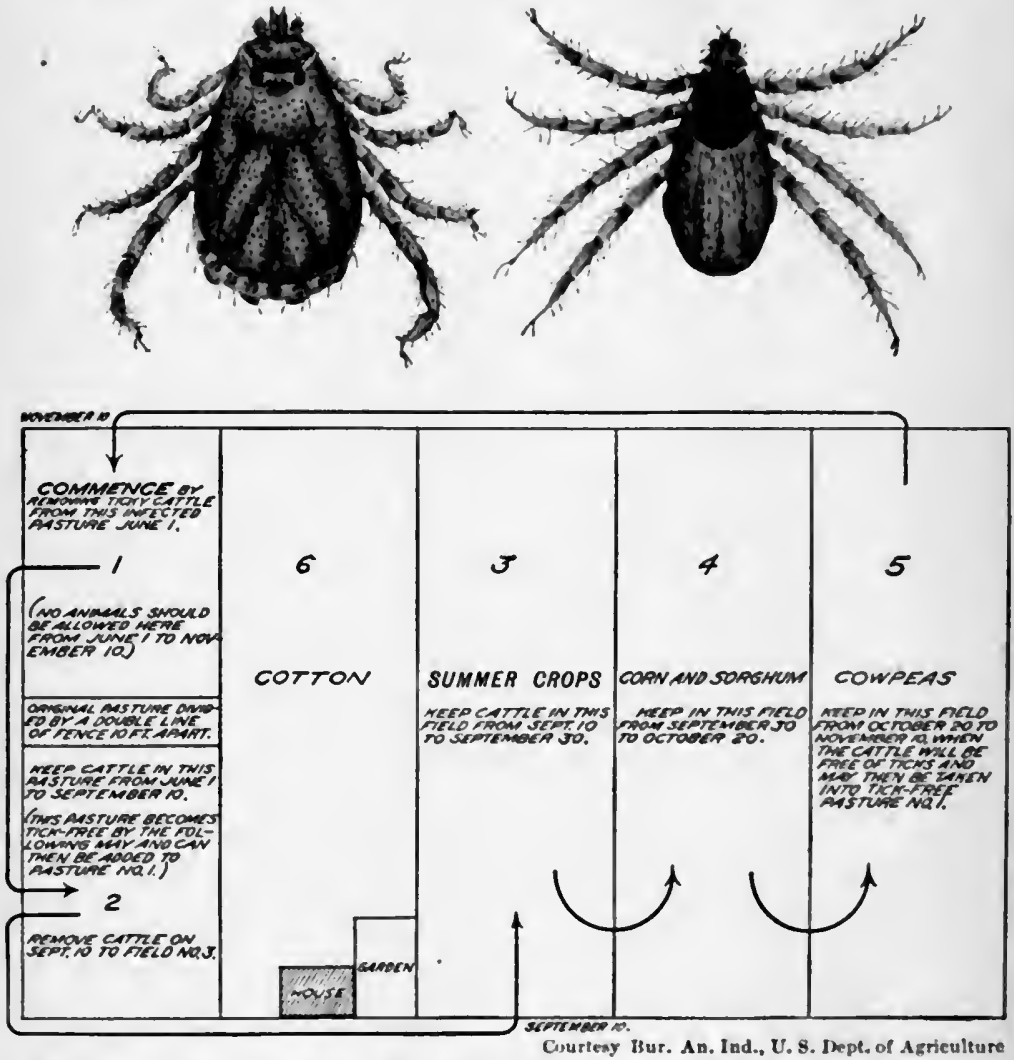

Fig. 212. - The Cattle Tick, entarged. Male on left; Young Female on riglit; also one Plan of cleaning Cattle and land by Rotation or Pastures 


\section{SECTION LXIV. FARM IMPLEMENTS AND MACHINERY}

MACHINERY now does much of the work on the farm once performed by human hands. Especially in grain growing the work has been lightened and the cost of production greatly decreased.

Machinery for the grain-grower. - The seeds and fertilizers are sown with a grain drill. The self-binder cuts and binds as much in a day as many men with cradles could have done fifty years ago. While the grain cradle is still used on farms where only a few acres of grain are grown, or where the fields are too rolling for the use of laborsaving machinery, yet the cost of producing grain by this system is greatly increased.

On some of the extensive grain fields of the West even a self-binder is displaced, and its work is done by still more powerful and effective machinery. The grain header, drawn by steam or many horses, cuts the heads from many acres in a day, and as it moves along threshes and sacks the cut grain.

Haymaking machinery. - In hay growing also invention has made the labor much less burdensome than it was in earlier years. There are horse-rakes for collecting the hay into windrows, tedders for lifting and more rapidly drying it, and sweep rakes (Fig. 213), drawn or pushed by 
horses, for collecting hay from the windrows and carrying it short distances to the barn or stack. These sweep rakes save the work of loading a wagon. Where the distance is greater, so that hauling on wagons becomes necessary,

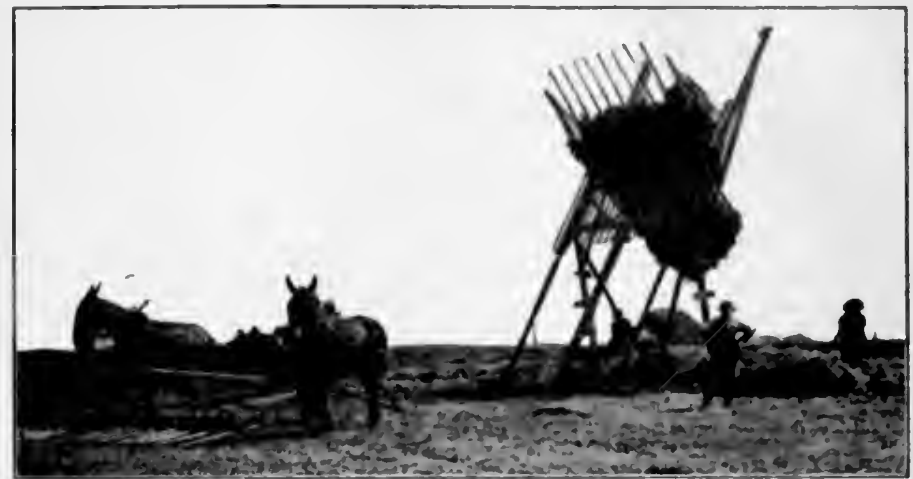

Fig. 283. - Machinery for Havdling hay

Swecp rake and stacker.

there are hay loaders which save pitching the hay. These are hitched behind the wagon, and as the wagon and loader are drawn along, the hay is elevated from the windrow to the wagon.

At the barn or stack one or two horses, hitched to a hay carricr, may lift the hay from the wagon to its place in the barn. Where sweep rakes are used to bring the hay to the stack, these deliver their burdens to a hay stacker (Fig. 213). Then the stacker, by means of horse power, raises the load to its position on the stack. Thus no lifting by human force need be done until the hay is on the stack.

Machinery for corn, sugar cane, and rice. - The corn 
grower, too, has profited by the mechanic's art. He uses corn havesters to cut and to tie his corn, shredders to separate the ears from the stalks, to remove the shucks, and to tear the forage into bits suitable for most convenient use

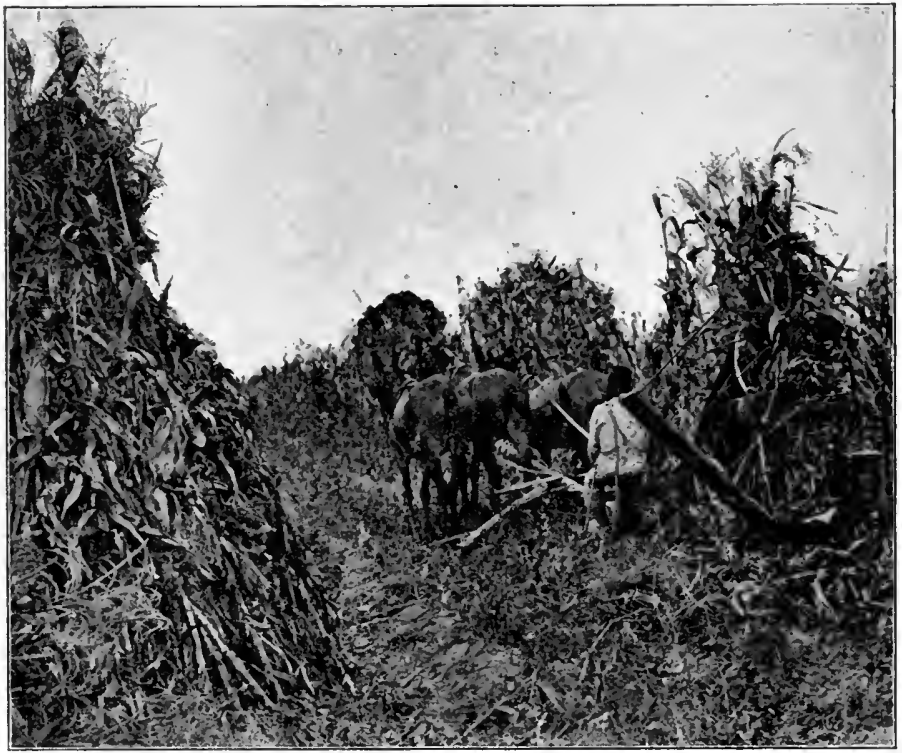

Fig. 2 I 4. - Corn Harvester, with Bundle-Carrier Attachment

as food or bedding. Even a bundle-carrying corn harvester, or shocking machine (Fig. 214), and a machine for pulling the ears, have been invented.

The rice-grower uses the grain-drill, the self-binder, and other machinery like that used in grain-farming. The sugar-planter is testing cane loaders, and cane harvesters are engaging the inventor's attention.

Labor-saving implements on cotton farms. - The cotton 
farmer has made less general use of labor-saving machinery than the grain and hay-grower. It is possible to grow cotton profitably with a few very inexpensive implements, and hence a beginning may be made in cotton culture by one who has very little capital. But here, too, it pays to utilize labor-saving machinery and the implements which make possible the most thorough preparation and cultiva-

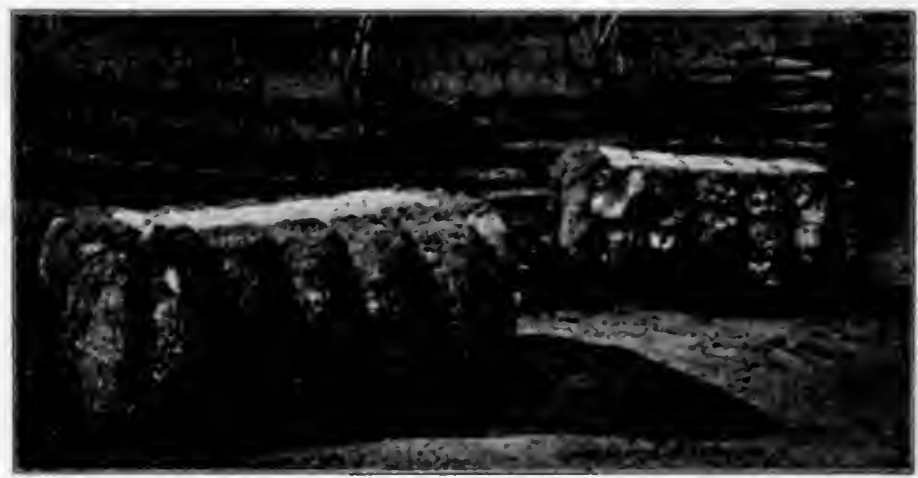

Fig. 215. - Showing the Wrong Way to store Cotron IN WiNter

tion. Most cotton farms on which scveral horses or mules are worked need a disk plow, large "turning plows," a spike-tooth harrow (and often others), a weeder, and the best cultivators. Riding on one of these labor-saving implements, one intelligent man often does well the work that two or more men would do while walking behind smaller implements.

The invention of the cotton gin was the greatest factor in building up the cotton industry of the South. Likewise a great cheapening of the cost of producing cotton will 
result when a cheap, simple, and durable cotton-picker shall be on the market. Recent successful public tests of at least two very different cotton-pickers point to the day of cotton-picking by machinery.

Farm buildings. - Not only are implements needed in farming, but also convenient farm buildings for sheltering implements, live-stock, and crops. A building too often absent from a cotton farm is a shed under which to store bales of cotton. If cotton is left exposed in winter, as in Fig. 215 , there is a considerable loss in the quality and price of the lint.

EXERCISE. - Write in your notebook a list of the kinds of plows you have seen. How many kinds of harrows have you seen? Ask your parents to tell you some of the farm implements that they consider most useful. Write this list in your notebook and also what each is used for. What farm or household work needs some new inventions to make it lighter?

Note to the Teacher. - Pictures of farm implements shown during the recitation will interest the class. By writing a postal to some hardware companies or to manufacturers of farm implements, you will often find them willing to send free catalogues containing pictures of farm machinery. Addresses of manufacturers can be obtained from the advertising columns of almost any agricultural paper, an old copy of which some pupil can probably bring you from home. 


\section{SECTION LXV. EARTH ROADS}

Good roads make country life more attractive. They also make possible in the country good schools, churches, and social gatherings. They soon pay for their cost in the labor of men and teams saved by hauling with a few loads over good roads the same weight that requires many loads over bad roads. Good roads pay, too, because they save wear and tear on tcams and vehicles. Improving a road increases the value of the land near it.

Location of roads. - A road is no better than its worst part. The load hauled is as large as the team can pull up the steepest hill or most boggy part of the road. Hence, the first work in improving a road ought to be to improve the worst places. It pays to change the location of a road to avoid the worst hills. Roads ought not to go straight up steep hills, but should curve around their sides.

The best roads are made of a thick layer of broken stone or gravel. Stone roads cost several thousand dollars for each mile, and an engincer is needed to plan or build them. At slight expense earth roads can be much improved by proper grading, rounding, and draining.

Avoid a steep rise or grade. - A road ought to be as nearly level as possible. The grade or slope of an earth road ought not to be more than six feet rise in each hundred feet of length, though steeper grades are sometimes necessary. The load that one horse can pull on a level 
requires four horses to pull up a grade with a rise of ten feet in each hundred feet.

Keep the center highest. - The center of a road should be arched so as to be at least five to eight inches above the sides. Whenever ruts or depressions remain long unfilled, mud-holes or washes occur.

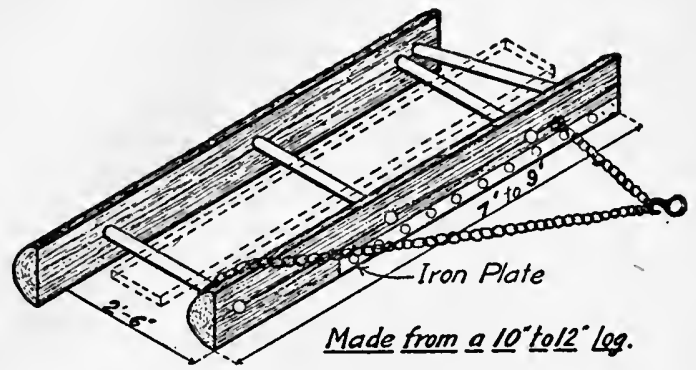

Fig. $2 \times 6 .-$ A Split-log Road Drag

A cheap road drag. - Ruts should be filled as soon as formed. This can be done by running a split-log drag along one side of the road and back on the other side. The drag shown (Fig. 216) is made from a split log and costs very little.

A little work in filling ruts as soon as they form is worth much more than the same amount of work after the ruts have caused washes in the road. The best way to keep earth roads good is not by having many men to work them once or twice a year, but by having a few men, with team and split-log drag, ready to fill the ruts as soon as they form. This use of the drag arches the center, fills ruts and low places, and hastens drying. There should be a ditch on each side to carry off the water and to keep the road-bed dry. 
Sand-clay roads. - Deep sand-beds make the roads bad in many parts of the South. Some counties have changed these sand-beds into good firm roads by hauling clay and thoroughly mixing it with the upper six inches of sand. The clay and sand are mixed while wet by means of plows and harrows, or by the wheels of vehicles. Then the road is kept constantly rounded, so that water does not stand on it.

EXERCISE. - Are sandy roads best when dry or wet? Are clay roads best when dry or wet? Watch the teams struggle up some steep hill and then consider whether the road could easily be changed to avoid that hill or to climb it more gradually.

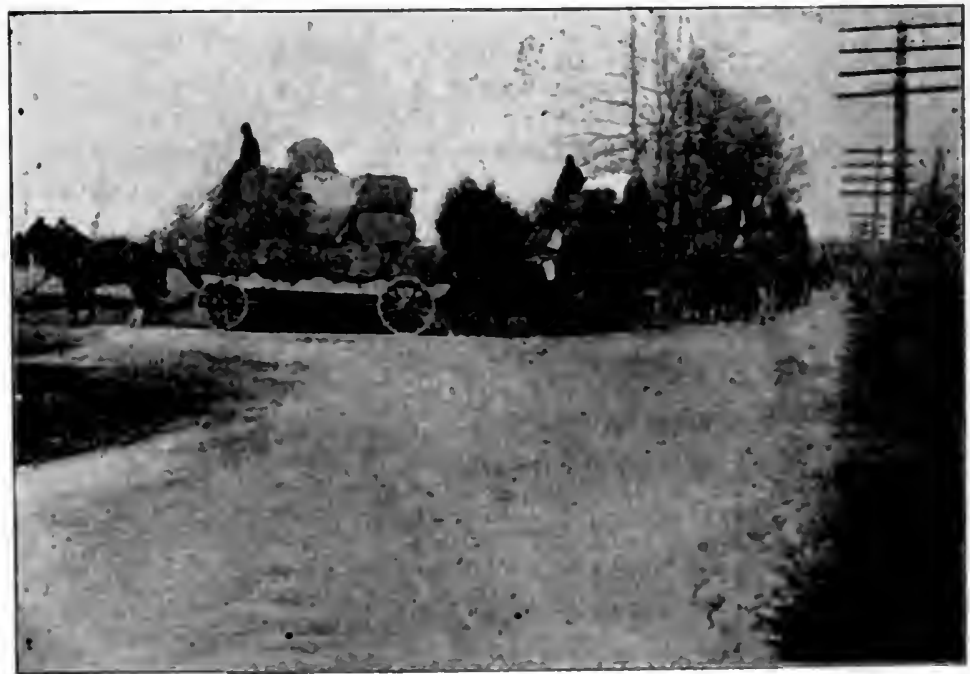

Courtrsy of I: S. Dept of Agricalture

Fig. 217. - Jusction of Two Gravel Roads in Texsessre

Showing the size of loads sometimes hauled over the best roads. 


\section{APPENDIX}

\section{FERTILIZER EQUIVALENTS}

\section{The nitrogen in}

I pound nitrate of soda $=2 \frac{1}{4}$ pounds cotton-seed meal.

I pound cotton-seed meal $=2 \frac{1}{4}$ pounds cotton seed.

I pound sulfate of ammonia $=\mathrm{I} \frac{1}{3}$ pounds nitrate of soda.

I pound sulfate of ammonia $=3$ pounds cotton-seed meal.

I pound (h.g.) dried blood $=1 \frac{4}{5}$ pounds cotton-seed meal.

\section{The potash in}

I pound muriate of potash $=4$ pounds kainit.

I pound sulfate of potash $=4$ pounds kainit.

Substitutions may be made in the following formulas, or in any others, on the basis of the figures above.

\section{SOME FERTILIZER FORMULAS}

As pointed out in the text, the only positive means of finding the best fertilizer for a certain crop on a given soil is by making a field test of fertilizers. Until such a test is made, the following formulas may be used as suggestive and general, rather than as suiting every soil. Many other formulas having the same composition can be calculated as directed in Section XVIII. Acid phosphate is assumed below to contain 14 per cent of available phosphoric acid.

I. For cotton on poor clay and land, where cotton-rust does not occur:-

Acid phosphate, 150 to 300 pounds per acre.

Cotton-seed meal, 150 to 300 pounds per acre.

2. For cotton on fair or good clay land, where cotton-rust does not occur:-

Acid phosphate, 200 to 300 pounds per acre.

Cotton-seed meal, 100 to 150 pounds per acre. 
3. For cotton on poor, unimproved, sandy soil, where cotton-rust occurs : -

Acid phosphate, 150 to 300 pounds per acre.

Cotton-seed meal, 150 to 300 pounds per acre.

Kainit, 75 to 100 pounds per acre.

4. For cotton on sandy soil somewhat improved by previous crops of cowpeas, or other legumes, but on which cotton-rust occurs :-

Acid phosphate, 150 to 300 pounds per acre.

Cotton-seed meal, up to 150 pounds per acre.

Kainit, 75 to 100 pounds per acre, or

5. Acid phosphate, 150 to 300 pounds per acre.

Nitrate of soda, 50 pounds per acre.

Kainit, 75 to 100 pounds per acre.

6. For corn on clay and loam soils :-

Acid phosphate, 100 to 200 pounds per acre.

Cotton-seed meal, 100 to 200 pounds per acre.

7. For corn on very poor, sandy soils : -

Acid phosphate, 150 to 200 pounds per acre.

Cotton-seed meal, 150 to 200 pounds per acre.

Kainit, 75 pounds per acre.

8. For oats and wheat on poor soils :-

Acid phosphate (when seed are sown), 200 pounds per acre.

Nitrate of soda (after the leaves are three inches long), 100 pounds per acre.

9. For cowpeas, soy beans, velvet beans, alfalfa, vetch, or clovers : Acid phosphate, 200 to 400 pounds per acre.

(If the soil is very sandy and poor, add 100 to 200 pounds kainit, or 25 to 50 pounds muriate of potash.)

10. For tobacco or vegetables : -

Acid phosphate, 200 to 300 pounds per acre.

Cotton-seed meal, 200 to 300 pounds per acre.

Nitrate of soda, 50 to 75 pounds per acre.

High-grade sulfate of potash, 50 to 75 pounds per acre.

11. For vegetables : -

Acid phosphate, 300 to 600 pounds per acre.

Cotton-seed meal, 150 to 300 pounds per acre.

Nitrate of soda, 75 to 225 pounds per acre.

Muriate of potash, 50 to 150 pounds per acre. 


\section{II. TO DESTROY INSECTS}

\section{Bisulfid of Carbon}

For weevils and other insects in corn, cowpeas, or other grain or seed stored in tight cribs or bins.

About one teaspoonful of liquid to each one or two cubic feet of space; pour the liquid into an open shallow can placed on top of the grain; cover the grain with cloth. The liquid evaporates and the heavy fumes settle downward. The fumes are very inflammable; hence, keep all lights and all smokers away until the odor has disappeared.

\section{Paris Green}

For biting insects, including the potato beetle, and other insects eating the leaves of field crops, vegetables, or fruits.

\section{Dust on as a dry pozeder}

Paris green, I pound.

Slacked lime or flour, to to 40 pounds.

\section{Spray with}

Paris green, $\frac{1}{4}$ pound.

Lime, $\frac{1}{2}$ pound.

Water, about 50 gallons.

\section{Kerosene Emulsion}

For soft-bodied, sucking insects, as scale, plant-lice, etc.

Hard soap (in fine shavings), $\frac{1}{2}$ pound.

Kerosene,

Water (soft or rain water), I gallon.

Dissolve the shavings of soap in the water while it boils. Remove the water from the fire; add the kerosene, and churn the mixture by pumping it through a spraying pump until a creamy liquid, without free oil, is formed. This mixture contains 66 per cent of kerosene. Dilute it with from 6 to 10 gallons of water for scale insects, and with 1o to 20 gallons for softer insects.

\section{Lime-SUlfur WASH}

For scale insects, applied while there are no leaves on the trees.

I 5 pounds flowers of sulfur.

20 pounds of unslaked lime.

50 gallons of water.

( 5 pounds of salt is sometimes added.)

Mix the sulfur with a very small amount of water. Slack the lime in 5 to 10 gallons of hot water; add the sulfur; dilute to 25 gallons; boil 
for 45 minutes. Then dilute with hot water to 50 gallons and apply it while hot.

\section{TO PREVENT OR DECREASE DISEASES OF PLANTS}

\section{Bordeaux Mixture}

Bluestone (copper sulfate), 5 pounds.

Best unslacked lime, about 5 pounds.

Water,

50 gallons.

Slack the lime with enough water to make a creamy wash. Add the lime and the bluestone to separate lots of water. Dilute each as much as convenient before pouring the two liquids together. Strain through a coarse cloth before using. Consult your experiment station regarding further details about mixing and testing Bordeaux mixture, etc. When applied to the foliage of peaches, plums, or cherries, double the amount of water mentioned above.

Apply Bordeaux mixture in a fine spray. It is used to prevent or decrease molds and most fungi attacking fruit trees and vegetables. Paris green can be added just before using the mixture, pound of Paris green to 50 gallons, thus destroying both fungi and leaf-eating insects at the same time.

\section{Formalin}

To prevent oat smut, concealed smut of wheat, scab and other diseases of Irish potatoes.

For wheat or oats, pour one ounce of formalin into three gallons of water. Dip or thoroughly moisten the seed-grain, and leave it moist and covered for two hours. Then dry the grain, and sow it before it comes in contact with more smut germs.

To prevent scab, soak the seed-potatoes for two hours in a solution of 1 ounce of formalin in 2 gallons of water.

\section{TO MEASURE GRAIN APPROXIMATELY}

Multiply the average depth by the average width, and the product by the average length of the pile, crib, or bin. To get the number of bushels of shelled grain, divide this figure (number of cubic feet) by 11 ; to find the number of "bushels" of shucked ear corn, divide by 2\}; to find the number of "bushels" of unshucked ear corn, divide by 4 . 


\section{DIMENSIONS OF ONE ACRE}

4840 square yards, or 43,560 square feet.

To find the length or width of an acre when the other dimension is given, divide 43,560 square feet by the length or width in feet, or divide 4840 square yards by the length or width in yards.

\section{STATE AGRICULTURAL EXPERIMENT STATIONS}

\section{Alabama : -}

College Station, Auburn.

Canebrake Station, Uniontown.

Tuskegee Station, Tuskegee.

Arizona, Tucson.

Arkansas, Fayetteville.

California, Berkeley.

Colorado, Fort Collins.

Connecticut : -

State Station, New Haven.

Storrs Station, Storrs.

Delaware, Newark.

Florida, Gainesville.

Georgia, Experiment.

Idaho, Moscoze.

Illinois, Urbana.

Indiana, Lafayette.

lowa, Ames.

Kansas, Manhattan.

Kentucky, Lexington.

Louisiana :-

State Station, Baton Ronge.

Sugar Station, Audubon Park, N.O.

North Louisiana Station, Calhoun.

Maine, Orono.

Maryland, College Park.

Massachusetts, Amherst.

Michigan, East Lansing.

Minnesota, St. Anthony Park.

Mississippi, Agricultural College.
Missouri :-

College Station, Columbia.

Fruit Station, Mountain Grove.

Montana, Bozeman.

Nebraska, Lincoln.

Nevada, Reno.

New Hampshire, Durham.

New Jersey, New Brunswick.

New Mexico, Agricultural College.

New York :-

State Station, Geneva.

Cornell Station, Ithaca.

North Carolina : -

College Station, West Raleigh.

State Station, Raleigh.

North Dakota, Agricultural College.

Ohio, Wooster.

Oklahoma, Stillwater.

Oregon, Corvallis.

Pennsylvania, State College.

Rhode Island, Kingston.

South Carolina, Clemson College.

South Dakota, Brookings.

Tennessee, Knoxville.

Texas, College Station.

Utah, Logan.

Vermont, Burlington.

Virginia, Blacksburg.

Washington, Pullman.

West Virginia, Morgantown.

Wisconsin, Madison.

Wyoming, Laramie. 


\section{SCHOOL GARDENS}

Below are given simple plans for planting inexpensively the individual plot or bed assigned to each pupil. A length of 12 feet and a width of 5 feet are convenient dimensions to accommodate 6 rows across each bed. Select and modify as convenient that one of the suggested plans that most nearly corresponds to the time when the planting can be done most conveniently. The plan for planting in the fall, and the one for planting in April or May, can be conducted on the same bed.

It is better to have two or more plans or sets of seed, so as to give each pupil some choice, and so as to increase the variety of plants under observation. In addition to small, individual beds, there should be rows or plots of the common field-crops of the locality, which require more room than can well be spared for them in the individual beds. These rows or plots should be considered the property of the whole school, and observed, cultivated, and protected by all.

Write to United States Department of Agriculture, Washington, D.C., for Farmers' Bulletin No. 2,18, on "School Gardens." As subjects for compositions, drawing lessons, etc., make frequent use of the school garden. 
Rows of

\section{Cotton}

\section{Corn}

Cowpeas, etc.

4-ft. Walk

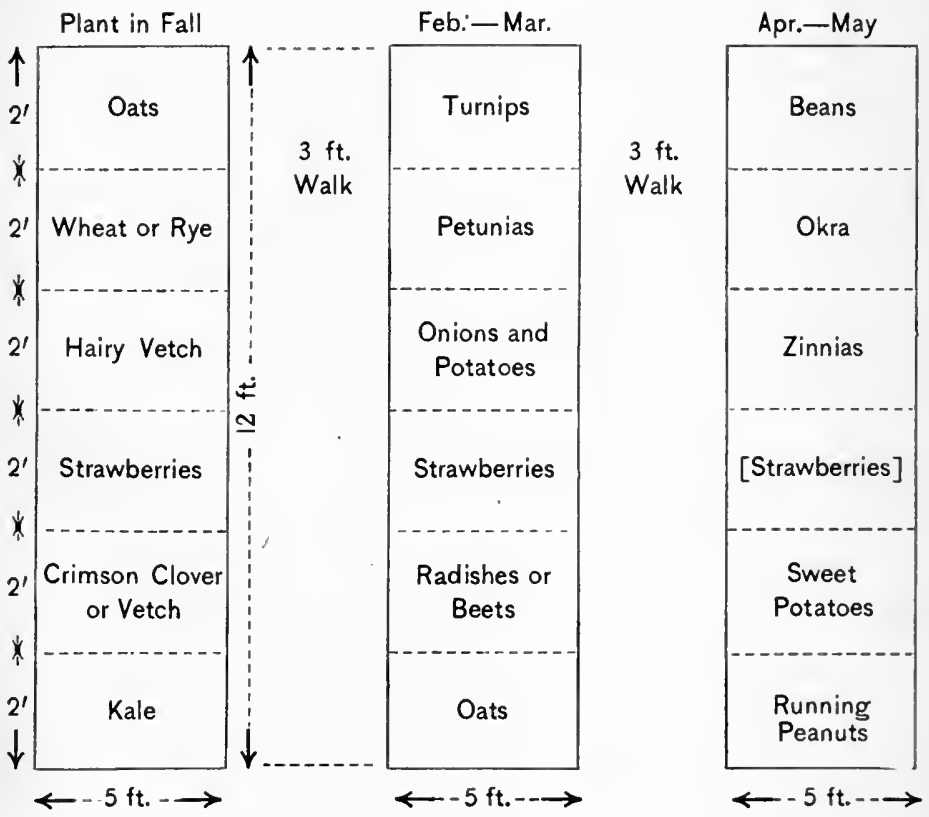





\section{INDEX}

A list giving definitions of words is not needed in this book. As few unusual words as possible have been employed, and these have been explained or defined when first used. The index will enable the pupil to turn to the definition of technical words.

Aberdeen-Angus breed, 293.

Acid phosphate, roo.

Acid soils, $112,1 \times 3$.

Adult insect, $25 \mathrm{I}$.

Agriculture, definition of, 4 ; reasons for studying, 4 .

Air, 24, 34, 54 .

Air-spaces in soil, 68.

Alfalfa, 63 , 114; composition of, 322 ; culture, 176; dodder on, $x 77$; inoculation, 172 .

American saddle horse, 288.

American trotter, 288.

Ammonia, 98.

Andalusian fowls, 310.

Andrews, Miss F. E., 192 .

Antennæ of insects, 247.

Anther, 13.

Apples, 9, 17, 39, 215; diseases of, 230.

Apple worm, $25^{8}$.

Ash, 314.

Asparagus, 189 .

Available plant food, 56 .

Babcock milk-tester, 323 .

"Bachelor's buttons," I 95 .

Bark, 42.

Barley, $23, x_{37}, 138$.

Bean family, ro.

Beans, 24, 187 .

“Bear's grass," r 95 .

Beef cattle, 290.

Bees, $x 5,277$.

Beets, $114,187,189$.
Berkshire hogs, 304 .

Bermuda grass, $82, x 80, x 8_{3}, 193$.

Biennials, 38 .

Bitterweed, 182 .

Blackberry, ro.

Blue grass, $\mathrm{r} 78$.

Bluestone, 227 , iv.

Boll weevil, 262, 264 .

Bordeaux mixture, 227 , iv.

Bracts, 9.

Brahmas, 313.

Breed, definition of, $28 \mathrm{I}$.

Breeding corn, 46.

Bridal wreath, 195 .

Budding, 39, 4I, 43, 44 .

Buds, propagation by, 38 .

Bugs, true, 250.

Bulbs, 197,198 .

Bur clover, 77,180 .

Butter flavor, 327 .

Butterfly, 251, 254 .

Butter making, 326 .

Cabbages, I14, 188.

Calculation of fertilizer formulas, ro2.

California poppy, $x 99$.

Canna, 199.

Capillary moisture, 65 .

Carbon dioxid, 35 .

Carbon in air, 33 .

Castor bean, 20.

Catalpa tree, $2 \times 2$.

Caterpillars, $250,25 \mathrm{r}$.

Cattle, beef, 290; dairy, 295; tick, 330;

tick fever of, 330 . 
Cedar tree, 212.

Cell, 29.

Chemical fertilizers, 102.

Chester White hogs, 305.

Chickens, breerts and varieties, 310.

Chinaberry trees, 212.

Chinch-bug, 257.

Churning, 328.

Chrysalis, 250.

Chrysanthemums, 195, 199.

Cion, 41.

Clasps on leaves of grains, 137 .

Clay, size of grains, 59.

Climate, effect on carliness, 49.

Clover, crimson, 120, 175,322 ; red, $38,63,114,120,370,877,322$; white, 192.

Clovers, 10, 87, 90 .

Clydesdale horses, 286.

Coach horses, 287.

Cochin, 313 .

Cocoons, 252.

Codling-moth, 258.

Coldframe, 187.

Commercial fertilizers, 98.

Composition of fertilizers, 106.

Compost, 95, 115.

Copper sulphate, iv.

Corn, $12,21,38,46,119,121,123,125$; composition of, 322; crossing, 123, 125; culture of, 126 ; fertilizers for, 127; germination test, 134; harvesting machinery, 335 ; judging 129 ; races of, 123 ; score-card, 131 ; selection of, 46; show, 135 ; silage, 322 ; stover, 322.

Corolla, 8.

Cosmos, 196.

Cotton, 23, 61, 113, 119, 121, 144, 217; black rust of, 242; bloom, 9; boll rot, 242; boll weevil, 264; boll worm, 261; breeding, 149; cultivation of, 151 ; diseases of, $23^{8}$; hastening maturity of, 270; fertilizer for, 153; leaf worm, 262; long-staple, 146; machinery for, 336; pickers, 337; plant-food removed in, 84; root rot of, 240; Sea Island, 146; short-staple, 147; varicties of, 147 ; wilt, 238.
Cotton seed, 106; composition of, 322; treatment of, 153 ; hulls, 322 ; cottonseed meal, 98, 106, 322.

Cottonwood trees, 2 r 2.

Cow, parts of, 298.

Cowpeas, 10, 23, 90, 113, 118, 121, 172. $174,217,322$.

Crab grass, 182, 11, 182; composition of, 322.

Cream, ripening, 326 .

Cream separator, 326 .

Crops, suiting fertilizer to, rog.

Crosby's exercises, 6, 31, 45, 69.

Crossing plants, 50.

Cross-pollination, 15, 52.

Cultivation of soils, 70.

Curculio, 260.

Cuttings, 40, 198.

Daffodils, 195.

Dairy cattle, 295.

Diseases of plants, 118 ; causes of, 225.

Ditches, 79, 80, 8I.

Docks, 182.

Dogwood, I.

Dorset sheep, 301 .

Draft horses, 284.

Drainage, 74, 84.

Duggar, Dr. B. M., 225.

Duroc-Jersey hogs, 304.

Earth roads, 338.

Elements, chemical, 33 .

Elm, 209, 210.

Evaporator, for syrup making, 360.

Families of plants, ro.

Farm implements, 333 .

Fat, 316.

Fattening animals, 315 .

Feeding animals, principles of, 315.

Feeding stuffs, composition of, 322.

Fertilizer, agricultural value of, rog; amount of, 108: commercial value of, 102; experiments with, 110 ; fillers in, 106; for fruit trees, 216; formulas, to calculate, 102; for strawberries, 219; for sugar cane. 158; for sweet potatoes, 163: home mixing of, ro5; commercial, 97; 
not mixing well, II ; problems, 107; requirements, of soils, 1 I 0 .

Fertilizing by feeding, 93 .

Figs, propagation of, 40.

Fire, 83 .

Flag, 195 .

Floats, 100.

Florida phosphate, roo.

Flower garden, planning the, 192.

Flower, parts of, 7 .

Food, stored in seed, 21,24 ; uses made of, $3_{1} 6$.

Forests, 86, 203; fires, 204; trees, 203.

Formalin, 233, iv.

Four o'clocks, 195 .

Foxtail, 182.

Fruit growing, essentials for, 216 .

Fruits, orchard, 39, 215.

Fruit trees, fertilizers for, 216; pruning, $22 \mathrm{I}$.

Fungi, 225.

Germ enemies in the soil, $\cdot \mathbf{2 4 5}$

Germs in milk, 326 .

Germs, nitrogen-fixing, 89.

Germination of seeds, 23, 24, 26.

Grade, definition of, 28 r .

Grafting, 4I, 42; wax, 45.

Grain header, 333 .

Grapes, 18, 40, 21 5, 224.

Grasses for hay and pasture, 176 .

Grass family, II.

Grass hay, 322 .

Grit for poultry, 308 .

Grubs, 250.

Guard cells, 35 .

Guernsey breed, 297.

Gum, 208, 210.

Hackberry, 209.

Hamburgs, 3 Iо.

Hay carrier, 334 .

Hay loaders, 334 .

Hay-making machinery, 334 .

Hay stacker, 334 .

Hemp, 20.

Hereford breed, 293.

Hessian fly, 257 .

Hilly land, 63 .

Hinds, Dr. W. E., 246 .
Hog cholera, $3 \circ 3$.

Hogs, 303; judging, 305 .

Hollyhocks, 2or .

Holstein-Friesian breed, 298.

Honeybee, 277.

Honey-producing plants, 280.

Horses, 284.

Host plant, 90.

Hotbed, 187 .

Humus, 56, 86.

Hyacinths, 195.

Hydrometer, Baumé, I60

Improvement of plants, 46,48 .

Inoculation of legumes, 169,171 .

Insects, $118,246$.

Insects and health, 272; beneficial, 254; biting, 253; changes in, 250; definition of, 246; feeding habits of, 253; growth in, 249; parts of, 247; stages of, 249; sucking, 254 .

Iris, 195.

Irish potatoes, 187 .

Iodine test for starch, 37.

Japan clover, $178 ;$ i 80.

Japan quince, 195 .

Jersey breed, 296.

Johnson grass, $63,178,182,184$.

Kafir, 181 ; composition of, 322 ; stover. 322.

Kainit, ror, ro6.

Ladybirds, 254 .

Langshan, 3 I 3 .

Larkspurs, 195 .

Larva, 250.

Leaching, 82 .

Leaves, 31,35 .

Leghorn breed, 310.

Legumes, 87, 91, 92, 169.

Lettuce, 189 .

Level, drainage, $77,8 \mathrm{r}$.

Level lands, 63 .

Lichens, 55 .

Light for plants, 36 .

Lilies, 195 .

Lime, 32, 112, 245. 
Lime soils, crops for, 63 .

Linsed meal, composition of, 322 .

Live-stock, advantages of, 282; improvement of, 28 ?

Loam, 59.

Locust tree, 10, 212.

Louisiana Experiment Station, 856, 157, $159,161$.

Machinery, farm, 333 .

Making butter, 326 .

Malaria and mosquitoes, 273.

Mallow family, 145 .

Manure, effect of food on, 92.

Marigolds, 196.

Merino sheep, 302.

Milk vessels, cleaning, 324 .

Milk, composition of, 322 ; impurities in, 324; keeping pure, 323 ; production of, 323 ; souring of, 228 ; testing, 323.

Millet, 178.

Mills for sugar cane, 160 .

Minorca breed, $3: 2$.

Mites, 247.

Moisture, 23, 245.

Molds, 225.

Mosquitoes, 254; and yellow fever, 272; destroying, 275; malarial, 274.

Mosses, 55.

Moth, 252.

Miulberry, 208.

Mulch, 69 .

Mules, 289.

Muriate of potash, 101, 106.

Mustard flower, 7 .

Narcissus, 195.

Nasturtium, 200.

Nitrate-destroying germs, 245.

Nitrate of soda, 99, 106.

Nitrogen, 33, 98, 117, 168; fixation of, 90 ; how used by legumes, 90 .

Nitrogen-trapping germs, 244.

Nodules, 88,89 .

Nut grass, 182.

Oak, 20, 208, 2 to.

Oat hay, composition of, 322 .
Oat straw, composition of, 322 .

Oats, $11,23,38,119,121,136$; culture of, 139; composition of, 322; smut of, 233.

Oklahoma Experiment Station, 181.

Okra, 187 .

Onions, $114,190$.

Orangeburg soils, 61 .

Orchard, 19, 215.

Orchard grass, 178.

Orpington breed, $3 \times 3$.

Osage orange tree, $2: 2$.

Ovule, 8.

Ovule case, 7 .

Oxygen, 34,57 .

Pansies, 199, 200.

Pastures, 179, 331.

Pea, 10, 25, 188.

Peach, 8, 39, 215, 223, 224.

Peach borer, 259.

Peaches, diseases of, 229.

Peach tree, 216, 221, $223,224$.

Peanut meal, composition of, 322 .

Peanuts, 23, $114,165$.

Pear blight, 231.

Pears, 17,215 .

Pecans, 20, 216.

Percheron horses, 286.

Perennials, 38.

Perfume, uses of, 7 .

Periwinkles, 195.

Persimmons, Japanese, 215.

Petals, 8.

Petunias, 200.

Phlox, 199.

Phosphate, 32, 57, 100 .

Phosphate, acid, 100, 106.

Phosphoric acid, $1 \infty$.

Phosphorus, 33, 100.

Pistil, 7, 9, $12,19$.

Plank drag, $7 x$.

Plants, food for, 32.

Plowing, depth of, $7^{2}$; time of, 70 .

Plums, 10, 215.

Poisons for fungi, 227.

Poland-China hogs, 304.

Pollen, $7,13,18$.

Pollination, 12, 16 .

Pomegranates, 216. 
Popcorn, 15.

Poplars, propagation of, $4 \mathrm{I}$.

Poppy, 199.

Potash, 33, 57, ror.

Potato, $47,187$.

Potato beetle, 260 .

Potato, diseases of, 236.

Poultry, food for, 307 ; management of, 306.

Preparation of soil, 70.

Principles of feeding animals, 3 r 4 .

Prince's feather, 194.

Propagation by division, 38 .

Propagation by seed, 38 .

Protein, 315.

Pruning fruit trees, 221 .

Pumpkins, $187,322$.

Pupa of insects, 250.

Ragweed, I 82.

Raspberries, 224.

Rations, calculating, 318; standard, 321 .

Red Polled breed, 293.

Red-top grass, 178 .

Rhode Island Red breed, 3 I 3 .

Rice, 322, 335; polish and bran, composition of, 322 .

Road drag, 339 .

Roads, earth, 338; sand-clay, 340 .

Rolling land, 63.

Root-hairs, 30, 3x, 68.

Roots, 22, 34 .

Rose, ro, 41, 195, 198, 227.

Rotation, I $16,240$.

Rusts of grain, 234.

Rye, $23,138$.

Salsify, 187 .

San José scale, 259.

Sap, 29, 34.

Scarlet sage, 195, 201.

School garden, 191, 196, 202.

School grounds, I 96, 208.

Score-card for corn, $13 \mathbf{r}$.

Seed, home-grown best, 49; selection of, 46 .

Seeds, 21, 25, 46 .

Self-binder, 333 .
Self-pollination, 15,52 .

Sepals, 8.

Sheep, 299.

Shetland ponies, 288.

Shorthorn cattle, 293

Shropshire sheep, zоr.

Shrubs, wild, 196.

Silt loam, 59.

Small grains, differences, 136,137 ; resemblances, 136 .

Snowball, 194, 195 .

"Snow on the Mountain," 195

Soil, cultivation of, 70; granulation of, 58; how formed, 54; how impoverished, 82; preparation of, 70; suiting fertilizer to, rog.

Soils, $54,56,59,61,62,65,70,244$; acid, I12; properties of, 58 ; rules for fertilizing, 109; testing for acidity, 113 .

Soil survey, 64.

Southdown sheep, 3 or.

Sorghum, I $14,169,180$.

Soy beans, 180,322 .

Spiders, 247.

Spiræa, 195.

Spores of fungi, 225 .

Spring, 227, 229.

Squash, 19, 25 .

Stamens, 8, 19.

Starch, 21, 315.

Starter in souring milk, 327 .

Stems of plants, 23 .

Stigmas, 7 .

Stock, $4 \mathrm{r}$.

Strawberries, 10, 17, 21 7, 219.

Subsoil plowing, 72 .

Sugar, 315.

Sugar cane, 39, 84, 154; fertilizers for, 158; culture, 158; rotation for, 120 , I 58 ; varieties, 155 .

Sulfur, liver of, 227.

Sunflowers, 194 .

Sweep rake, 334 .

Sweet clover, 182 .

Sweet gum, 208, 210.

Sweet pea, ro.

Sweet potatoes, 62,187 ; diseases of, 236 ; storing, 164 .

Sweet william, 194, 199. 
Swine, 303 .

Syrup making, 160.

Vetches, 77, 176.

Violets, 195, 199.

Terracing, $74,75,78$.

Thistle, 182 .

Tick fever, 330 .

Ticks, on cattle, $33^{\circ}$.

Timothy hay, 322 .

Tobacco, 14,61 .

Tomatoes, 16, 187, 190.

Trees, forest, 86, 203 ; telling age of, 207 ; leaves of, 210.

Tubercles, $88,89,168$.

Turnips, 187 .

Turpentine, boxing for, $205,206$.

Unavailable plant food, 56 .

Underdrains, 79.

Vegetable garden, 185 .

Vegetable matter, $55,56,83,117,245$.

Velvet beans, 184 .

Verbenas, $195,200$.

Walnut tree, 212, 213.

Washes in ficlds, $63,74,76$.

Water, current, 30 ; forming soil, 54; how lifted, 29; how used, 28; kinds of, 65; lost by leaves, 28; movement in soil, 66.

Watermelons, 11 3, 866 ; wilt of, 167 .

Weeder, 126.

Weeds, 116,182 .

Weevil, Mexican cotton-boll, 264.

Wheat, 12, 23, 114, 118, 121, 138 ; culture of, 139; diseases of, 233 .

Wheat bran, composition of, 322 .

Wheat shorts, composition of, 322 .

Wheat straw, composition of, 322 .

Window gardens, 20x.

Wistaria, 193.

Wyandotte breed, 312 .

Yeast, 228. 


\section{ON FRUIT GROWING, ETC.}

L. H. Bailey's Nursery Book Fruit Growing The Pruning Book

F. W. Card's Bush Fruits

$\$ 1.25$ net

1.25 net

1.50

1.50

ON THE CARE OF LIVE STOCK

Nelson S. Mayo's The Diseases of Animals $\$ 1.25$ net W. H. Jordan's The Feeding of Animals 1.25 net I. P. Roberts's The Horse

George C. Watson's Farm Poultry

1.25 net

1.25 net

ON DAIRY WORK

Henry $\mathrm{H}$. Wing's Milk and Its Products

C. M. Aikman's Milk

Harry Snyder's Dairy Chemistry

W. D. Frost's Laboratory Guide in Elementary Bacteriology

1.60 net

\section{ON ECONOMICS AND ORGANIZATION}

Henry C. Taylor's Agricultural Economics $\$ 1.25$ net Isaac P. Roberts's The Farmer's Business Hand Book

George T. Fairchild's Rural Wealth and Welfare

S. E. Sparling’s Business Organization

In the Citizen's Library. Includes a Chapter on Farming

1.00 net

ON EVERYTHIING AGRICULTURAL

L. H. Bailey's Cyclop-dia of American Agriculture Vol. I. Farns, Climates and Soils. Just Ready

To be complete in four roy 18 8vo. volumes, with over 3000 illustrations.

Price of sets: Cloth, $\$ 20$; half morocco, $\$ 32$

For further information as to any of the above, address the publishers,

\section{THE MACMILLAN COMPANY}

64 and 66 Fifth Ave. - - NEW YORK 


\section{BOOKS ON AGRICULTURE}

On Selection, etc.

Thomas F. Hunt's How to Choose a Farm . \$1.75 net

E. W. Hilgard's Soils: Their Formation, and Relations

to Climate and Plant Growth in the Humid and Arid

Regions . . . . . . 4.00 net

Isaac P. Roberts' The Farmstead . . . 1.50 net

On Tillage, etc.

F. H. King's The Soil . . . . . . \$1.25 net

Isaac P. Roberts' The Fertility of the Land - . 1.25 net

Elwood Mead's Irrigation Institutions - • • 1.25 net

F. H. King's Irrigation and Drainage . . . 1.50 net

Wm. E. Smythe's The Conquest of Arid America - 1.50 net

Edward B. Voorhees' Fertilizers . . . . 1.25 net

Edward B. Voorhees' Forage Crops . . . . 1.50 net

H. Snyder's Chemistry of Plant and Animal Life - 1.25 net

L. H. Bailey's Principles of Agriculture . . . 1.25 net

W. C. Welborn's Elements of Agriculture, Southern and

Western . . . . . . . . .75 net

On Plant Diseases, etc.

George Massee's Plant Diseases . . . . . \$1.60 net

E. C. Lodeman's The Spraying of Plants . • . 1.25 net

H. M. Ward's Disease in Plants (English) . . 1.60 net

A. S. Packard's A Text-book on Entomology . . 4.50 net

On Production of New Plants

L. H. Bailey's Plant Breeding . . . . . \$1.25 net

L. H. Bailey's The Survival of the Unlike . . . 2.00

L. H. Bailey's The Evolution of our Native Fruits - 2.00

W. S. Harwood's New Creations in Plant Life . . 1.75 net

\section{On Garden Making}

L. II. Bailey's Practical Garden Book . . . \$1.00

L. H. Baiiey's Garden Making . . . • . t.50 net

L. H. Bailey's Vegetable Gardening . . . . 1.50 net

L. H. Bailey's Horticulturist's Rule Book . $\quad$. $\quad .75$

L. H. Bailey's Forcing Book . • . . . 1.25 net

A. French's Book of Vegetables . . . . 1.75 net 
On Fruit-growing, etc.

L. H. Bailey's Nursery Book . . . . . \$1.50 net

L. H. Bailey's Fruit-growing . . . . . . I.50 net

L. H. Bailey's The Pruning Book . . . . 1.50

F. W. Card's Bush Fruits . • . . . . 1.50 net

On the Care of Live Stock

Nelson S. Mayo's The Diseases of Animals . . . . \$1.50 net

W. H. Jordan's The Feeding of Animals . . . 1.50 net

I. P. Roberts' The Horse . . . . . . 1.25 net

George C. Watson's Farm Poultry . . . . 1.25 net

\section{On Dairy Work}

Henry H. Wing's Milk and Its Products . . . \$1.50 net

C. M. Aikman's Milk . • . . . . 1.25

Harry Snyder's Dairy Chemistry . . . . 1.00 net

W. D. Frost's Laboratory Guide in Elementary Bacteri-

ology . . . . . . . . . . . 1.60 net

On Economics and Organization

Henry C. Taylor's Agricultural Economics . . \$ \$1.25 net

I. P. Ruberts' The Farmer's Business Handbook - 1.25 net

George T. Fairchild's Rural Wealth and Welfare • 1.25

S. E. Sparling's Business Organization . . . I.25 net

In the Cirizen's Library. Includes a chapter on Farming.

On Everything Agricultural

L. H. Bailey's Cyclopedia of American Agriculture :

Vol. I. Farms, Climates, and Soils.

Vol. II. Farm Crops.

To be complese in four royal 8 vo volumes, with over 3000 illustrations.

Price of sets: Cloth, $\$ 20$ net; half-morocco, $\$ 32$ net.

For further information as to any of the above, address the publishers

\section{THE MACMILLAN COMPANY}


This book is DUE on the last date stamped below

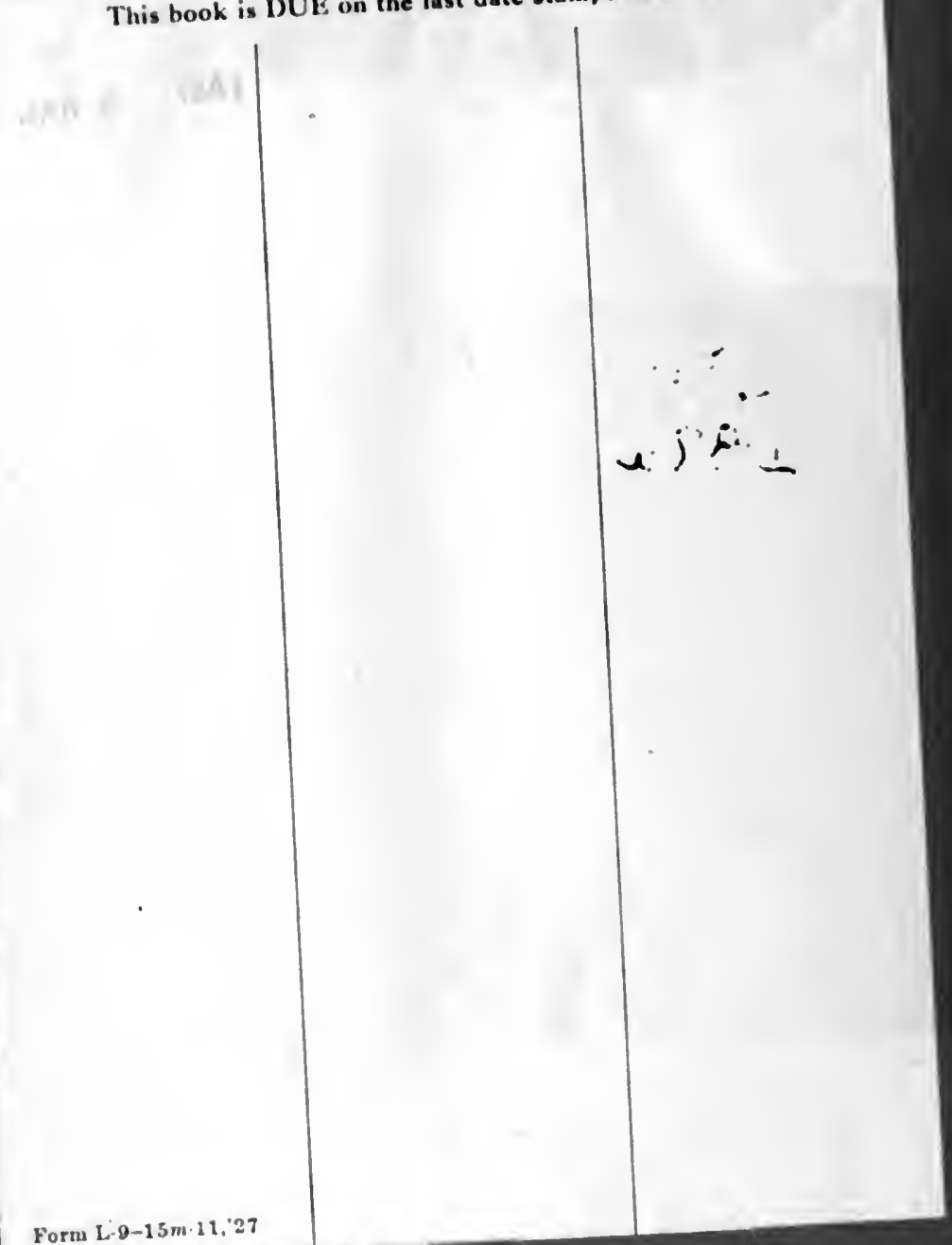




$$
\begin{gathered}
5 \\
495 \\
\text { D8?a }
\end{gathered}
$$


